Interreg

ITALIA-SLOVENIJA

INTEGRA

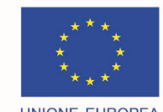

UNIONE EUROPEA ROPSKA UNIJA

Progetto standard co-finanziato dal Fondo europeo di sviluppo regionale

Standardni projekt sofinancira Evropski sklad za regionalni razvoj
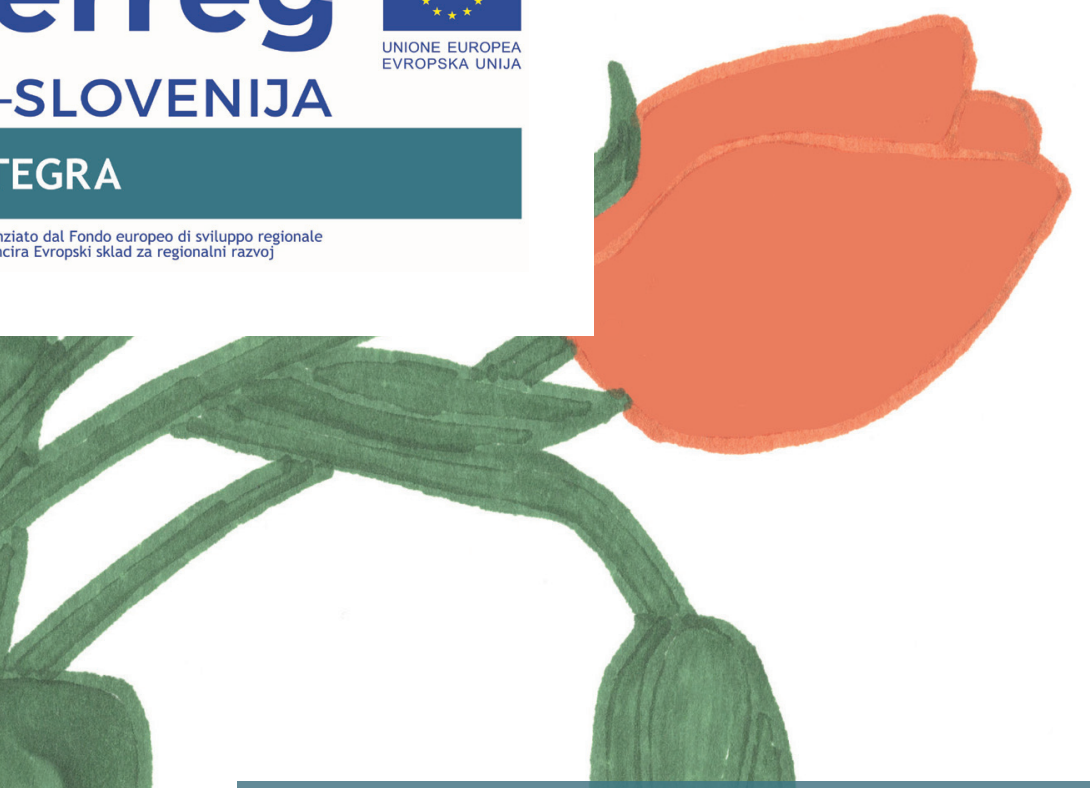

Women, Migrations

and Health

Ensuring Transcultural

Healthcare

Donne, migrazioni e salute Assicurare l'assistenza transculturale sanitaria

Ženske, migracije in zdravje Zagotavljanje transkulturne zdravstvene oskrbe 

Women, Migrations and Health Ensuring Transcultural Healthcare

Donne, migrazioni e salute Assicurare l'assistenza transculturale sanitaria

Ženske, migracije in zdravje Zagotavljanje transkulturne zdravstvene oskrbe 


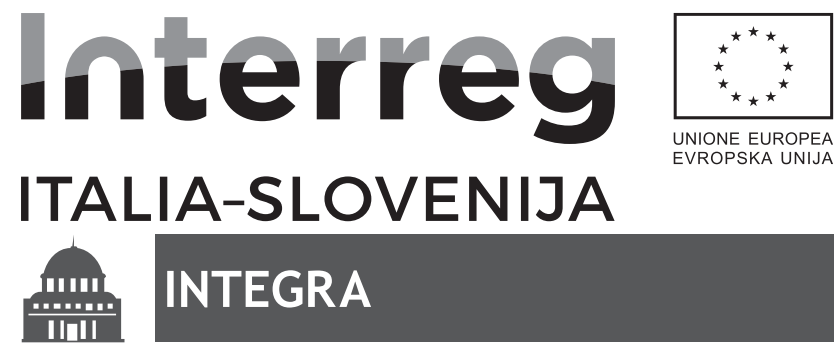

Progetto standard co-finanziato dal Fondo europeo di sviluppo regionale Standardni projekt sofinancira Evropski sklad za regionalni razvoj
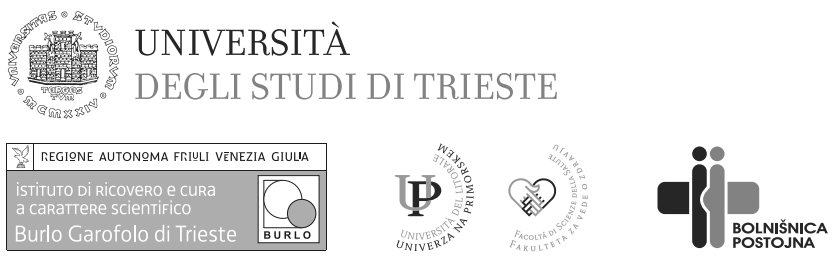

Lead Partner/Partner capofila/Vodilni partner - Università degli Studi di Trieste, Dipartimento di Scienze Politiche e Sociali - DiSPeS, Italia.

Project Partners/Partner progettuali/Projektni partnerji $\cdot$ I.R.C.C.S. materno infantile Burlo Garofolo, Italia; Univerza na Primorskem, Fakulteta za vede o zdravju, Slovenija; Bolnišnica za ženske bolezni in porodništvo Postojna, Slovenija.

Associated Partner/Partner associato/Pridruženi partner - ANOLF - Associazione Nazionale Oltre Le Frontiere.

The project is co-financed by the call for standard projects no. 4/2016 Program INTERREG V A Italy-Slovenia. Total project value: $611,072.85$ EUR.

Progetto finanziato a valere sul bando per progetti standard n. 4/2016 nell'ambito del Programma INTERREG V A Italia-Slovenia. Budget totale di progetto: 611.072,85 EUR.

Projekt je sofinanciran v okviru razpisa za standardne projekte št. 4/2016 Program INTERREG V A Italija-Slovenija. Skupna vrednost projekta: 611.072,85 EUR.

The content of this publication does not necessarily reflect the official positions of the European Union. The responsibility for the content of this publication belongs to the author(s).

Il contenuto della presente pubblicazione non rispecchia necessariamente le posizioni ufficiali dell'Unione europea. La responsabilita del contenuto della presente pubblicazione appartiene all'autore(i).

Vsebina publikacije ne odraža nujno uradnih stališč Evropske unije.

Za vsebino publikacije je/so odgovoren/-ni izključno avtor/-ji.

https://www.ita-slo.eu/integra 
Women, Migrations and Health

Ensuring Transcultural Healthcare

Donne, migrazioni e salute

Assicurare l'assistenza

transculturale sanitaria

Ženske, migracije in zdravje

Zagotavljanje transkulturne

zdravstvene oskrbe

Edited by

Sabina Ličen

Igor Karnjuš

Mirko Prosen

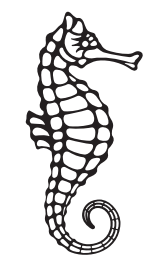


Women, Migrations and Health

Ensuring Transcultural Healthcare

Donne, migrazioni e salute

Assicurare l'assistenza transculturale sanitaria

Ženske, migracije in zdravje

Zagotavljanje transkulturne zdravstvene oskrbe

Edited by · Sabina Ličen, Igor Karnjuš, and Mirko Prosen

Reviewers · Nada Gosić and Joeri Vermeulen

Translators for Italian · Helena Bažec in Jadranka Cergol Gabrovec

Cover Design · Nina Čelhar

Published by - University of Primorska Press

Titov trg 4, 6000 Koper

www.hippocampus.si

Editor in Chief - Jonatan Vinkler

Managing Editor · Alen Ježovnik

Print-run $\cdot 200$

Koper $\cdot 2019$

(C) 2019 University of Primorska

Distributed free of charge

ISBN 978-961-7055-43-6 (pdf)

ISBN 978-961-7055-44-3 (html)

ISBN 978-961-7055-45-0 (printed)

https://doi.org/10.26493/978-961-7055-43-6

(c) $(1) \Theta \Theta$

Kataložni zapis o publikaciji (CIP) pripravili

$\checkmark$ Narodni in univerzitetni knjižnici v Ljubljani

COBISS.SI-ID $=298382336$

ISBN 978-961-7055-43-6 (pdf)

ISBN 978-961-7055-44-3 (html) 


\section{Table of Contents}

Preface

Sabina Ličen $\cdot 7$

Gendered Migration and the Social Integration of Migrants in Slovenia Karmen Medica $\cdot 11$

Sexual and Reproductive Health as an Indicator of Social Integration:

The Obstacle of a Patriarchal Culture and Forced Marriage in Migrant Communities Ornella Urpis $\cdot 23$

Reproductive Health of Migrant Women in Slovenia: State of the Art Blaž Lenarčič and Mateja Sedmak · 35

Working on Epidemiological Data: Problems Encountered and Lessons Learned Giovanni Delli Zotti 59

Human Papillomavirus Infection and Cervical Cancer in Immigrant and Refugee Women Andrej Cör $\cdot 73$

Use of Modern Contraceptive Methods among Migrant Women Living in Slovenia Igor Karnjuš, Mirko Prosen, Urška Bogataj, Doroteja Rebec, and Sabina Ličen · 81

Migrants' Experiences in the Healthcare System

Marie-Louise Luiking and Harshida Patel · 95

Current Issues and Future Possibilities for Improving Healthcare for Migrant Women in Slovenia Urška Bogataj, Mirko Prosen, Igor Karnjuš, Doroteja Rebec, and Sabina Ličen · 107

Migrant Women's Perspectives on Reproductive Health Issues and Their Healthcare Encounters

Mirko Prosen, Sabina Ličen, Urška Bogataj, Doroteja Rebec, and Igor Karnjuš $\cdot 117$

Monoligual Health? Linguistic Barriers in Slovene Healthcare Experienced by Migrant/Refugee Women

Uršula Lipovec Čebron, Lea Bombač, Nike Kocijančič Pokorn, and Miha Lučovnik · 139

When Language and Culture Interfere: Sexual and Reproductive Health of Migrant Women in the Coastal Region of Slovenia

Zorana Medarić and Mateja Sedmak · 155 
Cultural Competence in Nursing and Its Impact on the Quality of Care for Patients from Culturally Diverse Groups: A Systematic Literature Review

Sabina Ličen, Igor Karnjuš, Urška Bogataj, Doroteja Rebec, and Mirko Prosen $\cdot 173$

Strengthening Cultural Awareness of Nursing Students

Barbara Donik, Mateja Lorber, and Majda Pajnkihar $\cdot 187$

Culturally Sound Midwifery Care for Migrant Mothers: How Well the Midwifery Curriculum Prepares Graduates

Ana Polona Mivšek, Nastja Pavel, Mateja Kusterle, and Petra Petročnik · 199

Sintesi $\cdot 211$

Povzetki $\cdot 219$ 


\section{Preface}

\section{Sabina Ličen}

University of Primorska

sabina.licen@fvz.upr.si

Today, migration is a global reality. People leave their homelands for various reasons such as poverty and low incomes, high unemployment, persecution and poor respect of human rights, internal conflict and war, etc. In recent times, our region and the area of neighbouring Italy have seen a growing number of migrant women migrate from their own country for reasons to do with reproductive health or birth. In fact, for many migrant women, issues associated with insufficient or poor sexual and reproductive health in their countries can lead to worse perinatal outcomes than those experienced by women generally. Moreover, migrant women in developed countries often experience more complicated pregnancy outcomes and less women are able to access preventive gynaecology services. The latter may be due to poor cultural competence knowledge among health professionals or other barriers encountered by migrant women. With a view to delivering culturallysensitive healthcare to migrant women, the EU programme INTERREG V-A Italy-Slovenia 2014-2020 funded the project 'Cross-Border Network for Migrant Women: Social Integration, Sexual and Reproductive Health (INTEGRA), led by the University of Trieste in Italy.

The project outcomes included this scientific monograph 'Women, Migrations and Health: Ensuring Transcultural Healthcare' which addresses various aspects of migration and women's health like social integration, sexual and reproductive health, along with related cultural practices, and the development of cultural competencies among healthcare professionals in delivering culturally sensitive healthcare.

Chapter 1 introduces the reader to the main theme of the book - migrant women. Women are often heavily involved in the survival of their families and communities, but today the 'feminisation of migration' and 'feminisation of survival' processes are very evident. Observation of the sexual and reproductive health of women can provide a good indicator of the extent of integration of cultural communities by revealing women's capacity for autonomy and self-determination, a fundamental condition for recognition of their rights and for identifying with the models and values of democratic society, as discussed in Chapter 2. Chapter 3 presents data on the number of migrant 
women in Slovenia which is constantly rising, and notes it will be even higher in the future whereas a comprehensive and systematic approach to migrant women's reproductive health is still missing. Chapter 4 considers the development of a sexual and reproductive health index that aims to identify at-risk individuals, or which require 'targeted' interventions. This implies the need to identify suitable indicators; namely, another of the INTEGRA project's purposes. Chapter 5 explains that immigrant women from low- and mediumincome countries have a higher prevalence of HPV and thus a greater risk of cervical pre-cancer and cancer than native women also due to barriers to access to screening programmes and vaccination uptake. Moreover, Chapter 6 discusses the available evidence on the factors associated with migrant women's use of modern contraceptive methods in Slovenia. Chapter 7 addresses the factors associated with migrants' healthcare experiences in the host country. The model presented in the chapter can help increase nursing professional's awareness of the need to provide person-centred care and overcome transcultural differences. Chapter 8 describes migrant women's social integration in terms of their reproductive health relative to the healthcare system in Slovenia. Chapter 9 outlines a qualitative content analysis approach applied to a maternity hospital in Slovenia. The analysis highlights two themes: the experiences, expectations and barriers of a different healthcare system; and the impact of culturally-based beliefs on women's reproductive health. Chapter 10 presents the main obstacles related to the main language barriers that arise between migrant/refugee patients and healthcare personnel in the area of gynaecology and obstetrics. Chapter 11 discusses migrant women's reproductive health, with an emphasis on the perspectives of migrant women and healthcare professionals (doctors, midwives, community nurses, etc.) on existing practices, intercultural differences, access to reproductive healthcare services, etc. Chapter 12 looks at cultural competence in nursing and its impact on the quality of care for patients from culturally diverse groups. The final two chapters present the measurement of nursing students' cultural awareness in Chapter 13 and of midwifery students in Chapter 14, which shows the curriculum lacks specific information on cultural competencies.

The monograph is a great example of the forces of various health and other professionals from different countries coming together to support efforts to improve the health of migrant women. The material contained in the chapters may be helpful for healthcare and other professionals in expanding their perspectives and developing the skills and techniques they need to work effectively with migrant women in a multicultural environment. The mono- 
graph is written in English with the aim of ensuring the project's ideas and results can reach a wider international audience. Abstracts in the Slovenian and Italian languages can also be found towards the end of the monograph.

I truly believe the monograph will be of interest to all health workers, academics, researchers and interested readers curious to know what has been going on in this specific field.

S. Ličen, I. Karnjuš, \& M. Prosen (Eds.). (2019). Women, migrations and health: Ensuring transcultural healthcare (pp. 7-9). Koper, Slovenia: University of Primorska Press.

https://doi.org/10.26493/978-961-7055-43-6.7-9 



\title{
Gendered Migration and the Social Integration of Migrants in Slovenia
}

\author{
Karmen Medica \\ University of Primorska, Slovenia \\ karmen.medica@fhs.upr.si
}

\begin{abstract}
Several topical issues arising from the contemporary migrant context, at both regional and global levels, are addressed in the chapter. First, when it comes to the sphere of the European Union, the emphasis is on the issues of integration in the migrant context, as well as the security situation. Women have often been heavily involved in the survival of their families and communities, but today the 'feminisation of migration' and 'feminisation of survival' processes are very evident. These two phrases highlight the increasingly public and visible forms of women's contribution to families, along with their contribution to the state and society (immigrant and emigrant), especially the growing world demand for their services. Although women have always migrated, developments in the last decades sustain both their presence in international migration flows and their recognition as migrants. The focus of this contribution on presenting certain results of ongoing research, chiefly on the social integration of migrants in Slovenia.
\end{abstract}

\section{Introduction}

Contemporary modernisation and migration processes have put the issue of regulating migration policies and integration strategies in the centre of interest in the social sciences, despite the national security interest which primarily entails positive identification of target (Bade, 2005; Scheffer, 2011).

The migration of women has always been an important component of international migration. The United Nations Population Division estimates that in the year $200049 \%$ of all international migrants were women or girls, and that the proportion of women among international migrants had reached $51 \%$ in more developed regions. Women often migrate officially as dependent family members of other migrants or to marry someone in another country. Female migrants are, however, increasingly joining flows of migrant workers, moving on their own to become the principal wage earners for their families. Most migrant women move voluntarily, but women and girls also include migrants forced to leave their countries to flee conflict, persecution, environmental degradation, natural disasters or other situations that 
affect their security, livelihood or habitat (Women and International Migration, 2018).

The comparison of migrants, especially female migrants as workforce or 'non-free workers,' over time also seems appropriate to Stephen Castles for the following reasons: Migrants as a rule have limited access to health and economic rights, as well as work contracts. They are also frequently excluded from certain professions, senior positions and functions, and have problems when acquiring work permits as they are specific to a single employer, for which reason female (and male) migrant workers generally cannot seek employment with another employer, ultimately leaving some with no alternative but to return to their home countries (Castels, 2006; Papastdergiadis, 2000; Tapinos, 1999).

\section{About New Research Approaches: 'Where Are You from?/ Where Are You at?'}

Contemporary migration and integration processes necessitate new research approaches that strive to find answers to the questions: 'Where are you from? vs. Where are you at?'

Zimmermann, Gataullina, and Constant (2018) used the so-called ethnosizer (a means of measuring ethnic identity) in a study on ethnic identity and ethnic belonging. The ethnosizer, a measure of the intensity of a person's ethnic identity, is constructed from information on these elements: language, culture, societal interaction, history of migration, sex, and ethnic selfidentification. The two-dimensional concept of the ethnosizer classifies immigrants in four states: integration, assimilation, separation and marginalisation. Based on individual characteristics - such as language, culture, social interaction, the time of immigration and ethnic self-identification - they determined levels of the four mentioned states.

The general characteristics of the intensity of ethnic identity among the immigrant group show the following. The researchers find a few general characteristics; namely: ethnic identity is stronger for females, those who were schooled in the home country, and who were older age at the time of entry; young migrants are assimilated or integrated the most; Catholics and other Christians integrate and assimilate faster than other religion; immigrants with a college or higher education in the home country integrate very well, but do not assimilate; having some schooling is worse than no education for integration or assimilation; those with a tertiary education integrate more easily, but do not assimilate; those with an elementary education integrate and assimilate more slowly than those without any education; there 
are also individual differences like in attachment to the homeland, parents, friends, etc.

\section{The Slovenian Context: Between the Local and Global Dimension}

When it comes to identifying and integrating migrants in Slovenia, most of whom are from former Yugoslavia, it would not be out of place if we first take a small 'excursion.' Although this is a matter of a minority that is not constitutionally recognised as such, their minority status was acquired upon a change in national-legal belonging - that is, with the fall of Yugoslavia and Slovenia's independence. The Slovenian example is not a classic immigrant situation. The rapid rise of industry after World War II depleted much of the region's 'reserve' workforce, thereby creating the conditions for employing workers from other republics of former Yugoslavia. Some figures show the influx began around 1961 and already by 1963 23,203 seasonal workers had come to Slovenia. Most came from Bosnia and Herzegovina and Croatia, and then from Serbia (Medica, 2010).

A large share of these workers came from generally less developed regions where opportunities for basic and higher education were limited. The migrants were predominantly unskilled, low-wage labour and from the poorest societal classes. A certain percentage of these people were officer corps from the former country who had chosen to remain in Slovenia; others came for schooling and higher education and stayed. During the war in former Yugoslavia, refugees also arrived in Slovenia, with some later remaining. Workers from former Yugoslavia are actually a fixture in Slovenia as their destination country. Migration from countries in the region is quite typical of Slovenia to this day as they make up the biggest share of migration with them representing more than $85 \%$ of all migrants. Much like in other countries, stronger migration flows from Asia (China, Thailand) are also seen in Slovenia. However, the share of migrants from non-European countries in Slovenia is very low at below $3 \%$ of all migrants (Pajnik, 2012, p. 148).

In terms of gender specificities, Slovenia shows a pattern where more than two-thirds of migrants are men, whereas in Hungary, Finland and Germany the balance is more even. There are more migrant women than men in Italy and Cyprus, where the feminisation of migration has been noted in the last few years. Sectors that involve migrant women, particularly the so-called feminised sectors, are domestic and care work, healthcare, beauty spas and wellness business, as well as sex work (Pajnik, 2012, p. 149).

About female migrants in Slovenia in general, we can say that they primarily migrate for marriage or family reunification (see http://www.ess.gov.si). 
The research demonstrated that in the majority of cases the main reason for female migration was to re-unite with a spouse working/living in Slovenia. However, many female migrants in the study stated they had migrated for better employment opportunities and education (see http://www.mddsz .gov.si).

\section{Identity and Integration}

How to detect the identity options of migrant minorities from the area of former Yugoslavia remains quite an unsettled question. Touching on this, the Slovenian-Bosnian writer Josip Osti wrote (Medica, 2006):

In terms of the preserving of identity models with the help of language, it is clear that a more or less common language of these groups no longer exists today. Of the former Serbo-Croatian, I myself say that it is the language of my memory. In the novel by Andrej E. Skubic, Fužine Blues (Fužinski bluz), on which a theatre production was also based, this language is present as part of the folklore of the Fužine quarter of Ljubljana, where this population is greatest. A similar situation is seen in the Markovec quarter of Koper. In the novel Skubic, similar to the director of the theatre production of the same name, Ivana Đilas, concerns himself with the language of the Fužine district as part of the identity of this minority group. This language is a theme, although not everything that lies behind the language and which is even more important. Only the contrast in mentality comes to expression, the stereotype of problematic Southerners continues to exist. A theatrical production, let's say, of a Bosnian in Slovenia that is not about a stereotyped figure, who is not a manual labourer, is not stupid and where someone named Fata is not necessarily a cleaning woman - that would be a welcome production. If you only partly destroy the established stereotypes, something will begin to change in people's consciousness. There's no need to hold great illusions of any radical change since the way of thinking is deeply rooted. But if a change in thought is brought about, something substantial will be set in motion. These may be small steps, but they are important; if you don't take a small step, you'll take no step at all.

Marijanca Ajša Vižintin (Vižintin, 2018) calls for changes, chiefly to the education system. She claims that teachers exert a substantial influence on success in including immigrant and refugee children through their knowledge and attitude. Even greater effectiveness would be attained if teach- 
ers who support the inclusion of migrant children were to be employed full time (instead of on temporary projects) and if concrete learning objectives and teaching content that tackles those topics were to be included in multiperspective syllabuses, including in academic programmes (Vižintin, 2018; Torpey, 2000; Aragones \& Salgado, 2018).

'As active citizens, teachers should respond to prejudices and discrimination in their (school) environments and through their knowledge and activities promote the development of intercultural education. A significant part of this involves the development of intercultural dialogue at their educational institution and in the local community, in line with genuine diversity (multilingualism, multi-ethnicity, multi-religiosity) and, importantly, together with the immigrants' (Vižintin, 2018, p. 98).

\section{Central Integration Barriers}

The welfare state is withdrawing to the market and market relations, but the fundamental area of activity is the everyday world of people, the everyday interaction with people different than 'we' are. It is precisely in this context that the power and adaptability of ethnic and national identity models express themselves.

We express them through everyday expressions, phrases, jokes, ambiguities. When it is a matter of everyday situations and our responses to fleeting encounters with others, prejudices seem harmless, innocent. At such times, we hardly notice them - exactly because they are so quotidian. But it is these everyday prejudices that have the unsettling quality that they very soon reach epidemic proportions. Prejudices are then transformed into tools of aggression, they presage lynching, excuse all sorts of discrimination, persecution, witch hunts or the leaving of threatened groups to their 'fate.' In this way, the status quo in a given society is supported, rationalised and legitimised.

The main obstacles to integration, especially when it comes to female migrants, are psychological and economic. They are chiefly seen in the presence of prejudice, stereotypes, poor knowledge of the situation, ignorance of the problem, and ignorance in general. Moreover, in research we are often dealing with the presence of prejudice and stereotypes, about economic migrants, whom Slovenia urgently needs, and even more about refugees from Syria and Afghanistan.

\section{Gendering Migration - Gendering Identities}

Today's divide or border between the foreign and the domestic, exacerbated by rapidly growing immigration into Europe, which still has to be essentially 
gendered (and racialised), but also to be determining for contemporary European racial and gendered identities. Thus, a very open question is how can this imaginary border or, in Stoler's (2018) terms 'internal frontiers,' created within the receiving society between the foreigner and the citizen be seen as fundamentally sexualised and gendered? Or, can and, if so, how can it be seen as a constitutive force for both local society itself and for the gendered and sexual performances of immigrants? Today, the site of an internal other for European countries has been shifting more and more towards the space of the expanding immigrant communities. More concretely, Slovenia's contemporary, pro-European, national, cultural and gendered normative identities are increasingly influenced by recent migration from the ex-Yugoslav countries, along with other countries from the Balkan peninsula - Albania, Bulgaria and Romania.

Although women have always migrated, development over the last decades sustains both their presence in international migration flows and their recognition as migrants. Women have been regularly heavily involved in the survival of their families and communities, but today the 'feminisation of migration' and 'feminisation of survival' processes are very present. Both phrases highlight the increasingly public and visible forms of women's contribution to families, also their contribution to the state and society (immigrant and emigrant), especially the growing world demand for their services.

The literature on immigrant women's health shows that they abort, give premature birth and need Caesarean sections more often, while delivery among them is higher and they have more birth-related psychological problems (Doctors of the World, 2014). This information is not surprising because female migrants are more restricted in access to healthcare and less informed of their possible rights to healthcare, while possibly being afraid of both their husbands and interaction with all sorts of officials.

The contemporary experiences of immigrant women in Slovenia do not fully reflect the effects of gender, immigrant stratification systems and the impacts of alterable, and in many cases chaotic, immigration policies.

In this chapter, the focus is on presenting some results of ongoing research, primarily on the social integration of women migrants in Slovenia, and the processuality of the integration processes in everyday life and common situations. A key element of their integration relates to their social status, employment, health status, both physical and psychological.

This paper is a work in progress, and follows a few central topics:

- Women migrants who have been in Slovenia for a long time and are 
educated, employed and have already acquired citizenship of the Republic of Slovenia.

- Women migrants who came more recently, most often to join a husband who works in Slovenia, with this process mainly entailing family reunification.

- Experiences of healthcare workers and doctors with whom migrant women have been in contact.

- The perceptions of students of the Faculty of Humanities and the Faculty of Health Sciences at the University of Primorska, and their opinions on the integration of migrants into Slovenia, with an emphasis on migrant women.

\section{Experiences of Healthcare Workers with Whom Migrant Women Have Been in Contact}

This chapter looked at the perceptions of students of the Faculty of Humanities and the Faculty of Health Sciences at the University of Primorska, and their views on the integration of migrants in Slovenia, with a stress on migrant women.

The research was conducted in March 2018 using focus groups made up of students of the Faculty of Humanities and the Faculty of Health Sciences at the University of Primorska, especially students, who are also in direct contact with migrants, healthcare workers and doctors with whom migrant women have been in contact. Interviews in the focus groups were conducted at the Faculty of Health Sciences in Izola on 9.3.2018 and 16.3.2018.

We concentrated on the focus groups by applying high-quality, nonstandardised, structured data-bundling techniques. The intention was to gain an insight into the research problem so as to illuminate the actual situation in practice. It is also important that the focus group participants were selected on the basis of specific characteristics, and that they were employed in healthcare, which is the main research topic.

\section{Focus Group Participation, and Relationship with Migrants in Slovenia's Healthcare System}

Students from the Media Department at the Faculty of Humanities played the role of interrogators and commentators. The focus group research involved 2 groups and 22 students, namely, 20 from the Faculty of Health Sciences, and 2 students from the Faculty of Humanities - Sabrina Husejnović and Emanuel Lipovac. The Faculty of Health Sciences students were respondents due to 
their experiences. Some participants were more actively involved in the discussion.

The students - future healthcare professionals - participating in the focus groups say they treat all patients in the same way, whether they are migrants or Slovenian citizens. Still, they think that migrants do not respect their advice, sometimes they pretend to be sick.

Migrants are usually most afraid that the healthcare service will be too expensive for them. Accordingly, they delaying visiting a doctor, but that is unnecessary.

One student, a nursing student from the surroundings of Izola, explained there are language problems, especially with young Albanian mothers. The staff thus often need considerable time in contact with them compared to a Slovenian patient. The biggest problems are due to the lack of language knowledge. All participants agreed.

Poor communication practices between the healthcare professional and the patient can lead to a variety of problems.

One student with practice with female migrants warned of the 'Albanian mothers' improper treatment of their children,' which she considers to be the result of ignoring the advice given by nurses. It is very possible that this negative opinion mainly arises from the poor training of health professionals in the language area (i.e. poor communication), as well as unfamiliarity with different cultural practices and customs.

In the focus group, some student health professionals referred to the linear development of culture. This is a belief that emerged in the 19th and 2oth centuries, and is nowadays unaccepted and irrelevant.

One student who is also a medical worker linked 'progression' and 'socialisation' with a better understanding of other EU languages (e.g. Slovenian and English) and everyday family practices.

\section{Migrants' Reliance on Slovenian Healthcare}

The participants believed that migrants, especially females, only visit a doctor when the situation is urgent. There is a reluctance to visit the doctor and distrust in doctors. The reasons mentioned by the migrants are ignorance of the situation, the environment and language, followed by a fear of having to pay, and a fear of excessive costs.

\section{Visiting Doctors}

One of the crucial problems/obstacles migrants experiences concerns visiting a doctor. They only see a doctor when it is truly necessary and urgent. 
When asked whether migrants (mainly female Muslims) attend a medical examination by themselves, the participants answered that this is rarely the case. They are most often accompanied by a child ( 9 to 12 years old) who, due to their compulsory attendance at an educational institution, can speak Slovenian. Slovenia's migration policy plays a key role in this issue. Cost-free Slovenian language courses are only available to migrants after being resident in Slovenia for 2 years. Privately paid courses are very expensive.

\section{Health Institutions' Preparedness for Cultural Diversity}

In the case of dealing with an unknown culture (customs, practices, behaviour, way of dressing etc.), Slovenian health professionals are left to themselves. The focus group participants stated that Slovenia is very poorly organised in this area.

It is also important to note that, due to poor communication skills (notably ignorance of the language) and ignorance of different cultures, disputes between healthcare workers and migrants are frequent. For example, one participant argued that migrants do not want to obey the advice given by medical staff, with explanation, that they don't want any progress and changes.

\section{The Problem of the Health System's Poor Adaptation}

While discussing the preparedness of health institutions for cultural diversity, one participant said that migrants do not want to adapt to the Slovenian system. In comparison, another participant stated that Slovenians who have migrated abroad have adapted exceptionally well to foreign cultures and new social (political) systems.

Statements like: 'They will not adapt to us!' mainly derived from:

- ignorance of the wider migration process;

- evaluations based on prejudice and unjustified claims; and

- justification of thinking based on isolated (one-off) cases.

A proposed solution is clearly to make integration more interactive and to give training in communication bias. This is confirmed by examples from the practice of British health professionals who have been permanently educated about the customs of migrants arriving in the United Kingdom. Such knowledge can speed up integration and ensure the effective functioning of healthcare institutions. 


\section{In Lieu of a Conclusion}

The chapter is based on the research project Cross-border Network for Immigrant Women: Social Integration, Sexual and Reproductive Health, Program INTERREG V A Italy-Slovenia 2014-2020, the project leader of which in Slovenia is Dr Mirko Prosen from the Faculty of Health Sciences. Based on the focus group work within the said project, we can say that the Slovenian health system encounters several problems with the reception of migrants, especially female ones.

This is largely due to at least two issues:

- the absence of any course (education) on how to treat migrants or members of foreign cultures - health professionals are left to themselves; and

- poor language knowledge - by both migrants who, due to Slovenian legislation, can only learn the language without cost after having been resident in Slovenia for 2 years, as well as health professionals who have no possibility of taking cost-free courses in other languages.

The fact there are no communication channels between medical professionals and migrants is a problem that stems from prejudices which, in our opinion, are due to sensational media reporting of the migrant crisis (e.g. making a mess on the train, destroying food and destroying seats on the train, bus etc.). These statements were obtained in a focus group interview, Faculty of Health Sciences in March 2018.

Any stereotyping indulged in by health professionals will not contribute to successful integration and social cohesion, on the contrary. As long as a widespread stereotypical conception of immigrants is held among the public, as long as the state's attitude to immigrant workers and their political, religious and cultural expectations allow them to be scorned by their immediate community or at work, and to be marginalised by society at large, it is hard to talk of the implementation of integration into wider society.

Identity changes, belonging and non-belonging are actually hallmarks of a challenge brought by the presence of different cultures in society, including the contributions these groups make and by maintaining contact with their home culture. The key identifications in society occur at the local, micro level, in various forms of everyday contact with the inhabitants of a specific region. If neither (immigrant and native populations, migrant minorities and the majority population) is prepared to play a role, then even the best models and concepts of integration, all the good measures and good intentions, will 
not bring about the desired results. The former main way of adapting and integrating into a new environment, arising from the Darwinist assumption that one must adapt or die, is being superseded. New processes are increasingly adopting an evolutionary form, proceeding from primary adaptation to universal progress in the new environment. A positive integration praxis can now be restated: adapt and integrate, integrate and thrive.

Accordingly, it should be emphasised that the interaction of migrants and the majority population as important societal phenomena and processes is a subject that must be constantly and repeatedly opened up. Female migrants have become a topic in everyday political, media, education and scientific settings that are vital to the prospects for the development of Slovenian society. Interactive integration into society can be achieved when migrants' interactive integration is accepted from all social actors, especially those in direct contact with migrants - healthcare workers, social services, media, politicians, and, above all 'ordinary' people.

First and foremost, it is important to deal with them on a local as well as global level, in a context which includes both 'place' and 'space.'

\section{References}

Aragonés, A. M., \& U. Salgado. (2018). Denmark and Norway: Matching labor market needs with qualified migrants. Dve domovini, 44, 93-109.

Bade, K. (2005). Evropa v gibanju: migracije od poznega 18. stoletja do danes. Ljubljana: *f.

Castels, S. (2006). Guestworkers in Europe: A resurrection? International Migration Review, 40(4), 741-766.

Doctors of the World. (2014). Access to healthcare for the most vulnerable in a Europe in social crisis. https://issuu.com/dotw/docs/mdm_2014_eu_report _access_to_care

Medica, K. (2006). Večkulturnost in diskriminacija $v$ evropskem kulturnem okolju in v medijskih diskurzih. Monitor ISH, 8(1), 117-131.

Medica, K. (2007). Sodobne migracije in dileme varnosti. Socialno delo, 46(3), $125-133$.

Medica, K. (2010). Sodobni integracijski procesi in kontroverznosti krožnih migracij. In K. Medica, G. Lukič, \& M. Bufon (Eds.), Migranti v Sloveniji - med integracijo in alienacijo (pp. 37-56). Koper, Slovenia: Annales.

Medica K., \& Lukič, G. (2011). Migrantski circulus vitiosus. Koper, Slovenia: Annales.

Pajnik, M. (2012). Migrants as cheap labourers in Europe: Towards critical assessment of integration. Migracijske i etničke teme, 28(2), 143-163.

Papastdergiadis, N. (2000). Turbulence of migration, globalization, deterritorializatin and hybridity. Cambridge, England: Polity. 
Scheffer, P. (2011). Immigrant nations. Cambridge, England: Polity.

Stoler, A. L. (2018, 18 January). Interior frontiers' as political concept, diagnostic, and dispositif, Retrieved from https://culanth.org/fieldsights/1045interior-frontiers-as-political-concept-diagnostic-and-dispositif

Tapinos, G. (1999). Clandestine immigration: Economic and political issues. In Trends in international migration (pp. 229-251). Paris, France: OECD.

Torpey, J. (2000). The invention of the passport: Surveillance, citizenship and the state. Cambridge, England: Cambridge University Press.

Vižintin, M. A. (2018). Developing intercultural education. Dve domovini, 47, 89106.

Zimmermann, K. F., Gataullina, L., \& Constant, A. F. (2006). Ethnosizing immigrants (CEPR Discussion Paper No. 5636). London, England: Centre for Economic Policy Research.

S. Ličen, I. Karnjuš, \& M. Prosen (Eds.). (2019). Women, migrations and health: Ensuring transcultural healthcare (pp. 11-22). Koper, Slovenia: University of Primorska Press.

https://doi.org/10.26493/978-961-7055-43-6.11-22 


\title{
Sexual and Reproductive Health as an Indicator of Social Integration: The Obstacle of a Patriarchal Culture and Forced Marriage in Migrant Communities
}

\author{
Ornella Urpis \\ University of Trieste, Italy \\ ornella.urpis@dispes.units.it
}

Patriarchal family structure is the paradigm of human relations in many parts of the world. In these societies the relationships are structured on the rigid separation of the sexes and on the different capacity of empowerment of men and women. In migratory processes, loyalties to the traditional model of the patriarchal family often remain unchanged. Migration dynamics intertwine with the marriage strategies of families or communities, and the maintenance of certain traditional practices, including forced marriage, becomes functional to the maintaining of the boundaries of identity and to 'traditional' social system. The observation of the sexual and reproductive health of women can provide a good indicator of the integration of cultural communities because it reveals women's capacity for autonomy and self-determination, a fundamental condition for the recognition of their rights and identification with the models and values of democratic society. The access of women to health and territorial facilities, the repeated abortions, the presence of repeated sexual diseases, knowledge of family planning, knowledge of the language of the host country, the capacity for autonomy and choice on reproduction, the abandonment of behaviors of submission to traditions (endogamous marriages, forced marriages and female genital mutilation) are all indicators useful for understanding the degree of social inclusion of women and the integration of communities in the host country.

\section{Introduction}

When speaking of the integration of migrants, reference is always made to their inclusion in the labor market, their living conditions, their ability to access services, their interaction with the surrounding environment, etc. (Boccagni \& Pollini, 2012); however, equal attention is not paid to measuring the changes in their identification models or their ability to reshape the cognitive and evaluative picture in the new cultural system that now be- 
longs to them (Sayad, 2002). It is undoubtedly very difficult to assess one's ability of social adaptation and the changes gradually undergone over time by someone having the status of a migrant in a new social context. One of the fundamental yet completely neglected indicators to measure the above concerns the behavioral models between the sexes and the persistence of actions of patriarchal power (in countries where it is widespread) that restrict the life of women and negatively impact their sexual and reproductive health in particular.

Even in more advanced approaches (Bocacgni \& Pollini, 2012; Cesareo \& Blangiardo, 2009) pools of indicators are used in regards to the differing dimensions of institutional, relational, cultural, socio-temporal, socio-spatial existence; however, the relationship between the gender and the consequent to sexual and reproductive healt of women are never observed as the 'basket of integrated processes,' as defined in social science studies (Sciortino, 2015), does not include them.

The principles of personal freedom and self-determination are at the basis of the co-habitation system in every democratic host country. An individual's freedom is precondition in order for all the other constitutional freedoms to be guaranteed and it is essential so that an individual can benefit from the independence required to exercise any other right.

When it comes to women, slavery has always been associated with their bodies inasmuch as a woman's sexual and reproductive health is crucial for her self-determination and represents a fundamental indicator of her degree of independence and personal freedom.

Besides being a biological experience or a mere instinctive act, human sexuality may be viewed more broadly as a social act among individuals, having a symbolic dimension and leading to social relations and relations with the environment. Indeed, William Simon e di John H. Gagnon (Rinaldi \& Scarcelli, 2016) distance themselves from the idea of sexuality being merely a natural impulse to be held back by means of rules and rather see it from the perspective of cultural production (Rinaldi, 2016).

In this light, sexual and reproductive health becomes an indicator of integration in cultural communities, measured via women's access to: health facilities throughout the territory, legal abortion, family planning systems, learning the language of the host country, freedom of choice on reproduction, the abandonment of traditional submissive practices (endogamy, forced marriage, and female genital mutilation-FGM).

When examining only social, economic, employment, and housing factors, one might conclude that many immigrants are perfectly integrated as the 
men have jobs, their children go to school, they live in a house, etc. However, by taking a closer look at the power relations between men and women and the socio-economic integration of women, in many families the woman cannot speak the language of the host country, has no personal independence, and in particular cannot decide on her own reproductive health, is subject to her husband's or husband's family decisions in terms of contraception, number of children to be had, types of health treatment, and is sexually unhealthy.

Regarding the integration processes in society, Parsons (1971) claims that a society can be independent insofar as it can 'count' by and large on the fact that its members adequately 'contribute' to its well-functioning. In this respect, integration requires the degree of alienation of its members to be reasonably low, whereas in many communities women seem to be totally on the margins of society.

Parsons (1971) adds that the integration process of members into society is linked with a zone of inter-penetration between the social system and the personal system. It is a three-way relationship in that part of the cultural system in addition to part of the social structure are interiorized by one's personality and part of the cultural system in turn is institutionalized in society.

Unfortunately, the process of interiorization of the host country's cultural system may not be welcomed or accepted. The persistence of a patriarchal model which completely permeates the homeland's organizational structure of society and the conceptual and value-based references of many migrants prevent the natural permeation between cultural systems from happening and people from being equals (Urpis, 2017). This leads to the creation of an insurmountable barrier between men and women thus ratifying women's inferiority and estrangement from a model of open society.

\section{Loyalty to the Patriarchal Model and the diminutio of the Female Role in Society}

A patriarchal family structure is at the heart of many societies built almost exclusively on the affirmation of values. On the contrary, in more complex societies people are kept together through consensus on the procedures intended to lawfully put into effect the law and to lawfully exercise power rather than through the substantive consensus on values (Habermas, 1998).

In patriarchal societies the relationship between men and women is one based on the rigid separation of gender, on the valorization or de-valorization of differences between genders and on differing empowerment skills. Social segregation is a reflection of segregation within the family (Johnson, 1997).

Examining the persistence of patriarchal models which inevitably imply 
the discrimination of women and are fixed in traditional practices means observing how different cultures relate to each other on issues like wedding agreements, women's access to social and economic goods, discrimination and inequality.

In migratory processes loyalty to one's traditional patriarchal family model continues. Differentiated relations and the imbalance of power between genders continue, sometimes taking even more shape in the host countries and often leading to the immigrants' children also suffering the consequences as they are torn between the loyalty they owe to their family and a totally different kind of social loyalty (Lannutti, 2016). Migratory dynamics are interlinked with the marriage strategies of families and communities and the preservation of traditional practices serves as a tool for the preservation of borders of identity (Urpis, 2012).

The difficult relationship with the new society, the cultural gap, the lack of integration often lead to migrants intermingling only with members of their own cultural groups. Changes in lifestyle and customs, as well as the changes in identity which often follow, are not automatic processes at all. On the contrary, conforming with 'traditional' values and behavior become necessary conditions in order to be accepted in the host country by those who come from the same cultural milieu.

As a consequence, some foreign communities become impenetrable to the social environment around them and some practices like forced marriage and female genital mutilation, which function as differentiation elements, continue within the new cultural group of reference in order to secure the shared common values in the group.

In migratory processes an awareness of the cultural features of certain communities, in which women are particularly subject to discrimination, can help the host society choose the necessary tools to promote policies favoring social inclusion (Ambrosini \& Berti, 2009).

It is for these reasons that a crucial factor for the integration of foreigners is - in my view - the condition of female immigrants, ie their level of economic and social emancipation, their knowledge of the language spoken in the host country, their rapport with their husband/partner, their refusal to accept harmful traditional practices, their active participation in the social and political life in the new society, all of which positively impact their sexual and reproductive health.

If having a job is a condition that favors female empowerment, personal independence and the exercise of rights, one can easily doubt about immigrant women's power of self-determination and integration in Italy today. 
Data on immigrant women and the labor market show a very low level of economic integration and very widespread inactivity and unemployment on their part. As mentioned in the 5th Annual Report of the Ministry of Labor and Social Policies (Ministero del Lavoro e delle Politiche Sociali, 2015), women of extra-European origin have $10 \%$ lower employment rates compared to European women ( $46 \%$ versus $56 \%$ ) and $10 \%$ higher rates in regards to inactivity ( $43 \%$ for extra-European women and $33 \%$ for European women). The inactivity rate is up to $70 \%$ among Egyptian and Indian women and even up to $80 \%$ among those from Bangladesh and Pakistan.

This condition of emargination directly impacts their ability to interact with the new social environment they live in and to make the appropriate choices in their lives. Healthcare professionals at the hospital Burlo Garofano in Trieste complain about the language difficulties they have in communicating with certain patients from particular areas of the globe: 'We often find ourselves trying to communicate with patients who can't speak our language despite their having been in our country for several years. We need to contact cultural-linguistic mediators, but in case of an emergency we just learn to cope.' (Doctor at the Burlo Garofalo hospital). A bigger issue is the 'informed consent' procedure. Patients cannot be forced to accept a certain type of health treatment, if not by the law. Therefore, the 'informed consent' procedure allows a patient to authorize a particular type of health treatment after having been informed about it by a health professional. Unfortunately, however, patients who do not speak the local language need a translator and the cultural-linguistic mediator in charge does not always happen to be at the hospital when needed. Therefore, the woman's spouse or her relatives will intervene and often times she will leave it entirely to her husband given her condition of subordination to him: 'I have found myself in very difficult situations in which the woman would not speak and relied on her husband completely. He would decide and she would consent. On one occasion there were delivery complications and the baby showed signs of fetal distress. I had to perform a C-section but my patient would not reply. She let her husband make all the decisions and he claimed that in their culture C-sections are prohibited [...]' (Doctor at the Burlo Garofalo hospital).

As can be seen by examining the responses to the INTEGRA project questionnaire, women are almost totally dependent on their husbands. The greater their language difficulties and their inability to relate with others in the host society, the smaller their personal independence. Women from Kossovo, Bangladesh, Nigeria, Pakistan, Turkey are particularly isolated.

All of the elements above help us gain a greater understanding of how 
integration is nowhere near for those communities characterized by a patriarchal type of traditional cultural model. They also show how social policies underestimate the status of women and their sexual and reproductive health as important indicators for the measurement of a woman's degree of social inclusion in a community.

The patriarchal system, which compels women to be housewives and to have many children, prevents them from getting employment, freely interacting with the outside world and gaining personal independence. The role of a housewife is so internalized by women that even when men express the hope to find a woman who has a job and is a bit independent, the women themselves refuse to: 'I've been living here for seven years. My wife arrived after me. I always tell her to look for a job and to learn Italian, but she refuses to and is always at home. She's used to it. (Husband of a Kosovan 25-year-old woman)

In other cases, the likeliness of getting a low-level type of job instead of working at home as a housewife discourages immigrant women from job hunting altogether. The challenge of having their education qualifications earned abroad recognized lowers women's chances of ever growing socioeconomically. This seems to be the major obstacle, mentioned by foreignborn working women, in finding a job related to the education earned and the skills acquired (Centro Studi e Ricerche IDOS, 2016).

Most women who migrate to Italy today, however, come to reach their husbands. As can be seen from the data on the number of women arriving and on the number of permits to stay released, family is the key factor for women in choosing to start the migratory experience altogether.

In the past, women arrived in Italy unaccompanied to work as domestic workers, caretakers for the elderly, babysitters, which gave Italian women the freedom to look for a job. The former left their countries alone (most of them were from the Horn of Africa and later from the Philippines, the Mauritius Islands, India and Sri Lanka).

One of the major issues in the current situation is the lack of motivation to learn the Italian language or the inability to access free language courses. Language problems are the main cause for migrant women's lack of integration and they necessarily lead to difficulties with: establishing relations with society and the institutions, the lack of awareness of women's rights in Italy and of the family code, taking care of themselves and of their children.

\section{Traditions and Cultural Violence}

'Tradition' is based on cultural systems in which the patriarchal component in many societies is dominant. The institution of marriage is the most signifi- 
cant traditional practice that structures the features of communities around 'the sense of belonging,' perpetuates the sense of attachment to one's community, and more importantly maintains a social order established by men. Forced marriage, in particular, perfectly meets all the criteria for the maintenance of male power, the supervision of female sexuality, and the limitation of solidarity and cohesion among women in the light of lineage: 'Women transfer reproductive power which men have nothing to do with [...]. Such reproductive power not based on lineage leads to the solidarity with another species, almost of a mystical order, different from that determined by family relationships which are equivalent to a socially organized world of males. Nevertheless, given the ideology of patrilineal descent, women are terminologically included in the agnatic relationship, the guidelines, in which they participate and which are based on nature, disrupt the pre-established social order and continue to call it into question' (Héritier, 2004, p. 62).

The concept of forced marriage (FM) includes a series of actions aimed at the coercion of an individual (mostly women) and at binding him or her in a legal relationship without consent: 'a wedding in which one or both of the spouses does not consent (in particular, disabled adults cannot give their consensus) to the wedding and in which constraint is exercised. Constraint may include physical, psychological, financial, sexual or emotional pressure' (Serughetti, Ruggerini, Lotti, Misiti, \& Virgilio, 2014, p. 5).

The institution of marriage includes certain types of contract featuring the 'ownership of a person;' in societies based on the patriarchal model, women become the subject of economic exchange given their reproductive qualities. The concept of ownership of a person is thus the means by which relationships of subordination and devaluation of women and of their social role continue to replicate (Hamel, 2011).

Let us consider FM the series of limits imposed upon freedom in a marital relationship, for example arranged weddings, child marriage, marriage of convenience or based on interest, but also the inability to interrupt a marital relationship due to social, cultural and family pressure, and lastly the impossibility of interrupting the marital relationship (Danna, 2013).

Forced Marriage is a global issue present in large areas of the world and which takes place in migratory contexts in both traditional and new forms for the purpose of isolation from the host society. Any sort of violation of the freedom of marital choice is the violation of a fundamental human right, as established by Art. 16 of the Universal Declaration of the UN: 'Wedlock is only possible with the free and full consent of the future spouses.' Furthermore, FM is a form of violence with a clear gender profile as it mostly affects women and girls and affects their sexual freedom. 
The places where weddings are pre-arranged and the countries where such practices are still preserved feature a number of dominant cultural factors which have been identified by the Council for human rights of the United Nations (Kabasakal Arat, 2008):

- controlling female sexuality in connection with the topic of male honor,

- protecting cultural/religious traditions from modernity,

- the relationship with cultural identity, the sense of belonging and the identification with one's country of birth.

In the first case, the causes have to do with forms of cultural pressure in relation to family and male honor which result in control of female sexuality and virginity, security at an old age - given the lack of a welfare state the desire not to lose property. In many cultures the dominant principle of sexual morality links the honor of a man with the integrity of 'his woman' or of 'his women.' In order for their chastity to be guaranteed, it is essential that their sexuality and their lives be controlled very strictly. Regarding adolescents, their virginity needs to be controlled until they wed, otherwise the whole family will undergo economic and social ruin (dishonor). Let us not forget that a marriage contract informally provides for dowry which is linked directly with the virtues of a woman. Early marriage and any other imposed form of marriage is cloaked with considerations on 'the protection' of a woman and of her virtues, and minimizes precocious sexual intercourse and enhances the power of the elderly (parents and grandparents) within the family and social community. The system of authority remains unaltered and roles are clearly fixed.

The socialization of this behavior is so strong that even when a woman chooses to wed a man, she will continues to feel a sense of guilt: 'In Bangladesh women wed at the age of 16 and then begin to have children. She will not have a job, she cooks and looks after her husband. In Bangladesh everyone talks and everyone knows everything about everyone. When a young woman weds, she is at the center of all attention in the village. Everyone observes her and checks whether she is behaving the way she should. Unless you wed based on your parents' recommendations or if you are separated and you live at home with your parents you will be subject to scorn by the community. You will be the shame of the family. When I was married, I got pregnant, but then my husband left me, and my brother claimed that I could not keep a child without a husband and that if I kept my child he would abandon the family. My mother also said that if I came back home with a child but 
without a husband we would be the talk of the town. Don't you ever come back to Bangladesh. Stay in Italia. You will bring only shame here [...] and everyone will say that you are a bad woman. If I had married the man recommended by my family, perhaps things would not have ended this way, but I fell in love with him [...]' (18-year-old woman from Bangladesh)

In some cultures, elderly women and those who have a higher social status are very powerful and use every means they avail of to sexually 'educate' young women and lead them back to a condition of subordination through magic: 'By us there is a ceremony called Kpessosso which takes place in September. It is a sort of a voodoo ritual. I do not belong to that culture. It is about magic, the Vudunera. They control women. They say there is a snake that needs to be subordinated. They tell you that you need to pay the Soma otherwise you will die. And you must do what they say, so if they say you must marry a man, you must do it [...]' (A 30-year-old woman from Togo).

In the second case, it is the parents who prevent their children from becoming too European, creating their own life space, and integrating completely with the host society. In this case the spread of religious fundamentalism is also relevant. In the case examined in the Bangladesh community in Monfalcone, where the choice of a future spouse is obviously made by the parents of the families, the practice of preserving traditional costumes continues unchanged. Even after years' residing in Italy, the women do not know the Italian language, they wear traditional clothes, lead the same lifestyle they used to lead in Bangladesh, force their daughters to wear a traditional dress. Everyone knows that at the age of 18 they will wed and will have to have their first child: 'My daughter dresses like me. Our life is led among the community. I've been here for many years, almost seven. I have never had anything to do with Italian women, I do not care, it has never happened. I do only when I go shopping and when I went to the hospital, but there my husband did the talking as I am unable to speak the local language. When my daughter turns 18 , she will get married and have children. I live like I used to in the village. I go shopping, cook, speak to other women, clean, wait for my husband to get back from work. Here it is better. I have a home and we live all together. If I have problems I go to the hospital, together with my children. My children go to school. We are many here and we always stick together.' (A 31-year-old woman from Bangladesh).

The third case has to do with the identification of the country of emigration, the hope to go back one day and the emigrants' regular contact with family back home thanks to the new technologies. All of this makes the emigrant a living symbol of his nation of origin, and every disconnection with 
his traditional culture is viewed as a betrayal towards his own country and all its history.

Let us not forget that a woman's body belongs to her family and community. In politics, identification takes place by means of symbols conveyed by the female body: 'This dress belongs to my country, to my people. I must respect my culture because it is my country. One day I want to go back and be respected for not having changed who I am.' (A 27-year-old woman from Bangladesh).

The element of choice is always very problematic and many unions experience the intervention of the family in the choice of a spouse. The degree of intervention may be very high, in which case the choice is made by the family directly, or very open, in which case the candidate may express her preference among a number of candidates selected by the family.

However, 'in some cases the differences between forced marriage and prearranged marriage are merely semantic' (Thomas, 2009, p. 2); psychological pressure and other forms of manipulation are so strong and binding that they serve as a deterrent to the woman's parents' choice.

If we include in forced weddings all the forms of family or institutional violence that prevent women from ending a relationship or divorcing, then the phenomenon is much more vast and complex. No less important are the socalled 'structural constraints' (Danna, 2013), ie poverty, for example, which causes women to leave everything behind and leave with a migrant or to marry a man in order to gain citizenship in the host country and benefit from the social rights acquired through marriage.

In the INTEGRA research project by questionnaire, 77 women at the OB/GYN clinic of the hospital of Trieste were asked questions about the nature of weddings in their country of origin. When asked about freedom of choice, five women did not answer whereas 45 women claimed that 'every individual is free' (just over $60 \%$ ). The question, however, confirms that in some countries 'choice' is an issue: nine women were completely denied any choice or claimed that it was possible only on certain conditions (there is a divide between urban and rural areas) or only in certain types of family ( 16 respondents). Even though some of the interviewees claim that the situation is changing, about $35 \%$ has lived in areas of the world where forced/prearranged marriage is still current. Most of them are from Bangladesh, Pakistan, Morocco, Cameroon. The total number of Bengalese and Pakistani women admitted that forced marriage is a normal practice still today in their country.

When asked the following questions: 'Have you been promised to some- 
one? If so, to whom and at what age' most (88\%) replied that they had not been promised to anyone, but nine of those interviewed admitted that their marriage had been pre-arranged and organized by the family. Among these are Pakistani, Bengalese, Kosovan, and two African women. Of the nine women who admitted they had been promised to someone, only two named those responsible (family and parents) and one Cameroonian woman admitted she had been promised when she was only three years old.

\section{Conclusions}

'Traditions' in many cultures are based on patriarchal models that strongly influence the sexual and reproductive health, and more generally speaking the self-determination, of migrant women. In migratory processes, loyalty to one's cultural community of origin and to the system of values in one's traditional social organization does not change very easily. The role of women, which is crucial in processes of social inclusion, remains secondary. It is therefore extremely important to measure the degree of integration of a community by means of new tools including the concept of women's selfdetermination which is expressed first and foremost through the woman's ability to manage her sexuality and reproductive functions.

The INTEGRA research project shows that the interviewees are totally dependent on their husbands and live a sort of parallel life while being excluded by the host society. Family is their one and only environment for action. Integration is a mere illusion.

\section{References}

Ambrosini, M., \& Berti, F. (2009). Persone e migrazioni: integrazione locale e sentieri di co-sviluppo. Milan, Italy: Franco Angeli.

Boccagni, P., \& Pollini, G. (2012). L'integrazione nello studio delle migrazioni:Teorie, indicatori, ricerche. Milan, Italy: Franco Angeli.

Cesareo, V., \& Blangiardo, G. (Ed.). (2009). Indici di integrazione: un'indagine empirica sulla realtá migratoria italiana. Milan, Italy: Franco Angeli.

Danna, D. (2013). I confini dell'azione pubblica: matrimoni forzati e combinati. Athenea Digital, 13(2), 65-81.

Centro Studi e Ricerche IDOS. 2016. Dossier statistico immigrazione 2016. Rome: Author.

Habermas, J. (1998). Multiculturalismo: lotte per il riconoscimento. Milan, Italy: Feltrinelli.

Hamel, C. (2011). Immigrées et filles d'immigrés: le recul des mariages forces. Population \& Sociétés, No. 479. Retrieved from https://www.ined.fr/fichier/s _rubrique/19147/479.fr.pdf 
Héritier, F. (2004). Dissolvere la gerarchia. Milan, Italy: Cortina.

Johnson, A. G. (1997). The gender knot: Unraveling our patriarchallegacy. Philadelphia, PA: Temple University Press.

Kabasakal Arat, Z. F. (2008). Women's rights as human rights. The Magazine of the United Nations, 45(2/3). Retrieved from https://unchronicle.un.org/ article/womens-rights-human-rights

Lannutti, V. (2016). La formazione identitaria delle seconde generazioni. La critica sociologica, 50(198), 145-150.

Ministero del Lavoro e delle Politiche Sociali. (2015). I migranti nel mercato del lavoro in Italia. Rome, Italy: Author.

Parsons, T. (1971). The system of modern societies. Englewood Cliffs, NJ: PrenticeHall.

Rinaldi, C. (2016). Sesso, sé e societá: per una sociologia delle sessualita. Milan, Italy: Mondadori.

Rinaldi, C., \& Scarcelli, C. M. (2016). Copioni sessuali. Lecce, Italy: Kurumny.

Sayad, A. (2002). La doppia assenza: dalle illusioni dell'emigrato alle sofferenze dell'immigrato. Milan, Italy: Cortina.

Sayad, A., \& Bourdieu, P. (2004). The suffering of the immigrant. Cambridge, Italy: Polity Press.

Sciortino, G. (2015). É possibile misurare l'integrazione degli immigrati? Lo stato dell'arte (Quaderno 63). Trento, Italy: Dipartimento di Sociologia e Ricerca Sociale.

Serughetti, G., Ruggerini, M. G., Lotti, M. R., Misiti, M., \& Virgilio, M. (2014). I/ matrimonio forzato in Italia: conoscere, riflettere, proporre. Rome, Italy: Dipartimento Pari Opportunitá.

Thomas, C. (2009). Forced and early marriage: A focus on Central and Eastern Europe and Former Soviet Union Countries with selected laws from other countries. Geneve, Switzerland: United Nations Division for the Advancement of Women.

Urpis, O. (2012). Patrie, migrazioni e culture. Udine, Italy: Casamassima.

Urpis, O. (2017). Ethnicity: Some conceptual definitions. In S. Baldin \& M. Zago (Eds.), Europe of migrations: Policies, legal issues and experiences (pp. 239254). Trieste, Italy: Edizioni Università di Trieste.

S. Ličen, I. Karnjuš, \& M. Prosen (Eds.). (2019). Women, migrations

and health: Ensuring transcultural healthcare (pp. 23-34).

Koper, Slovenia: University of Primorska Press.

https://doi.org/10.26493/978-961-7055-43-6.23-34 


\title{
Reproductive Health of Migrant Women in Slovenia: State of the Art
}

\author{
Blaž Lenarčič \\ Science and Research Centre Koper, Slovenia \\ blaz.lenarcic@zrs-kp.si

\section{Mateja Sedmak} \\ Science and Research Centre Koper, Slovenia \\ mateja.sedmak@zrs-kp.si
}

\begin{abstract}
The chapter presents the state of the art in the area of reproductive health of migrant women in Slovenia. At the beginning authors presents the demographic and socio-economic characteristics of migrant women, a review of national legislation regulating the area of reproductive health (for migrant women), a review of scientific literature and research dealing with the issue and a presentation of existing best practices. Data on the number of migrant women in Slovenia show that their number is constantly increasing (a six-fold increase between 1995 and 2016) and it is expected that it will be even higher in the future while at the same time a comprehensive and systematic approach to reproductive health in relation to migrant women is missing. The literature review and best practices overview indicate that the first and the most urgent step towards improvement of the situation in this area would be to educate health providers interculturally in order that they can recognize reproductive health norms and practices within different cultural contexts. This would allow them to provide culturally safe medical care, health education, and health promotion, and finally increase access to reproductive health for migrant women.
\end{abstract}

\section{Introduction}

The United Nations Guidelines on Reproductive Health (United Nations Population Information Network, 1994) characterize reproductive health as a state of complete physical, mental and social well-being, and not merely the absence of reproductive disease or infirmity. Furthermore, they highlight that reproductive health is an important component of general health and a prerequisite for an individual's social, economic and human development. In spite of the wide international adoption of norms and standards for the universal right to health, and reproductive health as an inseparable part of that, there remain significant gaps in access for certain groups of individuals. One such group is migrant women, who frequently confront specific challenges in this field. There is a general consensus that migrant women are an 
especially vulnerable group, which should have guaranteed early access to reproductive health services, preventive health services, health promotion, screening and diagnostic care, as well as prenatal and obstetric services. Unfortunately, as reported by Keyganert et al. (2014), compared with the general EU population, migrant women from non-EU Member States are less often screened for cervical and breast cancer, have less access to family planning and contraception and a lower uptake of gynecological care, are more at risk of unintended pregnancies, have fewer and later antenatal care visits, have poorer pregnancy outcomes and higher infant and maternal mortality rates. Because entitlements to health services are based on legal status, and because migrant women usually face communication obstacles and are subjected to discriminatory practices and lack of cultural understanding, the consequence is their limited access to a range of (reproductive) health information, goods, facilities and services (Bofulin \& Bešter, 2010).

The aim of this chapter is to present an overview of the current situation of migrant women in Slovenia with regard to reproductive health through (1) a presentation of the demographic and socio-economic characteristics of migrant women, (2) a review of national legislation regulating the area of reproductive health (for migrant women), (4) a review of scientific literature dealing with the issue and (5) a presentation of existing best practices.

\section{Demographic, Social and Economic Characteristics of Migrant Women in Slovenia}

The available statistical data' reveal a relatively low prevalence of migrant women in Slovenia. The highest percentages of migrant women are from other states of former Yugoslavia. Slovenia is not the final destination for those who, for various reasons, migrate to Europe from other continents. Slovenia is a small country, economically not very developed and less recognized in the wider political arena. Consequently, for economic, political, climate or other reasons, the number of immigrants coming to Slovenia is not high in comparison with other EU countries. The same is true when we look at the immigration of women.

In Slovenia, as already mentioned, immigration from the states of former Yugoslavia prevail, which started mostly for economic reasons back in the 1960 s and 1970 s. Slovenia faced a bigger migration wave, especially from the territory of Bosnia and Herzegovina, in the 1990 due to the war in Balkan

\footnotetext{
${ }^{1}$ Statistical data were obtained from the Slovenian national statistical agency (SURS, see http:// pxweb.stat.si).
} 
area, when more than 70,000 refugees came and some of them settled permanently, and also from Kosovo. Like other EU Members States in the last five-year period, Slovenia has also been challenged by migration flows due to the conflicts in the Middle East and Africa. However, it still remains mostly a transition country.

\section{Percentages of Migrant Women}

In the period 2011-2018 the percentage of foreigners in the overall Slovenian population has increased by $1.8 \%$ (from $4.1 \%$ to $5.9 \%$ ); in absolute terms, from 84,854 to 121,875 . In the same period, the number of foreign women increased from 25,728 to 43,019 . As a percentage of the female population, it has gone from $2.4 \%$ in 2011 to $4.1 \%$ in 2018.

In terms of statistical regions (Table 1), the presence of foreign women is highest in Central Slovenia $(40,716)$, followed by the Drava region $(161,607)$, Savinja region $(14,974)$ and Coastal-Karst region $(11,910)$. However, looking at the percentages, the highest percentage of foreign women in relation to the whole female population is registered in the Costal-Karst region (10.5\%),

Table 1 Population of the Statistical Regions of Slovenia by gender

\begin{tabular}{|c|c|c|c|c|c|c|c|c|}
\hline \multirow{2}{*}{$\begin{array}{l}\text { Statistical } \\
\text { region }\end{array}$} & \multirow[t]{2}{*}{ Total } & \multirow[t]{2}{*}{ Women } & \multicolumn{2}{|c|}{ Foreign pop. } & \multicolumn{4}{|c|}{ Foreign pop. - women } \\
\hline & & & (1) & (2) & (1) & $(2)$ & (3) & (4) \\
\hline Central Slovenia & 542,306 & 276,369 & 40,716 & 7.5 & 14,534 & 2.7 & 35.7 & 5.3 \\
\hline Drava & 322,058 & 161,607 & 16,408 & 5.1 & 5,089 & 1.6 & 31.0 & 3.1 \\
\hline Savinja & 254,760 & 126,834 & 14,974 & 5.9 & 4,828 & 1.9 & 32.2 & 3.8 \\
\hline Coastal-Karst & 113,961 & 57,536 & 11,910 & 10.5 & 4,727 & 4.1 & 39.7 & 8.2 \\
\hline Upper Carniola & 203,636 & 102,618 & 10,691 & 5.3 & 4,104 & 2.0 & 38.4 & 4.0 \\
\hline Gorizia & 117,260 & 58,552 & 6,426 & 5.5 & 2,422 & 2.1 & 37.7 & 4.1 \\
\hline $\begin{array}{l}\text { Sautheast } \\
\text { Slovenia }\end{array}$ & 142,819 & 70,752 & 6,426 & 4.5 & 2,084 & 1.5 & 32.4 & 2.9 \\
\hline Lower Sava & 75,359 & 37,431 & 4,085 & 5.4 & 1,380 & 1.8 & 33.8 & 3.7 \\
\hline $\begin{array}{l}\text { Litoral-Inner } \\
\text { Karniola }\end{array}$ & 52,334 & 25,864 & 3,369 & 6.4 & 1,216 & 2.3 & 36.1 & 4.7 \\
\hline Central Sava & 57,061 & 28,878 & 2,406 & 4.2 & 941 & 1.6 & 39.1 & 3.3 \\
\hline Charintia & 70,550 & 35,131 & 2,539 & 3.6 & 890 & 1.3 & 35.1 & 2.5 \\
\hline Mura & 114,776 & 58,267 & 1,925 & 1.7 & 804 & 0.7 & 41.8 & 1.4 \\
\hline Total Slovenia & $2,066,880$ & $1,039,839$ & 121,875 & 5.9 & 43,019 & 2.1 & 35.3 & 4.1 \\
\hline
\end{tabular}

Notes Column headings are as follows: (1) number, (2) total population percentage, (3) foreign population percentage, (4) woman population percentage. Residents on 1 January 2018, ordered by female foreign presence. Based on data from Statistical Office of the Republic of Slovenia (https://www.stat.si). 
Table 2 Foreign Women in Slovenia by Country of Citizenship in the Period 2011-2018

\begin{tabular}{lrrrrrr}
\hline Country & & 2011 & 2013 & 2015 & 2017 & 2018 \\
\hline States of former Yugoslavia & $n$ & 18,953 & 23,064 & 24,115 & 28,551 & 30,673 \\
& $\%$ & 78.8 & 78.8 & 70.5 & 71.2 & 71.3 \\
\hline European Union Member States & $n$ & 2,260 & 2,906 & 6,239 & 6,838 & 7,192 \\
& $\%$ & 9.4 & 9.9 & 18.3 & 17.0 & 16.7 \\
\hline Other countries & $n$ & 2,836 & 3,294 & 3,826 & 4,735 & 5,154 \\
& $\%$ & 11.8 & 11.3 & 11.2 & 11.8 & 12.0 \\
\hline Total & $n$ & 24,049 & 29,264 & 34,180 & 40,124 & 43,019 \\
& $\%$ & 100.0 & 100.0 & 100.0 & 100.0 & 100.0 \\
\hline
\end{tabular}

Notes Residents on 1 January. Based on data from Statistical Office of the Republic of Slovenia (https://www.stat.si).

followed by Central Slovenia (7.5\%) and Litoral-Inner Karniola (6.5\%). At the administrative level in relation to absolute numbers of foreign women, the highest numbers of foreign women are in Ljubljana $(10,502)$, Maribor $(3,256)$, Koper $(2,128)$, Kranj $(1,692)$, Celje $(1,634)$ and Velenje $(1,062)$. The highest percentages of foreign women in relation to whole population are seen in the Coastal municipalities: Izola (4.9\%), Sežana (4.8\%), Koper (4.1\%).

\section{Origins and Age Structure}

Among all foreign immigrant women in Slovenia in the period 2011-2018, the highest share had arrivals from the states of former Yugoslavia, followed by European Union Member States and other countries. The available statistical

Table 3 Foreign Women in Slovenia from Main European Countries in the Period 2011-2017

\begin{tabular}{|c|c|c|c|c|c|c|}
\hline \multirow[t]{2}{*}{ Country } & \multirow[t]{2}{*}{2011} & \multirow[t]{2}{*}{2013} & \multirow[t]{2}{*}{2015} & \multicolumn{3}{|c|}{2017} \\
\hline & & & & $F$ & $F+M$ & $\mathrm{~F} / \mathrm{M}(\%)$ \\
\hline Bosnia and Herzegovina & 8,194 & 10,043 & 11,986 & 14,341 & 50,378 & 28.5 \\
\hline Kosovo & 2,457 & 3,683 & 4,653 & 5,945 & 14,397 & 41.3 \\
\hline Macedonia & 3,222 & 3,885 & 4,329 & 4,853 & 10,835 & 44.8 \\
\hline Croatia & 2,609 & 2,779 & 2,971 & 3,187 & 9,230 & 34.5 \\
\hline Serbia & 2,205 & 2,351 & 2,791 & 3,060 & 10,632 & 28.8 \\
\hline Russia & 423 & 559 & 884 & 1,310 & 2,341 & 56.0 \\
\hline Ukraine & 897 & 989 & 1,043 & 1,218 & 1,898 & 64.2 \\
\hline Slovakia & 224 & 266 & 303 & 291 & 455 & 64.0 \\
\hline Romania & 144 & 158 & 189 & 196 & 392 & 50.0 \\
\hline
\end{tabular}

Notes Resident on 1 January, ordered by female foreign presence. Based on data from Statistical Office of the Republic of Slovenia (https://www.stat.si). 
Table 4 Foreign Women in Slovenia from the Main Non-European Countries in the Period 2011-2017

\begin{tabular}{|c|c|c|c|c|c|c|}
\hline \multirow[t]{2}{*}{ Country } & \multirow[t]{2}{*}{2011} & \multirow[t]{2}{*}{2013} & \multirow[t]{2}{*}{2015} & \multicolumn{3}{|c|}{2017} \\
\hline & & & & $\mathrm{F}$ & $F+M$ & F/M (\%) \\
\hline China & 388 & 433 & 453 & 490 & 1,082 & 45.3 \\
\hline Thailand & 159 & 184 & 191 & 213 & 238 & 89.5 \\
\hline Dominican Republic & 142 & 141 & 135 & 141 & 163 & 86.5 \\
\hline Philippines & 45 & 63 & 79 & 94 & 113 & 83.2 \\
\hline Brazil & 43 & 50 & 55 & 66 & 100 & 66.0 \\
\hline Kazakhstan & 16 & 19 & 33 & 57 & 114 & 50.0 \\
\hline Japan & 26 & 31 & 36 & 41 & 79 & 51.9 \\
\hline India & 17 & 22 & 28 & 38 & 136 & 27.9 \\
\hline Turkey & 20 & 17 & 26 & 37 & 145 & 25.5 \\
\hline Iran & 10 & 11 & 17 & 31 & 90 & 34.4 \\
\hline Cuba & 23 & 22 & 25 & 30 & 58 & 51.7 \\
\hline Indonesia & 10 & 19 & 23 & 29 & 37 & 78.4 \\
\hline Columbia & 15 & 19 & 20 & 26 & 33 & 78.8 \\
\hline Syria & 4 & 4 & 16 & 24 & 84 & 28.6 \\
\hline Peru & 9 & 11 & 12 & 19 & 34 & 55.9 \\
\hline Vietnam & 4 & 10 & 12 & 18 & 19 & 94.7 \\
\hline Mexico & 9 & 12 & 15 & 16 & 41 & 39.0 \\
\hline Venezuela & 10 & 13 & 13 & 16 & 27 & 59.3 \\
\hline South Korea & 11 & 11 & 15 & 15 & 21 & 71.4 \\
\hline Nigeria & 7 & 9 & 11 & 12 & 60 & 20.0 \\
\hline Argentina & 11 & 12 & 11 & 10 & 23 & 43.5 \\
\hline Morocco & 3 & 6 & 8 & 10 & 16 & 62.5 \\
\hline
\end{tabular}

Notes Resident on 1 January, ordered by female foreign presence (the table includes countries from which the number of immigrant women exceeds 10). Based on data from Statistical Office of the Republic of Slovenia (https://www.stat.si).

data (Table 2) also tells that around 90\% of migrant women originate from European countries.

Women migrating to Slovenia mostly come from economically less developed European countries and, as already shown, mainly from the states of former Yugoslavia. As evident from Table 3, in the period 2011-2017 the highest number of women migrating to Slovenia came from Bosnia and Herzegovina $(14,341)$, followed by Kosovo $(5,945)$, Macedonia $(4,853)$, Croatia $(3,187)$ and Serbia $(3,060)$.

As evident from Table 4, the highest number of women from non-European countries migrating to Slovenia in the period 2011-2017 came from Asia, 
specifically from China (490), Thailand (213) and the Philippines (94). A significant number of women also migrated from South America, namely from the Dominican Republic (141) and Brazil (66). Meanwhile, there is a relatively low number of women immigrating from Africa (i.e. Nigeria and Morocco).

Detailed insight into the age structure of the migrant women in Slovenia is shown in the data presented in Table 5. Namely, the proportion of foreign women in Slovenia is generally higher in the age groups 30-34 years old (12.8\%) and 35-39 years old (11.3\%). Meanwhile, the average age of migrant women in Slovenia is 33.7 years. However, there are some differences in distribution regarding the continent from which the women originate - for example, in economically less developed countries (Africa, Asia, the Caribbean, South and Central America), there is a higher number of immigrants in the age group 15-54 years old, while in the case of more developed countries (North America, Australia and Oceania), relatively high numbers of immigrant women are also present in older cohorts. This could be explained by the reason for migration: whereas women from less developed countries migrate to Slovenia mainly for economic (work opportunities) and matrimonial purposes, women from more developed countries migrate for other reasons, such as searching for a better quality of life.

\section{Level of Education}

An important relationship exists between migration and education because decisions about migration and education are closely intertwined. Furthermore, level of education is of great importance in the context of reproductive health, particularly in relation to migrant women. As shown by data in Table 6 , the educational level of migrant women living in Slovenia is generally low. In 2011 and in 2015 almost 50\% of all migrant women accomplished no higher than primary school education; almost $40 \%$ had high school education and approximately $10 \%$ had higher education qualifications (university).

However, when looking more carefully at the data, one can notice big differences in education taking into account the state of origin (considering the year 2015). Comparatively speaking, women migrating from South America are the most educated (approximately $36 \%$ accomplished high school and $40 \%$ university education). Women from other European states are also well educated (one-third completed primary school, one-third high school and one-third higher education); and this is similar for women from Australia and Oceania. Approximately $40 \%$ of women from EU states have primary school education or less, $40 \%$ have high school education and only roughly $20 \%$ university education. The lowest level of education among European countries 


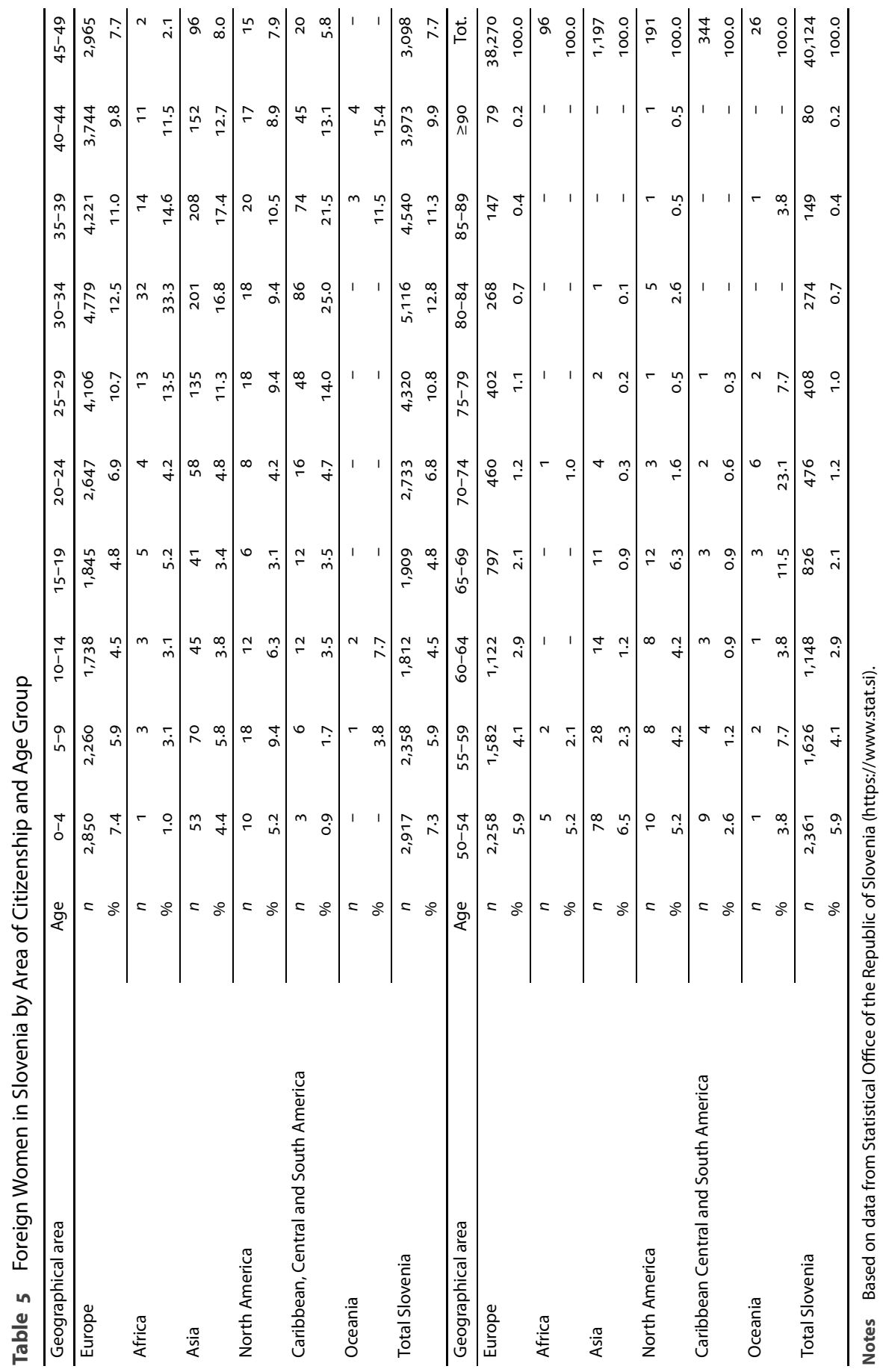


Table 6 Educational Level of Migrant Women in Slovenia (more than $15 \mathrm{y} / \mathrm{o}$ )

\begin{tabular}{|c|c|c|c|c|c|c|}
\hline & \multicolumn{3}{|c|}{2011} & \multicolumn{3}{|c|}{2015} \\
\hline & (1) & (2) & (3) & (1) & (2) & (3) \\
\hline States of ex-Yugoslavia & 41,755 & 29,045 & 8,133 & 31,615 & 21,922 & 6,056 \\
\hline EU Member States & 3,090 & 4,295 & 2,083 & 13,266 & 13,775 & 6,123 \\
\hline Other European states & 946 & 882 & 636 & 1,012 & 1,084 & 1,010 \\
\hline Africa & 60 & 77 & 33 & 67 & 80 & 47 \\
\hline South America & 100 & 123 & 107 & 87 & 130 & 146 \\
\hline North and Central America & 280 & 192 & 129 & 275 & 186 & 129 \\
\hline Asia & 338 & 305 & 121 & 380 & 435 & 211 \\
\hline Australia and Oceania & 56 & 81 & 56 & 44 & 61 & 48 \\
\hline Total & 46,625 & 35,000 & 11,298 & 46,746 & 37,673 & 13,770 \\
\hline
\end{tabular}

Notes Column headings are as follows: (1) primary school or less, (2) high school, (3) university. Based on data from Statistical Office of the Republic of Slovenia (https://www.stat.si).

was achieved by migrant women from the former Yugoslav countries: $53 \%$ accomplished no higher than primary school education, $37 \%$ high school and 10\% university.

A closer look at the educational structure of the individual states of former Yugoslavia (Table 7) reveals that there are no big differences when comparing both observed years, and that more than a half of migrant women obtained no higher than primary school education, more than one-third high school and approximately one-tenth obtained university education. Among all migrant women from former Yugoslav countries, the least educated are women from Kosovo (64\% finished primary school or less, $29 \%$ high school and only $7 \%$ university), while a relatively high educational level can be found among women migrating from Serbia.

Table 7 Educational Level of Women from the States of ex-Yugoslavia (more than $15 \mathrm{y} / \mathrm{o}$ )

\begin{tabular}{lrrrrrrrr}
\hline & \multicolumn{3}{c}{2011} & & \multicolumn{3}{c}{2015} \\
\cline { 2 - 3 } & & $(1)$ & $(2)$ & $(3)$ & & $(1)$ & $(2)$ & $(3)$ \\
\hline Bosnia and Herzegovina & 21,527 & 12,174 & 1,981 & 21,550 & 13,862 & 2,679 \\
Montenegro & 672 & 442 & 121 & 665 & 465 & 154 \\
Kosovo & 1,479 & 562 & 166 & 2,341 & 1,043 & 269 \\
Macedonia & 2,577 & 1,490 & 550 & 2,967 & 2,030 & 770 \\
Serbia & 4,229 & 4,411 & 1,880 & 4,092 & 4,522 & 2,184 \\
Total & 30,484 & 19,079 & 4,698 & 31,615 & 21,922 & 6,056 \\
\hline
\end{tabular}

Notes Column headings are as follows: (1) primary school or less, (2) high school, (3) university. Based on data from Statistical Office of the Republic of Slovenia (https://www.stat.si). 


\section{Employment Status}

Since health insurance in Slovenia depends to a large extent on an individual's employment status, it is important to consider the activities of migrant women in the labour market. As evident in Table 8 (p. 44), there are some interesting differences (considering year 2015) among migrant women according to the state of origin. Women who migrate to Slovenia from economically more developed EU Member States have different reasons compared with 'other' migrant women. The latter can also be seen from the obtained data, which show that the highest number of women from EU Member States are retired. We can anticipate that some of them came to Slovenia for reasons other than employment, such as higher quality of life, lower costs of living, safer environment, etc. Meanwhile, a significant number of migrant women from other European states (except countries of former Yugoslavia) are employed and the same is true for those who migrated from Africa, South America, North and Central America, Asia, and Australia and Oceania. Women from the states of former Yugoslavia are employed $(23,874)$ but there is a significant number of women who are unemployed $(7,385)$ or 'other' inactive $(11,284)$.

Table 9 (p. 44) is very informative, since it shows that there is quite a high number of unemployed women and women who are inactive in other ways from the states of former Yugoslavia. By far the highest number of inactive women migrating and living in Slovenia are from Kosovo. It seems that migrant women from Kosovo have in general the lowest educational level (Table 7) and are also most often unemployed or otherwise inactive. In 2015 there were more than 2000 women from Kosovo who were inactive, 600 registered as unemployed, and only 509 employed. It can be assumed that those registered as 'other inactive' are housewives who are not actively searching for a job, as those searching for a job would be registered as unemployed. Also, numbers from 2015 showing the situation for women coming from Macedonia reveal a very high number of inactive women - 1,682 in comparison with 1,974 employed (in addition to 771 unemployed). It can be anticipated that among them the biggest number represent ethnic Albanian women, so that the pattern of in/activity is very similar to those of women coming from Kosovo.

\section{(Reproductive) Health in Relation to Migrant Women in the National Legislation}

As already mentioned, reproductive health represents one of the individual's universal rights framed in the international human rights instruments and 


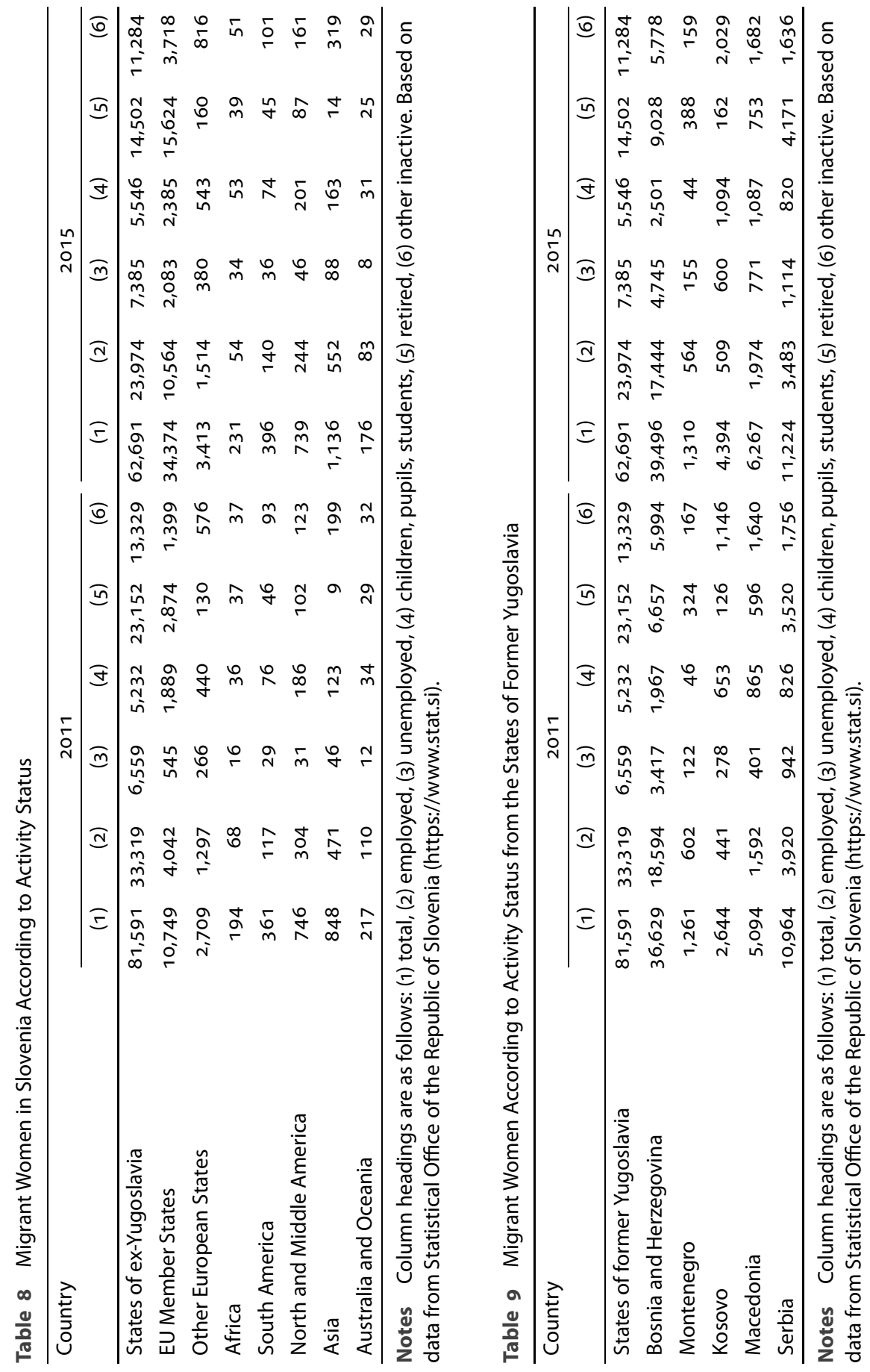


individual national legislation. ${ }^{2}$ Slovenia is a signatory of the main human rights documents (e.g. International Bill of Human Rights, Convention on the Rights of the Child, Convention on the Elimination of All Forms of Discrimination Against Women), through which it commits to ensure the right to reproductive health, as a part of the right to health. As an EU Member State, Slovenia is also obliged to respect documents concerning the area of reproductive health that were produced by the European Union (e.g. Charter of Fundamental Rights of the European Union, Health 2020: A European Policy Framework Supporting Action Across Government and Society for Health and WellBeing, EU Guidelines on Violence against Women and Girls and Combating all Forms of Discrimination against Them), although primary responsibility for regulating these rights lies with the country itself, which is to some extent independent in establishing its own (reproductive health) system.

In Slovenia access to public health services depends on an individual's compulsory health insurance, which is financed mainly by taxes, but does not cover all treatment costs. According to national legislation, i.e. Health Care and Health Insurance Act, ${ }^{3}$ full-coverage healthcare insurance is ensured for systematic and other preventive examinations of underaged children, pupils, students up to 26 years old, women in relation to pregnancy and other adult persons with certain health conditions (Article 23). The main legal documents regulating healthcare in Slovenia are the Constitution of the Republic of Slovenia, ${ }^{4}$ Health Service Act (1992), Patients' Rights Act, ${ }^{5}$ and Health Care and Health Insurance Act. It is important to mention that the Constitution of the Republic of Slovenia does not explicitly provide the right to health but foresees the right to health insurance (Article 50), healthcare (Article 51) and a healthy living environment (Article 75). According to the Constitution, all rights related to health are realized in accordance with the law that can set the conditions for carrying and exercising these rights.

According to legislation, migrants' entitlements to health services depend on their legal status: migrants with legal status are covered by the same healthcare system as citizens. Articles 15 and 20 of the Health Care and Health Insurance Act define on what grounds an individual is insured, the main criterion being employment in the Republic of Slovenia. Concerning underage

\footnotetext{
${ }^{2}$ All quoted laws, rules and guidelines are translated by the authors, because official English language translations are not available.

${ }^{3}$ Zakon o zdravstvenem varstvu in zdravstvenem zavarovanju, see http://www.pisrs.si/Pis.web/ pregledPredpisa?id=ZAKO213.

${ }^{4}$ Ustava Republike Slovenije, see http://www.pisrs.si/Pis.web/pregledPredpisa?id=USTA1.

${ }^{5}$ Zakon o pacientovih pravicah, see http://pisrs.si/Pis.web/pregledPredpisa?id=ZAKO4281.
} 
children, Lipovec Čebron, Zorn, Pistotnik, \& Meh (2016) stress that they have special protection regarding access to the healthcare system. Namely, the Health Care and Health Insurance Act (Article 15, Point 24) extends the right to healthcare to all minors enrolled in school, even if they do not have health insurance, citizenship or permanent residency status.

As the supreme law of the country, the Constitution of the Republic of Slovenia stipulates in Article 55 that 'individuals have freedom to decide on the birth of their own children. The state provides opportunities for exercising this freedom and creates such conditions as will enable parents to decide to have children.' This right is governed by the Health Measures in Exercising Freedom of Choice in Childbearing Act, ${ }^{6}$ which regulates the conditions under which the right of prevention of conception (Chapter II), abortion (Chapter III), diagnosis and treatment of impaired fertility (Chapter IV) are exercised. Legislation also dealing with reproductive health is Rules on Carrying out Preventive Health Care at the Primary Level, ${ }^{7}$ which initially explains that reproductive health ensures 'the right to a satisfying and safe sexual life, to decide freely on childbirth, to equal access to information on family planning and reproductive health regardless of gender, to safe and effective methods of family planning and the right to health services which provide women with a safe pregnancy and childbirth, and effective prevention and early detection of diseases that cause premature morbidity and mortality.' Furthermore, the document defines the following areas of reproductive health:

- the content of prevention programmes (family planning, use of contraceptives, sexually transmitted infections and subsequent infertility, preventive examinations during pregnancy, examinations and counselling after childbirth, spontaneous and permitted terminations of pregnancy and ectopic pregnancy, preventive activities for the protection of reproductive health in nursing care, preventive screening for the different types of cancer);

- programmed health education and health promotion in primary healthcare for women (guidelines for the protection of reproductive health of population groups with increased risk, guidelines for health education work with young people and with women before and after a permitted abortion and prenatal health education);

\footnotetext{
${ }^{6}$ Zakon o zdravstvenih ukrepih pri uresničevanju pravice do svobodnega odločanja o rojstvu otrok, see http://pisrs.si/Pis.web/pregledPredpisa?id=ZAKO408.

${ }^{7}$ Pravilnik za izvajanje preventivnega zdravstvenega varstva na primarni ravni, see http://www .pisrs.si/Pis.web/pregledPredpisa?id=NAVO59.
} 
- contractors of reproductive health prevention programmes (methods of implementation, coordination and control).

In addition, family members of migrants with permanent residence status can be insured on the basis of Article 20 of the Health Care and Health Insurance Act; namely, as close (spouses and children) or as extended family members (grandchildren, brothers, sisters and other children who live with the insured person in a common household and do not have sufficient means of subsistence and are permanently and completely incapable of work). Also, able to be insured under the extended family category are the father and mother of the insured person, or a spouse or cohabiting partner who live in the same household and are economically dependent on the insured person and are permanently and completely incapable of work.

Migrants who are not included in the health insurance system (asylum seekers and illegal migrants) have the right to emergency healthcare services, which, according to the Health Care and Health Insurance Act (Article 7), encompass 'urgent treatment of persons of unknown residence, aliens from countries which have not concluded an international agreement, as well as aliens and citizens of the Republic of Slovenia with permanent residence abroad who are temporarily residing in Slovenia or are travelling through the country and were unable to obtain payment for medical services, as well as for other persons who, under the provisions of this Act, are not included in the compulsory health insurance and are not insured with a foreign health insurance holder.' Situations of emergency care are defined in more detail in Article 25 of this Act: urgent treatment comprises essential rescusitation services, preservation of life and prevention of the deterioration of the health status of the sick or injured. The urgency of treatment is evaluated by a personal physician or competent medical committee in accordance with the general acts of the institution. The scope and situations of emergency medical help are also explained by the Rules on Compulsory Health Insurance, ${ }^{8}$ which, in Article 103 , specify that emergency medical help embraces rescusitation services, services necessary for maintaining life functions, services for the prevention of sudden serious deterioration of the ill person's health condition, treatment of injuries and chronic illness. The emergency healthcare services to asylum seekers are accurately defined in Article 86 of the International Protection Act, which, among other things,

\footnotetext{
${ }^{8}$ Pravila obveznega zdravstvenega zavarovanja, see http://www.pisrs.si/Pis.web/ pregledPredpisa?id=PRAV 3562 .
} 
regulates healthcare for women (contraception, abortion, healthcare during pregnancy and while giving birth). ${ }^{9}$

\section{Existing National Topic-Related Literature}

Reproductive health in relation to migrant women is an under-researched topic in Slovenia. However, there are a few articles which deal with the issue of reproductive health and indirectly mention migrant women as a vulnerable group that demands special attention. In addition, the academic literature on health issues of migrants encompasses a range of views from disciplines including social work, law, anthropology, sociology and health sciences as well.

The literature review revealed that health issues in relation to immigration began to generate attention among academics from the late 1990s, with the arrival of refugees from the countries of former Yugoslavia. For example, in their 2010 literature review Bufolin and Bešter cite Health Protection of Special Social Groups published in 1996 by the National Institute for Public Health, in which refugees and migrants were recognized as special social group. In this volume Mikuš Kos (1996) published an article theorizing on the issue but emphasizing that there are among migrants and refugees certain characteristics (e.g. high level of mortality, modest use of support services, lack of knowledge of (health) rights, low quality of life, high degree of dissatisfaction with life, poor functional literacy and marginalization) which make them vulnerable and consequently require special attention. Some of the earliest empirical work related to the reproductive health of women in Slovenia came from the field of social work. In 2005 Ličer published an article entitled 'Social Aspects of Women's Reproductive Health Protection.' For the purposes of her study she conducted ten interviews with women who went through their pregnancy without regular gynaecological examinations (not by choice); two women from the sample were immigrants. The results of the study revealed that for all women included in the sample the main reasons for not attending gynecological examination during the pregnancy derived from unregulated medical insurance, time constraints of being a single mother and privacy issues in the treatment room. The common denominator in the sample of interviewees was difficult socio-economic circumstances (unemployment, single-parent family and social exclusion). Based on the study results, it can be concluded that women have less information about reproductive health (1) when they are out of regular education and employment, (2) where ac-

\footnotetext{
${ }^{9}$ Zakon o mednarodni zaščiti, see http://pisrs.si/Pis.web/pregledPredpisa?id=ZAKO7103.
} 
cess to a gynecological clinic in their place of residence is problematic, and (3) where there is inconsistent respect for privacy, confidentiality and the right to make an independent decision on pregnancy.

Another important issue concerning the reproductive health of migrant women is access to medical services. There have been recent efforts to improve knowledge of (equal) access to health services of immigrants, which is reflected in the fact that a majority of available literature deals with the issue. Thus, Bufolin and Bešter (2010) have questioned the existence of inequalities between immigrants and non-immigrants regarding access to health services, their quality and general satisfaction with healthcare. Their study revealed that, with the (partial) exception of applicants for international protection and refugees, immigrants in the Slovenian health system are not recognized as a group that should have special attention in healthcare and integration policies. Their results indicated that the main problems faced by immigrants in the Slovenian health system include: language barriers, lack of intercultural competences of health personnel and their (hidden) discriminatory relationship towards migrants. These factors were also confirmed as a main source of unequal access to the health system in a recent study implemented by Lipovec Čebron (2017).

Healthcare as a human right is the starting point of the article published by Rajgelj (2012). Because of its universal status, an individual is entitled to healthcare regardless of his/her personal circumstances, but in the legislative process different systems have different criteria for the accessibility and funding of this right. In the case of Slovenia, the author observed how respective social priorities affect inclusion and exclusion of beneficiaries of healthcare on the ground of their legal status. To that end, she analyzed national and international legislation regarding the constitutional right to healthcare, health insurance, employment and family relations. Based on the analysis, the conclusion was drawn that since the enjoyment of the right of health insurance depends on an individual's employment, citizenship and family status, users of healthcare are treated unequally. The author also emphasizes that the most vulnerable group in the context of the access to health are immigrants without permanent residence.

Although in Slovenia applicants for international protection are eligible (only) for emergency treatment, research has identified several discrepancies between the rights afforded on paper and experiences in practice. Two similar studies were implemented with the purpose of examining conditions and opportunities for applicants for international protection to have access to health services. Lipovec Čebron (2009) and Jazbinšek and Palaić (2009) 
conducted interviews with employees in Asylum Home and applicants for international protection. Based on the data obtained, both studies came to the identical conclusion that health treatment for applicants for international protection in Slovenia is, in the majority of cases, inappropriate and limited. One of the main obstacles is the legally defined right to emergency health treatment, because it is not clear what exactly this means, and as such it can be subject of different interpretations.

Another important work regarding migrants' access to health services was published by Lipovec Čebron (2010). The author begins from the concept of medical citizenship and argues that it is an important category in examining the healthcare aspects of migration to Slovenia. Namely, the welfare services that had been available to all citizens prior to Slovenian independence in 1991 were converted into a source of inequality and exclusion after that date. 'Health policy has consistently become less socially oriented, as is reflected in increasingly restrictive and selective access to health services - or in other words, restrictive and selective medical citizenship in Slovenia' (Lipovec Čebron, 2010, p. 193). However, the main goal of this research is to prove that the seemingly regulated access to medical services still often deprives migrants of their medical entitlements. The author starts from the assumption that due to their frequent failure to assert healthcare rights, it is very important for migrants how health workers perceive them. To that end empirical data were obtained by interviews with health workers and administrative staff in Ljubljana and in the Slovenian part of Istria who had the most frequent contacts with the immigrant population. ${ }^{10}$ Based on the comments of medical professionals, the author concludes that their views of people without health insurance mirror neoliberal health policies. Namely, 'they perceive them as "foreigners" who should be taken care of in other countries, as a disorderly, "impure," "incompetent" people who represent a "burden" for the Slovenian health system' (Lipovec Čebron, 2010, p. 207).

In recent decades, researchers have identified the great impact of socioeconomic factors on various health outcomes. The results of a recent comprehensive health study were published in the report Inequalities in Health in Slovenia (Buzeti et al., 2011). Although the study does not mention immigrants specifically, it offers detailed insight into the sphere of inequalities in

\footnotetext{
${ }^{10}$ The survey included 42 persons: unstructured and semi-structured interviews were conducted with 13 specialist medical doctors, four general practitioners and six nurses. Responses to the questionnaire were received from five specialist medical doctors, three general practitioners and 11 administrative workers from healthcare institutions.
} 
health and identifies key challenges that Slovene society must face in the future if it wants to successfully manage health inequalities. One of main challenges, which is also evident from the reviewed scientific literature dealing with the topic, is that as a country we need a new vision for reducing inequalities in health. To that end, a strategic national framework (health policy) must be prepared, which will set out coordinated objectives and priorities for different sectors at national and local level. It is also important that individual departments at different levels recognize the benefits of reducing health inequalities, which can then contribute towards establishing more coherent sectoral and cross-sectoral policies. As the authors of the study argue, the prerequisite for planning and action in relation to health inequalities is the systematic monitoring of the situation and trends, which is the basis for designing measures and evaluating the achievement of the set goals. Collecting data at different levels is a prerequisite for the systematic monitoring, analysis and evaluation of health inequalities and the set goals.

At this point it is important to stress that at the national level no information is officially and systematically collected about the health of migrants (and migrant women) or of healthcare services that they use. According to the Healthcare Databases $\mathrm{Act}^{11}$, health providers are not required to collect data on a patient's nationality or his/her country of origin. Furthermore, the Act stipulates that if personal data relate to racial, national or other origin, political, religious or other beliefs or sexual orientation, database administrators may obtain this information directly or indirectly only with the written consent of the individual. The present situation makes it impossible to obtain information regarding reproductive health in relation to migrant women.

Reproductive health is closely related to gender-based violence, ${ }^{12}$ but this topic is also rarely addressed in public discourse and, unfortunately, hardly ever in scientific studies. However, research was recently implemented by Vah Jevšnik (2016) in which the impact of immigrant status on the vulnerability of migrant women in the context of family violence was observed. According to the research, migration status can significantly influence fre-

\footnotetext{
${ }^{11}$ Zakon o zbirkah podatkov s področja zdravstvenega varstva, see http://www.pisrs.si/Pis.web/ pregledPredpisa?id=ZAKO1419

${ }^{12}$ In Slovenia the term gender-based violence is used interchangeably with the term violence against women (Resolution on the National Program for Equal Opportunities for Women and Men 2015-2020 (Resolucija o nacionalnem programu socialnega varstva za obdobje 2013-2020, see http://www.pisrs.si/Pis.web/pregledPredpisa?id=NACP68), as most gender-based violence is inflicted by men on women and girls, although we must not overlook the fact that victims of gender-based violence can be also men.
} 
quency, responses and measures of violence against migrant women, as well as the support provided by public services. This leads to the conclusion that women who are in the country with unregulated legal status are even more vulnerable than those obtaining legal status; since illegal migrant women do not have a legal personal income, they are consequently not entitled to social benefits and support services provided by public institutions. In other words, they depend on the perpetrator and live in fear of deportation. With the purpose to obtain qualitative data, Vah Jevšnik (2016) conducted 30 interviews with professionals working with victims of gender-based violence, one of them being employed in Asylum Home. The study identified several risk factors in this social group, among which the most important are: lack of information regarding support systems, language barriers, mistrust and suspicion towards professional workers (especially men), absence of social networks, problems with integration, prejudice and discrimination against their way of life, low socio-economic status and low level of education.

\section{Best Practices Overview}

As evident from the review of national legislation and scientific literature, the specific needs and rights of migrant women in relation to reproductive health lack attention. Persistent efforts to resist this trend nonetheless make it possible to identify examples of good practice which are presented below.

As discussed above, migrant women in Slovenia are recognized as an especially vulnerable group and as such they have also limited access to a range of (reproductive) health information and services. With the purpose to improve access to healthcare services for different vulnerable groups in Slovenia, a chain of clinics (i.e. Pro Bono Clinic) was established. These clinics are intended for persons without medical insurance, such as people who are not residents in the territory of the Republic of Slovenia, asylum seekers, rejected asylum seekers, illegal refugees and refugees. Currently, there are four clinics located in Ljubljana, Maribor, Koper and Kranj. In the context of improving access to healthcare services, it is necessary to mention the project Towards Better Health and Reducing Inequalities in Health (2013-2016, financed by the Norwegian Financial Mechanism Programme). The first aim of the project was to recognize different vulnerable groups of the population of Slovenia which face difficulties with access to the healthcare system as well as barriers within health institutions. Among these groups were migrants, especially migrant women. With the purpose of improving access to these groups, several suggestions (legislative, administrative) were developed and transmitted to the competent authorities (Ministry of Health, Ministry of Labour, Family, So- 
cial Affairs and equal opportunities). Translated and adapted to the national context was the Standard for Equity in Health Care for Vulnerable Groups (Farkaš \& Lipovec Čebron, 2016), which was originally produced by the International Network of Health Promoting Hospitals and Health Services. The tool is designed as a 'barometer' for discrimination in the health sector and allows health institutions to find out the level of inclusion of different marginalized or socially weak groups in their services. At the final conference of the project, a Declaration on the Importance of Implementation of Intercultural Mediation in Healthcare Institutions in Slovenia was presented (Farkaš et al., 2016). Throughout the project, solutions were also introduced at a local level. One of them was in the city of Celje where it became evident that women from Albania faced language and cultural obstacles in health institutions. In an attempt to overcome these obstacles, an intercultural mediator was introduced in the local community, who was trusted by the Albanian community and at the same time possessed good knowledge of both the Slovenian and Albanian languages. During the project a pilot interdisciplinary educational course was also developed, titled Training for Development of Intercultural Competencies of Health Professionals, which was implemented in three public healthcare centres (Sevnica, Vrhnika and Celje) from February 2015 to March 2016.

As revealed by the literature review, migrant women face twofold difficulties in obtaining information and available services regarding reproductive health: the first obstacle is language and cultural barriers and the second is the absence of appropriate dissemination of already scarce existing information. This paradoxical situation is to a certain degree solved mainly by NGOs (specifically Slovenian Philanthropy) which offer various mainly project-based information services for migrants and provide cultural mediators for migrants in healthcare institutions.

In the context of gender-based violence and reproductive health, the project Recognizing and Treating Victims of Domestic Violence in Healthcare Settings should be mentioned (implemented during the period 20092014), which was co-financed by the Norwegian Financial Mechanism Programme. Specific project goals were: (1) implementation of the Family Violence Prevention Act in the health sector; (2) education of health workers based on professional guidelines for responding to violence against women in healthcare settings (developed by the Ministry of Health of the Republic of Slovenia); (3) increasing clinical, communication and cultural competencies of health workers to recognize and treat victims of domestic violence and to work with vulnerable groups; and (4) establishing intersectoral treat- 
ment of victims and perpetrators of violence against women comparable with international practices. The main outcome of the project was the publication of Recognizing and Treating Victims of Domestic Violence in Healthcare Settings: Guidelines and Training for Health Professionals (Šimenc, 2015) suggesting recommended conduct in responding to child victims of abuse and violence and adult victims of violence. The guidelines aim to equip health professionals encountering victims of violence with basic skills and knowhow for identifying abuse and properly responding to it.

In 2015 the Ministry of Health of the Republic of Slovenia adopted Professional Guidelines for Addressing Domestic Violence in The Implementation of Healthcare Activities (Ministrstvo za zdravje, 2015) which contained a series of recommended practices, steps for the treatment of child victims of abuse and violence and adult victims of violence against women, for various health professionals who may encounter this kind of violence. Specific guidelines have been developed for dealing with victims of domestic violence in hospitals and in gynecology and obstetrics, used in accordance with basic medical ethical rules.

\section{Conclusions}

In Slovenia a comprehensive and systematic approach to reproductive health in relation to migrant women is missing. The first major issue is the absence of a national periodical study on the topic. Systematic collection of data on migrant women included in the health insurance system and excluded from it should be started. This is necessary step and a base for any further measures in the field.

Data on the number of migrant women in Slovenia show that their number is constantly increasing (a six-fold increase between 1995 and 2016) and it is expected that it will be even higher in the future. The majority of migrant women come from the states of former Yugoslavia (Bosnia and Herzegovina, Kosovo, Macedonia and (roatia) and they migrate mostly for economic reasons (work) and family reasons (following husbands). Meanwhile, women from economically richer countries are migrating to Slovenia mostly for reasons connected with a better quality of life. The educational level of women migrating to Slovenia is relatively low, since almost $50 \%$ of all migrant women accomplished no higher than primary school education, which has crucial consequences for the information about and accessibility to reproductive health services. In general, one of the most marginalized groups of migrant women in Slovenia is Albanian women from Kosovo and Macedonia, who have the lowest educational level in comparison with all other 
migrant women; they are to a large extent non-active on the labour market (unemployed, but not registered as job seekers) and, finally, they mostly do not have Slovenian citizenship, do not speak the Slovenian language and do not have contacts and a social life outside the (extended) family and ethnic community. Due to the language barriers and other cultural and traditional norms (patriarchal values), it is a husband or male relative (e.g. father-in-law) who communicates with the 'outside' world on her behalf. As empirical studies show, this situation also has important implications for the reproductive health of these women (Sedmak, Medarić, Lenarčič, \& Gornik, 2018).

Although international and EU documents refer to health as a human right, specific needs and rights, in particular regarding reproductive health, are currently not ensured through Slovenian legislation. This is particularly true for migrant women with irregular status who have limited access to services of any kind beyond emergency care (and even for this service it is not clear exactly what it encompasses) through the public health system, including those related to their reproductive health rights. Similar findings were reported in studies dealing with the issue of equal access to health services among immigrants. Besides barriers specifically linked to their legal status, migrant women also face obstacles related to their status as foreigners, which results in limited familiarity with the national health system, different customs and experiences related to sexual and reproductive health, and languages that may be unfamiliar to healthcare practitioners. In this respect, several empirical studies have identified the main obstacles in accessing (reproductive) health services as being language barriers, lack of intercultural competences of health personnel and their (hidden) discriminatory relationship towards migrants. Resulting from this, it is clear that in Slovenia there exist quite a few discrepancies between the rights afforded on paper and the experiences of migrant women in practice. Although the activities of several NGOs aim to raise awareness about reproductive health in relation to migrant women, the literature review indicates that this is an under-researched field in Slovenia and we still lack theoretically and empirically supported analysis. The bottom line is that assessment of the current situation in Slovenia clearly unveils both blurred legal and policy frameworks and patchy practices, which are major shortcomings in terms of the realization of a rightsbased approach to reproductive health in relation to migrant women. The literature review and best practices overview indicate that the first and the most urgent step towards improvement of the situation would be to educate health providers interculturally in order that they can recognize reproductive health norms and practices within different cultural contexts. This 
would allow them to provide culturally safe medical care, health education, and health promotion, and finally increase access to reproductive health for migrant women.

\section{References}

Bofulin, M., \& Bešter, R. (2010). Enako zdravstvo za vse? Imigranti v slovenskem zdravstvenem sistemu. In M. Medvešek \& R. Bešter (Eds.), Državljani tretjih držav ali tretjerazredni državljani? Integracija državljanov tretjih držav $v$ Sloveniji (pp. 270-311). Ljubljana, Slovenia: Inštitut za narodnostna vprašanja.

Buzeti, T., Djomba, J. K., Gabrijelčič Blenkuš, M., Ivanuša, M., Jeriček Klanšček, H., Kelšin, N., ... Zver, E. (2011). Neenakosti v zdravju v Sloveniji. Ljubljana, Slovenia: Inštitut za varovanje zdravja.

Farkaš Lainščak, J., \& Lipovec-Čebron, U. (Eds.). (2016). Standard za zagotavljanje enakosti v zdravstveni oskrbi 'ranljivih' skupin in orodje za samoocenjevanje zdravstvenih ustanov. Ljubljana, Slovenia: Nacionalni inštitut za javno zdravje.

Jazbinšek, S., \& Palaić, T. (2009). Zdravje - človekova pravica? Prosilke in prosilci za mednarodno zaščito. Časopis za kritiko znanosti, 37(238), 154-162.

Keygnaert, I., Guieu, A., Ooms, G., Vettenburg, N., Temmerman, M., \& Roelens, K. (2014). Sexual and reproductive health of migrants: Does the EU care? Health Policy, 114(2/3), 215-225.

Ličer, Z. (2005). Socialni vidiki varovanja reproduktivnega zdravja žensk. Socialno delo, 44(6), 377-385.

Lipovec Čebron, U. (2009). Od kulture nezaupanja do selektivnega sočutja: prosilci in prosilke za mednarodno zaščito v slovenskem zdravstvenem sistemu. Časopis za kritiko znanosti, 37(235/236), 190-203.

Lipovec Čebron, U. (2010). The construction of a health uninsurant: People without medical citizenship as seen by some Slovene health workers. Studia ethnologica Croatica, 22, 187-212.

Lipovec Čebron, U. (2017). Ko nujno postane nenujno: raziskovanje zdravstvenih vidikov migracije v Slovenije. Glasnik Slovenskega etnološkega društva, $57(1 / 2), 54-64$.

Lipovec Čebron, U., Zorn, J., Pistotnik, S., Meh, E. (2016). MIPEX health strand: Country report Slovenia. Retrieved from http://www.nijz.si/sites/www.nijz .si/files/uploaded/podatki/slovenia_mipex_health.pdf

Mikuš Kos, A. (1996). Promocija zdravja migrantov in beguncev. In E. KraševecRavnik (Ed.), Varovanje zdravja posebnih družbenih skupin v Sloveniji (pp. 73109). Ljubljana, Slovenia: Inštitut za varovanje zdravja republike Slovenije.

Ministrstvo za zdravje. (2015). Strokovne smernice za obravnavo nasilja v družini pri izvajanju zdravstvene dejavnosti. Ljubljana, Slovenia: Author.

Rajgelj, B. (2012). Vpliv delovnopravnega, državljanskega in družinskopravnega 
statusa na neenako obravnavo v zdravstvenem zavarovanju. Zdravstveno varstvo, 51(1), 43-52.

Sedmak, M., Medarić, Z., Lenarčič, B., Gornik, B. (2018). Spolno in reproduktivno zdravje migrantkv Sloveniji:Študija primera treh obalnih občin. Koper, Slovenia: Znanstveno-raziskovalno središče Koper.

Šimenc, J. (Ed.) (2015). Prepoznava in obravnava žrtev nasilja v družini: priročnik za zdravstveno osebje. Ljubljana, Slovenia: Zdravniška zbornica Slovenije.

United Nations Population Information Network. (1994). Guidelines on reproductive health. Retrieved from http://www.un.org/popin/unfpa/taskforce /guide/iatfreph.gdl.html

Vah Jevšnik, M. (2016). Vpliv migracijskega statusa na ranljivost žrtev nasilja v družini. Socialno delo, 55(1-2), 67-76.

S. Ličen, I. Karnjuš, \& M. Prosen (Eds.). (2019). Women, migrations and health: Ensuring transcultural healthcare (pp. 35-57).

Koper, Slovenia: University of Primorska Press.

https://doi.org/10.26493/978-961-7055-43-6.35-57 



\title{
Working on Epidemiological Data: Problems Encountered and Lessons Learned
}

\author{
Giovanni Delli Zotti \\ University of Trieste, Italy \\ giovanni.dellizotti@dispes.units.it
}

\begin{abstract}
In addition to the epidemiological analysis of hospital admissions and outpatient services, the INTEGRA Project envisages the development of a sexual and reproductive health index that aims to identify situations at risk or which require 'targeted' interventions. This implies the need to identify suitable indicators, whose characteristics are described in the first part of the article, with reference to the specific needs of the INTEGRA Project. A discussion follows on the distinction between micro and macro level indicators and some examples are illustrated. Some problems found by analyzing the Hospital Discharge Cards are then described and some solutions are proposed. A final specific topic concerns the implications of the transition from a database having 'hospital demission' as unit of analysis to a data archive based on 'patient' as the unit of analysis.
\end{abstract}

\section{Introduction}

The INTEGRA Project, in addition to the epidemiological analysis of hospitalizations and outpatient services provided, foresees the development of a Sexual and Reproductive Health Index that aims to identify situations at risk or which require 'targeted' interventions. Being a 'health' index, high values would indicate the absence of criticality; on the contrary, low values would signal more or less severe problems that need to be removed. Alternatively, an index of 'pathology' might be developed; however, it is more effective to 'think positive' and, after all, 'health' is the word used in international documents, starting from The Beijing Declaration promoted by the United Nations in 1995. The Declaration included the recognition of the human rights of women as integral to the achievement of optimal health and well-being: 'The human rights of women include their right to have control over and decide freely and responsibly on matters related to their sexuality, including sexual and reproductive health, free of coercion, discrimination and violence. Equal relationships between women and men in matters of sexual relations and reproduction, including full respect for the integrity of the person, require 
mutual respect, consent and shared responsibility for sexual behavior and its consequences' $(1995$, p. 36).

Making an index means starting from a general concept to arrive at its 'measurement' at the end of a process that can be quite complex. Even if we succeed in defining the concept with some precision, the property to be measured remains relatively abstract until we move on to its concrete specification. The concept of 'health' is perhaps less abstract than others, but rather complex, because we can talk about health (sexual, reproductive or otherwise) only after verifying the absence of several situations that could undermine it, or the presence of factors that can positively affect it. In methodological terms, it is therefore necessary to identify suitable 'indicators' and to define them operationally, meaning that we must specify how we intend to measure them. The indicators this way become variables that need to be opportunely combined in order to obtain the foreseen index.

Using the term 'opportunely,' we intend to recall the fact that indicators overlap more or less broadly the semantic range of the concept/property that we intend to measure. It is therefore legitimate to attribute to the indicators/variables appropriate weights, trying to replicate their degree of validity. In fact, when choosing indicators validity is an important requisite, since we need indicators that clearly point at the property we aim at measuring (face validity, see Drost, 2011). When establishing how to translate each indicator into a variable, the most important characteristic to seek is instead reliability of the outcome of measurement.

Other criteria may also be relevant, such as those listed in a site dedicated to the construction of indicators for Family Planning/Reproductive Health (FP/RH) (measureevaluation.org):

- Relevance: there is a clear relationship between the indicator and FP/RH

- Accuracy: the indicator measures what it purports to measure

- Importance: the measurement captures something that 'makes a difference' in program effectiveness

- Usefulness: the results point to areas for improvement. Furthermore, the indicator captures information that helps move FP/RH strategies, priorities, or programming forward

- Feasibility: data can be obtained with reasonable and affordable effort

- Credibility: the indicator has been recommended - and is being used - by leading experts and organizations such as WHO, UNAIDS, USAID, and UNFPA

- Validity: to the extent possible, the indicator has been field-tested (in- 
cluding those measured in Demographic and Health Surveys (DHS) and Reproductive Health Surveys (RHS)) or used in practice ${ }^{1}$

- Distinctiveness: the indicator lacks redundancy and does not measure something already captured under other indicators.

- In addition, where indicators are presented as part of a set, this set should meet another criterion, namely that the overall set is coherent and balanced.

Authors also point out that the indicators presented and analyzed where harmonized with those already in use, giving high priority to indicators from key initiatives such as the Millennium Development Goals ${ }^{2}$ and USAID's Global Health Initiative $(\mathrm{GHI}){ }^{34}$

The recent Guide for Monitoring and Evaluating Population-Health-Environment Programs (Moreland \& Curran, 2018), insists that each indicator must be valid to accurately measure a behavior, practice or task, reliable (consistently measurable in the same way by different observers), precise and, of course, measurable, that is quantifiable using available tools and methods. Authors add that indicators should also be timely, thus providing measurement at intervals that are relevant and appropriate for program goals and activities, and programmatically important, that means linked to a public health impact or to achieving the objectives needed for impact. The last criterion, labeled in the list above as 'usefulness', needs to be stressed, being significantly important for the scope of INTEGRA Project. The project has in fact mainly application purposes, because the Index of Sexual and Reproductive Health (SR Index) 'will be used by health professionals when it comes to migrant women and will have the possibility of being transferred to different health facilities and to ensure holistic care, as it enhances both the medical and the social dimension.'

The World Health Organization (1997), sometimes uses different words for features already mentioned, but adds also something new in her description of the 'good indicator:'

- Ethical: Data must respect people's rights to confidentiality, freedom of

\footnotetext{
1 'Validity' is here meant in a more technical sense but, being attributed to indicators tested in the field, also in comparison with similar instruments, it seems to be more appropriate to refer to reliability (test-retest reliability).

${ }^{2}$ See http://www.un.org/millenniumgoals.

${ }^{3}$ See https://www.usaid.gov.

${ }^{4}$ This is quite relevant for the INTEGRA Project, since the 'new index' aims to be inserted among the other indexes used for the assessment of integration policies.
} 
choice in supplying information, and informed consent regarding the nature and implications of the data required.

- Useful: the indicator acts as a marker of progress toward improved reproductive health status or as a measure of progress toward specified process goals.

- Scientifically robust: the indicator should be a valid, specific, sensitive, and reliable reflection of what it purports to measure.

- Representative: the indicator must adequately encompass all the issues or population groups it is expected to cover.

- Understandable: the indicator should be simple to define and its value easy to interpret.

- Accessible: it uses data that are already available or are relatively easy to acquire by feasible methods that have been validated in field trials.

In addition, the Canadian International Development Agency (CIDA) (1996) recommends that good indicators have the following characteristics:

- Participatory: the indicator has been developed in a participatory fashion.

- Relevant: the indicator has been formulated at a level the user can understand and is relevant to the users' needs.

- Sex-disaggregated: data are collected so that analysis can be conducted separately for males and females, if appropriate.

- Qualitative or quantitative: data are either quantitative or qualitative, as appropriate to the objectives of the project.

Noting that these are the characteristics authoritatively identified, a researcher intending to collect original data is responsible for operating in a way to satisfy them; intending instead to use pre-existing data, he can only ascertain the existence of these characteristics. Finding any shortcoming, he may look for alternative sources and/or recommend enhancing accuracy in collecting the data. This is the case of the INTEGRA Project, since researchers have the opportunity to suggest improvements, having also the task of proposing guidelines.

\section{Micro and Macro Level Indicators}

When dealing with indicators and indexes, the level of measurement is another aspect that must be carefully considered: it is a matter of deciding whether indicators will be measured and/or used at an individual (micro) 
or collective (macro) level. ${ }^{5}$ The list of Recommended Sexual and Reproductive Health and Rights Indicators for Post-2015 Sustainable Development Goals (Guttmacher Institute, 2015, p. 3) provides examples of macro-level indicators and specifies whether indicators are available, or just 'aspirational' (Table 1). ${ }^{6}$

As can be easily understood from terms such as 'proportion,' 'percentage' or 'rate', many indicators are built by gathering information at the individual level, later aggregated to estimate the health status of categories or groups of people defined according to gender, social status, country or cultural origin, etc. In other instances, indicators genuinely refer to the 'macro' level, since they do not derive from the aggregation of individual data (it deals, for example, of legislation, policies, or cultural traditions of the countries considered).

Undoubtedly, one may use 'macro' health indices to attribute a presumptuous degree of health/risk to single women coming from, or belonging to, specific countries or categories.

However, it is necessary to underline that some indicators, designed to monitor sexual and reproductive health in different countries of the world, are not necessarily useful for evaluating the situation of immigrant women. For example, the Reproductive health indicators lists, among others, antenatal care coverage, births attended by skilled health personnel and availability of basic essential obstetric care are (World Health Organization, 2006). In the countries of origin, these services may be lacking but, when dealing with women and their health, once immigrated to Italy and Slovenia we can consider these services available. Therefore, instead of ascertaining the availability of such services, it will be necessary to check whether women use them, particularly in the case of antenatal assistance.

Furthermore, using macro indices is a rough approximation since every woman, while sharing a social or ethno-national belonging, and thus a generic level of sexual and reproductive health, bears a specific situation that can improve or completely nullify the level determined by macro indicators. It is therefore evident that the information gathered at the individual level, useful for the contribution they can make to the construction of macroindices, are essential for determining the sexual and reproductive health of single women who, in the case of the INTEGRA project, are mainly those that use the services offered by hospitals and outpatient facilities.

\footnotetext{
${ }^{5}$ For a preliminary approach, see (https://en.wikipedia.org/wiki/Level_of_analysis).

${ }^{6}$ By citing not yet available indicators, the list is particularly useful for the INTEGRA Project, as it suggests directions to which it would be advisable to proceed.
} 
Table 1 Recommended Sexual and Reproductive Health and Rights Indicators

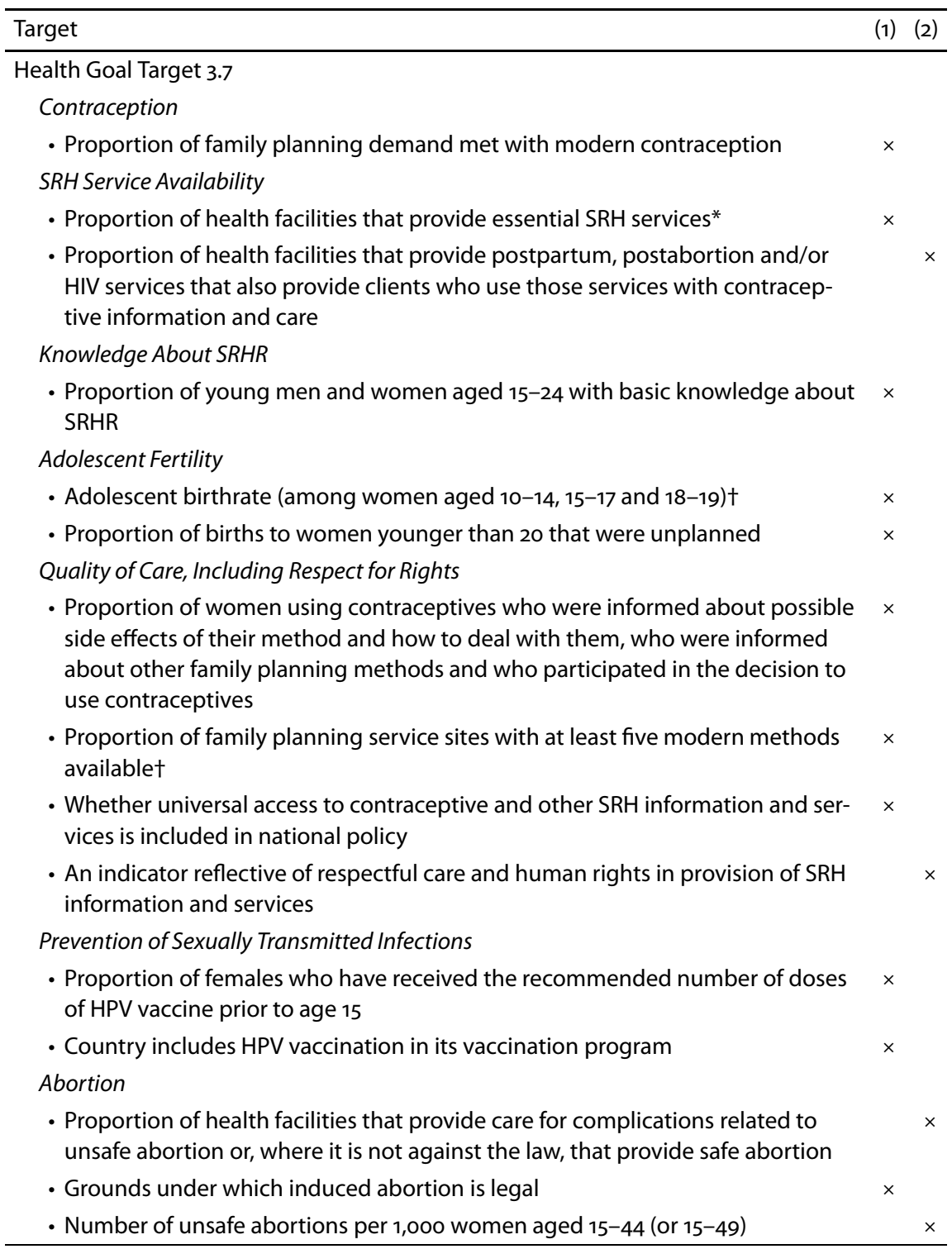

Continued on the following page

\section{The Hospital Demission Record (HDR)}

Having ascertained that many macro level indicators and indexes are already available, we will here focus on the micro level, dealing with the character- 
Table 1 Continued from the previous page

\begin{tabular}{lc}
\hline Target & (1) (2) \\
\hline Education Goal Target 4 & \\
- Comprehensive Sexuality Education & $\times$ \\
- Proportion of schools that serve students in the age range of $12-17$ years in & \\
$\quad$ which comprehensive sexuality education is available & \\
\hline Gender Equality Goal Target 5.6 & $\times$ \\
Gender Equality in SRHR & \\
- Respect for women's sexual autonomy within marriage & \\
- Whether universal access to contraceptive and SRH information and services is & $\times$ \\
\hline & included in national policy
\end{tabular}

Notes Column headings are as follows: (1) available, (2) aspirational. * Currently available only in a small number of countries with special surveys. $\dagger$ Available for very few countries for those aged 10-14. Adapted from Guttmacher Institute $(2015$, p. 3).

istics and criticalities that had an impact on the epidemiological survey carried out by analyzing the Hospital Demission Records (HDR) provided by the IRCCS Burlo Garofolo. In the following, we will thus comment on some of the fields contained in the Excel files received, together with the technicalmethodological choices adopted to cope, where possible, to some critical issues encountered.

The basic information on the demission division of the patient highlighted a problem that must be taken into account, wanting to use this variable in a longitudinal analysis. A complex structure sometimes provides internal reorganizations and this may force interventions on past data. ${ }^{7}$ While the incorporation of a previously autonomous divisions can be easily manages, when part of a structure becomes autonomous we are faced with a more complex problem to face. Even more complex is the situation when hospital admissions become outpatient services, since information to analyze move from the hospital demission records to the outpatient services archive. In our case, this happened when the Medical Assisted Reproduction Division was abolished in 2014 and their activity passed to the outpatient services.

During a meeting with the Burlo Hospital partners, it was also learned that in some periods of time patients were admitted to the two main divisions (Obstetrics and Gynecology) taking into account organizational and not only diagnostic aspects. Hence the consequence that Hospitalization Division is a

\footnotetext{
${ }^{7}$ The situation is similar to that of the change from national currencies to Euro, which forces the conversion of past economic data into the new currency to allow analyses in a longitudinal perspective.
} 
variable to be used with caution in order to select the case studies of interest, resulting more reliable, to avoid the risk of losing relevant cases, the use the fields reporting the diagnoses and interventions performed on patients.

The database also reports the 'Progressive HDR', which shows an anomaly: starting from the first patient of the year, each admission is assigned an incremental HDR code, but the highest code number does not correspond to the total number of hospitalizations. The analysis of 'missing' HDR records shows that they tend to grow over time, reaching over $10 \%$ in the last two years. There are also some inexplicable oscillations, such as the sudden upsurge in 2007 and the halving in 2012. By ordering HDR records inside each year, one may note that the lack of HDR codes does not present a discernable 'pattern.' The deleted cards may be related to a demission followed by admission to another Department, although a new HDR should only be created in a few wellspecified cases. In fact, according to the prescriptions of the Ministry of Health: 'the identification number, attributed to each medical record and of the relative HDR, must be the same for the entire duration of admission, regardless of internal transfers within the same health institution. Exceptions are the transitions from ordinary to day hospital and from acute to rehabilitation or long-term care, or vice versa. In the latter cases, a new medical record and a new HDR must be completed' (Ministero della Salute, 2018, p. 10). One may guess that the removal of numerous HDRs depends on controls that detected duplications or induced to delete incomplete HDR cards, but it is necessary that these aspects are clarified in order to allow a correct use of this information.

Marital status, education and profession variables are present in the database, but unusable because in most cases the fields are not filled out. It is not clear why, given that marital status and education are classified as compulsorily fields in the Functional Specifications of the Ministry of Health (Ministero della Salute, 2017). These provisions are recent, but they do no more than reiterate that marital status is a mandatory field, since the introduction of the HDR with the D.M. October 27, 2000, n. 380, and education has been defined mandatory with the D.M. July 8, 2010, n. 135. Unfortunately, the unavailability of this information for the vast majority of hospitalizations deprives INTEGRA Project of important cognitive elements that would be useful for socially identifying hospitalized women and for the construction of the Sexual and Reproductive Health Index. Moreover, these shortcomings make it difficult to compare with the hospitalization analyzes carried out by Slovenian partners, who can count on the availability of complete information regarding the education and marital status of patients. 
Unfortunately, these deficiencies are generalized, to the point that the Ministry of Health summary of the history of the introduction of the HDR and the characteristics of this important tool ends with the paragraph 'Limitations and cautions in the use of data,' thus recognizing the existence of the problem. 'It is necessary to keep in mind that the HDR database, even if it has a very rich information content and an almost total coverage of the Italian hospitals, has limits and criticalities in the use, such as problems of homogeneity of compilation, completeness and accuracy for some variables (mainly in the first years) and variation of the classification systems over the years. ${ }^{8}$

In addition to incompleteness of information, data analysis showed an even more worrying aspect. Information about marital status and education, in addition to being available for only about a third of hospitalizations, revealed serious inconsistencies that are not acceptable because they undermine the reliability of the database. For example, crossing education and marital status with age, underage patients with a university degree were noticed and less than ten years old girls turn out to be married and sometimes even already separated. If there were few cases, we could think of inattention in writing data on paper or when recording on electronic media, but dozens of inconsistencies of this type suggest that they may also due to some kind of systematic error.

Faced with a rather generalizes situation, according to the Ministry of Health, it may be appropriate that the INTEGRA project guidelines will contain a strong recommendation to support the completeness and correctness of the compilation of the HDRs. The HDR database contains also fields in which up to six different diagnoses may be recorded. Specific diagnoses are very numerous and detailed, but they can be grouped into a smaller number of categories, identified by the first 3 digits of the codes used for registration. These categories may then be further grouped in 17 chapters, according to the International Classification of Diseases ICD-9-CM. Another six fields are reserved for the interventions to which the patient has been submitted during the hospitalization and interventions too may be aggregated, for the purposes of the analysis, in 17 general categories.

The plurality of recordable diagnoses and interventions caused a shortcoming detected by the analysis of the database that revealed the frequent duplication of similar diagnoses within the same HDR card. This appears to be

\footnotetext{
${ }^{8}$ See http://www.salute.gov.it/portale/temi/p2_6.jsp?id=1232\&area=ricoveriOspedalieri\&menu =vuot.
} 
imputable to the attribution of a general code together with a more specific code to the same diagnostic situation. In the case of childbirths, a frequent situation is that of the diagnosis ' 650 - Normal birth' coupled to the ' $V_{270}-$ Simple birth: born alive' diagnosis.

The problem could be solved by using the 'DRG - Diagnosis Related Group' code, which assigns the reasons for admission to a single category by identifying, using an algorithm, the 'prevalent diagnosis.' However, this may result in the loss of essential information, because a diagnosis, relevant to the construction of the Health Index, may not be 'intercepted' due to the attribution of that hospitalization to a DRG that does not appear to be significant.

Other anomalies found in the data may depend on errors in the registration of information or on an uneven application of the criteria for registration by the plurality of operators who contribute to the compilation of HDR cards. In any case, as we learn from the most recent Annual Report on Hospitalization in the section 'Completeness and Quality of the HDR Survey' (Ministero della Salute, 2017), compilation errors significantly affect the quality of the recorded information. The consequences of this situation are not trivial, as claimed by Roberto Vattovani (2009) in his doctoral thesis 'Italian-Slovenian Hospital Health Mobility after Slovenia's Accession to the European Union:' 'Even if HDRs do not have a strictly epidemiological purpose, being part of an administrative-accounting processes, the analysis of admissions by diagnosis provides a broad and articulated picture of hospitalization, a phenomenon of great importance for Public Health, both for the importance of the pathologies for which patients access this service, and for the considerable financial commitment that the various local health authorities dedicate to hospitals' (p. 25).

The author adds that the Ministry of Health, differently from the FVG Region, usually does not provide the individual HDR records, but only data aggregated according to some relevant attributes, thus limiting the execution of possible analyzes. For example, not knowing the place of residence of Slovenian citizens, the actual extent of the phenomenon of international health mobility cannot be estimated, even if this information is partially derivable through the table on hospitalization charges (Vattovani, 2009, p. 116). Even if this is a rather specific example, it is useful to underline the need to be able to count on detailed information at the 'micro' level, in order to carry out analyzes aimed at tasks such as the construction of a health index. In fact, while performing some aggregation towards the 'macro' level is possible, it is difficult to go down from the macro level to minute group segmentations, and impossible to reach the individual level. 


\section{From Hospitalizations to the Patients}

Since patients may repeatedly resort to hospital care, to estimate the number and type of user it is necessary to pass from data on admissions to a database in which the unit of analysis is the patient. After recording in the new database the number of admissions, it should be decided which other information contained in the 'demission' database should be associated with each patient. The procedure does not present any problems for the characteristics who remain stable over time, which are however few because only the place and date of birth certainly remain unchanged.

In case of multiple admissions, in addition to age, citizenship, residence, marital status, department of demission, diagnoses, interventions, etc. may also change. It is therefore necessary to decide whether to register, for example, citizenship at first or last admission, but it may be advisable to register both because, by comparing the two situations, one can obtain the useful additional information of a possible change of citizenship.

Similarly, you can record the year of the first, last or all admissions but, working in a longitudinal perspective, the choice between producing tables in which patients are 'anchored' to the first, or last, year is not neutral. In the first instance, there will be an artificial decline in patients over time: for example, a patient 'assigned' to 2006 (first admission), will not appear in the following years. On the contrary, assigning patients to the year of the last hospitalization, going back in time we will be confronted with an artificial rarefaction of patients.

In both cases, distortions do not allow an effective longitudinal analysis. Therefore, it seems reasonable to propose a different solution: patients are counted only once in case of multiple admissions in the same year and reinserted it in the database if admitted in a different year. Moreover, while aggregating the hospitalizations carried out in any wider period needs some kind of 'justification' (could be longer or shorter), year by year solution is supported by the Ministry of Health, using it for the Annual Report on Hospital Admission (Ministero della Salute, 2017) and hospital facilities too yearly allocate resources, report activities, etc.

Even this solution, however, presents a criticality, because it does not put all patients on the same level. In fact, about patients admitted at the beginning of the year we know the subsequent 'hospital history', but any previous admission is not detected; about patients admitted at the end of the year we know if they have already been hospitalized, but we cannot know what will happen in the future. In practice, if you want to study the hospital history 
of each patient in a year, once identified for each patient a referral hospitalization, from that date one should add to the clinical history of that patient all the possible hospitalizations occurred in the six months before and after. Similarly, extending the observation period to two years, starting from the 'central' admission date, the observation should be extended to the previous and following 365 days.

\section{Conclusions}

The Italian Parliamentary Commission of Inquiry into the System of Reception, Identification and Expulsion, as Well as the Conditions for the Detention of Migrants and Public Resources Committed, approved a Report on the Protection of the Health of Migrants and of the Resident Population on 8 November 2017 (Camera dei Deputati, 2017) which includes an analysis of the 'epidemiological situation' with which the conditions are laid for improving the health system in relation to the situation of subjective vulnerability of the migrants. Quite interesting, for the purposes of this work, is to cite the epidemiological analysis, stating that: 'Salgari Syndrome, i.e. the stereotype of the migrant "infector," a dangerous source of diseases, namely of infectious type, is supported today by no scientific evidence derived from formal epidemiological studies or from health surveillance. [...] On the contrary, the data on the health of migrants derived from studies and surveillance experiences unexpectedly outline a population exposed to the dangers of marginality. It deals of the so-called "exhausted migrant effect," which implies the more or less rapid depletion of the health patrimony of migrants, regardless the situation on their arrival, because of the continuous exposure to risk factors, due to the conditions of poverty in which they live' (Camera dei Deputati, 2017, p. 28).

The Report explicitly refers to the Strategy and Action Plan for Refugee and Migrant Health in the WHO European Region and to the homonymous resolution, approved on December 15, 2016. As for some aspects relevant to the INTEGRA project, the WHO document underlined that migrant women may often wish to be treated by female doctors, based on a principle of greater closeness, cultural sensitivity and gender equity. The document also speaks of an important effort of 'promotion of health literacy' (Camera dei Deputati, 2016, p. 40).

The Conclusions of the Report state: 'Among the priorities to be addressed is also that of a selection of the categories most in need of assistance. If it is true that migrants are in themselves a weak category, it is also true that there are categories in greater difficulty, the weak among the weak. These are those that the legislator defines "vulnerable categories." From the point of 
view of healthcare, attention paid to those most in difficulty means particular attention to issues such as sexual and reproductive health, family planning, gender-based violence and rape (linked to important sociocultural phenomena, such as forced marriage and teenage pregnancy), mental health, people suffering from trauma or injury, among which victims of torture are of particular importance' (Camera dei Deputati, 2017, pp. 72-73).

Quite evidently, the Conclusions of the Italian Parliament Commission legitimize the attempt to construct a Sexual and Reproductive Health Index, based on valid and reliable indicators.

\section{References}

Camera dei Deputati. (2017). Relazione sulla tutela della salute dei migrantie della popolazione residente (8 novembre 2017) della Commissione parlamentare di inchiesta sul sistema di accoglienza, di identificazione ed espulsione, nonché sulle condizioni di trattenimento dei migranti e sulle risorse pubbliche impegnate. Rome, Italy: Author.

Canadian International Development Agency. (1996). Guide to gender-sensitive indicators. Ottawa, Canada: Author.

Drost, E. A. (2011). Validity and reliability in social science research. International Perspectives on Higher Education Research, 38(1), 105-124.

Guttmacher Institute. (2015). Sexual and reproductive health and rights indicators for the SDGs post-2015 recommendations. New York, NY: Author.

Ministero della Salute. (2008). Classificazione delle malattie, dei traumatismi, degli interventi chirurgici e delle procedure diagnostiche e terapeutiche. Rome, Italy: Author.

Ministero della Salute. (2017). Rapporto annuale sull'attivitá di ricovero ospedaliero. Rome, Italy: Author.

Ministero della Salute. (2018). Specifiche funzionali. Rome, Italy: Author.

Moreland, S., \& Curran, J. (2018). A guide for monitoring and evaluating population-health-environment programs (2nd ed.). Chapel Hill, NC: University of North Carolina.

United Nations. (1995). Report of Fourth World Conference on Women. New York, NY: Author.

Vattovani, R. (2009). La mobilitá sanitaria ospedaliera italo-slovena dopo l'adesione della Slovenia all'Unione Europea (Unpublished PhD thesis). University of Trieste, Trieste, Italy.

World Health Organization. (1997). Selecting reproductive health indicators: A guide for district managers; Field testing version. Geneva, Switzerland: Author.

World Health Organization. (2006). Reproductive health indicators: Guidelines for their generation, interpretation and analysis for global monitoring. Geneva, Switzerland: Author. 
World Health Organization. (2016). Strategy and action plan for refugee and migrant health in the WHO European Region. Geneva, Switzerland: Author.

S. Ličen, I. Karnjuš, \& M. Prosen (Eds.). (2019). Women, migrations and health: Ensuring transcultural healthcare (pp. 59-72).

Koper, Slovenia: University of Primorska Press.

https://doi.org/10.26493/978-961-7055-43-6.59-72 


\title{
Human Papillomavirus Infection and Cervical Cancer in Immigrant and Refugee Women
}

\author{
Andrej Cör \\ University of Primorska and Valdoltra Orthopaedic Hospital, Slovenia \\ andrej.coer@fvz.upr.si
}

Cervical cancer is primary caused by infection with human papillomavirus (HPV), and annually results in the deaths of 266,000 women worldwide. Cervical cancer prevention strategies have significantly decreased its incidence in Slovenia due to efficient screening program named ZORA; however, it continues to be an important health problem for immigrant and refugee women. Immigrant women from low- and medium income countries have a higher prevalence of HPV and consequently a higher risk of cervical pre-cancer and cancer than native women also due to barriers in access to screening programs and vaccination uptake. Data from other countries show as that refugee girls had significantly lower HPV immunization uptake compared with native born girls. There is an urgent need for health providers to understand sociocultural barriers for HPV screening programs and vaccination in order to provide comprehensive healthcare for all immigrant and refugee women.

\section{Introduction}

Sexual and reproductive health (SRH) is one of human rights applied to sexuality and reproduction. Migrant and refugee women are at risk of negative SRH outcomes due to low utilisation of SRH services (Metusela et al., 2017). Inadequate SRH knowledge combined with low use of sexual health services can have serious negative health consequences for migrant and refugee women (Henderson \& Kendall, 2011). Identifying how SRH is constructed and experienced by migrant and refugee women is essential in order to provide culturally safe medical care, sexual health education and health promotion and to increase capacity for all women in accessing SRH services.

\section{Cervical Cancer}

Infection with human papillomavirus (HPV), the most common sexually transmitted infection, may result in cervical cancer and cancers of the anus, penis, vulva and oropharynx, among others. According to the WHO cervical cancer is the fourth most frequent cancer in women and with an es- 
timated 570,000 new cases in 2018 representing $6.6 \%$ of all female cancers (see http://www.who.int/immunization/diseases/hpv/en/). Wide differences in cervical cancer incidence and mortality have been observed around the word. Rates of cervical cancer are inversely proportional to screening and treatment access, and poor and minority women face more barriers to healthcare access (Jeudin et al., 2014).

Almost all cervical cancer deaths could be avoided if known effective interventions were available to all women and implemented, including immunizing adolescent girls against HPV and cervical screening and treatment of pre-cancerous lesions. In Slovenia, we observe significant decreases in incidence and mortality of cervical cancer in recent decades, and this has been attributed to appropriate screening program named ZORA. Screening aims to detect precancerous changes, which, if not treated, may lead to cancer. The crude incidence rate of invasive cervical cancer in Slovenia increased from 22.5/100,000 in 1950 to $33.4 / 100,000$ in 1962 and then decreased to 20.7/100,000 in 2003 and much more to 7.9/100,000 in 2017 (see https://zora.onko-i.si/program-zora). In Slovenia screening program ZORA for early detection of cervical cancer was established in 2003 and covers most of the resident population. Screening rates remain low for certain subgroups of women, including immigrants and refugee women and delayed sexual health screening may result in late diagnosis and treatment of cervical cancer (Mcmullin, Alba, Chávez, \& Hubbell, 2005).

Increased effort to screen for cervical cancer predominantly via Papanicolau (Pap) tests has tremendously reduced cervical cancer morbidity and mortality in many developed countries; however, in many low- and medium- income countries efficient screening programs have not been established. Unfortunately those countries have also high prevalence of HPV infection.

Cervical cancer continues to be important health problem in Slovenia for immigrant and refugee women. Several studies have shown that migrant women from low- and medium- income countries have higher risk of cervical cancer than native women. This population has a comparatively high incidence of pre-invasive cervical lesions, cervical cancer, and mortality from the disease (McComb, Ramsden, Olatunbosun, \& Williams-Roberts, 2018). During the years 2000-2004 the cervical cancer in women from Central and Eastern Europe and living in Italy was 38.3 per 100,000, which is statistically significant higher than that of the native Italian women (6 per 100.00) (Tornesello, Giorgi Rossi, Buonaguro, Buonaguro, \& HPV Prevalence Italian Working Group, 2014). These disparities may be explained by lower participation in screening programs as well as higher rates of fertility and HPV infection. 
They usually maintain the same cervical cancer risk as that of their countries of origin for several years. Pap test coverage in migrant women is lower than in native women because the diffusion of screening in the countries of origin is very low and because there could be several barriers to screening access in the host country. Multiple socioeconomic factors were indicators for low screening rates. Refugees and immigrants are often of low education and income. Language and cultural barriers can result in lack of knowledge and understanding of preventative procedures, and, especially when coinciding with past trauma, can result in fear authoritative physician with whom they would likely struggle to communicate (Beckett, 2016). Important factors are also older ages and recent entry into host county.

Among immigrants, limited knowledge about cervical cancer and screening guidelines has been described so the need for provision of culturally appropriate sexual health information has been emphasise (Vahabi \& Lofters, 2018). To enhance immigrant women screening uptake, efforts should made to increase their knowledge of the Slovenian healthcare system and preventive services at the time of entry to our country. Health professionals need to take an active role in offering screening during health encounters, be educated about sexual health communication with minority women, and be aware of the detrimental impact of preconceived assumptions about sexual activity of immigrant women.

\section{Prevalence of HPV Infection}

The association between certain oncogenic (high-risk) strains of HPV and cervical cancer is well established. HPV are remarkably diverse DNA viruses, which are etiologically linked to various benign and malignant neoplastic lesions. Nowadays more than 50 HPV genotypes have been found to infect the anogenital mucosa and most of them have been classified by the International Agency for Research on Cancer (IARC) as group I 'high risk' viruses for cancer (Komloš et al., 2011). Genital HPV infections are highly prevalent among sexually active man and women worldwide. Most HPV infections are asymptomatic and resolve spontaneously with cervical smear abnormalities only occurring in those women with persistent HPV infection.

HPV prevalence depends largely on age, and on sexual practice. The international survey on the HPV type distribution in cytological normal women, coordinated by IARC showed a variation of nearly 20 times in the overall HPV prevalence between different regions of the world (Clifford et al., 2005). Meta-analysis assessing the burden of cervical HPV infection among more than one million women without cervical disease showed that $11.7 \%$ of the 
women worldwide are positive for HPV DNA (Bruni et al., 2010). The prevalence of high risk HPV ranges from $11 \%$ in healthy women in Belgium, $20 \%$ in female university students in the USA to $46 \%$ in Spanish women in prisons (Beckett, 2016). Study from 2010 shows that $59.2 \%$ of Slovenian women in life have been infected (they have genotypically specific antibodies in the blood) with at least one of the 12 high-risk HPV genotypes and that at the time of the study, in $12.2 \%$ of women HPV genotype was proven in a cervical smear (Komloš et al., 2011).

More than $83 \%$ of the global burden occurs in developing countries including Eastern, Western and Middle Africa, Central America, South Central Asia and Melanesia, where is the leading cause of cancer-related death among women (Arbyn et al., 2011). Migration and population mixing has been shown to increase the risk of sexual transmitted disease including HPV infection in several regions of the world (Tornesello et al., 2011). Several studies have documented a higher occurrence of infection-related cancer, including cervical cancer, in immigrants from low and medium-income developing countries compared to the native populations (Arnold et al., 2013; Beiki, Allebeck, Nordqvist, \& Moradi, 2009).

Tornesello et al. (2014) reported 51.9\% overall prevalence of HPV infection observed among 499 migrant women living in Southern Italy, much higher compared to the infection frequency of $13.4 \%$ observed among 3,817 Italian women attending organised cervical cancer screening, and of $19.7 \%$ found in 183 Italian women with normal cytology self-referring for gynaecological care. The high burden of HPV infection in migrants may reflect the high viral prevalence in their country of origin. Besides, the HPV genotypes are not equally distributed in different populations. They reported, that among HPVpositive migrant women, the fraction of HPV16 infections varied between 15.4\% from Africa and 51.1\% from Southern and Eastern Europe (Tornesello et al., 2011). Other common viral types were $\mathrm{HPV}_{31}$ that cause infections in migrant women from Southern and Eastern Europe, Southern and Central America, and Southern Asia; as well as HPV 58 and HPV 53 in African HPVpositive women (Tornesello et al., 2014).

To analyse the barriers impeding adequate cervical cancer screening in immigrant and refugee women, one must become familiar with the challenges faced by this population and the ways in which their incoming culture and experiences may be incompatible with our current approaches to preventative care. Among migrant and refugee communities, talking about sex is often forbidden due to cultural and religious taboos. Patriarchal values culturally prescribed gender roles may impact on women's access to sexual health screening (Metusela et al., 2017). 
The highest prevalence of HPV has been described in female sex workers as they have multiple risk factors for HPV infection, such as young age and multiple sexual contacts. There is wide heterogeneity in reported HPV prevalence in female sex workers in different geographical areas; $43 \%$ in Mexico, $48 \%$ in Japan and $63 \%$ in India. In Spain, the HPV prevalence among migrants Latin American countries was found three times higher than the $8.2 \%$ prevalence in Spanish-borne women (Gonzalez, 2006) and a pick of 61\% in HPV prevalence was observed among sex workers from Eastern Europe (del Amo, 2005). Over the last few years, an increasing proportion of the female sex workers in European countries are migrants especially from Eastern Europe. (Tornesello et al., 2007). The Eastern European countries are still experiencing high incidence of cervical cancer, lack of appropriate cervical cancer prevention programs and paucity of HPV epidemiological surveys (Bruni et al., 2010). It is likely that migrant female sex workers differ from other groups of the population in terms of sociodemographic characteristics, sexual and health seeking behaviour, as well as HPV prevalence and types. The knowledge of these characteristics is essential to design appropriate preventive and curative strategies for immigrant sexual workers.

\section{Vaccination against HPV}

HPV vaccination is a safe and effective primary prevention strategy for cervical cancer especially in developed countries. Vaccination against HPV shows great potential. Unfortunately, refugee and recently immigrated women are among the least likely to participate in screening or vaccination. Gerend, Zapata, and Reyes (2013) reported that despite generally favourable views of HPV vaccination, observed rates of vaccine uptake among Hispanic adolescents living in the United States were substantially lower than national estimates (Gerend et al., 2013).

In Slovenia, HPV vaccination became the first non-mandatory vaccine to be included in the national vaccination program in the $2009 / 2010$ school year (Troha, Šterbenc, Mlaker, \& Poljak, 2018). Routine vaccination is for girls aged 11 or12 years whereas boys are not included in the program. Because parental permission is required for vaccination of girls under age 18 years, parental attitudes and behaviour play a central role in vaccine uptake. There are significant differences in HPV vaccine uptake among different regions in Slovenia, ranging from very high (79.0\%) to very low (32.2\%) (Učakar, Poljak, \& Klavs, 2012). There is no research dedicated to analysing HPV vaccination rates of refugees in Slovenia.

Lower uptake of HPV vaccination among immigrants and refugees has been documented in other countries, although exploration of underlying 
reasons remains an understudied area. Möller, Kristiansen, and Norredam (2018) found that refugee girls had significantly lower HPV immunization uptake compared with Danish-born girls in the ordinary immunization program. They also identified that region of origin, duration of residence, and income were predictors of HPV vaccination uptake among refugee girls. Unfortunately, those factors that corelate with low screening participation, such as low education, low income, and minority status, also correlate with low HPV vaccination rates (Becket, 2016). A study in the Netherlands has drawn attention to the cultural differences that can act as a barrier to HPV vaccination for immigrants and refugees in Western countries (Salad, Verdonk, de Boer, \& Abma, 2015). Immigrant parents' concerns related to lack of information with respect to vaccine efficacy and safety, fear that vaccine was experimentation on their daughter, cost, long term side effect, and a belief that vaccination may increase early sexual behaviour have been implicated in the lack of vaccination acceptance. Cultural attitude and the fear of shame and stigma also inhibited vaccination uptake (Salad et al., 2015). The decision-making process of women of this population generally relies upon social connections and support of cultural peers. Greater efforts are needed to increase knowledge about HPV among immigrant and refugee parents and support for physicians to discuss and offer vaccination to this underserved population.

\section{Conclusions}

With vaccination against HPV and efficient screening program to detect precancerous cervical lesions, we believe that Slovenia could be free of cervical cancer within 20 years. The high prevalence of HPV infections and cervical cancer risk among immigrant women demands for an urgent implementation of preventive strategies to increase screening and vaccine coverage. It is imperative that we understand the current state of screening and vaccination in this population, and the cultural and systemic barriers by which they are affected. Further research should explore rates of HPV vaccination and screening in refugees in Slovenia, and the barriers that prevent refugees from taking this preventive measure.

\section{References}

Arbyn, M., Castellsague, X., de Sanjose, S., Bruni, L., Saraiya, M., Bray, F., \& Ferlay, J. (2011). Worldwide burden of cervical cancer in 2008. Annals of Oncology, 22(12), 2675-2686.

Arnold, M., Aarts, M. J., Siesling, S., Aa, M. van der, Visser, O., \& Coebergh, J. W. (2013). Diverging breast and stomach cancer incidence and survival in 
migrants in The Netherlands, 1996-2009. Acta Oncologica, 52(6), 1195-1201.

Beckett, M. (2016). The borders that remain: Prevention of cervical cancer in refugee and immigrant women in Canada. University of Ottawa Journal of Medicine, 11(30), 61-66.

Beiki, O., Allebeck, P., Nordqvist, T., \& Moradi, T. (2009). Cervical, endometrial and ovarian cancers among immigrants in Sweden: Importance of age at migration and duration of residence. European Journal of Cancer, 45(1), 107118.

Bruni, L., Diaz, M., Castellsagué, X., Ferrer, E., Bosch, F. X., \& de Sanjosé, S. (2010). Cervical human papillomavirus prevalence in 5 continents: Meta-analysis of 1 million women with normal cytological findings. The Journal of Infectious Diseases, 202(12), 1789-1799.

Clifford, G., Gallus, S., Herrero, R., Muñoz, N., Snijders, P., Vaccarella, S., ... Franceschi, S. (2005). Worldwide distribution of human papillomavirus types in cytologically normal women in the International Agency for Research on Cancer HPV prevalence surveys: A pooled analysis. The Lancet, 366(9490), 991-998.

del Amo, J. (2005). Influence of age and geographical origin in the prevalence of high risk human papillomavirus in migrant female sex workers in Spain. Sexually Transmitted Infections, 81(1), 79-84.

Gerend, M. A., Zapata, C., \& Reyes, E. (2013). Predictors of human papillomavirus vaccination among daughters of low-income latina mothers: The role of acculturation. Journal of Adolescent Health, 53(5), 623-629.

Gonzalez, C. (2006). Higher prevalence of human papillomavirus infection in migrant women from Latin America in Spain. Sexually Transmitted Infections, 82(3), 260-262.

Henderson, S., \& Kendall, E. (2011). Culturally and linguistically diverse peoples' knowledge of accessibility and utilisation of health services: Exploring the need for improvement in health service delivery. Australian Journal of Primary Health, 17(2), 195-201.

Jeudin, P., Liverigh, E., Del carmen, M. G., \& Perkins, R. B. Race, ethnicity, and income factors impacting human papillomavirus vaccination rates. Clinical Therapy, 368(1), 24-37.

Komloš, K. F., Kocjan, B. J., Košorok, P., Rus, T., Toplak, J., Bunič, M., \& Poljak, M. (2011). Distribution of HPV genotypes in Slovenian patients with anal carcinoma: Preliminary results. Acta Dermatovenerologica Alpina, Panonnica Et Adriatica, 20(3), 141-143.

McComb, E., Ramsden, V., Olatunbosun, O., \& Williams-Roberts, H. (2018). Knowledge, attitudes and barriers to human papillomavirus (HPV) vaccine uptake among an immigrant and refugee catch-up group in a western Canadian province. Journal of Immigrant and Minority Health, 20(6), 1424-1428.

Mcmullin, J. M., Alba, I. D., Chávez, L. R., \& Hubbell, F. A. (2005). Influence of 
beliefs about cervical cancer etiology on pap smear use among Latina immigrants. Ethnicity \& Health, 10(1), 3-18.

Metusela, C., Ussher, J., Perz, J., Hawkey, A., Morrow, M., Narchal, R., ... Monteiro, M. (2017). 'In my culture, we don't know anything about that:' Sexual and reproductive health of migrant and refugee women. International Journal of Behavioral Medicine, 24(6), 836-845.

Möller, S. P., Kristiansen, M., \& Norredam, M. (2018). Human papillomavirus immunization uptake among girls with a refugee background compared with Danish-born girls: A national register-based cohort study. European Journal of Cancer Prevention, 27(1), 42-45.

Salad, J., Verdonk, P., de Boer, F., \& Abma, T. A. (2015). 'A Somali girl is Muslim and does not have premarital sex. Is vaccination really necessary?' A qualitative study into the perceptions of Somali women in the Netherlands about the prevention of cervical cancer. International Journal for Equity in Health, 14(1). https://doi.org/10.1186/s12939-015-0198-3

Tornesello, M. L., Cassese, R., De Rosa, N., Buonaguro, L., Masucci, A., Vallefuoco, G.,... Buonaguro, F. M. (2011). High prevalence of human papillomavirus infection in Eastern European and West African women immigrants in South Italy: HPV distribution in women immigrants in Southern Italy. Acta Pathologica, Microbiologica, et Immunologica Scandinavica, 119(10), 701-709.

Tornesello, M. L., Duraturo, M. L., Buonaguro, L., Vallefuoco, G., Piccoli, R., Palmieri, S., \& Buonaguro, F. M. (2007). Prevalence of human papillomavirus genotypes and their variants in high risk West Africa women immigrants in South Italy. Infectious Agents and Cancer, 2(1), 1-9.

Tornesello, M. L., Giorgi Rossi, P., Buonaguro, L., Buonaguro, F. M., \& HPV Prevalence Italian Working Group. (2014). Human papillomavirus infection and cervical neoplasia among migrant women living in Italy. Frontiers in Oncology, 4. https://doi.org/10.3389/fonc.2014.00031

Troha, M., Šterbenc, A., Mlaker, M., \& Poljak, M. (2018). Human papillomavirus (HPV) infection and vaccination: Knowledge and attitudes among healthcare professionals and the general public in Slovenia. Acta Dermatovenerologica Alpina Pannonica et Adriatica, 27(2).

Učakar, V., Poljak, M., \& Klavs, I. (2012). Pre-vaccination prevalence and distribution of high-risk human papillomavirus (HPV) types in Slovenian women: A cervical cancer screening based study. Vaccine, 30(2), 116-120.

Vahabi, M., \& Lofters, A. (2018). HPV self-sampling: A promising approach to reduce cervical cancer screening disparities in Canada. Current Oncology, 25(1), 13-18.

S. Ličen, I. Karnjuš, \& M. Prosen (Eds.). (2019). Women, migrations and health: Ensuring transcultural healthcare (pp. 73-80). Koper, Slovenia: University of Primorska Press. https://doi.org/10.26493/978-961-7055-43-6.73-80 


\section{Use of Modern Contraceptive Methods among Migrant Women Living in Slovenia}

\section{Igor Karnjuš}

University of Primorska, Slovenia

igor.karnjus@fvz.upr.si

\section{Mirko Prosen}

University of Primorska, Slovenia

mirko.prosen@fvz.upr.si

Urška Bogataj

University of Primorska, Slovenia urska.bogataj@fvz.upr.si

\section{Doroteja Rebec}

University of Primorska, Slovenia

doroteja.rebec@fvz.upr.si

\section{Sabina Ličen}

University of Primorska, Slovenia

sabina.licen@fvz.upr.si

The use of modern contraceptives by immigrants may be constrained by various factors such as poor language skills, socio-economic background, and inadequate knowledge. Limited evidence is available on the factors associated with the use of modern contraceptive methods by migrant women in Slovenia. The study included 52 migrants who were treated in a maternity hospital in Slovenia between March and September 2018. Data were collected using a questionnaire that contained items related to sexual and reproductive health. Bivariate analysis (Spearman's correlation coefficient and Chi square) was used to examine the association between independent variables and the use of contraceptive methods. The study highlights that two main factors affect contraception use: (a) Migrant women with better knowledge of modern contraceptive methods were more likely to use them ( $r=0.69 ; p<0.05)$; (b) If the partner/husband has a positive attitude to the use of modern contraceptives, there is a greater probability migrant women will use them $\left(\chi^{2}=14.465\right.$; $p=0.001$ ). Based on the results, sexual and reproductive health education for migrant women and men, particularly on the use of modern contraception, is needed.

\section{Introduction}

Migration has always been a major cause of population change. People migrate from low-income countries to high-income ones for better jobs and 
to improve their socio-economic circumstances. Further, in recent years the presence of wars around the world has also been affecting migration flows (Adanu \& Johnson, 2009). The European Union (EU) is today facing the most serious migration crisis since World War II (European Migration Network, 2017). Despite the general belief that the lion's share of migrants is men, since migration is generally associated with the search for work, data for 2015 show that women made up about $48.0 \%$ of international migrants worldwide (Shah, Kiriya, Shibanuna, \& Jimba, 2018). Migration is a major event in life that can have an extreme impact on women's sexual and reproductive health (SRH). In fact, studies demonstrate that migrant women's SRH can be negatively affected by the challenges of migration (Botfield, Newman, \& Zwi, 2016; McMichael \& Gifford, 2010). Moreover, depending on the policies and practices of the host country regarding migrants, they may experience discrimination and a loss of their socio-economic status (Mengesha, Perz, Dune, \& Ussher, 2017).

$\mathrm{SRH}$ is one of the most important components of quality of life (Metusela et al., 2017) which includes 'physical, emotional, mental and social well-being' as well as 'pleasurable, safe sexual experiences that are free from coercion, discrimination or violence' (WHO, 2010). The use of SRH care is associated with improved mental health and nutrition, positive economic and social outcomes for women, as well as clinical benefits such as reduced rates of unplanned pregnancy and sexually transmitted infection (Cohen, 2004; Mengesha et al., 2017).

However, the literature states (Keygnaert et al., 2014) that migrant women are, compared to the EU population, less often screened for cervical and breast cancer, made fewer visits to a gynaecologist, have more induced abortions and pregnancy complications, and have less access to family planning and contraception. Further, migrant women are at greater risk of sexually transmitted infections. Although SRH is an important aspect of women's quality of life, migrant women have much less access to SRH services than the EU population (Sebo, Jackson, Haller, Gaspoz, \& Wolff, 2011). At the beginning, due to resettlement changes, migrant women attribute low importance to sexual health needs, and knowledge about health resources and services in the host country is often very limited (Metusela et al., 2017). While knowledge is a major barrier regarding SRH behaviour, the latter may be influenced by various factors such as cultural and religious norms from the country of origin. Migrant women often come from countries in which they hold a disadvantaged position in society. These norms affect the acquisition of sexual health literacy and behaviours, and can contribute to a lack 
of knowledge and access to SRH services (Metusela et al., 2017; Raben \& Mujisenbergh, 2018). Among some migrant communities, discussing a person's sexual needs is often forbidden since it is still considered a taboo. In such cases, sexual healthcare services may be seen as culturally inappropriate, and are thus avoided (Guerin, Allotey, Hussein Elmi, \& Baho, 2006; Rogers \& Earnest, 2015). Consequently, many migrant women may possess little knowledge about risk factors for unwanted pregnancies and about contraception due to limited health literacy. Young migrant adults often do not receive sufficient education on sexual health, and unmet contraceptive needs are common (Aptekman, Rashid, Wright, \& Dunn, 2014; Raben et al., 2018).

Based on effectiveness level, contraceptive methods can be categorised in three large groups. ${ }^{1}$ The safest contraception methods include male and female sterilisation, implants, and intrauterine devices. Pills, injectables, vaginal rings, hormonal patches, and the diaphragm are placed in the group of mid-level effectiveness. The least effective methods of contraception are considered male and female condoms, spermicides, withdrawal, and fertilityawareness-based methods. However, migrant women may be unaware of the newest modern contraception methods available in the host country. In addition, women from less developed countries are less likely to use them, which probably influences their lower use even after migration (Shah et al., 2018). In fact, the use of contraception is affected by access to affordable and preferred contraception, and to supportive SRH services. For immigrants, access is made even more difficult by social and religious differences and linguistic barriers (Ellawela et al., 2017). It should be emphasised that migrant women may improve their quality of life by using modern contraceptive methods. They can reduce the fear of unwanted pregnancy, which is present when using traditional methods such as withdrawal and the rhythm method. Consequently, this can have a positive impact on sexual life and promote psychosocial well-being (Caruso et al., 2016). Hormonal contraceptives also provide medical benefits such as a decrease in menstrual pain and regulation of the menstrual cycle (Shah et al., 2018).

Yet, contraceptive awareness and their use among migrant women is poorly explored in the academic literature, even though it is a key determinant of SRH. Limited evidence is available on the factors associated with the use of contraceptive methods by migrant women. Thus, the study examines the factors associated with the modern contraceptive methods used by migrant women in Slovenia.

\footnotetext{
${ }^{1}$ See https://www.cdc.gov/reproductivehealth/contraception/index.htm.
} 


\section{Methods}

\section{Study Design}

A quantitative, cross sectional design was employed. The study is part of the INTEGRA project (INTERREG programme V A Italy-Slovenia 2014-2020) concerning migrant women's population characteristics, as well as their sexual and reproductive health and social integration into Italy and Slovenia.

\section{Sample}

Convenience sampling was used. Migrant women treated in a maternity hospital in Slovenia between March and September 2018 as either an ambulatory or hospitalised patient were invited to participate in the study. Participation in the study was voluntary. Only adult migrant women older than 18 years were included in the study.

\section{Instrument}

The research instrument was a semi-structured questionnaire developed by the lead partner (University of Trieste in association with the Burlo Garofolo Pediatric Institute) and submitted in January 2018 (16.1.2018; 12:11). The Italian version of the questionnaire was translated into the Slovenian language and adapted to the Slovenian cultural context, and aligned with the healthcare system established in the Republic of Slovenia. Finally, the questionnaire was reviewed by a panel of experts composed of five independent nursing lecturers. Besides the socio-demographic part, the questionnaire contains 69 items related to the social integration of migrant women in the host county and their sexual and reproductive health.

\section{Data Collection Procedure}

The survey was conducted between March and September 2018. The questionnaire was distributed with the assistance of hospital staff involved in the project. Two midwives were additionally provided with a one-day training session to familiarise them with the study's objectives, the study protocol and the questionnaire contents. They also supported migrant women while responding to the questionnaire if needed (e.g. linguistic barriers).

The participants' confidentiality and anonymity were assured and maintained during the completion and submission of the questionnaire. Oral informed consent was obtained. All participants were informed about the aims, objectives and study methods used. The study was conducted in accordance with the Helsinki-Tokyo Declaration and the Code of Ethics for Nurses and 
Nurse Assistants of Slovenia. The study was approved by the National Medical Ethics Committee (26.10.2017; No. 0120-544/2017/7).

\section{Data Analysis}

Data were processed and analysed using SPSS version 23 (SPSS Inc., Chicago, IL, USA). Bivariate analysis (Spearman's correlation coefficient and Chi square) was conducted to examine the association between the independent variables and the use of contraceptive methods. Statistical significance was set at $p<0.05$.

\section{Results}

\section{Demographic Data of the Sample}

The convenience sample included 52 migrant women. The participants' average age was $32.46(s=8.06)$. The youngest was 19 and the oldest 56 years. The survey included migrant women who left their country of birth between 2003 and 2018. Most participants ( $n=32 ; 61.5 \%$ ) had migrated to Slovenia in the last 5 years (2014-2018). The length of their stay in Slovenia varied from less than 1 year to 15 years (mean $=4.16$ years, $s=7.25$ ). The participants' average age when arriving in Slovenia was 27.53 ( $s=7.25$ ) years; the youngest participant was 17 and the oldest 53 years.

Table 1 summarises some of the socio-demographic characteristics of the migrant women participating in the study. Most of these women come from the former republics of Yugoslavia $(n=36 ; 69.2 \%)$ or Russia $(n=11 ; 21.2 \%)$. Half the participants claimed they are members of the Orthodox Church $(n=26$; $50.0 \%)$, followed by members of Islam $(n=19 ; 36.5 \%)$. Regarding their current employment status in Slovenia, 28 migrant women (53.8\%) stated they are unemployed or run a household and are at home; 24 (46.1\%) women stated they have a job. The majority of these women $(n=34 ; 65.4 \%)$ had lived in a city in their country of birth; 18 (34.6\%) stated they had lived in the countryside. The majority of the migrant woman $(n=39 ; 75.0 \%)$ stated they already had one or more children, while 13 (25.0\%) had no children. Ten migrant women $(19.2 \%)$ included in the study had one or more induced abortions in the past.

\section{Knowledge and Current Use of Contraceptive Methods}

Half the participants $(n=26 ; 50.0 \%)$ stated that upon arrival in Slovenia they were given access to new methods of contraception. Tables 2 and 3 illustrate the use of contraceptive methods and knowledge concerning them among the migrant women participating in the study. In answering these two questions, participants were able to give multiple responses. The modern contra- 
Table 1 Socio-Demographic Characteristics of The Migrant Women

\begin{tabular}{llrr}
\hline Variables & & $n$ & $\%$ \\
\hline Country of birth & Bosnia and Herzegovina & 16 & 30.8 \\
& Croatia & 2 & 3.8 \\
& Kosovo & 5 & 9.6 \\
& FYR Macedonia & 9 & 17.3 \\
& Russia & 11 & 21.2 \\
& Slovak Republic & 1 & 1.9 \\
& Serbia & 4 & 7.7 \\
& Ukraine & 4 & 7.7 \\
\hline Education & $<$ Higher secondary & 10 & 19.2 \\
& Higher secondary & 20 & 38.5 \\
& $\geq$ Undergraduate & 22 & 42.3 \\
\hline Religion & Catholic & 2 & 3.8 \\
& Protestant & 2 & 3.8 \\
& Muslim & 19 & 36.5 \\
& Orthodox & 26 & 50.0 \\
& Other & 1 & 1.9 \\
& Not a member of any religion & 2 & 3.8 \\
\hline No. of children & Housewife & 17 & 32.7 \\
\hline Employment status & Unemployed & 11 & 21.2 \\
& Employed & 24 & 46.1 \\
\hline & None & 13 & 25.0 \\
& 1 & 13 & 25.0 \\
& $\geq 2$ & 50.0 \\
\hline
\end{tabular}

ception methods migrant women mostly use are oral contraceptive pills and condoms. While only a small number of participants claimed they also use traditional methods, this was always in combination with some other modern contraceptive method. However, 21 (40.4\%) participants stated they did not use any contraception method. Regarding their knowledge of modern contraceptives, of the 43 participants who answered this question, $37 \mathrm{knew}$ of at least one modern contraceptive method (with the number ranging from 1 to 7). Migrant women are least familiar with the use of subcutaneous implants, patches and hormonal injections.

The participants were also asked whether their partner agrees to the use of contraception. Eleven migrant women (21.6\%) stated their partner disagrees with the use of contraception; 4 (7.7\%) participants stated he is indifferent on this question and $32(61.5 \%)$ stated that he agrees with its use. For a ques- 
Table 2 Current Use of Contraceptive Methods among the Migrant Women

\begin{tabular}{llrr}
\hline Contraceptive methods $(n=52)$ & & $n$ & $\%$ \\
\hline Modern methods & Oral contraceptive pills & 14 & 26.9 \\
& Condom & 20 & 38.5 \\
& Diaphragm & 1 & 1.9 \\
& Intrauterine device & 3 & 5.8 \\
& Subcutaneous implants & 0 & 0.0 \\
& Patches & 1 & 1.9 \\
& Hormonal injections & 3 & 5.8 \\
\hline Traditional methods & Rhythm method & 3 & 5.8 \\
& Withdrawal & 3 & 5.8 \\
\hline Others & & 0 & 0.0 \\
\hline None & & 21 & 40.4 \\
\hline
\end{tabular}

Notes Multiple responses allowed.

Table 3 Knowledge of Contraceptive Methods among the Migrant Women

\begin{tabular}{llrr}
\hline Contraceptive methods $(n=43)$ & & $n$ & $\%$ \\
\hline Modern methods & Oral contraceptive pills & 36 & 83.7 \\
& Condom & 36 & 83.7 \\
& Diaphragm & 20 & 46.5 \\
& Intrauterine device & 21 & 48.8 \\
& Subcutaneous implants & 11 & 25.6 \\
& Patches & 15 & 34.8 \\
& Hormonal injections & 15 & 34.8 \\
\hline
\end{tabular}

Notes Multiple responses allowed.

tion regarding the type of contraception used by women, 41 (78.8\%) participants stated this is exclusively the decision of the woman, 4 (7.7\%) participants stated this is a joint decision of the two partners and 4 (7.7.\%) stated that it is a decision of the husband/partner.

\section{Factors Associated with the Use of Contraceptive Methods}

Table 4 presents an analysis of factors associated with the migrant women's use of contraceptive methods. Two main factors influencing the use of contraception are knowledge regarding modern contraceptive methods and the partner's attitude to their use. In fact, migrant women with better knowledge of modern contraceptive methods were more likely to use them. Further, if the partner has a positive attitude to contraception use there is a greater probability the woman will use it. We were unable to determine the influ- 
Table 4 Factors Associated with the Currently Used Contraceptive Methods

\begin{tabular}{llrrrr}
\hline Variables & & Yes & No & $p$-value & \\
\hline Living environment & City & 23 & 11 & 0.140 & $\left(\chi^{2}=2.632\right)$ \\
in country of birth & Countryside & 8 & 10 & & \\
\hline Education & < Higher secondary & 3 & 7 & 0.103 & $\left(\chi^{2}=4.554\right)$ \\
& Higher secondary & 13 & 7 & & \\
& $\geq$ Undergraduate degree & 15 & 7 & & \\
\hline Partner's attitude & Disagrees & 2 & 9 & $0.001^{* *}\left(\chi^{2}=14.465\right)$ \\
to contraception & Neutral & 2 & 2 & & \\
& Agrees & 26 & 6 & & \\
\hline History of abortion & Yes & 8 & 2 & 0.280 & $\left(\chi^{2}=1.927\right)$ \\
& No & 23 & 18 & & \\
\hline No. of children & None & 10 & 3 & 0.382 & $\left(\chi^{2}=1.923\right)$ \\
& 1 & 7 & 6 & & \\
\hline Contraceptive knowledge & 14 & 11 & & \\
\hline Age & $\geq 2$ & \multicolumn{5}{c}{$0.031^{*}$} & $(r=0.690)$ \\
\hline Length of stay in host country & & & & 0.243 & $(r=0.165)$ \\
\hline
\end{tabular}

Notes * Significant at the level $p<0.05 .{ }^{*}$ Significant at the level $p<0.001$.

ence of other factors like length of stay in the country, education level etc., on use of contraceptive methods (Table 3 ).

We also analysed the influence of religion and country of birth on the use of contraceptive methods. Although we found no statistically significant differences between the subgroups (religion: $\chi^{2}=4.166, p=0.526$; country of birth: $\chi^{2}=8.403, p=0.298$ ), women from Bosnia and Herzegovina, FYR Macedonia and Kosovo use contraception somewhat less than women from other countries. Of 30 women from these countries, 14 do not use any contraception.

\section{Discussion}

The key findings of this study are: (1) Migrant women who possessed better knowledge of modern contraceptive methods were more likely to use them; (2) If the partner/husband has a positive attitude to the modern contraceptive use, there is a greater probability a migrant woman will use them.

Several studies show that knowledge of contraception has a great influence on its use in everyday life, not only among immigrants. There is an established link between knowledge and responsible sexually protective behaviours (Cleland, Conde-Agudelo, Peterson, Ross, \& Tsui, 2012; Poncet, 
Huang, Rei, Lin, \& Chen, 2013; Raben et al., 2018; Shah et al., 2018). In our study, 37 migrant women (71.2\%) claimed they are familiar with at least one contraception method among those listed, and 11 stated they are familiar with all 7 modern methods on the list. The least familiarity was found with newer methods like subcutaneous implants, patches and hormonal injections. Several authors emphasise that among migrant women knowledge regarding contraception is mainly sourced from peers, the media, magazines and other informal sources allowing incorrect knowledge and myths to be present among community members (Metusela et al., 2017; Ip et al., 2011). Therefore, the danger of passing false information on regarding contraception among this population should be taken seriously.

In recent years, the range of contraceptives available has expanded and the overall distribution of contraceptive methods has changed. The use of permanent methods such as sterilisation has decreased, and barrier and long-acting hormonal methods have increased (Ellawela et al., 2017). In our study, $50.0 \%$ of the migrant woman stated that upon arriving in Slovenia they were given access to new contraception methods. The most common form of contraception reported by the participants is the use of oral contraceptive pills and condoms. Women's choice of contraceptive methods is affected by demographics, socio-economic status, cultural norms, level of commitment to avoiding pregnancy, and perceived access to healthcare (Poncet et al., 2013). Further, Raben et al. (2018) emphasise that migrant women tend to adapt to the contraceptive trends in their host countries. According to the National Institute of Public Health, hormonal contraception is currently the most commonly used contraceptive method in Slovenia (see http://www.nijz.si/sl/26-september-2014-svetovni-dan-kontracepcije). A report from 2016 states that almost $94.0 \%$ of hormonal contraception is due to the use of oral contraceptive pills. The latter are mostly used by young women between the ages of 15 and 30. Young woman at the start of a new sexual relationship, in an unstable relationship or having sex with multiple partners most commonly use condoms as a contraception method. Intrauterine devices are the typical birth control method used by women aged between 30 and 44. In Slovenia, the use of permanent methods like sterilisation is very low; estimated at around $3.0 \%$ of couples.

Another important factor influencing the use of contraception among couples is the partner's attitude to its use. Women are more likely to use contraception when their partner/husband agrees with the decision and when members of their community approve of family planning (Poncet et al., 2013), which was confirmed by our results. A study by Zheng et al. (2001) demon- 
strated that inequality between partners may affect the woman's contraceptive attitude since young women were found to rely on their partners when making decisions on contraceptive use. Culturally prescribed gender roles, combined with patriarchal values, may affect a woman's ability to have control over her sexual and reproductive needs (Metusela et al., 2017). However, it has been reported that in some cases migration to an economically more developed country can result in positive changes in men's attitudes to sexual and reproductive health (Adanu \& Johnson, 2009). The use of contraceptives can be further enhanced by good communication between partners. A study by Kamal and Islam (2012) showed that frequent communication between partners about family planning leads to greater use of contraceptives.

Level of education is also recognised as an important factor in family planning. Although we were unable to demonstrate the influence of this factor on contraception use, the utilisation of modern contraceptives in this study was somewhat higher among immigrants who possessed a higher education. A French survey investigating the use and method of contraception among immigrant and non-immigrant women found that immigrant women with a lower level of educational attainment were less likely to use contraception (Poncet et al., 2013). Similar results were found in previous studies in China and Australia (Ip, Chan, Chan, \& Chan, 2011; Shah et al., 2018). Women with a higher level of education have a better social status, which gives them more options for contraception and they are thus more likely to use them (Shaukat \& Pell, 2015).

We also observed that migrant women from some former republics of $\mathrm{Yu}$ goslavia which are less economically developed, like Bosnia and Herzegovina, FYR Macedonia and Kosovo, tend to use contraception less than women from other countries. The lower utilisation rate of contraceptives may be partly the result of complex social processes associated with an immigration background, such as values and norms involving contraceptive practices, socio-cultural beliefs, awareness or knowledge of reproductive health or the freedom to make safe reproductive choices (Poncet et al., 2013). Although people from the former Yugoslav republics (mainly Bosnia and Herzegovina, Macedonia, Serbia and Kosovo) still account for most of the foreign immigrants in Slovenia, the country has increasingly become a target country for other immigrants like Iranians, Syrians, people from Afghanistan etc. (European Migration Network, 2017). We must be aware that today and in the near future the number of immigrants settling in high-income countries will grow, and that it is essential to have culturally competent healthcare staff in place for that scenario because every woman, regardless of her background 
or origin, has the right to adequate SRH care (Raben et al., 2018). Interventions designed to raise awareness and use of contraceptives among the migrant population can bring multiple payoffs (Lindstrom \& Hernández, 2006). It is therefore important for health services to provide culturally relevant and readily understood information to enable migrant women and men to make informed decisions about contraception (Ellawela et al., 2017).

Several limitations of this study should be considered. The sample size was relatively small $(n=52)$. In addition, our study only included migrant women treated at just one regional maternity hospital in Slovenia. Therefore, caution needs to be taken when generalising the study's findings. In addition, the study's duration was quite limited (March to September 2018). Although our questionnaire took a broad approach to the subject of migration (it also included issues related to the social integration of migrant women and not only subjects regarding their $\mathrm{SRH}$ ), in the future it should be focused on a more specific area. Despite these limitations, this study is one of the first to identify the factors associated with contraceptive use among migrant women in Slovenia and, as such, provides a good platform for further research in this area.

\section{Conclusions}

This study showed that migrant women are more likely to use modern contraceptive methods when they have better knowledge of them and if their partner has a positive attitude to contraception use. These results suggest there is a need for SRH education courses for all migrants, both male and female, especially pertaining to modern contraceptive use. Targeted culturally appropriate campaigns to improve awareness of and access to affordable contraceptive options are recommended. This study also informs the necessity to conduct a large-scale epidemiological study on the sexual and reproductive health of migrant women in Slovenia in the near future.

\section{References}

Adanu, R. M., \& Johnson, T. R. (2009). Migration and women's health. International Journal of Gynaecology and Obstetrics, 106(2), 179-181.

Aptekman, M., Rashid, M., Wright, V., \& Dunn, S. (2014). Unmet contraceptive needs among refugees. Canadian Family Physician, 6o(12), e613-9.

Botfield, J. R., Newman, C. E., \& Zwi, A. B. (2016). Young people from culturally diverse backgrounds and their use of services for sexual and reproductive health needs: A structured scoping review. Sexual Health, 13(1), 1-9.

Caruso, S., Iraci, M., Cianci, S., Fava, V., Casella, E., \& Cianci, A. (2016). Comparative, open-label prospective study on the quality of life and sexual func- 
tion of women affected by endometriosis-associated pelvic pain on $2 \mathrm{mg}$ dienogest $/ 30 \mu \mathrm{g}$ ethinyl estradiol continuous or $21 / 7$ regimen oral contraceptive. Journal of Endocrinological Investigation, 39(8), 923-931.

Cleland, J., Conde-Agudelo, A., Peterson, H., Ross, J., \& Tsui, A. (2012). Contraception and health. Lancet, 380(9837), 149-156.

Cohen, S. A. (2004). The broad benefits of investing in sexual and reproductive health. The Guttmacher Report on Public Policy, 7(1), 5-8.

Ellawela, Y., Nilaweera, I., Holton, S., Rowe, H., Kirkman, M., Jordan, L., ... Fisher, J. (2017). Contraceptive use and contraceptive health care needs among Sri Lankan migrants living in Australia: Findings from the understanding fertility management in contemporary Australia survey. Sexual \& Reproductive Healthcare, 12, 70-75.

European Migration Network. 2017. Kratko poročilo o gibanju migrantov v Sredozemlju. Retrieved from https://emm.si/publikacije/emn-kratko -porocilo-o-gibanju-migrantov-v-sredozemlju-december-2017/

Guerin, P. B., Allotey, P., Hussein Elmi, F., \& Baho, S. (2006). Advocacy as a means to an end: Assisting refugee women to take control of their reproductive health needs. Women \& Health, 43(4), 7-25.

Ip, W. Y., Chan, M. Y., Chan, D. S., \& Chan, C. W. (2011). Knowledge of and attitude to contraception among migrant woman workers in mainland China. Journal of Clinical Nursing, 20(11-12), 1685-1695.

Kamal, S. M., \& Islam, M. A. (2012). Interspousal communication on family planning and its effect on contraceptive adoption in Bangladesh. Asia-Pacific Journal of Public Health, 24(3), 506-521.

Keygnaert, I., Guieu, A., Ooms, G., Vettenburg, N., Temmerman, M., \& Roelens, K. (2014). Sexual and reproductive health of migrants: Does the EU care? Health Policy, 114(2-3), 215-225.

Lindstrom, D. P., \& Hernández, C. H. (2006). Internal migration and contraceptive knowledge and use in Guatemala. International Family Planning Perspectives, 32(3), 146-153.

McMichael, C., \& Gifford, S. (2010). Narratives of sexual health risk and protection amongst young people from refugee backgrounds in Melbourne, Australia. Culture, Health \& Sexuality, 12(3), 263-277.

Mengesha, Z. B., Perz, J., Dune, T. \& Ussher, J. (2017) Refugee and migrant women's engagement with sexual and reproductive health care in Australia: A socio-ecological analysis of health care professional perspectives. PLoS One, 12(7), e0181421.

Metusela, C., Ussher, J., Perz, J., Hawkey, A., Morrow, M., Narchal, R., Estoesta, J. \& Monteiro, M. (2017). 'In my culture, we don't know anything about that:' Sexual and reproductive health of migrant and refugee women. International Journal of Behavioral Medicine, 24(6), 836-845.

Poncet, L. C, Huang, N., Rei, W., Lin, Y. C., \& Chen, C. Y. (2013). Contraceptive use 
and method among immigrant women in France: Relationship with socioeconomic status. The European Journal of Contraception \& Reproductive Health Care, 18(6), 468-479.

Raben, L. A. D., \& van den Muijsenbergh, M. E. T. C. (2018). Inequity in contraceptive care between refugees and other migrant women? A retrospective study in Dutch general practice. Family practice, 35(4), 468-474.

Rogers, C., \& Earnest, J. (2015). Sexual and reproductive health communication among Sudanese and Eritrean women: An exploratory study from Brisbane, Australia. Culture, Health \& Sexuality, 17(2), 223-236.

Sebo, P., Jackson, Y., Haller, D. M., Gaspoz, J. M., \& Wolff, H. (2011). Sexual and reproductive health behaviors of undocumented migrants in Geneva: A cross sectional study. Journal of Immigrant and Minority Health, 13(3), 510517.

Shah, R., Kiriya, J., Shibanuma, A., \& Jimba, M. (2018). Use of modern contraceptive methods and its association with QOL among Nepalese female migrants living in Japan. PLoS One, 13(5), e0197243.

Shaukat, S., \& Pell, A. W. (2015). Personal and social problems faced by women in higher education. FWU Journal of Social Sciences, 9(2), 101-107.

World Health Organisation. (2010). Measuring sexual health: Conceptual and practical considerations and related indicators. Geneva, Switzerland: Author.

Zheng, Z., Zhou, Y., Zheng, L., Yang, Y., Zhao, D., Lou, C., \& Zhao, S. (2001). Sexual behaviour and contraceptive use among unmarried, young women migrant workers in five cities in China. Reproductive Health Matters, 9(17), 118127.

S. Ličen, I. Karnjuš, \& M. Prosen (Eds.). (2019). Women, migrations and health: Ensuring transcultural healthcare (pp. 81-93). Koper, Slovenia: University of Primorska Press. https://doi.org/10.26493/978-961-7055-43-6.81-93 



\title{
Migrants' Experiences in the Healthcare System
}

\author{
Marie-Louise Luiking \\ Leiden University, The Netherlands \\ marie-louise@luiking.com \\ Harshida Patel \\ University of Gothenburg, Sweden \\ harshida.patel@gu.se
}

\begin{abstract}
Mass migration in Europe raises many issues of societal concern. Migrants struggle with complex health problems related to causes and consequences of migration. It is no longer a question about migrants having unique health needs, concerns and challenges. The effects of language and cultural differences, lack of access to transportation and other barriers are common. These barriers hamper nurses and other healthcare professionals to deliver high quality care. An essential dimension of quality of care mirroring both patients' expectations and their exposure is the migrant patient's experience of healthcare. This chapter addresses the factors associated with migrants' healthcare experiences in the host country. A model presented here may increase nursing professionals'awareness and help to provide person centred care and overcome cultural differences.
\end{abstract}

\section{Migration}

The picture of migration, is vastly more complex than at first glance and ease of movement promises greater complexity in the future. The International Organisation for Migration (see http://www.iom.int/key-migration-terms) defines a migrant as: 'any person who is moving or has moved across an international border or within a state away from his/her habitual place of residence, regardless of the person's legal status, voluntary or involuntary, causes, and the length of the stay.' With the number of international migrants escalating (United Nations, 2016), it becomes more acute that migrants face numerous barriers to access an appropriate level of healthcare (World Health Organisation, 2008).

\section{Addressing Migrant Health Issues}

The media conversation often sticks narrowly to the question of how the migrant arrives. The focus on such migration issues sidetracks the important needs of migrant populations, by moving the focus away from addressing 
health needs of persons in the host countries. It also stalls needed adjustments of the rigid healthcare systems that are largely unequipped to cater for migrants in need of care.

The health issues faced by migrant populations are similar to those faced by the general population but are often compounded by their migratory history. Mobility results in poor continuity of care and simultaneously increases the need for care (Kugel \& Zuroweste, 2010). Poor mental and physical health lead to a greater risk of morbidity and mortality in comparison to the rest of the population of the host country.

\section{Access to Healthcare}

Access has been found to be a leading health indicator (Anderson, Scrimshaw, Fullilove, Fielding, \& Normand, 2003). Health is one of the most fundamental resources for an individual's potential for development to be fulfilled (Marmot, Friel, Bell, Houweling \& Taylor 2008), as well as a key component for an immigrant's integration into the host society and the labour market. However, findings from research show a decline in health status among the refugees after settling in their host country (Newbold, 2005; Salman \& Resick, 2015; Taylor et al., 2014).

Migrants struggle with similar challenges as other underserved populations regarding access to healthcare, but face the additional barriers of mobility, language, cultural differences, and lack of familiarity with local healthcare services. Migrants on the move are brought out of their provider networks, reducing further access. It is even more complicated for the undocumented migrants to contact healthcare as they often fear for deportation.

An extensive variety of barriers is reported in literature including: healthcare professionals' views of migrants' health issues, problems with adaptation and little understanding of migrants' expectations of healthcare services within the host country. (Hakonsen, Lees, \& Toverud, 2014; Kalich, Heinemann, \& Ghahari, 2016; Suphanchaimat, Kantamaturapoj, Putthasri, \& Prakongsai, 2015). These barriers hamper nurses and other healthcare professionals to deliver high quality care. An essential dimension of quality of care mirroring both patients' expectations and their exposure is the migrant patient's experience of healthcare.

The main challenges for healthcare professionals are lack of awareness of the migrants' specific healthcare problems, language and intercultural communication problems, as well as access and integration of migrant seekers into the healthcare system. Awareness of these conditions is mandatory to ensure good clinical practice for this patient population, which has a huge 
burden in chronic, infectious, mental, and neurological diseases (Salman \& Resick, 2015).

The major impact factors on migrants' health are linked to experiences and exposure in the country of origin, in camps and en route and in the process of immigration into the host country and living in foreign countries. Migrants' health is also affected by psychological problems and by infectious diseases due to the exceptional and hazardous conditions of their journey.

High quality patient care should be effective, efficient, accessible, patient centred, equitable and safe (WHO, 2008). Due to the extensive barriers, however, migrant healthcare is not always meeting high quality care standards. Of all healthcare professionals, nurses are the largest staff group which also has most direct patient contact. Nurses are therefore a staff group that is particularly important in ensuring the quality of migrant patient care.

\section{Healthcare-Seeking Behaviour: Influencing Factors}

Healthcare seeking behaviour (HCSB) is a term that refers to patterns of utilization, treatment seeking, delay in seeking care, predicting the future probable burden of diseases, facilitation of the health status, early diagnosis, complete and effective treatment, and complication control. HCSB relies on time and context and are associated with social, cultural, economic, disease pattern and issues related to health services (Poortaghi et al., 2015). Multiple factors such as educational level (Ahmed et al., 2016; Chau et al., 2018; Dawood et al., 2017, Jurcev-Savicevic \& Kardum, 2012), occupation, marital status, economic status, age and sex, healthcare costs, type and severity of illness, distance and physical access, and perceived quality of service provision (Caitlin \& Austen, 2009; Tipping \& Segall, 1995) are associated with HCSB. Further factors include time, insecurity, social status, language barriers, lack of information (Ahmed et al., 2016; Kalich et al., 2016) and cultural differences (Ahmed et al., 2016; Chau et al., 2018; Kalich et al., 2016).

The migrant population is diverse and each person has individual health needs (Luiking et al., 2018). Indeed, the most recent project conducted by our research group, a meta ethnography study (Luiking et al., 2018) showed that a multitude of factors influence the HCSB decision-making process. Migrants seek care according to their needs and legal status and they often consult trusted individuals within their own community about how to address a health problem before seeking formal help (Luiking et al., 2018). Further considerations are time and financial resources (Herdman et al., 2016; Lattof, 2018). The framework derived from our investigation provides a more comprehensive overview on HCSB in migrants (Luiking et al., 2018) and de- 
scribes the personal and healthcare system-inherent barriers and enablers to accessing and provision in this population. These include personal factors, the healthcare system, accessing healthcare, the encounter and healthcare experiences (see Figure 1 on p. 102).

The decision to seek care is therefore not a simple move taken by an individual person, instead, it is a more complex process that is embedded within a social, cultural and community context. Importantly, modern Information Technology may play a crucial part in health seeking in the migrant population.

\section{Determinants of Health Seeking Behaviours}

Self-efficacy and attitude may also play an important role in HCSB. Selfefficacy is the belief in one's competence to tackle tasks and to cope with adversity in a broad range of stressful or challenging situations (Bandura, 1977). For example, while ill and in need of healthcare, self-efficacy emerged as a dominant determinant of engagement in health compromising or health promoting behaviours (Bandura, 1977, 1993). However, the relationship between self-efficacy and healthcare seeking behaviours within the migrant population are to date unknown. Studies on the health of migrants in Europe focus on care experiences of those actively seeking care. Little is known about factors that prevent migrants from seeking care and self-efficacy may play an important role in ensuring personal health. The role and importance of self-efficacy, personal networks and indeed, modern technologies such as internet or apps on mobile phones in seeking care has not been reported, despite technology becoming increasingly important in decision-making and information seeking in all areas of life. An investigation of the role of selfefficacy in HCSB and associated resources such as personal networks and information technology will provide new perspectives on how to promote effective care-seeking in the migrant population.

\section{Literature Review of Migrant Patients' Experiences of Healthcare}

Insight into health disparities and associated barriers to care in the group of migrant patients can be obtained by looking into the migrant patients' perspective of their healthcare (Tilburt, 2010). Although a fair amount of attention in research has been given to migrant health, there was no systematic synthesis of the evidence on migrant patient experience.

To address this gap in knowledge a review was done to synthesize published literature related to adult migrant patients' experiences of healthcare and their healthcare seeking behaviours. The objective was a comprehen- 
sive overview of barriers at various stages of the patient journey. Metaethnography was chosen to synthesize the studies; this enables the interpretation of the findings from the individual studies into a larger, whole picture that provides deeper understanding of an issue (Noblit \& Hare, 1988). The population included in this review were adult migrant patients, but not specific maternity care.

\section{The Review Process}

Any peer-reviewed, qualitative research study in English, exploring migrant patients' experiences of healthcare published between January 2000-June 2016 was considered. The search in 7 databases initially delivered 264 studies, which were further assessed according to the inclusion criteria and for their study quality. 27 studies were included in the meta ethnographic analysis.

Hundred sixteen first and second order constructs were identified across the studies, which were condensed and interpreted into 15 third order constructs. These third order constructs were contextualised into the following dimensions: (1) personal factors; (2) healthcare system; (3) access to healthcare; (4) the encounter; and (5) healthcare experience (Luiking et al., 2018).

\section{Findings}

The third order constructs, dimensions are described below. In italics are quotations from the studies in the review to illustrate the dimensions.

\section{Personal Factors}

This dimension comprises a number of constructs that define a migrant patient's personality and inform about their health-seeking behaviours, such as a person's enculturation or society of origin with its religious or value system, but also life experiences. In some cases, exceptionally traumatic experiences such as becoming a refugee because of war and being forced to migrate are powerful: 'I did not want to live because of what is gone. I was eating, sleeping only [...] I tried to forget it but I can't. My history, my life is stamped into my heart.' (Fang, Sixsmith, Lawthom, Mountian, \& Shahrin, 2015)

In effect these personal factors determine a person's overall life context (Biswas, Kristiansen, Krasnik, \& Norredam, 2011; Krupic, Sadic, \& Fatahi, 2016; Seffo, Krupic, Grbic, \& Fatahi, 2014).

\section{Healthcare System}

The healthcare system and legal framework of the host country determines the care provision available for natives as well as for migrant patients. De- 
pending on the healthcare model, service provision and the quality of care might differ between a migrant's home country and host country. This can result in a mismatch between the care provided and the individual's expectations from the healthcare system: 'It is not easy for a foreigner to cure our diseases. The Chinese [...] when they go to school, they don't teach them about African sicknesses. [...]' (Lin et al., 2015)

\section{Access to Healthcare}

This dimension addressed the barriers or enablers to healthcare in the host country. When a need for services is identified by migrants, their socioeconomic and legal status can affect their access to services. To even access the correct service, the individual migrant and/or their families need to know how to go about such access. Language difficulties and lack of information can serve to adversely affect their rights. An additional issue is that service providers can turn out to be gatekeepers to the required services (Biswas et al., 2011; Legido-Quigley, Nolte, Green, la Parra, \& McKee, 2012; Lin et al., 2015). Care-seeking can become outright dangerous for undocumented persons: 'If I go to the doctor and the doctor is a very good Danish person, a good citizen, then maybe he will call the police. And then I would be handed over to the police and then I would have a great problem. Then my life is risky.' (Biswas et al., 2011). These issues can have a detrimental effect on the individual migrant's health and they may apply alternative health-seeking strategies (Biswas et al., 2011; Krupic et al., 2016; Main, 2016) 'When I am not feeling well, I will call my doctor in my home country. He will ask about my symptoms and tell me what medicine to get over the phone' (Lin et al., 2015).

\section{The Encounter}

When individual migrants do access the services, the way they are treated as a person and as a patient is determined by the staff they encounter. This juncture has huge implications for the trajectory of a person's care. Yet the encounter can prove problematic due to language difficulties and a lack of mutual knowledge of how to act in a culturally appropriately way. This also covers the misunderstandings of what an individual migrant wants from service providers, what they are used to in their own countries and what the service provider states that the person with migrant status needs 'In Poland, people go to the doctor more often. Pregnancy is the best example. In Poland, your pregnancy is over-medicalized. You are constantly under medical surveillance, constantly tested. Here it is the opposite [...] pregnancy is not an illness; you don't need to be on sick leave all these months [...]' (Main, 2016) 
It is therefore important for service providers to treat the individual in an holistic manner, ascertaining their expectations and perceived need. Such care is at the heart of person-centeredness. Within a true person-centred approach, the individual's cultural background is fundamental to effective care.

\section{The Healthcare Experiences}

This dimension comprises the constructs of healthcare needs as being 'met' or 'unmet.' Healthcare needs need to be satisfied in terms of emotional support or information. The overall positive or negative evaluation of a healthcare experience depends on whether a migrant patient feels their care and information needs and expectations have been met or not. Migrant patients use the familiar healthcare system of their home country as a template to compare and evaluate the care they received in the host country. 'I wouldn't go to the [British] NHS. My experience of medical care is good [in Spain] [...] The biggest difference about Spain and England is that people care about nursing and the people in England they are more worried about targets.' (Legido-Quigley et al., 2012)

From the findings, a model has been designed using the five dimensions and grounded in a person-centred care approach (Figure 1). This model is in the form of a flow diagram that illustrates the antecedents and succedents of the migrants' healthcare experience. These include lack of linguistic abilities, clashing cultures or social or cultural taboos that may inhibit them from seeking healthcare and, when found, of making the best use of it. This model may help healthcare providers to identify and address antecedents to poor quality migrant healthcare, identify weak points, improve the organisation and help healthcare professionals to provide person-centred care to migrant patients.

The model points out that language difficulties and differences with migrants' experience in the home countries are important factors in all stages. The comparison with migrants' experience in the home countries implies that the mere provision of linguistically congruent information might not serve all migrants' needs, as it is generally aimed at people who already understand the workings of a healthcare system. However, migrant patients may lack this basic understanding. Information should therefore be adapted to the different needs of 'migrants' (for example refugees and illegal immigrants). This would include providing a basic explanation of access to and routes through the healthcare system. In addition, understanding of the host cultures, how patients relate to healthcare professionals and which behaviours are acceptable, or not, should be explained. 


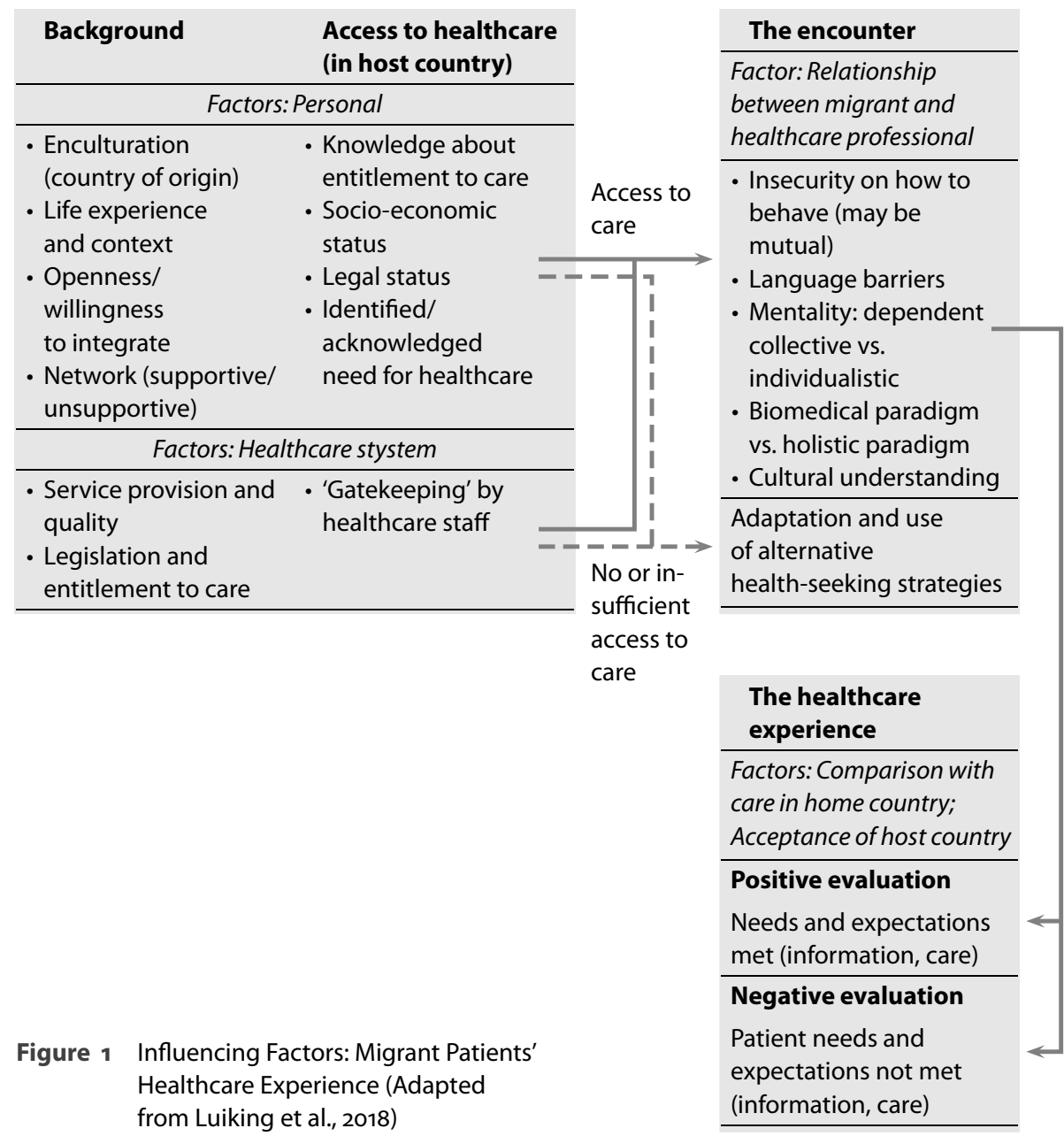

\section{Clinical Relevance}

For the nurse in her encounter with a migrant the flow diagram shows the personal factors and healthcare system factors that ante cede and shape the encounter. It also shows the factors of the encounter itself which matter and the factors which determine how the migrant experiences the encounter subsequently. Healthcare professionals, nurses often perceive migrants as 'others', as being different from 'them.' This 'othering' prevents an open-minded encounter and healthcare professionals, nurses need to be mindful of potential prejudice. Migrants, like every individual, are shaped by 
their culture of origin as well as their life experience and they have thus diverse needs. Migrants' backgrounds may be alien to healthcare professionals and difficult to understand. Awareness of one's own preconceived ideas can enable healthcare professionals to approach migrants as the unique individuals they are: people with specific health needs that need special attention, just as any other patient (Grove \& Zwi, 2006).

The model can help the healthcare professional, nurse as a reminder of what determines the healthcare experience of a migrant. Perhaps with the model in hand it will be easier for the healthcare professional, nurse to adapt the care provided to fit the migrant patient better.

\section{References}

Ahmed, S., Shommu, N. S., Rumana, N., Barron, G. R., Wicklum, S., \& Turin, T. C. (2016). Barriers to access of primary healthcare by immigrant populations in Canada: A literature review. Journal of Immigrant and Minority Health, 18(6), 1522-1540.

Anderson, L. M., Scrimshaw, S. C., Fullilove, M. T., Fielding, J. E., Normand, J. (2003). Culturally competent healthcare systems: A Systematic review. American Journal of Preventive Medicine, 24(3), 68-79.

Bandura, A. (1977). Self-efficacy: Toward a unifying theory of behavioral change. Psychol Review 84(2), 191-215.

Bandura, A. (1993), Perceived self-efficacy in cognitive development and functioning. Educational Psychologist, 28(2), 117-148.

Biswas, D., Kristiansen, M., Krasnik, A., \& Norredam, M. (2011). Access to healthcare and alternative health-seeking strategies among undocumented migrants in Denmark. British Medical Council Public Health, 11(560). Retrieved from http://doi.org/10.1186/1471-2458-11-560

Caitlin, M., \& Austen, D. (2009). Health care seeking behaviour in Somalia: A literature review (Report 10). Retrieved from https://www.unicef.org/somalia/ SOM_HealthcareseekingbehaviourReport_10-WEB.pdf

Chau, P. H., Moe, G., Lee, S. Y., Woo, J., Leung, A. Y. M., Chow, C. M., Kong, C., Lo, W. T., Yuen, M. H., \& Zerwic, J. (2018). Low level of knowledge of heart attack symptoms and inappropriate anticipated treatment-seeking behaviour among older Chinese: A cross-sectional survey. Journal of Epidemiology and Community Health, 72(7), 645-652.

Dawood, O. T., Hassali, M. A., Saleem, F., Ibrahim, I. R., Abdulameer, A. H., \& Jasim, H. H. (2017). Assessment of health seeking behaviour and self-medication among general public in the state of Penang, Malaysia. Pharmacy Practice, 15(3), 991.

Fang, M., Sixsmith, J., Lawthom, R., Mountian, I., \& Shahrin, A. (2015). Experiencing 'pathologized presence and normalized absence:' Understanding health related experiences and access to healthcare among Iraqi and So- 
mali asylum seekers, refugees and persons without legal status. British Medical Council Public Health, 15(1), 923.

Grove, N., \& Zwi, A.(2006). Our health and theirs: Forced migration, othering, and public health. Social Science \& Medicine, 62(8), 1931-1942.

Herdman, M. T., Maude, R. J., Chowdhury, M. S., Kingston, H. W., Jeeyapant, A., Samad, R., Karim, R., Dondorp, A. M., \& Hossain, M. A. (2016). The relationship between poverty and healthcare seeking among patients hospitalized with acute febrile illnesses in Chittagong, Bangladesh. PLoS One, 11(4), e0152965.

Hakonsen, H., Lees, K., \& Toverud, E. L. (2014). Cultural barriers encountered by Norwegian community pharmacists in providing service to non-Western immigrant patients. International Journal of Clinical Pharmacy, 36(6), 11441151.

Jurcev-Savicevic, A., \& Kardum, G. (2012). Health-care seeking behaviour for tuberculosis symptoms in Croatia. The European Journal of Public Health, 22(4), 573-577.

Kalich, A., Heinemann, L., \& Ghahari, S. (2016). A scoping review of immigrant experience of health care access barriers in Canada. Journal of Immigrant and Minority Health, 18(3), 697-709.

Krupic, F., Sadic, S., \& Fatahi, N. (2016). Contact with health-care service expectation and reality of situation experienced by immigrants seeking Swedish health-care. Materia Socio-Medica, 28(2), 141-145.

Kugel, C., \& Zuroweste, E. (2010). The state of health care services for mobile poor populations: History, current status, and future challenges. Journal of Health Care for the Poor and Underserved, 21(2), 421-429.

Lattof, S. R. (2018). Health insurance and care-seeking behaviours of female migrants in Accra, Ghana. Health Policy and Planning, 33(4), 505-515.

Legido-Quigley, H., Nolte, E., Green, J., la Parra, D., \& McKee, M. (2012). The healthcare experiences of British pensioners migrating to Spain: A qualitative study. Health Policy, 105(1), 46-54.

Lin, L., Brown, K., Yu, F., Yang, J., Wang, J., Schrock, J., ... Wong, F. (2015). Healthcare experiences and perceived barriers to healthcare access: A qualitative study among African migrants in Guangzhou, Guangdong Province, China. Journal of Immigrant \& Minority Health, 17(5), 1509-1517.

Luiking, M., Heckemann, B., Ali, P., Dekker vanDoorn, C., Ghosh, S., Kydd, A., Watson, R., \& Patel, H. (2018). Migrants' healthcare experience: A metaethnography review of the literature. Journal of Nursing Scholarship. Retrieved from https://www.doi.org/10.1111/jnu.12442

Main, I. (2016). Biomedical practices from a patient perspective: Experiences of Polish female migrants in Barcelona, Berlin and London. Anthropology \& Medicine, 23(2), 1-17.

Marmot, M., Friel, S., Bell, R., Houweling, T. A., \& Taylor, S. (2008). Closing the gap 
in a generation: Health equity through action on the social determinants of health. The Lancet, 372(9650), 1661-1669.

Newbold, K. B. (2005). Self-rated health within the Canadian immigrant population: Risk and the healthy immigrant effect. Social Science \& Medicine, 60(6), 1359-1370.

Noblit, G., \& Hare, R. (1988). Meta-ethnography: Synthesizing qualitative studies (Vol. 11). London, England: Sage.

Poortaghi, S., Raiesifar, A., Bozorgzad, P., Golzari, S. E., Parvizy, S., \& Rafii, F. (2015). Evolutionary concept analysis of health seeking behavior in nursing: $A$ systematic review. BMC Health Services Research, 15(1), 523. Retrieved from https://doi.org/10.1186/s12913-015-1181-9

Salman, K. F., and Resick, L. K. (2015). The description of health among Iraqi refugee women in the United States. Journal of Immigrant and Minority Health, 17(4), 1199-205.

Seffo, N., Krupic, F., Grbic, K., \& Fatahi, N. (2014). From immigrant to patient: Experiences of Bosnian immigrants in the Swedish healthcare system. Materia Socio-Medica, 26(2), 85-89.

Suphanchaimat, R., Kantamaturapoj, K., Putthasri, W., \& Prakongsai, P. (2015). Challenges in the provision of healthcare services for migrants: A systematic review through providers' lens. BMC Health Services Research, 15(390). Retrieved from https://doi.org/10.1186/s12913-015-1065-z

Taylor, E. M., Yanni, E. A., Pezzi, C., Guterbock, M., Rothney, E., Harton, E., Montour, J., Elias, C., \& Burke, H. (2014). Physical and mental health status of Iraqi refugees resettled in the United States. Journal of Immigrant and Minority Health, 16(6), 1130-1137.

Tilburt, J. C. (2010). The role of worldviews in health disparities education. Journal of General Internal Medicine, 25(2), 178-181.

Tipping, G., \& Segall, M. (1995). Health care seeking behaviour in developing countries: An annotated bibliography and literature review. Brighton, England: Institute of Development Studies.

United Nations. (2016). International migration report 2015 (ST/ESA/SER.A/384). New York, NY: Author.

World Health Organisation. (2008). Overcoming migrants' barriers to health. Bulletin of the World Health Organisation, 86(8), 583-584.

S. Ličen, I. Karnjuš, \& M. Prosen (Eds.). (2019). Women, migrations and health: Ensuring transcultural healthcare (pp. 95-105).

Koper, Slovenia: University of Primorska Press.

https://doi.org/10.26493/978-961-7055-43-6.95-105 



\title{
Current Issues and Future Possibilities for Improving Healthcare for Migrant Women in Slovenia
}

\author{
Urška Bogataj \\ University of Primorska, Slovenia \\ urska.bogataj@fvz.upr.si \\ Mirko Prosen \\ University of Primorska, Slovenia \\ mirko.prosen@fvz.upr.si \\ Igor Karnjuš \\ University of Primorska, Slovenia \\ igor.karnjus@fvz.upr.si \\ Doroteja Rebec \\ University of Primorska, Slovenia \\ doroteja.rebec@fvz.upr.si

\section{Sabina Ličen} \\ University of Primorska, Slovenia \\ sabina.licen@fvz.upr.si
}

The research's purpose was to study the social integration of migrant women in terms of their reproductive health in relation to the healthcare system in Slovenia. The survey was based on 52 migrant women treated in a Slovenian hospital for female diseases and obstetrics between March and September 2018. Data were collected using a questionnaire that included questions on language knowledge and barriers related to communication, discrimination and violence against migrant women. Basic descriptive statistics were used and the results are presented in frequencies and percentages. For issues where the respondents were free to answer, the results are shown by the frequency of occurrence. Health services have the same task with regard to migrants as they have for the rest of the population, i.e. to provide them with accessible and high-quality care, as well as health promotion and education. Based on the results of this research, it is evident that one of the biggest problems perceived is 'language barrier,' referring to both respondents as users of the healthcare system and the healthcare system in Slovenia as such. In rare cases, respondents reported intolerance had been shown by healthcare professionals.

\section{Introduction}

Migration studies have in recent decades become a vibrant discipline due to the effects of increasingly dramatic migration waves, the economy, society 
and, last but not least, over-congested and undernourished health systems (Cox \& Marland, 2013). According to Josefová (2014), we are living in a stage of the world where whatever happens affects everyone, and the current situation Europe finds itself in concerns everyone who lives here. She also believes the issue of immigration has several solutions available. One solution is mutual tolerance and the search for compromise, such as acceptance of the language used by minorities and the need for elementary education in the language of the culture of the host country. Of course, this also establishes bilingualism, which brings diversity and plurality (Josefová, 2014). Multicultural societies are made up of people from different backgrounds who face life on a day-to-day basis amid cultural diversity. It is therefore important to understand the attitude to multiculturalism from the perspectives of the ethnic majority and members of minority groups (Rechel et al., 2006). It is also essential to understand that life in a multicultural society does not mean that one culture is better than another, because openness, mutual respect and tolerance lead to the better coexistence of people in any multicultural society (Josefová, 2014). The increasing diversity of populations in Europe is creating new challenges for health systems that then need to be adapted to remain responsive (Rechel et al., 2011).

The reasons women migrate are similar to those motivating men, and as numerous. However, they are made vulnerable by their characteristics, expectations and stereotypical performances in the cultural environment. Thus, they are also subject to inequality and discrimination, which affects their health status (O'Neil, Fleury, \& Foresti, 2016). Therefore, any consideration must take account of all aspects and characteristics of cultural practices, traditions and behaviour. Depending on cultural beliefs and values, a particular culture may hold deep-rooted beliefs about the concept of illness and healing. Health professionals must therefore also have the necessary knowledge and skills to be able to treat patients of different cultures appropriately.

\section{Methods}

\section{Study Design}

The study forms part of the INTEGRA project (INTERREG programme $V$ A ItalySlovenia 2014-2020) concerning migrant women's characteristics, their sexual and reproductive health and social integration into both Italy and Slovenia. The research purpose was to investigate the process of the social integration of migrant women in terms of their reproductive health within the healthcare system in Slovenia. For the study's purposes, a combined quantitative and qualitative design was used. 


\section{Sample}

In this study, convenience sampling was applied to migrant women who had been treated in a Slovenian hospital for female diseases and obstetrics between March and September 2018 as either an ambulatory or hospitalised patient. Participation in the study was voluntary. The study only included adult migrant women older than 18 years.

The convenience sample encompassed 52 migrant women. The participants' average age was $32.46(s=8.06)$. The youngest was 19 and the oldest 56 years. The average age of the participants when arriving in Slovenia was $27.53(s=7.25)$ years; the youngest participant was 17 and the oldest 53 years. Most participants $(n=32 ; 61.5 \%)$ had migrated to Slovenia within the last 5 years (2014-2018). The length of their stay in Slovenia varies from 1 to 15 years (average $=4.16$ years, $s=7.25$ ).

Most participants come from the former republics of Yugoslavia $(n=36$; $69.2 \%)$ or Russia ( $n=11 ; 21.2 \%)$.

\section{Instrument}

The research instrument used was a semi-structured questionnaire developed by the lead partner (University of Trieste in association with the Burlo Garofolo Pediatric Institute) and submitted in January 2018 (16.1.2018; 12:11). The Italian version of the questionnaire was translated into the Slovenian language, adapted to the Slovenian cultural context, and aligned with the healthcare system established in the Republic of Slovenia. Besides the sociodemographic part, the questionnaire contains 69 items which are related to the social integration of migrant women in the host country, and their sexual and reproductive health. For the purposes of this paper, only relevant issues were analysed.

\section{Data Collection Procedure}

The survey was conducted from March to September 2018. The questionnaire was distributed with the assistance of hospital staff also involved in the project.

Oral informed consent was obtained. The participants' confidentiality and anonymity were ensured. All participants were informed about the aims, objectives and study methods used. The study was conducted in accordance with the Helsinki-Tokyo Declaration and the Code of Ethics for Nurses and Nurse Assistants of Slovenia. The study was approved by the National Medical Ethics Committee (26.10.2017; 0120-544/2017/7). 
Table 1 Socio-Demographic Characteristics of the Respondents

\begin{tabular}{llrr}
\hline Variable & & $n$ & $\%$ \\
\hline Country of birth & Bosnia and Herzegovina & 16 & 30.8 \\
& Croatia & 2 & 3.8 \\
& Kosovo & 5 & 9.6 \\
& FYR Macedonia & 9 & 17.3 \\
& Russia & 11 & 21.2 \\
& Slovakia & 1 & 1.9 \\
\hline Religion & Catholic & 2 & 3.8 \\
& Protestant & 2 & 3.8 \\
& Muslim & 19 & 36.5 \\
& Orthodox & 26 & 50.0 \\
& Other & 1 & 1.9 \\
& Not a member of any religion & 2 & 3.8 \\
\hline
\end{tabular}

\section{Data Analysis}

Data were processed and analysed using SPSS version 22. Basic descriptive statistics were used with the calculation of frequencies and percentages. For issues where the respondents were free to answer, the respective units of words were ranked and shown by the frequency of occurrence.

\section{Results}

The results are presented in three sections. The first part shows some sociodemographic data on the respondents. The second section relates to the language of the host country and the obstacles encountered by the respondents. In the third part, certain issues referring to discrimination and the difficulties migrant women encounter are outlined.

\section{Socio-Demographic Data}

Table 1 summarises selected socio-demographic characteristics of the migrant women participating in the study. Most are from the former republics of Yugoslavia or Russia. Half the participants stated they are members of the Orthodox Church, followed by the members of Islam.

Regarding their current employment status in Slovenia, 28 respondents indicated they are unemployed or stay at home to run the household and 24 women stated that they are working. Respondents often stated their reason for moving to Slovenia was to join a family member who was already living in Slovenia. A similar share mentioned marriage or work as the reason for moving to Slovenia. Only two respondents stated their reason for coming to Slovenia was to study (Table 2). 
Table 2 Socio-Demographic Characteristics of the Respondents

\begin{tabular}{llrr}
\hline Variable & & $n$ & $\%$ \\
\hline Employment status in the & Housewife & 17 & 32.7 \\
host country & Unemployed & 11 & 21.2 \\
& Employed & 24 & 46.1 \\
\hline Reasons for moving to Slovenia & Work & 11 & 21.2 \\
& Study & 2 & 3.8 \\
& Joining a family member & 29 & 55.8 \\
& Marriage & 10 & 19.2 \\
\hline
\end{tabular}

Table 3 Knowledge of the Language of the Host Country

\begin{tabular}{llrr}
\hline Question & & $n$ & $\%$ \\
\hline Do you speak Slovenian? & No & 6 & 11.8 \\
& A little & 22 & 43.1 \\
& Fairly well & 12 & 23.5 \\
& Very well & 11 & 21.6 \\
\hline Have you attended any form of & Language course & 20 & 42.6 \\
formal or non-formal education & Professional training course & 5 & 10.6 \\
in Slovenia? & Education in schools & 3 & 6.4 \\
& None & 19 & 40.4 \\
\hline
\end{tabular}

\section{Host Country Language Barriers}

Respondents were asked if they speak the Slovenian language and also if they had participated in any form of education in Slovenia. The results are shown in Table 3. In response to the question of whether they would attend advanced courses in the Slovenian language, $24(46.2 \%)$ respondents did not answer. Out of the remaining answers, $24(46.2 \%)$ stated they would attend some language training, and just $4(7.7 \%)$ indicated they would not attend such forms.

\section{Violence, Discrimination and Language Issues}

The respondents were asked whether they had ever encountered violence and discrimination in healthcare institutions. Table 4 shows they had rarely encountered discrimination, while $8 \%$ had experienced violence. According to the last question, some respondents also gave their answer in written form. Most of them stated that they had no problems, then the answers that follow (by frequency) relate to (mis)understanding of the language. A couple stated they had difficulty arranging matters at the administrative unit. For the question on where they see the main problem in communication between 
Table 4 Presence of Violence and Intolerance

\begin{tabular}{llrr}
\hline Question & & $n$ & $\%$ \\
\hline Have you ever experienced any form of violence & Yes & 4 & 8.0 \\
in a healthcare institution? & No & 46 & 92.0 \\
\hline Have you ever experienced any form of discrimination & Yes & 1 & 2.0 \\
in a healthcareinstitution? & No & 50 & 98.0 \\
\hline
\end{tabular}

healthcare professionals and patients of other cultures, 38 respondents submitted their answers in written form.

The answers were ranked by frequency of occurrence. The majority of respondents stated the main problem/reason is the language barrier $(n=32)$. Another group of respondents said they did not see any particular problems, thereby disregarding this as an issue of weight.

The question as to what should be done in the future to improve the relationship between healthcare professionals/institutions and patients from other countries was answered by 28 respondents. Half of them stated they do not know $(n=14)$, a larger proportion of the remaining half respondents expressed the belief that it's necessary to provide more interpreters/translators in clinical environments. Others said there should be more staff available who either speak other languages or even come from other countries.

\section{Discussion}

The results show that most of the migrants come from the former Yugoslav republics or Russia. Moreover, half the respondents are members of the Orthodox Church, followed by members of Islam. Culture not only includes ethnicity and religion, but also socio-economic factors such as level of education, housing conditions and access to information (Durieux-Paillard, 2011). All of this, of course, affects their assimilation into society and their perception of the world and the culture of the country in which they are attempting to build a new life.

The study shows a relatively low understanding and/or speaking of the Slovenian language among the respondents. Further, no desire is expressed for education in this area or for improving language skills. This is seen in the fact that half the respondents did not answer when asked if they would like to attend an advanced Slovenian language course.

It is encouraging that the respondents have not often experienced discrimination in the health system, nor encountered violence or discrimination in healthcare institutions. Yet the finding that $8 \%$ of the respondents 
reported they had experienced violence in health facilities should be taken seriously. Individuals may also have different criteria and different desires for health and healthcare (Clarke, 2017) and that may also be an issue to consider.

It should also be recalled that inequality, as O'Neil, Fleury, and Foresti (2016) state, causes the expectation that women are responsible for unpaid domestic care and responsibilities. This aspect also significantly affects and intersects with inequality and discrimination.

Most respondents stated they had not encountered any problems in a healthcare institution. Throughout the questionnaire, the respondents constantly indicated serious difficulties are present. And those difficulties are mostly related to (mis)understanding of the language. Respondents frequently mentioned suggestions to provide more interpreters/translators in clinical environments. Some also stated there should be more staff who either speak other languages or even come from other countries and cultures. There is also extensive evidence showing the importance of ethnic, religious and linguistic factors that affect socio-economic factors and that problems which arise are both language barriers and the lack of relevant information and resources for migrants (Durieux-Paillard, 2011). Respondents frequently mentioned suggestions to provide more interpreters/translators in clinical environments and healthcare settings. Some also said there should be more staff available who either speak other languages or even came from other countries. This, in fact, also acts as a call for both the state and the political sphere to move in the direction of solving such problems so as to meet the needs of migrants. Ingelby (2011) highlights and indicates interactions in healthcare, where a variety of methods are proposed to overcome language barriers:

- Professional face-to-face interpretation as one of the most accurate methods, but with many drawbacks. It is an expensive method. Patients sometimes also do not want the presence of a third person because they fear that intimate details will not be kept confidential (especially if the translator come from the same community);

- Professional interpretation by telephone where the interpreter is not physically present, with this able to solve a number of logistical and cost problems. The disadvantage is that this method has fewer visual cues, despite technological progress;

- Informal face-to-face interpretation where reliance on family members (especially children) may impact on the confidentiality of the meeting 
and can be emotionally difficult for those involved. Sometimes, an employee at the medical institution who speaks the same language can take the place of an interpreter. The main concern in conjunction with informal interpreters is that they simply do not have the skills and specialised vocabulary required to avoid any possible misunderstandings in medical treatment;

- Bilingual professionals who know the patient's language have numerous advantages over the abovementioned methods;

- Cultural mediators are professionals who not only provide a linguistic explanation, but also actively mediate among healthcare professionals and patients. They attempt to overcome not only language barriers, but cultural and social barriers as well. This method has many advantages and the role of 'cultural mediator' can be diverse and comprehensive. The main problem of this method is payment. Some countries provide state subsidies for interpreting and translation services, while others require service providers to pay.

The chief aim of intercultural healthcare is to ensure culturally harmonious care that meets the individual's lifestyle, values and value system. Recognition, respect and adaptation to the cultural needs of patients, families and communities are key elements of healthcare (Clarke, 2017) which seeks to prevent health inequalities. Cultural competence needs to be part of the overall skills, knowledge and attitudes of health professionals and they must be adequately trained if they are to provide appropriate care to a wide range of patients (Durieux-Paillard, 2011).

Narayanasamy and White (2005) mention in their research that healthcare professionals also have a stronger obligation to promote cultural competence in the direction of reducing racism and oppressive practices. Our multicultural society of the 21st century also encourages teachers and students to prepare themselves carefully to deal with their own differences, by developing their cultural competencies and increasing their intercultural awareness (Catana, 2014). Multicultural ideologies are not only support for cultural diversity, but are also important for enabling equal opportunities for all people (Rechel et al., 2006).

\section{Conclusions}

Every day, health professionals meet people from both the same and other cultural backgrounds. In the face of relatively rapid social changes, our healthcare system has remained fairly rigid and it is vital that both the sys- 
temic and individual levels of healthcare are adapted to the currently expressed needs of the people entering this system. It is important that migrants who seek care in our healthcare system are given appropriate and adequate healthcare. This not only includes professional knowledge, but knowledge regarding other cultures and the needs of the people health professionals encounter on a daily basis. Finally, it is both necessary and humane to create an environment for everyone that is devoid of violence and discrimination.

\section{References}

Catana, S. E. (2014). Teaching cross-cultural communication issues: A way of successfully integrating into the multicultural knowledge society. Procedia: Social and Behavioural Sciences, 128, 343-348.

Clarke, S. (2017). Cultural congruent care: A reflection on patient outcome. Journal of Healthcare Communications, 2 (51): 1-3.

Cox, C., \& Marland H. (2013). Introduction: Migration, health and ethnicity in the modern world. In C. Cox \& H. Marland (Eds.), Migration, health and ethnicity in the modern world (pp. 2-13). Basingstoke, England: Palgrave Macmillan.

Durieux-Paillard, S. (2011). Differences in language, religious beliefs and culture: The need for culturally responsive health services. In B. Rechel, P. Mladovsky, W. Devillé, B. Rijks, R. Petrova-Benedict, \& M. McKee (Eds.), Migration and health in the European Union (pp. 203-212). Maidenhead, England: McGraw Hill/Open University Press.

Ingelby, D. (2011). Good practice in health service provision for migrants. In B. Rechel, P. Mladovsky, W. Devillé, B. Rijks, R. Petrova-Benedict, \& M. McKee (Eds.), Migration and health in the European Union (pp. 227-246). Maidenhead, England: McGraw Hill/Open University Press.

Josefová, A. (2014). Teaching cultural diversity as a phenomenon of the multicultural society. Procedia: Social and Behavioural Sciences, 152, 1019-1021.

Narayanasamy, A., \& White E. (2005). A review of transcultural nursing. Nurse Education Today, 25, 102-111.

O'Neil, T., Fleury, A., \& Foresti, M. (2016). Women on the move: Migration, gender equality and the 2030 Agenda for Sustainable Development. Retrieved from https://www.odi.org/sites/odi.org.uk/files/resource-documents/10731.pdf

Rechel, B., Mladovsky, P., Devillé, W., Rijks, B., Petrova-Benedict, R., Maykel, V., \& Martinovic, B. (2006). Understanding multicultural attitudes: The role of group status, identification, friendships and justifying ideologies. International Journal of Intercultural Relations, 30, 1-18.

Rechel, B., Mladovsky, P., Devillé, W., Rijks, B., Petrova-Benedict, R. \& McKee, M. (2011). Migration and health in the European Union: An introduction. In B. Rechel, P. Mladovsky, W. Devillé, W. Rijks, R. Petrova-Benedict, \& M. McKee 
(Eds.), Migration and health in the European Union (pp. 3-13). Maidenhead, England: McGraw Hill/Open University Press.

S. Ličen, I. Karnjuš, \& M. Prosen (Eds.). (2019). Women, migrations and health: Ensuring transcultural healthcare (pp. 107-116). Koper, Slovenia: University of Primorska Press.

https://doi.org/10.26493/978-961-7055-43-6.107-116 


\title{
Migrant Women's Perspectives on Reproductive Health Issues and Their Healthcare Encounters
}

\author{
Mirko Prosen \\ University of Primorska, Slovenia \\ mirko.prosen@fvz.upr.si
}

\section{Sabina Ličen}

University of Primorska, Slovenia

sabina.licen@fvz.upr.si

\section{Urška Bogataj}

University of Primorska, Slovenia

urska.bogataj@fvz.upr.si

\section{Doroteja Rebec}

University of Primorska, Slovenia

doroteja.rebec@fvz.upr.si

\section{Igor Karnjuš}

University of Primorska, Slovenia igor.karnjus@fvz.upr.si

Migration exposes women to greater health risks and health disparities. Healthcare professionals need to identify, prioritise and address these needs and risks in a holistic manner. The chapter explores migrant women's experiences with the health system and specifically their perspectives on reproductive health issues within the host country's healthcare system. A descriptive qualitative study using a qualitative content analysis approach was conducted in a maternity hospital in Slovenia. The purposive sample included $10 \mathrm{mi}-$ grant women. The analysis yielded two themes: (1) experiences, expectations and barriers of a different healthcare system; and (2) the impact of culturebased beliefs on women's reproductive health. The majority of the interviewed women felt they had received culturally responsive care, even though the language barrier was seen as one of the biggest obstacles in accessing healthcare. From the perspective of sexual and reproductive health, their migration was liberating for the women. Healthcare professionals need to learn more about cultural-based health practices since some of them are harmful to women and require their attention in the future.

\section{Introduction}

Migrants have had a considerable impact on population demographics in the European Union (EU) in the last decade. During this period, push and pull 
factors have changed dramatically, accompanied by new migration trends. Among others, migrant women are today slowly becoming the majority of migrants around the world and not just in the EU where it is estimated that women also make up a significant proportion of undocumented migrants (Jayaweera, 2018). The migration of women may be driven by individual factors, such as marital or reproductive status, education and skills, or by family or social factors like status or class (Fleury, 2016). In this context, migration can provide new opportunities for women either on their own or together with their spouses to improve their lives, escape oppressive social norms, and support children and other family members who are left behind. However, migration also exposes them to a series of vulnerable situations resulting from a precarious legal status, abusive working conditions, physical violence and health risks (de Leon Siantz, 2013; Fleury, 2016; Jayaweera, 2018).

Women's health risks related to migration vary. Migration may result in a worsening or an improvement of a woman's health. The resulting health impact of migration is generally determined by the conditions in which the migration occurred, the extent of integration, the woman's social status and the prevailing health conditions in the host country (Adanu \& Johnson, 2009; Hargreaves \& Friedland, 2013). Jayaweera (2018) listed multiple determinants of migrants' health status which indirectly or directly affect their health. These include biology, demography, socio-economic circumstances before, during and after migration, emigration policies in the sending countries and immigration and integration policies in the host countries, cultural traditions and cultural identity, social networks including transnational networks, length of residence in host countries, and impact of racism and discrimination. These and other determinants put women migrants at a disadvantage compared to male migrants for several reasons, where being both a woman and a migrant dominates. There is widespread evidence that women migrants face greater health disparities (Adanu \& Johnson, 2009; Hargreaves \& Friedland, 2013; Robertson, 2015), specifically greater health disparities related with sexual and reproductive health (Hargreaves \& Friedland, 2013; Merry, Vangen, \& Small, 2016; Perez Ramirez, Garcia-Garcia, \& Peralta-Ramirez, 2013; Reeske \& Razum, 2011; Saadi, Bond, \& Percac-Lima, 2015; Smith, LeVoy, Mahmood, \& Mercer, 2016). It has also been established that migrant women may often not have reliable access to healthcare or reproductive healthcare, which in turn negatively impacts maternal and perinatal outcomes (Fleury, 2016).

While most governments in the world recognise health as a basic human right and all EU member states have legally recognised the right to 
the highest attainable standard of health for everyone in their population (Pace, 2011), significant debates remain over the extent to which migrants share the same rights as non-migrants in relation to accessing healthcare. From this perspective, migrants clearly provide organisational challenges to healthcare systems across the EU member states since many of those systems are not prepared to give appropriate healthcare to so many culturally diverse patients. Any healthcare system's ability to respond within a reasonable time and holistically to migrant women's specific needs rests on its ability to identify and prioritise those needs and associated risks (Ruppenthal, Tuck, \& Gagnon, 2005). Exclusion in any way from healthcare means that women encounter delayed access to screening, treatment and care, limited access to contraception and pregnancy termination and heightened levels of discrimination and gender-based violence, all of which affects women's health and exacerbates health disparities (Smith et al., 2016).

When seeking to access the healthcare system, migrants, especially new arrivals, face barriers imposed by personal factors like age, sex, socio-economic status, ethnicity, language ability, proximity to healthcare services, social exclusion, health-seeking behaviour and health beliefs. In addition, barriers at the healthcare system level include public health policy and the legal status of migrants within the host country's health system, as well as specifics of the individual health system (Hargreaves \& Friedland, 2013). Hargreaves and Friedland (2013) also categorised key barriers in accessing healthcare services for newly arrived migrants by dividing them into two categories (Table 1). A similar division into two categories was presented by Nørredam and Krasnik (2011) where the first category 'formal barriers to access' was associated with health policies and the organisation of health systems. The second category 'informal barriers to access' was associated with language, communication, socio-cultural factors and 'newness' or the complex interaction of these factors.

By overcoming at least some of these barriers, healthcare professionals strive to ensure culturally sensitive healthcare for migrant women. Bjarnason, Mick, Thompson, and Cloyd (2009) emphasise it is imperative in serving the unique and diverse needs of patients, especially those who are most vulnerable, as women migrants are, that nurses, midwives, medical doctors and other healthcare professionals understand the importance of cultural differences by valuing, incorporating and examining their own health-related values and beliefs and those of their healthcare organisations, for only then can they support the principle of respect for persons and the ideal of transcultural care. It is a legal and moral obligation for all healthcare professionals 
Table 1 Key Barriers to Accessing Healthcare for Newly Arrived Migrants

\begin{tabular}{ll}
\hline Category & Barrier \\
\hline $\begin{array}{l}\text { System and } \\
\text { provider-level } \\
\text { barriers }\end{array}$ & Entitlement to publicly funded healthcare \\
& $\begin{array}{l}\text { Discriminatory practices and negative attitudes of frontline staff } \\
\text { Quality of care }\end{array}$ \\
\hline $\begin{array}{l}\text { Patient-level } \\
\text { barriers }\end{array}$ & Knowledge of health services and how to use them \\
& Adaptation to a new healthcare system \\
& Language barriers \\
& Asylum-seeker status \\
\hline
\end{tabular}

Notes Adapted from Hargreaves and Friedland (2013, p. 32).

to be culturally competent in order to provide high-quality care to patients from different cultural backgrounds (Prosen, 2018; Repo, Vahlberg, Salminen, Papadopoulos, \& Leino-Kilpi, 2017).

The aim of the study, as part of a large-scale EU-funded project (Crossborder network for migrant women: social integration, sexual and reproductive health - INTEGRA), was to explore the experiences of hospitalised migrant women and their encounters with healthcare professionals, as well as their perspectives on the care rendered that touches on reproductive health issues.

\section{Methods}

\section{Research Design}

A descriptive qualitative study using a qualitative content analysis approach was conducted in a maternity hospital in Slovenia (Gynaecological and Maternity Hospital Postojna). A descriptive qualitative approach is based on the general premises of constructivist inquiry and is often used in studies which are descriptive in nature, especially in examining healthcare phenomena (Polit \& Beck Tatano, 2014; Sandelowski, 2000). This research design was identified as important and appropriate for a research question focused on exploring the who, what and where of events or experiences and gaining insights into poorly understood phenomena (Kim, Sefcik, \& Bradway, 2017).

\section{Study Setting}

The Slovenian healthcare system is a public service organised on three levels that are mainly funded by the Health Insurance Institute of Slovenia. Hospital treatment is provided on secondary and tertiary levels in general and specialised hospitals located around Slovenia. Besides hospital treatment, the secondary level ensures specialised ambulatory care, which differs from am- 
bulatory care given at the primary level by treating more complicated diseases, offering more advanced diagnostics and methods of treatment.

There are 14 maternity clinics in Slovenia. Women in Slovenia have the right to use contraception, pregnancy and childbirth healthcare and the right to terminate a pregnancy (in accordance with the country's legislation). The majority of healthcare for women is, of course, delivered as primary care. Healthcare professionals included in caring for women's health are medical doctors, midwives and nurses.

\section{Participants}

Purposive sampling was used to select the participating women. This nonprobability sampling method was chosen since it allows the researcher to select participants based on a personal judgement about who will be the most informative, e.g. information-rich cases who are good informants about the phenomenon under investigation (Polit \& Beck Tatano, 2014). The sample included 10 migrant women who had been admitted to the hospital from the end of January till the end of April 2018. The criteria set for being included in the sample were, apart from a willingness to participate, the ability to overcome the language barrier and to understand each other during the interview and the saturation of data. The latter is reached when no new analytical information appears which would further the explanation of the phenomena (Moser \& Korstjens, 2018).

\section{Data Collection}

The data were collected using semi-structured interviews. This approach enables the researcher to follow the course of the content, reduce bias and at the same time maintain the same stimulus in all interviewees (Quinn Patton, 2015). The interview guide was based on an Italian questionnaire used in a previous study (AIDOS, ADUSU, \& Culture aperte, 2009). The questionnaire was translated from Italian into Slovenian by a researcher fluent in Italian and with expertise in healthcare. This was followed by the work of an expert group which over two rounds evaluated the translation, clarity and understanding of the questions. The questions were modified so that they suited the form of an interview guide and the research design used, as well as the cultural context in Slovenia. Examples of interview probes on healthcare are 'Tell me about the healthcare system in your home country' or 'Tell me about your experiences with the healthcare system in Slovenia' and on healthcare professionals 'Tell me about your gender preferences regarding the healthcare provider.'

Prospective participants were personally invited and given an exhaustive 
explanation of the study objectives and the methods used in a language they understood. Those who decided to participate were once again told about the purpose, research methods, ways of ensuring anonymity and confidentiality, and the possibility of feedback. Women were also informed of the opportunity to withdraw from the interview at any time. All the women had to give their written consent prior to the interview. For three women, the spoken language was Slovenian, for three it was English, for another three Slovenian and partially Serbian, and for one Slovenian and partially English. In no case was an interpreter or translator not present. On average, an interview lasted 38.30 minutes. The shortest was 18 minutes and the longest 71 minutes. The interviews were conducted in hospital rooms, paying special attention to the confidentiality and well-being of the participants. Each interview was audio-recorded and each participant was given a unique code.

\section{Data Analysis}

The interviews were transcribed verbatim. Names of persons, places and institutions were anonymised. After transcribing the interviews, the transcripts were once again checked against the audio-recorded transcripts. A qualitative data analysis was performed using the computer software program NVivo (version 12). Before the analysis commenced, the similarity metric of individual cases was analysed using cluster analysis and Pearson's coefficient. According to the highest $(r=0.907)$ and lowest $(r=0.745)$ values of Pearson's correlation coefficient, it can be argued that there is a positive and strong relationship between individual cases.

The transcripts were subjected to thematic analysis (Flick, 2002; Gibson \& Brown, 2009; Matthews \& Ross, 2010; Riessman, 2008; Sandelowski, 2000; Smythe, 2012) which relates to the process of analysing data in relation to communalities, differences and relationships. Data were reduced as part of the analysis. Data reduction is a form of analysis that sharpens, sorts, focuses, discards and organises data in such a way that 'final' conclusions may be drawn and verified (Miles \& Huberman, 1994, p. 11). The analysis followed these steps: the transcripts were read several times to obtain a clearer picture of the phenomena under study, the data were coded, codes were merged into sub-themes, and themes were formed on the basis of categories (Flick, 2002; Steen \& Roberts, 2011).

\section{Ethical Consideration and Funding}

The study was conducted in accordance with the Helsinki-Tokyo Declaration (World Medical Association, 2013), the Code of Ethics for Nurses and Nurse 
Assistants of Slovenia (Zbornica zdravstvene in babiške nege Slovenije, 2014) and the recommendations issued for ethics in qualitative research (British Sociological Association, 2002). The study was approved by the National Medical Ethics Committee (26.10.2017; No. 0120-544/2017/7). In addition, permission was obtained from the hospital.

The study formed part of the INTEGRA project and was co-funded by the cross-border co-operation Programme Italy-Slovenia 2014-2020 financed by the European Regional Development Fund.

\section{Findings}

\section{Background Information on the Participating Women}

The average age of the interviewees was 30.5 ( $S D=5.68$ ) years, with the youngest being 22 and the oldest 37 years. Three interviewees had migrated from Bosnia and Herzegovina, two from Russia and Serbia, one each from Ukraine, Kosovo and Iran. All, except one, had migrated directly from their home country to Slovenia. The reason for migration was for six of them to re-join their family (in most cases, their spouse who was 'work migrant' in Slovenia). Three women had migrated for work opportunities and one to be married. Two women had finished vocational education, four women secondary, one high school and three university level. Their lives in Slovenia are very much defined by their living conditions. More than half $(n=6)$ of them live in a rented apartment in an urban area. The average household includes $3.2(\mathrm{SD}=0.91)$ members. All interviewees, with the exception of one, have health insurance in the Republic of Slovenia. From the perspective of obstetrics anamnesis, eight women were primipara and two were multipara. Nine of them gave birth in 2018 in Slovenia. The average age of the first-time mothers was $28.80(S D=6.54)$ years. At the time of giving birth, the youngest was in their 205 and the oldest was aged 37 years.

\section{Main Themes}

Two themes emerged under 'Migrant women's perspectives on reproductive health issues and their encounters within healthcare' (Table 2). The first theme 'Experiences, expectations and barriers of a different healthcare system' summarises the migrant women's views on the healthcare delivered in their home country and later on in the host country. Their stories brought to the fore their perceptions of inequality in the home country and experiences and barriers with the host country's healthcare system. The second theme 'The impact of culture-based beliefs on women's reproductive health' 
Table 2 Identified Codes, Sub-Themes and Themes

\begin{tabular}{|c|c|c|}
\hline Codes & Sub-themes & Themes \\
\hline $\begin{array}{l}\text { Respecting a woman's cultural background while } \\
\text { delivering healthcare ensures a positive patient ex- } \\
\text { perience }\end{array}$ & \multirow{4}{*}{$\begin{array}{l}\text { Considering a } \\
\text { woman's cultural } \\
\text { background while } \\
\text { delivering health- } \\
\text { care in the host } \\
\text { country }\end{array}$} & \multirow{6}{*}{$\begin{array}{l}\text { Experiences, ex- } \\
\text { pectations and } \\
\text { barriers of a differ- } \\
\text { ent healthcare sys- } \\
\text { tem }\end{array}$} \\
\hline $\begin{array}{l}\text { Language barrier influences access to healthcare } \\
\text { services }\end{array}$ & & \\
\hline $\begin{array}{l}\text { Perceived absence of prejudice and discrimination } \\
\text { in interaction with healthcare professionals }\end{array}$ & & \\
\hline $\begin{array}{l}\text { Recognised quality of the healthcare system in host } \\
\text { country compared to the home country }\end{array}$ & & \\
\hline $\begin{array}{l}\text { Inequalities in accessing healthcare services have an } \\
\text { important impact on health }\end{array}$ & \multirow{2}{*}{$\begin{array}{l}\text { Health disparities } \\
\text { persist in the home } \\
\text { country }\end{array}$} & \\
\hline $\begin{array}{l}\text { Provision of care for women's reproductive health } \\
\text { does not follow advances concerning patient safety }\end{array}$ & & \\
\hline $\begin{array}{l}\text { Women's contraception is more or less based on a } \\
\text { joint decision of the partners }\end{array}$ & $\begin{array}{l}\text { Women's au- } \\
\text { tonomy and the } \\
\text { right to reproduc- } \\
\text { tive freedom }\end{array}$ & \multirow[t]{2}{*}{$\begin{array}{l}\text { Impact of culture- } \\
\text { based beliefs on } \\
\text { women's reproduc- } \\
\text { tive health }\end{array}$} \\
\hline Health- and illness-related traditions and customs & $\begin{array}{l}\text { Health-related } \\
\text { practices }\end{array}$ & \\
\hline
\end{tabular}

illustrates women's right to reproductive freedom and the ways that culture, along with tradition, influence health-related behaviour.

\section{Experiences, Expectations and Barriers of a Different Healthcare System}

The first theme revolves around two sub-themes showing the comparison of experiencing healthcare services in the home and host country. It was evident that socio-economic status in the home country was a determining factor in accessing high-quality healthcare and therefore often the reason for health disparities, while accessing healthcare services in the host country was often accompanied by a language barrier which functioned as a barrier to delivering culturally congruent healthcare. Each of these sub-themes is explained in more detail below.

\section{Considering a Woman's Cultural Background in Delivering Healthcare in the Host Country}

Almost all the interviewees emphasised that their cultural background had been respected and not rejected when in contact with healthcare professionals. The women's description shows that healthcare professionals were 
culturally sensitive in providing care. Some women were even surprised that their autonomy had been respected since it was unexpected. One interviewee from Ukraine said:

I was shocked [...]. When you are pregnant it is important that you are treated well and you are 'heard.' Both midwives present at my childbirth did what I asked them to do. I actuality cried, because it was like a dream come true. [INTE_32_1_UKR]

Although the majority of women considered the healthcare delivered to have been culturally appropriate, two of them had negative experiences. A migrant woman from Serbia described her story of being pregnant. Her gynaecologist at the primary level suggested the maternity clinic she works at, despite the woman's choice to give birth in another maternity clinic. After the woman insisted on going to a maternity clinic of her choice, the gynaecologist in her own words was 'feeling very insulted' and said:

You from foreign countries, you always want to do something on your own, you don't listen to advice. [INTE_22_1_SRB]

A woman from Kosovo described her experience with nurses because she felt they perceived her as different. She said:

Some nurses didn't want to speak to me in English. They looked at me as if they were angry at me. I do not know why. Perhaps because I'm a foreigner. We are all people [...] even though I'm not Slovenian. If I saw someone who needs help, I would be glad to help him [...] even though he or she is not Albanian, but he is human after all. [INTE_23_1_KOS]

The language barrier is indeed an overwhelming barrier for migrants and, as it seems, also for healthcare professionals. Women's experiences vary, from those who did not have any communication problems when in contact with healthcare professionals to those who had experienced some problems like the woman above. The first group of women prevailed and they did not stress the need for an interpreter or translator. These also included newly arrived migrant women, but because their language group (Slavic languages) was similar to the Slovenian language the language barrier was not great. On the contrary, a woman from Kosovo revealed that interpreting would be a good solution since Slovenians have trouble understanding Albanian: 
It is easier if you have with you an interpreter [...] the Albanian language is difficult to learn. It is hard to get someone who understands. [INTE_23_1_KOS]

A woman from Russia described her experience when hospitalised for the first time in Slovenia. She explained that the word 'better' (in Slovenian 'boljše') means bigger in Russian (in Slovenian 'večje').

[...] and then the nurse asked me about the presence of pain: 'Is it better?' and I said: 'Yes.' And then she left the room. I did not get the analgesics at that time. This happened only once and never again. [INTE_37_1_RU]

Another aspect of ensuring culturally sensitive care is the absence of prejudice and discrimination among healthcare professionals towards the patients they care for. The interviewees did not report any negative experiences with healthcare professionals, although one of them, a woman from Serbia, pointed out that 'rude people exist everywhere in the world, in the home country as well as in the host country.' She also described her encounter with a female gynaecologist, since she had desired to give birth in a maternity clinic different to that suggested by the gynaecologist (the woman further explained that her gynaecologist also works there part time). The woman declined and her gynaecologist gave the following answer:

'Yes, you foreigners, you always want to do things your way, you do not listen to advice.' I was quite offended and I mentioned to her that if my last name were the same as my husband's we would not be having this conversation. [INTE_22_1_SRB]

Despite this experience, and considering situations that the women did not mention, they all recognised the healthcare system in Slovenia as being superior to the healthcare system in their home country.

Slovenia has a good health system. In Kosovo, the physicians are good, but the system does not function. [...] we receive much more in Slovenia from the health system than we did in Kosovo. [INTE_23_1_KOS]

Healthcare is a disaster. There is no health system in Bosnia. [INTE_35_3 - BIH]

I believe Slovenia has a high-quality health system. In my opinion, the system here is even better than in Germany. [INTE_36_1_RU] 
The quality of the healthcare services in Slovenia and the existence of health disparities in the home country's healthcare system were reported by some interviewees as reasons that women from South-east Europe migrate to Slovenia. This issue was further elaborated by the interviewees from the perspective of the health disparities they had encountered while (they or their family members were) accessing healthcare services in their home country.

\section{Health Disparities Continue in the Home Country}

The majority of interviewees perceived the public healthcare system in their home country as unjust since high-quality care depended on the economic standard of the individual. This was noted by women from Ukraine, Serbia, Kosovo, and Bosnia and Herzegovina. Public healthcare services were experienced as services low in quality, as services lacking appropriate staff, standards and resources, while the private sector was described as the opposite.

We pay for healthcare services. We have health insurance. It's about EUR 10 per year, but they treat you as if you do not have any insurance at all. You are always first and if you do not pay you are always last. [INTE_35_3_BIH]

The women had greater trust in the private sector:

We have state health insurance. If possible, I preferred to use the services offered by the private sector. The state health institutions are crowded, without friendly staff. Communication is important. The truth is that I do not trust state health institutions so much. [INTE_36_1_RU]

The difference between private and public health services? In the private sector, you have to pay, but the services provided are higher in quality than in the public sector. [INTE_32_1_BIH]

Health disparities arose from the financial constraints of individuals, yet even with a lack of financial resources women and their families tried to find a way to better health. As seen, the situation in the described healthcare system was worsened by the fact that medications also had to be paid for. Even medications whose application and use are (and should be) limited to healthcare institutions are only available in pharmacies and must be purchased.

In Slovenia, you cannot get medication without a prescription. In Kosovo, we can have any medication without a prescription. You can take 
whatever you want. Perhaps not everything but, [...] when I had trouble with tonsillitis, I went to see to a physician working in the private sector. He sent me off to buy infusion, injections and an infusion set from the pharmacy. [INTE_23_1_KOS]

Corruption is another element of healthcare services and a further aspect or consequence of health disparities which considerably affects people's lives and health. A woman from Serbia described:

From another perspective, the public sector works by the same rules as the private one. If you bring them money, you will be taken care of, no matter what. My father broke a leg 10 years ago and, even though he was insured, my grandfather had to pay for his operation because the doctor knew he worked in Germany. My grandfather had to take the doctor to the store so that he could buy whatever he wanted. So [...] if you are poor, it's better that you don't go to the doctor. [INTE_22_1_SRB]

Women's health is also exposed to such health disparities and socioeconomic status is a powerful predictor of women's health. Two women from Bosnia and Herzegovina stated:

I went to a gynaecologist in both a public and private institution. In the private institution, I paid for the services, but I believe they were performed better. [INTE_25_3_BIH]

I can go to a public institution for a gynaecological examination but still, if you do not pay, no one will take a look at you. [INTE_32_1_BIH]

Healthcare services during childbirth seem to be limited in the public health institutions of some interviewees' countries of origin. A woman from Kosovo who gave birth in Slovenia said:

[...] I couldn't do it without an epidural. The physician (a woman) explained. I was scared [...] I'm glad I decided on an epidural (in Slovenia). I know that if I had given birth in Kosovo it would have been terrifying. [INTE_23_1_KOS]

A similar story was told by a woman from Bosnia and Herzegovina concerning prenatal check-ups as she experienced them in Slovenia. 
[...] in Bosnia some check-ups during pregnancy are only administrative in nature. It's not like in Slovenia. I tell you, it is better here (in Slovenia). [INTE_35_3_BIH]

Freedom of reproductive choice in countries where contraceptives must be purchased privately is particularly challenged, with serious consequences for women's lives, ranging from abortion to social marginalisation. One interviewee from Bosnia and Herzegovina (INTE_25_3_BIH) admitted that 'there was little knowledge about contraceptive methods among her friends' and that 'one's income limits the use of contraceptive pills.' In some countries, the different possibilities of contraception are also very limited.

In Slovenia, more kinds of contraceptives are available than in Bosnia. [INTE_25_3_BIH]

The practice of privately paying for oral contraceptives was also pointed out by a woman from Russia:

I was taking the same contraceptive pills in Russia as I'm taking now in Slovenia; however, I had to buy them in Russia. [INTE_37_1_RU]

At the end, this was seen as just one aspect of women's reproductive freedom. The women also described other factors that shape their right to use contraceptives and exercise their autonomy over reproductive freedom.

\section{The Impact of Culture-Based Beliefs on Women's Reproductive Health}

The second theme focuses on the culture-based beliefs surrounding women's health in relation to women's autonomy and their right to reproductive freedom. Societal expectations concerning reproduction and women's role in this process are challenging not only for women migrants in countries where reproductive freedom is fully exercised but also for societies themselves being challenged by the need to protect individuality as well as respect individual culture.

\section{Women's Autonomy and the Right to Reproductive Freedom}

Most interviewees stated they had used contraceptives in the past and some will probably continue to do so in the future. Yet they believe the decision for a woman to use contraceptives should be made together with the partner. All women confirmed that their partner was not opposed to the idea of using contraceptives, except in one case. 
My husband does not support the use of contraceptives. [...] with us, the husband decides about contraception use. [INTE_35_3_BIH]

Even though some of the migrant women are Muslim, it seems that religion does not impact reproductive freedom as much as one would expect. A woman from Iran, for example, noted:

Contraception is, of course, available in Iran. They both (the husband and wife) decide if they want to use it, if they want to have more children or not. [INTE_33_1_IR]

\section{Health-Related Practices}

Besides contraception, to treat gynaecological problems some women use complementary and alternative medicine methods. Certain methods may be hazardous to their health:

I use homoeopathic medicines and other herbs. In Slovenia, they are hard to get. It is easier in Ukraine, although some time ago they were forbidden for use. Today, they are available again in Ukraine. [INTE_32_1 _UKR]

A woman from Russia described a similarly hazardous experience involving oral contraceptives:

I talked to my friends from Russia living here in Slovenia. They bring something (meaning medication) from Russia, but I'm not sure whether I will still need contraception or not (laughs). [INTE_37_1_RU]

On the other hand, a few women only use medications prescribed by a medical doctor (school medicine) or over-the-counter medicines available in pharmacies. The use of such medicines ranges from occasional use in accordance with the prescribed intake regime to excessive use:

When I have PMS (premenstrual syndrome) [...] it's always unbearable and at that time l eat quite a lot of analgesics (names an analgesic that is available over the counter). [INTE_22_1_SRB]

\section{Discussion}

Evidence from this study focused on women's description of their experiences as patients in the health system of their host country (while looking 
back and comparing the care given in their home country) from the perspective of barriers to accessing healthcare. This study also explored the impact of the identified barriers on women's sexual and reproductive issues. As has been established, migrant women's health and well-being are very much determined by the societal factors surrounding the migration process as well as integration. However, their health status prior to their migration, namely, while still living in their home country, was subject to health disparities that largely derived from their socio-economic standing and gender-determined roles.

Due to unpleasant experiences as patients with their home country's health system, it seems that some women had low expectations of the health system in Slovenia. It came as a surprise later for them that healthcare in Slovenia may be described as high quality and, for all of them, a free service provided by the state. As part of this system, their encounters with healthcare professionals were perceived as culturally sensitive or responsive. A culturally responsive healthcare encounter requires the provider to take steps to moderate the power differential in order to form a more balanced partnership or therapeutic alliance with the patient. Even though any encounter in the context of diversity requires cultural responsiveness to be successful, mistakes in communications during the delivery of healthcare can be damaging due to the power differential between the provider and the recipient of care (Dreachslin, Gilbert, \& Malone, 2012). The latter was quite noticeable in two cases where women confided their experience. Yet, it should be emphasised that cultural responsiveness does not mean that 'anything goes' and does not require the healthcare provider to accommodate everything the patient wants (Dreachslin et al., 2012; Leininger, 2002). For example, Leininger (2002) states the focus of decision-making should include: (1) cultural care preservation, also known as maintenance; (2) cultural care accommodation, also known as negotiation; and (3) cultural care re-patterning or re-structuring.

Almost all of the interviewees reported that they did not feel discriminated by healthcare professionals due to their cultural background or their social status in the host country's health system. The right to access free healthcare services in the host country is insufficient for ensuring actual use of healthcare (Hargreaves \& Friedland, 2013). Healthcare professionals must therefore strive to deliver culturally responsive or congruent care for which cross-cultural competencies are essential. Cross-cultural competencies are one of the main ingredients in narrowing the health disparities gap as healthcare services which are respectful and responsive to the healthcare beliefs, practices, cultural and linguistic needs of a wide range of patients can con- 
tribute to positive health outcomes (Andrews \& Boyle, 2012). The implications for clinical practice derived from these findings point out to more intensive attempts to further develop cross-cultural competencies among healthcare professionals where, among other methods, transcultural education makes a significant contribution (Prosen, 2018).

A consistent finding is that the language barrier and trouble communicating with healthcare professionals continue for almost every woman interviewed, especially the new arrivals. Communication difficulties shape women's overall experience with a health system and directly negative impact her care and constitute a key factor in delayed diagnosis (Hargreaves \& Friedland, 2013). Women migrants who do not speak the native language and those from less affluent parts of the world are at increased risk of higher maternal morbidity and mortality and poor perinatal outcomes (Smith et al., 2016). For women coming from the former Yugoslav republics or women from Russia or Ukraine with which we share the Slavic language group, the Slovenian language sounded familiar, although women with an Albanian background had great difficulties establishing understandable communication with healthcare professionals. Among the interviewees, especially women from Kosovo who spoke Albanian expressed the need for an interpreter. This, of course, raises a few questions that deserve special attention when discussing the use of interpreters in gynaecology and obstetrics settings. The question of organising and financing such services should not be overlooked, although the question is related to the fact that sexual and reproductive health is still very much considered a societal taboo and under the influence of cultural traditions and practices. Some women may therefore feel unable to freely discuss their sexual and reproductive needs, making it harder for healthcare professionals to determine and provide appropriate care (Mengesha, Perz, Dune, \& Ussher, 2018). Professional interpreters are needed, albeit proficiency in the native language is not enough by itself and should also include, besides cultural knowledge, knowledge about privacy and confidentiality issues, knowledge about the health system etc. It should also be emphasised that effective communication between providers and patients requires attention to be paid to the cultural dimensions of not only verbal (or nonverbal) communication but also written communication, including health education materials, information related to the treatment plan and a patient's diagnosis (Dreachslin et al., 2012).

When women started elaborating more about healthcare services and encounters with healthcare professionals in their home country in comparison to Slovenia, it emerged that they had faced many health disparities in 
their home country based on their socio-economic status. That is why all the women recognised that superior healthcare services are delivered by the health system in Slovenia. Due to the women's previous experiences in their home country, the key element characterising healthcare services in Slovenia as superior was that they did not have to pay to obtain good quality services. It seems the public health policy in Slovenia works for migrant women, although in some cases inadequate health literacy was clearly present. Health literacy implies the achievement of a certain level of knowledge, personal skills and confidence to be able to take action to improve personal and community health (Tsai \& Lee, 2016). A lower level of health literacy was clearly noticeable among the newly arrived women. Inadequate health literacy may limit migrants' ability to take full advantage of health information and thus the services provided by the health system to make appropriate health decisions in the host country (Tsai \& Lee, 2016).

The women also recognised the quality of care related to reproductive health in the host country. As established in previous research (Reeske \& Razum, 2011; Smith et al., 2016), perinatal and maternal morbidity and mortality among migrant women are usually high. The migrations to that extent made the women more aware of their possibilities regarding reproduction and the freedom to choose. Religion did not, at least not directly, constrain the women's autonomy for reproductive freedom, although it is not easy to separate religion from sexuality and reproductive health. All major religions offer a distinct belief system which aims to guide devout followers in sexual and reproductive matters (Arousell \& Carlbom, 2016). Other culturally based traditions, such as inappropriate use of treatment methods or medications used for treatment, may also contribute to developing practices that harm women's reproductive health. For some, these practices seem to continue in the host country and this further supports calls for activities to increase health literacy among migrant women.

In qualitative research, the data as well as the conceptualised findings are prone to subjectivity. However, they allow an insight into migrant women's experiences with healthcare services in the host country from the sexual and reproductive health perspectives and have helped enrich other parts of large-scale research within the INTEGRA project. The study was also conducted in one hospital only, which could limit the responses obtained and the purposive sample could entail selection bias, yet the women selected for the interviews who had no difficulties communicating and expressing themselves in English or in a language familiar to the interviewer (Serbian). Future research should focus on exploring culturally based practices related to sex- 
ual and reproductive health, health literacy among newly arrived migrant women and those living in the host country for some time, gender-related barriers to accessing healthcare services along with re-examining ways to overcome the language barrier in the health system. Epidemiologic studies are also needed to determine the impact of health disparities on maternal morbidity and the mortality and perinatal outcomes of migrant women.

\section{Conclusions}

Migrant women form one of the most vulnerable and marginalised population groups, often excluded from healthcare services by a complex set of reasons, being either cultural, gender-related or based on their social status. Migrant women's health is much more challenged than men's, and not just during migration and arrival as shown by the study, and particularly so if we discuss sexual and reproductive health. Healthcare professionals have an important role in recognising health disparities and the diverse needs of migrant women deriving from their cultural background. Cultural responsiveness or cultural sensitivity must therefore become an imperative which obliges healthcare professionals to deliver culturally congruent care; however, without appropriate support, their efforts are often subject to improvisation. Healthcare services as well as policymakers should recognise the effect of migration on women's health and the need to address this issue systematically in clinical settings (for example, overcoming the language barrier) or in the community (for example, health promotion and health monitoring throughout the lifespan).

\section{References}

Adanu, R. M., \& Johnson, T. R. (2009). Migration and women's health. International Journal of Gynecology \& Obstetrics, 106(2), 179-181.

AIDOS, ADUSU, \& Culture aperte. (2009). Mutilazioni dei genitali femminili e diritti umani nelle communita migranti: Rapporto di ricerca nelle regioni Veneto e Friuli Venezia Giulia. Retrieved from http://www.aidos.it/wp -content/uploads/2009/01/MGF-rapporto-ricercacomunit\%C3\%Ao -migranti-_ok-1.pdf

Andrews, M. M., \& Boyle, J. S. (2012). Theoretical foundations of transcultural nursing. In M. M. Andrews \& J. S. Boyle (Eds.), Transcultural concepts in nursing care (6th ed., pp. 3-16). Philadelphia, PA:Wolters Kluwer/Lippincott Williams \& Wilkins.

Arousell, J., \& Carlbom, A. (2016). Culture and religious beliefs in relation to reproductive health. Best Practice \& Research: Clinical Obstetrics \& Gynaecology, 32, 77-87. 
Bjarnason, D., Mick, J., Thompson, J. A., \& Cloyd, E. (2009). Perspectives on transcultural care. Nursing Clinics of North America, 44(4), 495-503.

British Sociological Association. (2002). Statement of ethical practice for the British Sociological Association. Retrieved from https://www.britsoc.co.uk/ media/23902/statementofethicalpractice.pdf

de Leon Siantz, M. L. (2013). Feminization of migration: A global health challenge. Global Advances in Health and Medicine, 2(5), 12-14.

Dreachslin, J. L., Gilbert, M. J., \& Malone, B. (2012). Diversity and cultural competence in health care: A systems approach. New York, NY: Wiley.

Fleury, A. (2016). Understanding women and migration: A literature review (Knomad Working Paper 8). Washington, DC: World bank.

Flick, U. (2002). An introduction to qualitative research (2nd ed.). London, England: Sage.

Gibson, W. J., \& Brown, A. (2009). Working with qualitative data. London, England: Sage.

Hargreaves, S., \& Friedland, J. S. (2013). Impact on and use of health services by new migrants in Europe. In F. Thomas \& J. Gideon (Eds.), Migration, health and inequality (pp. 27-43). London, England: Zed Books.

Jayaweera, H. (2018). Access to healthcare for vulnerable migrant women in England: A human security approach. Current Sociology, 66(2), 273-285.

Kim, H., Sefcik, J. S., \& Bradway, C. (2017). Characteristics of qualitative descriptive studies: A systematic review. Research in Nursing \& Health, 40(1), 23-42.

Leininger, M. (2002). The theory of culture care and the ethnonursing research method. In M. Leininger \& M. McFarland (Eds.), Transcultural nursing: Concepts, theories, research and practice (3rd ed., pp. 71-98). New York, NY: McGraw-Hill.

Matthews, B., \& Ross, L. (2010). Research methods: A practical guide for the social sciences. New York, NY: Pearson Longman.

Mengesha, Z. B., Perz, J., Dune, T., \& Ussher, J. (2018). Talking about sexual and reproductive health through interpreters: The experiences of health care professionals consulting refugee and migrant women. Sexual \& Reproductive HealthCare, 16, 199-205.

Merry, L., Vangen, S., \& Small, R. (2016). Caesarean births among migrant women in high-income countries. Best Practice \& Research: Clinical Obstetrics \& Gynaecology, 32, 88-99.

Miles, M. B., \& Huberman, M. A. (1994). Qualitative data analysis: An expanded sourcebook (2nd Ed.). Thousand Oaks, CA: Sage.

Moser, A., \& Korstjens, I. (2018). Series: Practical guidance to qualitative research. Part 3: Sampling, data collection and analysis. European Journal of General Practice, 24(1), 9-18.

Nørredam, M., \& Krasnik, A. (2011). Migrants' access to health services. In B. Rechel, P. Mladovsky, W. Devillé, B. Rijks, R. Petrova-Benedict, \& M. McKee 
(Eds.), Migration and health in the European Union (pp. 67-78). Maidenhead, England: McGraw Hill/Open University Press.

Pace, P. (2011). The right to health of migrants in Europe. In B. Rechel, P. Mladovsky, W. Devillé, B. Rijks, R. Petrova-Benedict, \& M. McKee (Eds.), Migration and health in the European Union (pp. 56-66). Maidenhead, England: McGraw Hill/Open University Press.

Perez Ramirez, F., Garcia-Garcia, I., \& Peralta-Ramirez, M. I. (2013). The migration process as a stress factor in pregnant immigrant women in Spain. Journal of Transcultural Nursing, 24(4), 348-354.

Polit, D. F., \& Beck Tatano, C. (2014). Essentials of nursing research: Appraising evidence for nursing practice (8th ed.). Philadelphia, PA: Wolters Kluwer.

Prosen, M. (2018). Developing cross-cultural competences: Opportunity for ensuring health and healthcare equality and equity. Slovenian Nursing Review, 52(2), 76-80.

Quinn Patton, M. (2015). Qualitative research \& evaluation methods: Integrating theory and practice (4th ed.). Thousand Oaks, CA: Sage.

Reeske, A., \& Razum, O. (2011). Maternal and child health: From conception to first birthday. In B. Rechel, P. Mladovsky, W. Devillé, B. Rijks, R. PetrovaBenedict, \& M. McKee (Eds.), Migration and health in the European Union (pp. 139-153). Maidenhead, England: McGraw Hill/Open University Press.

Repo, H., Vahlberg, T., Salminen, L., Papadopoulos, I., \& Leino-Kilpi, H. (2017). The cultural competence of graduating nursing students. Journal of Transcultural Nursing, 28(1), 98-107.

Riessman, C. K. (2008). Narrative methods for the human sciences. Los Angeles, CA: Sage.

Robertson, E. K. (2015). 'To be taken seriously:' Women's reflections on how migration and resettlement experiences influence their healthcare needs during childbearing in Sweden. Sexual \& Reproductive HealthCare, 6(2), 5965.

Ruppenthal, L., Tuck, J., \& Gagnon, A. J. (2005). Enhancing research with migrant women through focus groups. Western Journal of Nursing Research, 27(6), 735-754.

Saadi, A., Bond, B. E., \& Percac-Lima, S. (2015). Bosnian, Iraqi, and Somali refugee women speak: A comparative qualitative study of refugee health beliefs on preventive health and breast cancer screening. Womens Health Issues, 25(5), 501-508.

Sandelowski, M. (2000). Whatever happened to qualitative description? Research in Nursing \& Health, 23(4), 334-340.

Smith, A. C., LeVoy, M., Mahmood, T., \& Mercer, C. (2016). Migrant women's health issues. Retrieved from http://www.euro.who.int/_data/assets/pdf _file/0017/330092/6-Migrant-womens-health-issues-irregular-status.pdf ?ua $=1$ 
Smythe, E. (2012). Discerning which qualitative approach fits best. New Zealand College of Midwives Journal, 46, 5-12.

Steen, M., \& Roberts, T. (2011). The handbook of midwifery research. Oxford, England: Wiley-Blackwell.

Tsai, T.-I., \& Lee, S.-Y. D. (2016). Health literacy as the missing link in the provision of immigrant health care: A qualitative study of Southeast Asian immigrant women in Taiwan. International Journal of Nursing Studies, 54, 65-74.

World Medical Association. (2013). World Medical Association Declaration of Helsinki: Ethical principles for medical research involving human subjects. Journal of the American Medical Association, 310(20), 2191-2194.

Zbornica zdravstvene in babiške nege Slovenije. 2014. Kodeks etike v zdravstveni negi in oskrbi Slovenije in Kodeks etike za babice Slovenije. Ljubljana, Slovenia: Author.

S. Ličen, I. Karnjuš, \& M. Prosen (Eds.). (2019). Women, migrations and health: Ensuring transcultural healthcare (pp. 117-137). Koper, Slovenia: University of Primorska Press. https://doi.org/10.26493/978-961-7055-43-6.117-137 



\title{
Monoligual Health? Linguistic Barriers in Slovene Healthcare Experienced by Migrant/Refugee Women
}

\author{
Uršula Lipovec Čebron \\ University of Ljubljana, Slovenia \\ ursula.lipovec@ff.uni-lj.si \\ Lea Bombač \\ University Medical Centre Ljubljana, Slovenia \\ bombac.lea@gmail.com \\ Nike Kocijančič Pokorn \\ University of Ljubljana, Slovenia \\ nike.pokorn@ff.uni-lj.si \\ Miha Lučovnik \\ University Medical Centre Ljubljana, Slovenia \\ mihalucovnik@yahoo.com
}

The aim of the article is to identify the main obstacles related to the language barriers that arise between migrants/refugee patients and healthcare personnel in the field of gynecology and obstetrics. To identify these obstacles a qualitative research was conducted from May 2017 to June 2018 among migrant/refugees and healthcare workers in Slovenia. The results show that first, linguistic obstacles are often the consequence of the lack of available professional healthcare interpreters/intercultural mediators; second, the absence of training of medical personnel on linguistic dimensions of healthcare causes inadequate awareness of interpreter's/intercultural mediator's role; and third, the linguistic obstacles that migrant/refugee women face hinder their access to basic health rights, entitlements and limitations, including reproductive rights. These obstacles significantly impair the ability of Slovene healthcare system to establish quality communication with migrant/refugee women and may cause inequalities among foreign-speaking healthcare users in their access to healthcare.

\section{Introduction}

European population is becoming increasingly diverse, not only due to the presence of migrants and refugees, but also because of a growing number of other people on the move (e.g. tourists, truck-drivers, business people or exchange students etc.). In this situation 'the idea of diversity has radically changed to include other dimensions of diversity such as immigration status, 
gradations in rights and entitlements, migration history, and socioeconomic status' (Chiarenza, 2014). Besides other areas of society, also healthcare sector is compelled to respond to a multiple-diversity needs as individual needs are expressed by the intersection of differences such as origin, class, gender, age, language, and other social distinctions (Yuval-Davis, 2006).

As previous research in Slovenia has shown (Bofulin \& Bešter, 2010; Farkaš, 2016; Bombač et al., 2017; Kocijančič Pokorn \& Lipovec Čebron, in press), healthcare institutions are slow to respond to the presence of increasingly diverse population. As a result, non-Slovene citizens living in this country face a series of obstacles when searching for health. Since legal, administrative and socio-cultural barriers in healthcare were already extensively addressed in other studies (Brovč, Ahčin, Šlajpah, \& Rotar-Pavlič, 2009; Jazbinšek-Palaić, 2009; Bofulin \& Bešter, 2010; Lipovec-Čebron, 2010a, 2010b; Lipovec Čebron et al., 2016; Bombač et al., 2017; Lipovec Čebron \& Pistotnik, 2015, 2018), in this chapter we will attempt to identify the main linguistic obstacles in providing patient care for migrant/refugee women in Slovenia.

A nation-wide survey of healthcare workers in Slovenia ( $n=564$, healthcare workers, incl. physicians, dentists, and nurses) on communication between healthcare workers in Slovene healthcare system and non-Slovenespeaking (NSSP) or limited Slovene proficient patients (LSPP) has shown that language diversity poses a great challenge to healthcare personnel to ensure quality healthcare (Kocijančič Pokorn \& Lipovec Čebron, in press). The results of this survey have shown that $94 \%$ of respondents have contacts with foreign-speaking patients in their work, and that the most challenging encounters are those with Albanian-speaking patients and with patients who speak Arab, Chinese, Russian, Roma and other languages. The same survey has also shown that communication problems arise in various medical fields, however, that they are most common in emergency services, family medicine, paediatrics, and obstetrics/gynecology. ${ }^{1}$ Moreover, health problems or diagnoses that are most frequent among users who do not speak Slovene fell in the following categories: first, antenatal, perinatal and postnatal care; second, injuries; third, psychiatric problems; fourth, gastrointestinal problems and fifth, respiratory infections etc. (Mikolič Južnič, in press).

\footnotetext{
${ }^{1}$ In the survey, the respondents were asked to indicate medical fields where they encounter most problems in communication with non-Slovene-speaking patients. Twelve medical fields were provided on the list and the respondents were able to add additional ones if they wanted. The majority of respondents (67\%) selected emergency services (and $27 \%$ emergency transportation related services). The second most frequently selected medical field was family medicine $(56 \%)$, followed by pediatrics $(34 \%)$, gynecology $(28 \%)$ and obstetrics $(24 \%)$.
} 
Since the medical field of gynecology and obstetrics was identified as one of the areas where linguistic barriers are most commonly present, we focus here on the analysis of the crucial linguistic barriers encountered by migrant/refugee women in search for gynecological/obstetric medical help. The analysis is based on qualitative research conducted from May 2017 to June 2018 among migrants/refugees ${ }^{2}$ with whom we conducted four semistructured interviews in different locations in Ljubljana and one focus group with six women residing in the reception center (Asylum seeker center). Since our interlocutors ${ }^{3}$ were native speakers of Arab and Farsi, interviews and the focus group discussion were translated from Farsi and Arab. Moreover, in the chapter we also present experiences of healthcare personnel of different profiles ${ }^{4}$ collected during two focus groups discussions of linguistic and cultural aspects of healthcare. The first focus group was organized in one of Slovene healthcare centers, where 12 healthcare workers participated; the second was held in two maternity hospitals in Slovenia, where 15 healthcare workers altogether collaborated. These healthcare institutions were chosen because they cater for a higher number of foreign-speaking users compared to other healthcare institutions in Slovenia. The interviews and the focus group discussions were transcribed, the material was classified according to different thematic areas and later analyzed. These findings are combined with findings of previous research on health aspects of migration (Lipovec Čebron, 2010a, 2010b, 2011; Lipovec Čebron \& Pistotnik, 2015, 2018, in press; Bombač et al., 2017). On the basis of our research we identified three levels of obstacles that are connected with language barriers and are presented in the following pages.

\section{Absence of Interpreters/Intercultural Mediators}

Unlike in some other countries of the European Union, Slovene healthcare does not have a national system of professional interpreting service avail-

\footnotetext{
${ }^{2}$ In the chapter we use both terms: 'migrant' as well as 'refugee' since we do not want to reproduce the problematic dichotomy between the 'economic migrant' and 'refugee' that was recently misused in xenophobic and racist anti-immigration political propaganda across Europe.

${ }^{3}$ All of our interlocutors were pregnant or had recently given birth; their age ranged from 20 to 30 years; six of ten interlocutors were asylum seekers, while other four were persons with recognised international protection. Due to the sensibility of the topic, we keep their other data anonymised.

${ }^{4}$ Their profiles were: 8 nurses, 4 general practitioners, 15 specialists and fellows in gynecology and obstetrics. Due to the sensibility of the topic, we keep the institutions anonymised.
} 
able in healthcare institutions. ${ }^{5}$ Although many professional interpreters exist, they lack the training for interpreting in healthcare setting, are often difficult to reach and their services are too expensive for an average patient (Lipovec Čebron \& Bombač, in press). This problem was addressed also in the document Country Report for Slovenia: 'Even though the Patient Rights Act (ZpacP) includes the patient's right to understand the procedure, to be informed and not to be discriminated against, in practice there is a great lack of systematic solutions (national or regional policy) regarding the availability of interpretation services.' (MIPEX, 2015 p. 19). The lack of available interpretation services is causing a series of consequences, as it is clear from the fragments of the interviews:

Tania gave birth in Slovenia. When asked what her birth experience in Slovenia was like, she answered: 'Nothing good. [...] I feel pain, I ask the doctor for caesari, doctor said "No. No." I do not know why. I say, I want. And doctor: "No, no." I do not understand why not. They gave 2 tablets at midnight. At 14 o'clock very painful. Then injection, then with a needle [artificial rupture of membranes, AN]. Then 20 hours, of pain, pain.' [Interview with Tania, Ljubljana, 18. 10. 2017]

The interview shows that she did not understand the procedure inducing labor and could not get the information why the physician refused to do caesarean section. She therefore felt maltreated and thought that this was because she was a refugee. Due to language problems, she was deprived of the right to autonomously decide on the course of childbirth, methods of pain relief during labor, and agree or disagree with utilized medical procedures.

During delivery [...] I could not explain to a woman in labor what was going on or give her instructions. Another day a foreign woman came to my office but I could not explain to her what was going on well enough because it would had taken me a lot more time since she spoke only a few Slovene and English words. But if she was accompanied by a female interpreter who would understand the language well, it would all be much easier! [Focus group in the maternity hospital, 11. 10. 2017]

The above responses of the interviewees show that the absence of interpreter or intercultural mediator is, on one hand, causing unsatisfactory expe-

\footnotetext{
${ }^{5}$ For instance, in Italy, Germany or Switzerland (Gosenca, 2017).

${ }^{6}$ All Slovene utterances were translated into English by Uršula Lipovec Čebron.
} 
rience in medical setting for migrant/refugee women who felt that her patient's rights were violated. On the other hand, they reveal how the absence of interpretation services is creating difficult situation for medical personnel who cannot perform their work in a professional and competent manner. In addition, the second example shows that overcoming language barriers adds additional strain since it is time consuming and often results in medical personnel not communicating effectively with the patient. Previous research (Gorjanc, 2013; Gosenca, 2017; Milavec Kapun et al., 2017; Rotar Pavlič et al., 2017; Kocijančič Pokorn \& Lipovec Čebron, in press) has shown that linguistic barriers are one of the crucial factors that limit the access to healthcare institutions for migrant population in Slovenia. The consequences of these barriers are multifold: from avoiding or delaying the visit to the doctor, to numerous misunderstandings or even traumatic experiences in medical settings.

These findings are in line with research in other countries (Bowen, 2001; Angelelli, 2008; Schapira et al., 2008; Verrept, 2008; Ingleby, Chiarenza, DEville, \& Kotsioni, 2012) that demonstrate that absence of or lack of quality interpretation and translation in healthcare constitutes not only violations of basic healthcare standards and poses a risk to the patients' safety, but also creates a significant financial burden for the healthcare system (Kocijančič Pokorn, in press).

The lack of systematic support leads to situations where patients as well as healthcare workers are left to their own inventiveness in their attempts to address communication obstacles, as the following case shows:

A young woman from Kosovo speaking only Albanian in her last week of pregnancy came to maternity hospital. She was accompanied by her husband and their five-year-old daughter. Due to the lack of amniotic liquid I suggested to induce labor the following day and described the method, but I noticed that her husband did not understand me well. Finally, I explained it with the following words: 'Baby has no water, so he can no longer swim, this is why he has to come out soon. I suggest your wife gives birth tomorrow. Please, translate it to her. He translated it to his wife with few words, and she started telling him something with a worried expression on her face. When I finally asked him to translate, he did it in a single sentence telling me that she was only surprised a little bit. He probably noticed my surprise and quickly added: 'You know, you Slovenes sometimes have hundred words, while we have just one.' [Focus group in the maternity hospital, 6. 6. 2018] 
The described situation shows how the patient's husband was inadequately interpreting due to his limited language skills and his unfamiliarity with medical terminology and maybe also due to some other reasons unknown to the healthcare worker. In order to respond to language barriers, friends, relatives or other acquaintances often step in the role of nonprofessional (ad-hoc) interpreters. As previous research has shown (Schapira et al., 2008; Bofulin et al., 2016), ad-hoc interpreters are more available, familiar and less expensive than professional interpreters, but at the same time they provide less reliable interpretation (they can interpret inaccurately, omitting and adding information), do not respect confidentiality of data and may contribute to many errors and miscommunication in medical settings. One of the wide-spread practices, also in Slovenia, is to assign to a child who accompanies his parents to medical examination the role of ad-hoc interpreter, as the following experience demonstrates:

When you treat patients speaking only Arabic, Albanian, Chinese ... It may happen that a mother comes with her daughter who speaks fluently Slovene: what to do? You ask the daughter to translate. My colleagues do it, I do it, nobody says it is wrong. But once there was a problematic situation: should a decision to abort be translated by a child to her mother? When I was going home I asked myself: what if my child was translating for me? I felt bad and after that I tried to find other solutions when I needed translation. [Focus group in the healthcare center, 5. 8. 2017]

As gynecologist's experience illustrates, the common practice to engage children in interpretation was not seen problematic by her co-workers. However, she began to question this practice and decided to abandon it. Unlike in Slovenia, in some other countries it is explicitly prohibited the use of children for these purposes (e.g. in the US state of California), since children in the role of interpreters could be exposed to stressful and traumatic experiences while interpreting about sensitive and delicate matters (for example, family violence, psychiatric illnesses, sexually transmitted diseases, abortion, terminal illnesses) (Kocijančič Pokorn, in press).

Besides using ad-hoc interpreters, there are other strategies adopted by medical personnel in Slovenia to facilitate the communication with foreignspeaking patients. The results of the already mentioned nation-wide survey has shown that the most commonly used strategy in the Slovene healthcare system is the use of lingua franca - a language of communication that is 
not a native language of either of communication participants (House, 2003). The survey has shown that Slovene healthcare workers usually use English (global lingua franca) and Croatian/Serbian/Bosnian/Montenegrin (regional lingua franca). This strategy is followed by the use of ad-hoc interpreters and by communication with mimics and gestures. To a lesser degree, Slovene health professionals ask for help their colleagues who know the language of the healthcare user. Quite often they also practice intercomprehension, i.e. practice when each speaker speaks their first language and assumes that their meanings will be understood by the other interlocutor (cf. House 2015, p. 101). It is also common to use online dictionaries and translators (such as, for example, Google Translate). However, all described strategies should be seen as temporary and provisional solutions, since they cannot guarantee accurate communication and cannot replace professional interpreter or intercultural mediator (Kocijančič Pokorn, in press).

\section{Lack of Training on Language Aspects of Healthcare}

Considering the fact that communication with patients who do not speak foreign languages was for decades systematically neglected in Slovenia, it is not surprising that health professionals are not well acquainted with linguistic aspects of healthcare provision. As our interlocutors emphasized, during their studies (at medical faculties and faculties of health sciences) as well as during their professional careers, there was no specific training that would prepare healthcare personnel for a work in a culturally and ethnically diverse healthcare setting. ${ }^{7}$

Interlocutor 1: All you have said [about cultural and linguistic aspects of healthcare, AN] is fine, but I don't know where to look for an interpreter.

\footnotetext{
${ }^{7}$ In last years some project-based initiatives are attempting to bridge this gap, e.g. by organizing a 2o-hours cultural competency training in three community health centres (in the city of Celje, Sevnica and Vrhnika) by National institute for public health in the framework of the project 'Together for health' (http://www.nijz.si/sl/publikacije/ucni-nacrt-usposabljanje -za-razvijanje-kulturnih-kompetenc-zdravstvenih-delavcev) as well as 11 similar trainings in the framework of the project 'MoST' (http://www.nijz.si/sl/most-model-skupnostnega-pristopa-za -krepitev-zdravja-in-zmanjsevanje-neenakosti-v-zdravju-v-lokalnih). Moreover, a specific training for healthcare workers on communication with foreign-speaking patients was organized in different Slovene cities as a part of the project 'Designing a Multilingual Aid for Better Communication of Migrants with Healthcare Personnel' (http://multilingualhealth.ff.uni-lj.si/). Just recently a summer school with the title 'Cultural Competences, Doctor-Patient Communication, and Minority Health' has been organized for students from different European medical faculties (http://www.mf.uni-lj.si/media-library/2018/02/22d71f322ddoebb69df169918dfc14C7_1.pdf).
} 
Interlocutor 2: Yes, I would also like to have an interpreter, especially for Albanian women, but how to get one? Nobody told us anything about this.

Interlocutor 1: No, nobody ... we didn't get any information that this is so important.

Researcher: What about during your studies?

Interlocutor 1: No, I don't remember that we have ever mentioned this [focus group in the healthcare center, 5. 8. 2017]

An Albanian-speaking woman came to the maternity hospital with her husband to induce labor. I suggested that I invite a female interpreter to attend the labor and she agreed to it. Therefore, I informed a senior doctor that her husband does not understand Slovene well and is not planning to assist the childbirth if not necessary, since, according to him, childbirth is a female thing, besides he has to work in another city. I suggested to medical personnel that we call a professional interpreter to come to help us in communication. Surprisingly, I was answered that her husband knows Slovene well enough to interpret and that we will call him when we need him. However, only few weeks ago we received information at the hospital that we could call an Albanian female interpreter for free, so I contacted her. She was willing to come to the hospital whenever we wanted, so I went to tell this to a midwife, print this interpreter's contacts and stuck it on the walls in different rooms for medical staff. Just before I left delivery room, I heard the midwife asking the patients' husband how they say 'push' in Albanian; when he answered, she repeated after him and wrote it down. Few hours later I come back to the delivery room, hearing baby crying and two women chatting in a foreign language. Well, midwife decided to call the interpreter and reported that woman in labor got so relaxed that the baby went out quicker than expected. The midwife, however, just in case tried to learn a word in Albanian to help the woman in labor. Besides, she wanted not only to understand the woman but also to be understood well, this is why she called the interpreter [Focus group in the maternity hospital, 6. 6. 2018]

The last case shows that besides insensitivity to different understandings of gender roles (husband did not want to participate at labor since he perceives the childbirth to be a 'female thing'), there exists a lack of knowledge about the importance of quality interpretation. Although the interpreter was 
available and free of charge for the patient, medical personnel was unwilling to contact her. Contrary to that, the midwife understood the significance of engaging the interpreter and even showed respect towards patient's native language by learning some basic words. Similar attitude is present among many other healthcare workers that show an increased interest in collaborating with interpreters/intercultural mediators as the already mentioned national survey demonstrates. For example, the most frequent answer $(n=$ 271 out of 564) to the question 'What would help you bridging linguistic and other barriers when dealing with users who do not speak Slovene?' was: 'the introduction of interpreters/intercultural mediators' ${ }^{8}$ (Lipovec Čebron, in press). ${ }^{9}$

\section{Lack of Information on Healthcare Rights}

Lack of information on patient rights, organization of healthcare system and use of health service can be seen as general problem among migrants/refugees with different legal statuses in Slovenia (Bofulin \& Bešter, 2010 p. 272). The problem that migrant population is not adequately informed was raised also in the Country report for Slovenia: 'Lack of information about entitlements is a serious barrier to exercising them: people who do not know their rights cannot claim them. [...] This situation is made worse when legislation is complex and changes rapidly. There is no systematic dissemination of information concerning entitlements and use of health service for the migrant population. [...] However, since the information is difficult to find, access to it depends on personal initiative and motivation.' (MIPEX, 2015 p. 17). Similar conclusions are found in a quantitative research on health of mi-

\footnotetext{
${ }^{8}$ The others suggested information support in the form of mobile applications and online translation tools and the multilingual handbook for basic medical treatment as well as the training in the field of cultural competences.

${ }^{9}$ Not only should healthcare workers be aware of the importance of interpreters/intercultural mediators in healthcare setting, they should also be trained to successfully collaborate with them: 'Simple recommendations for working effectively with interpreters include the need to warn the interpreter prior to the meeting if sensitive information will be discussed and a proper introduction of the interpreter to the patient that promotes collegiality and delineates roles and expectations. All parties should be positioned so that the clinician and patient can maintain proper eye contact throughout the interview, and, finally, both the physician and interpreter should use short phrases devoid of jargon. Asking the patient to repeat what he or she has understood, and having the interpreter "back translate" the content, provides an additional tool to check the accuracy of translation as well as the patient's understanding (B. Lubrano, R. Brown, C. Bylund, et al., personal communication)' (Schapira et al., 2008). For more information see Kocijančič Pokorn and Lipovec Čebron (in press) and International Medical Interpreters Association (2017).
} 
grant/refugee women with various legal statuses in Slovenia (Kulovec, 2012), which demonstrates that almost one fifth of the surveyed migrants/refugees (18.5\% out of 63 ) did not receive any information about their health rights (Kulovec, 2012 p. 31). The accurate information on health system is even more difficult to reach in cases when women live in isolation (e.g. in Detention centre in Postojna) or are marginalized from general society (Asylum seeker centers in Vič or Logatec).

Also interviews conducted in the focus group in the Asylum seeker center have shown that asylum seekers who participated in the focus group were unfamiliar with their reproductive rights:

They were highly motivated to talk about their experiences with giving birth and had many questions on reproductive rights and how to solve different gynecological and other medical problems [...] All women had little or no information on contraception, they did not know how to get it, what forms of contraception are available in Slovenia and what kind of contraception is available free of charge. Most of them were not informed that they can get free condoms from a social worker who works in the asylum center, in the same department as they were located [Notes from focus group in the Asylum seeker center, 18. 10. 2017]

The fact that refugees/migrants do not receive adequate healthcare information could be the result of different factors (social isolation, dissimilarity of healthcare systems in different countries, different legal and social statuses, education etc.) (Bofulin \& Bešter, 2010; Lipovec Čebron \& Bombač, in press). However, one of the most important factors is the linguistic barrier which numerous migrants/refugees who do not speak the Slovene language experience when searching for information on Slovene healthcare system. In this regard one of the recurrent assumptions shared by healthcare workers in Slovenia is that migrant/refugees do not make enough effort to understand and speak Slovene (Lipovec Čebron, in press). Contrary to these assumptions, a qualitative and quantitative research among asylum seekers in Ljubljana shows that this group of migrants has a very positive attitude towards the Slovene language and that all of the interviewed individuals who had been in Slovenia for 7 months or more, regardless of their level of educational, make an effort to learn Slovene by taking the statefunded course of Slovene. Nevertheless, the same research demonstrated that despite the fact that most asylum seekers learn Slovene very quickly or speak English, they need additional linguistic support in high-risk situations, 
for example when communicating with healthcare workers (Pokorn \& Čibej, 2018).

In the attempt to provide migrants/refugees in Slovenia with at least some basic information on healthcare in Slovenia, some project-based initiatives were carried out, and some ad-hoc brochures ${ }^{10}$ were translated in different languages (e.g. Albanian, Arabic, English, Pashtu, Persian, Russian, Tigrinya, Turkish, etc.) and mainly disseminated over websites. However, since this information is scattered across various webpages, those who are not fluent in Slovene might find it difficult to find. ${ }^{11}$

\section{Conclusions}

Looking at the Slovene healthcare system from a language perspective reveals that it is governed by a pronounced monolingual attitude. This is not evident only from the absence of interpreters/intercultural mediators, but also from different aspects of healthcare services: wayfinding signage system in healthcare institutions, various forms (e.g. informed consent, diagnoses or referrals to specialist examinations) and information on patient's healthcare rights can be rarely found in any other languages besides Slovene. In contrast, patients who enter Slovene healthcare institutions are increasingly diverse, speak a multitude of languages that are unfamiliar to healthcare workers. In this almost 'monolingual healthcare system' where linguistic problems are not addressed at the systemic level, patients and healthcare workers are left to fend for themselves. As a result, many obstacles related to the language barriers arise between them.

On the basis of our research we identified three levels of obstacles that are connected with language barriers in the field of gynecology and obstetrics. Firstly, we analyzed some linguistic obstacles that are the consequence of the lack of available professional interpreters/intercultural mediators. Secondly, we showed that absence of medical personnel training on linguistic aspects of healthcare service provision leads to the fact that they are unaware of the importance of the support provided by qualified interpreter/intercultural mediators. Lastly, we demonstrated that language barriers faced by migrant/refugee women hinder them to exercise their basic patient rights, including reproductive rights. These obstacles significantly impair the ability of Slovene healthcare system to establish quality communication with migrant/refugee women and thus provide quality healthcare service, and

\footnotetext{
${ }^{10}$ See http://www.infotujci.si and http://www.nijz.si/sl/projekt-care.

${ }^{11}$ Moreover, the information is often unattainable for those who are illiterate.
} 
may cause inequalities among different healthcare users in their access to healthcare. On the basis of our research, we can conclude that due to the absence of systemic approach to address language issues, healthcare workers in Slovene healthcare system encounter many obstacles which often hinder them to provide high quality healthcare, while migrant/refugee women experience several difficulties when searching for it. Their traumatic experience in healthcare settings is probably best described by Ramin: 'Knowledge of language literally means the difference between paradise or hell.' (Petrovčič, 2018, p. 33).

\section{References}

Angelelli, C. (2008). The role of the interpreter in the healthcare setting: A plea for a dialogue between research and practice. In C. Valero-Garcés \& A. Martin (Ed), Crossing borders in community interpreting: Definitions and dilemmas (pp. 147-164). Amsterdam, The Netherlands: Benjamins.

Bofulin, M., \& Bešter, R. (2010). Enako zdravstvo za vse? Imigranti v slovenskem zdravstvenem sistemu. In M. Medvešek \& R. Bešter (Eds.), Državljani tretjih držav ali tretjerazredni državljani? (pp. 270-311). Ljubljana, Slovenia: Inštitut za narodnostna vprašanja.

Bofulin, M., Farkaš Lainščak, J., Gosenca, K., Jelenc, A., Keršič Svetel, M., Lipovec Čebron, U., Pistotnik, S., Škraban, Š., \& Zaviršek, D. (2016). Kulturne kompetence in zdravstvena oskrba: priročnik za razvijanje kulturnih kompetenc zdravstvenih delavcev. Ljubljana, Slovenia: Nacionalni inštitut za javno zdravje.

Bombač, L., Lipovec Čebron, U., Pistotnik, S., Turk Šverko, A., Trojar, A., Repar Bornšek, S., Sodja, N., Hadžiahmetović, A., Liberšar, H., \& Zelko, E. (2017). Zdravstvena obravnava prosilcev in prosilk za mednarodno zaščita v Sloveniji. In E. Zelko (Ed.), 10. Zadravčevi dnevi: zbornik predavanj (pp. 28-.36). Ljubljana, Slovenia: Zavod za razvoj družinske medicine.

Bowen, S. (2001). Language barriers in access to health care. Ottawa, Canada: Health Canada.

Brovč, M., Ahčin, J. Šlajpah, M., \& Rotar-Pavlič, D. (2009). Ekonomski imigranti v Sloveniji in njihova stališča o boleznih: kvalitativna raziskava. Zdravstveno varstvo, 48(1), 26-32.

Chiarenza, A. (Ed). (2014). Standards for equity in health care for migrants and other vulnerable groups: Self-assessment tool for pilot implementation. Reggio Emilia, Italy: Regional HPH Network of Emilia-Romagna.

Farkaš-Lainščak, J. (Ed.). (2016). Ocena potreb uporabnikov in izvajalcev preventivnih programov za odrasle: ključni izsledki kvalitativnih raziskav in stališča strokovnih delovnih skupin. Ljubljana, Slovenia: Nacionalni inštitut za javno zdravje.

Gorjanc, V. (2013). Tolmačenje za skupnost in vprašanje nadnacionalne odgov- 
ornosti. In V. Gorjanc (Ed.), Slovensko tolmačenje (pp. 120-133). Ljubljana, Slovenia: Znastvena založba Filozofske fakultete Univerze v Ljubljani.

Gosenca, K. (2017). Medkulturna mediacija: Priložnost za boljšo zdravstveno oskrbo. (Unpublished master's thesis). University of Ljubljana, Ljubljana, Slovenia.

House, J. (2003). English as a lingua franca: A threat to multilingualism? Journal of Sociolinguistics, $7(4), 556-578$.

House, J. (2015). Translation quality assessment: Past and present. London, England: Routledge.

Ingleby, D., Chiarenza, A., Deville, W., \& Kotsioni, I. (Ed.). (2012). Inequalities in health care for migrants and ethnic minorities (COST Series on Health and Diversity 2). Antwerp, The Netherlands: Garant Publishers.

International Medical Interpreters Association. (2017). Medical interpreting standards of practice. Retrieved from http://www.imiaweb.org/uploads/pages/ 102.pdf

Jazbinšek, S., \& Palaić, T. (2009). Zdravje - človekova pravica? Prosilke in prosilci za mednarodno zaščito. Časopis za kritiko znanosti, 37(238), 154-162.

Kocijančič Pokorn, N. (in press). Reševanje jezikovnih ovir v slovenskem zdravstvu: analiza stanja. In N. Kocijančič Pokorn \& U. Lipovec Čebron (Eds.), Večjezično zdravje: komunikacijske strategije in večkulturni stiki s tujezičnimi bolniki v slovenskem zdravstvenem sistemu. Ljubljana, Slovenia: Filozofska fakulteta.

Kocijančič Pokorn, N., \& Lipovec Čebron, U. (Eds.). (in press). Večjezično zdravje: komunikacijske strategije in večkulturni stiki s tujezičnimi bolnikiv slovenskem zdravstvenem sistemu. Ljubljana, Slovenia: Filozofska fakulteta.

Kulovec, J. (2012). Zdravje imigrantk v Sloveniji (Unpublished undergraduate thesis). University of Ljubljana, Ljubljana, Slovenia.

Lipovec Čebron, U. (2010a). The construction of a health uninsurant. People without medical citizenship as seen by some Slovene health workers. Studia ethnologica Croatica, 22, 187-212.

Lipovec Čebron, U. (2010b). Slepa pega evropskega zdravstva: analiza nekaterih vidikov zdravja migrantov. In K. Medica, G. Lukič, \& M. Bufon (Eds.), Migranti v Sloveniji: med integracijo in alienacijo (pp. 57-81). Koper, Slovenia: Annales.

Lipovec Čebron, U. (2011). Reformiranje zdravstvenega sistema Slovenije: med 'Iustracijskimi' in 'jugonostalgičnimi' težnjami. Etnolog, 21, 179-201.

Lipovec Čebron, U. (in press). Medkulturni (in drugi) nesporazumi v zdravstvu. In N. Kocijančič Pokorn \& U. Lipovec Čebron (Eds.), Večjezično zdravje: komunikacijske strategije in večkulturni stiki s tujezičnimi bolniki v slovenskem zdravstvenem sistemu. Ljubljana, Slovenia: Filozofska fakulteta.

Lipovec Čebron, U., Keršič-Svetel, M., \& Pistotnik, S. (2016). Zdravstveno marginalizirane - 'ranljive' skupine: ovire v dostopu do sistema zdravstvenega 
varstva in v njem. In J. Farkaš-Lainščak (Eds.), Ocena potreb uporabnikov in izvajalcev preventivnih programov za odrasle: ključni izsledki kvalitativnih raziskav in stališča strokovnih delovnih skupin (pp. 14-25). Ljubljana, Slovenia: Nacionalni inštitut za javno zdravje.

Lipovec Čebron, U., \& Bombač, L. (in press). Pregnant women on the move and the response of Slovenian health system to their needs. Glasnik Etnografskog instituta SANU.

Lipovec, U., \& Pistotnik, S. (2015). Iluzija o univerzalnem dostopu do zdravstvenega zavarovanja: nedržavljani, prekarni, revni kot zdravstveno nezavarovani prebivalci. Etnolog, 25, 89-111.

Lipovec Čebron, U., \& Pistotnik, S. (in press). Migrants/refugees in Slovene healthcare: Many open questions and some possible answers. In M. Rajković Iveta, P. Kelemen, \& D. Župarić-Iljić (Eds.), Contemporary migration trends and flows on the territory of Southeast Europe. Zagreb, Croatia: Filozofski fakultet u Zagrebu.

Lipovec Čebron, U., \& Pistotnik, S. (2018). (Im)mobile populations and health rights: Accessing the healthcare system in slovenia. In C. Vindriola-Padros, G., A. Johnson, \& A. E. Pfister (Eds.), Health and care (im)mobilities (pp. 53-73). New York, NY: Berghahn.

Mikolič Južnič, T. (2018). Kdo dela z uporabniki zdravstvenega sistema, ki ne govorijo slovensko? In N. Kocijančič Pokorn \& U. Lipovec Čebron (Eds.), Večjezično zdravje: komunikacijske strategije in večkulturni stiki s tujezičnimi bolniki v slovenskem zdravstvenem sistemu. Ljubljana, Slovenia: Filozofska fakulteta.

Milavec Kapun, M. Rotar-Pavlič, D., Lipovec Čebron, U. Kocijančič Pokorn, N., Pistotnik, P., Milavec Kapun, M., Hirci, N., Jelenc, A., \& Zelko, E. 2017. Strategije premagovanja jezikovnih ovir med medicinskimi sestrami. In S. Majcen Dvrošak, T. Štemberger Kolnik, \& A. Kvasa-Predoslje (Eds.), Medicinske sestre in babice - ključne za zdravstveni sistem: zbornik prispevkov z recenzijo; 11. Kongres zdravstvene in babiške nege Slovenije (pp. 564-573). Ljubljana, Slovenia: Zbornica zdravstvene in babiške nege Slovenije.

MIPEX. 2015. MIPEX-Country Report for EQUI-HEALTH. Brussels, Belgium: International Organisation for Migration.

Pokorn, N. K., \& Čibej, J. (2018). Interpreting and linguistic inclusion - friends or foes? Results from a field study. The Translator, 24(2), 111-127.

Rotar-Pavlič, D., Lipovec Čebron, U., Kocijančič Pokorn, N., Pistotnik, P., Milavec Kapun, M., Hirci, N., Jelenc, A., \& Zelko, E. (2017). Jezikovne ovire in kako jih presegati. Družinska medicina, 15(2), 12-15.

Petrovčič, P. (2018, 17 August). Ramin Shadani, begunec. Mladina, pp. 33-37.

Schapira, L., Vargas, E., Hidalgo, R., Brier, M., Sanchez, L., \& Hobrecker, L. (2008). Lost in translation: Integrating medical interpreters into the multidisciplinary team. The Oncologist, 13, 586-592. 
Verrept, H. (2008). Intercultural mediation: An answer to health care disparities? In C. Valero-Garcés, \& A. Martin (Eds.), Crossing borders in community interpreting: Definitions and dilemmas (pp. 187-201). Amsterdam, The Netherlands: Benjamins.

Yuval-Davis, N. (2006). Intersectionality and feminist politics. European Journal of Women's Studies, 13, 193-209.

S. Ličen, I. Karnjuš, \& M. Prosen (Eds.). (2019). Women, migrations and health: Ensuring transcultural healthcare (pp. 139-153).

Koper, Slovenia: University of Primorska Press.

https://doi.org/10.26493/978-961-7055-43-6.139-153 



\title{
When Language and Culture Interfere: Sexual and Reproductive Health of Migrant Women in the Coastal Region of Slovenia
}

\author{
Zorana Medarić \\ Science and Research Centre Koper and University of Primorska, Slovenia \\ zorana.medaric@zrs-kp.si
}

Mateja Sedmak

Science and Research Centre Koper, Slovenia

mateja.sedmak@zrs-kp.si

\begin{abstract}
The aim of this chapter is to present and discuss the field of reproductive health of migrant women, with emphasis on the perspectives of migrant women and healthcare professional (doctors, midwives, community nurses, etc.) on existing practices, intercultural differences, access to reproductive healthcare services, etc. Within the chapter we discuss the results of the qualitative study and in-depth interviews that were implemented in the coastal region of Slovenia. The chapter presents different issues that emerged from the study, focusing on: (1) language barriers, (2) intercultural competencies of healthcare professionals, (3) (hidden) discriminatory practices/attitudes of medical personnel, (4) information and access of migrant women to health services and (5) the importance of social ties for the reproductive health of migrant women. Finally, the article proposes some guidelines for further action in this area.
\end{abstract}

\section{Introduction}

In this chapter we address the complex topic of the reproductive and sexual health of migrant women, with special emphasis on the personal experiences and perceptions of migrant women and healthcare professionals. This is an area that has rarely been researched in Slovenia. In the existing studies on migrants and the health system, the issue of migrant women has been addressed only indirectly; they are exposed as a vulnerable group which should be given special attention in this context. While none of the studies addressed the narrow area of the reproductive health of migrant women, there has been some research in the topic of general access to medical care for migrants. The results of these studies (Jazbinšek \& Palaić, 2009; Bofulin \& Bešter 2010; Rajgelj, 2012; Lipovec-Čebron, 2009, 2010, 2017) indicate that migrants within the health system in Slovenia are faced with various problems, 
among which the key issues are (1) language barriers, (2) lack of intercultural competencies of health professionals and (3) discriminatory attitudes and practices of health personnel towards migrants. These are also three of the main topics we consider in this chapter. In addition, we focus on the following two issues: (4) information and healthcare services access, and, finally, (5) the social ties of migrants and their relevance for the reproductive health of migrant women. Similarly, current research abroad focusing on the sexual and reproductive care of migrant women highlights linguistic challenges and the importance of providing relevant information (e.g. Zelalem, Janette, Tinashe, \& Ussher, 2018; Villadsen, Mortensen, \& Nybo Andersen, 2017; Small et al., 2014) and adequate access to healthcare services (Keygnaert et al., 2013). Villadsen et al. (2017), who researched this issue in Denmark, suggest that the key challenges in ensuring quality healthcare in the area of reproductive health are the inadequate use of interpreters and difficulties in intercultural communication. Small et al. (2014), who compared the experiences of maternity care of migrant women and non-migrant women, found that migrant women have less positive experiences, primarily due to problems related to communication, their perception of discrimination as well as disrespectful, unkind care, and lack of information about how the health system works. As presented below, similar obstacles and challenges are observed in our research.

Slovenian Constitution guarantees the right to healthcare for everyone and the freedom of choice in childbearing. In Slovenian legislation, reproductive health is regulated by the Health Measures in Exercising Freedom of Choice in Childbearing Act ${ }^{1}$ and the Rules on Carrying out Preventive Health Care at the Primary Level. ${ }^{2}$ The Act stipulates the conditions for exercising the right to prevent conception, artificial interruption of pregnancy and the diagnosis and treatment of reduced fertility, while the Rules specify the reproductive health rights and the content of preventive programs. Despite the fact that migrant women are recognized as one of the most vulnerable social groups in the context of reproductive health, they are not explicitly mentioned either in the law or in the regulations.

What follows is the presentation of the results of the qualitative research carried out as a case study in the border region of the three coastal munici-

\footnotetext{
${ }^{1}$ Zakon o zdravstvenih ukrepih pri uresničevanju pravice do svobodnega odločanja o rojstvu otrok, see http://pisrs.si/Pis.web/pregledPredpisa?id=ZAKO408.

${ }^{2}$ Pravilnik za izvajanje preventivnega zdravstvenega varstva na primarni ravni, see http://www .pisrs.si/Pis.web/pregledPredpisa?id=NAVO59.
} 
palities (the Municipality of Koper, the Municipality of Izola and the Municipality of Piran) (Sedmak et al., 2018a, 2018b, 2018c). The survey was carried out as a part of INTERREG cross-border project INTEGRA: Cross-border Network for Immigrant Women: Social Integration, Sexual and Reproductive Health, which takes place in Slovenia and Italy. We will present the five topics mentioned above, each of them affecting the reproductive and sexual health of migrant women in Slovenia, namely language and communication issues, intercultural competencies of health professionals, discriminatory behaviour and practices of health professionals, information and healthcare services access, and the importance of social ties for the reproductive health of migrant women.

\section{Methodology}

The implementation of semi-structured interviews within the case study of the coastal area took place between May and August 2018. Three health centres were included in the study, namely Health Center Koper, Health Center Izola and Health Center Piran, as well as Izola General Hospital. Ethical approval of the research was obtained by each institution. The survey was carried out among the health centre staff of the community nursing service and gynaecology clinics, and at Izola General Hospital at the Department of Obstetrics and Gynaecology. In this context, 18 semi-structured interviews with health professionals in the field of sexual and reproductive health were conducted, namely three in-depth interviews with gynaecologists (health centres and hospital), four interviews with midwives in the maternity ward, two interviews with nurses in the maternity ward and three group interviews with nine community nurses (HC Koper, $\mathrm{HC}$ Izola and HC Piran). A telephone conversation with a pro bono clinic in Ljubljana was also conducted and information on the pro-bono clinics in Koper was obtained from the management of $\mathrm{HC}$ Koper. All interviews with medical staff were carried out with prior personal consent and with the permission of the health institution concerned; they were carried out at workplaces and lasted between one hour and one and a half hours. Interviews were recorded and transcribed. In the period mentioned, eight in-depth interviews with migrant women from India, the Philippines, Ukraine, Russia, Thailand, Indonesia, Azerbaijan and Bosnia who live in the area of the three coastal municipalities were also conducted. $^{3}$ For a better understanding, it should be highlighted that the area

\footnotetext{
${ }^{3}$ In order to protect their anonymity, the statements given by the interviewees (in the chapter Findings) do not contain information about their characteristics, such as ethnicity, age etc. The
} 
of the case study is markedly multicultural. In addition to the presence of an autochthonous Italian minority, immigrant communities from the former Yugoslavia (Bosniacs, Albanians, Serbs, Croats, Macedonians, Montenegrins) are mostly present in the study area. They are very visible in everyday life and organized in the form of various cultural societies or religious communities. In addition, Russian, Chinese and Thai ${ }^{4}$ communities are also noticeable, while members of other ethnic groups are present, but, as an ethnic community in the local environment, largely unrecognized. The interpretation of the obtained results is interesting in light of the fact that, according to previous research, the area of Slovenian Istria is relatively more interculturally tolerant, meaning that in comparison with other Slovenian regions, members of other cultures, religions and languages are more accepted and there is less widespread xenophobia and nationalism (Sedmak, 2003, 2005). Finally, the proportion of ethnically mixed families is the highest in Slovenia (September 2006).

Although the results presented below refer to 'migrant women' as a particularly vulnerable group, which, as mentioned above, needs special care and treatment in the field of sexual and reproductive health, we must be particularly careful to avoid the following perceptions of migrant women (omnipresent in the medical field, in science and among the general public):

1. Migrant woman as a homogeneous group. Migrant women are a highly internally differentiated social group, according to cultural, religious and linguistic characteristics, as well as other indicators that have a key influence on the quality of their lives in terms of their ability to integrate into new social environments, access to health and other services, support networks, etc. There exist differences in terms of education, socioeconomic status, cultural capital and the causes of emigration, past life experiences, individual health situation, psychological characteristics and others. Although it is possible to draw certain parallels between the life stories and narratives of migrant women and draw some common conclusions, there still exist important differences among them.

2. Perception of migrant women as helpless, passive and victims of either

women interviewed differ according to the level of education, employment - some of them are employed, while some are housewives. They all have children and they are all married or live in a partnership, except one, who is divorced. Few have Slovenian citizenship, most of them have a status of foreigner with permanent residence in Slovenia.

${ }^{4}$ Particularly because of ethnically branded shops, restaurants or other activities (such as Thai massage salons). 
their husband, the wider family, ethnic community or external circumstances. Again, it is true that migrant women are an extremely vulnerable social group, often facing double discrimination (as women and as migrants), but they are also much more than that. They are active cocreators of their lives. Their activity, ingenuity, adaptability and perseverance are evident from their life stories, which speak of leaving their homeland, immigration to a new country and adaptation to a new, often completely different, cultural and social environment.

\section{Findings}

\section{Communication and Language Barriers}

(Successful) communication between the migrant woman and healthcare staff is crucial and has a significant impact on their satisfaction with medical care, understanding of their own state of health, coping with pregnancy, giving birth, postnatal care, as well as any illness, etc. It might also affect adherence to the instructions of medical staff (in our case the instructions of midwives, gynaecologists, community nurses, etc.) (Bofulin \& Bešter, 2010). In Slovenia, interpretation within the health system in the field of sexual and reproductive health is not systematically regulated, even though language barriers represent one of the central problems in ensuring quality reproductive healthcare for migrant women.

In the case of migrant women who do not speak Slovenian, it is crucial that both they and gynaecologists, midwives, nurses and other health professionals speak English, Italian or Croatian/Serbo-Croatian/Serbian.

Language was never a problem, because at least doctors speak English; when I started to speak a little Slovenian and explained, it was even easier.

If a migrant woman does not speak Slovene, a person speaking the Slovenian language often assists with interpreting. This might be her husband, a relative, a neighbour, a friend or an interpreter selected by the ethnic community (for example, the Albanian community in Koper and Izola).

When I come to the family, where they do not understand Slovenian, I always ensure that there is someone there who understands; the firsts visit especially are really important.

The husband can be present at the birth, he is translating; sometimes they bring along an interpreter. If she is alone, we need to be ingenious, 
you show them [...] For me in the delivery room this is not a big problem, because usually they have a companion, they have a part of home with them. When they are at the hospital department, they are a little more isolated. They do not have anyone near, they are alone. But I noticed that often they have a telephone and then they communicate in a way that they do not feel alone.

According to the narratives of health professionals, a particularly vulnerable group of migrant women are Albanians, who usually do not speak Slovenian, English or any other language.

They are from Kosovo, Albania, Macedonia, they do not speak Slovenian; usually the husband translates but he speaks Slovenian poorly. As a rule, they do not speak English.

Resolving communication problems is therefore left to individual health professionals and their ingenuity. They try to solve them with ad hoc interpreters (e.g. a husband, relative, neighbour, friend or an ethnic community translator), technology (cell phones), brochures, non-verbal communication.

Sometimes midwives asked a husband to tell us a couple of words, so we made a dictionary, so at the end of the delivery at least you can tell her that she should breathe, push.

Communication is sometimes such a problem that even Google translate does not help, or that book from the Ministry that they have given us, so that we are actually distressed, because we don't know whether they hear us, if they understand. And there is a greater possibility that we overlook something.

The lack of language knowledge and the inability to fully communicate has various implications. One of the main problems is that as a result some migrant women are actually excluded from prenatal and postnatal care: they do not attend maternity schools, courses, workshops, lectures, etc.

Language knowledge is the problem. And again, here we are, they cannot attend maternity school if they do not know the language [...] We have the right to visit the pregnant woman in the last trimester, but we do not get the data [about the women who are at this stage, ZM] and those who come to maternity school are already informed. [...] So, we 
could at least prepare them, give them specific information. When we come to their home, we do not have anything to 'grip on.'

Inadequate communication is problematic for both health centres and the hospital employees.

And they are in distress; not only them - we are too. Not only does a husband translate and filter information, but sometimes older children are even translating, which is absolutely inappropriate, but this is what we have. Sometimes they organize themselves, at least those who have been here for a longer time or those who stay here, they bring along a neighbour or someone, who has been here for a longer time to be an interpreter.

In addition to the distress of migrant women and health staff, the issue of possible (professional) mistakes due to communication problems has been raised. According to both migrants and health professionals, one of the ways to improve intercultural communication would be the inclusion of a cultural mediator at a systemic level, who could be shared by several community nursing services or could be contacted by a maternity hospital, a gynaecologist, etc. In their view, the cultural mediator should be a woman with specific medical knowledge and should be 'independent' - not a member of a local ethnic community.

\section{Intercultural Differences and Intercultural Competencies}

The concept of intercultural competencies highlights the importance of taking into account the linguistic, cultural and religious specifics of migrants who are being treated within the Slovenian health system. In our case study we could observe two broad approaches of health professionals: the first could be called (1) an interculturally aware approach, according to which health professionals recognize intercultural differences in the thinking and practices of migrant women as well as the functioning and significance of traditional cultural practices. These professionals do not adopt an institutional position of power in their approach to intercultural differences, and they allow traditional practices as long as these do not interfere with prevailing medical doctrine and do not directly harm the woman and/or the child.

They have this cradle [...] it looks as if one big tube was cut in half. And then they wrap newborn babies from the neck to the heels, and they stay in this cradle for four hours. And when I came to visit for the first 
time, I was shocked, but I said to myself, that's the way they do it. If the newborn is gaining weight, if the skin, the mucosa ... if it is pink, as it should be, then I have no right to interfere with their decision about how they will handle this newborn. I just told them and advised that after a few hours, when they decide to unwrap the newborn, they should put him on a bed or sofa so that he can move around a bit. [...] I think it is right if this is their system of life, a belief; we cannot oppose it, no. I do not have the right. I can advise, but not absolutely refuse or advise against something.

The second approach suggests the presence of cultural and ethnic prejudices and stereotypes, the process of exoticization, 'differentiation,' as well as nationalism and interethnic intolerance; this is (2) an interculturally unaware approach. Healthcare professionals see certain traditional practices of migrant women or their attitude towards birth control, the presence of patriarchal patterns etc. as errant.

I'm very annoyed by that rocking [rocking the cradle, MS], which is so striking. I once allowed myself to put a diaper around newborn's head, because that head was moving around as if you were ventilating his brains [...] Once he had a handkerchief on his face. They have wipes or handkerchiefs for their faces.

The narratives of migrant women show the other side of the same problem: the lack of intercultural competence or intercultural empathy of health professionals involved in work related to sexual and reproductive health, as well as within the Slovenian health system generally. For example, for a migrant from Asia the first gynaecological examination in Slovenia was very unusual, at times torturous and completely contrary to expectations:

- She missed the privacy: in the health centre clinics she had to remove her clothes and walk naked past the table to the other end of the room where the gynaecological chair stood. She would have liked to have a cape, a towel, anything that would make it possible for her to cover herself. She felt unnecessarily vulnerable, exposed, also ashamed. [Privacy and personal dignity problem]

- She did not like the approach of the gynaecologist who did not inquire about her health, medical history, contraception, childbirth, but immediately started the examination without explaining what she was doing and why. [Problem of medical staff approach] 
- She was disturbed by the absence of a nurse and the fact that she was alone with a gynaecologist. [The problem of gender relations]

Another immigrant woman from Asia describes a negative experience that relates to her delivery. She comes from an environment where the birth of a child is a 'less formal and more social event', involving more people from the community. If she gave birth in her place of origin, according to her testimony, a village woman who was trained to help with childbirth and one of her female relatives, her mother or sister, would all be present at birth. Even the birth itself would, in her opinion, be done differently. A midwife would massage her, massage her baby, and she would lead her through the birth in a different way. The birth protocol in Slovenian hospitals can therefore be a real culture shock for migrant women and a very unpleasant experience.

Giving birth, I really wanted my husband to be with me, I explained my nurse: 'Please call my husband!' But my husband was not there. I was so sad. [She started to cry, MS] The worst thing was that you were alone in the room, there were not many patients, no mothers, no doctors, no nurses, and I was: OK, who I could call? I can call my mother, my father, at home, and in my mind it was, oh no, it is too expensive [...] That was the worst.

Some women also pointed out that they wanted to have a woman gynaecologist, but most had no choice.

I wanted a female gynaecologist. There is no way I coud go to a man. At 22.

In recent years, intercultural competencies in Slovenian healthcare have been given a little more attention - for example, in the form of a pilot scheme for training health professionals in this area, the provision of cultural mediators by non-governmental organizations in individual institutions and other similar actions - but there still exists much potential for improvements in this area.

\section{Ethnic Stereotypes, Ethnic Prejudices, Nationalism, 'Racism' and Discriminatory Practices in Relation to Migrant Women}

Although medical staff are formally committed to acting in the patient's best interest, forms of discriminatory treatment can be observed in our interviews. This is sometimes more and sometimes less explicit. Health personnel are not 
immune from ethnic prejudices, stereotypes, culturalism and other forms of discriminatory behaviour. The most explicit expression of negative attitudes towards migrant women (as well as migrants in general) was expressed by one of the health professionals. He is against immigration and expressed the view that migration should be limited or prohibited completely. He also pointed out that 'with these people I don't have anything in common.'

You call me a nationalist, a chauvinist, a racist. I don't care. This is my opinion. Of course, you as a sociologist, you think differently.

Particularly in relation to Albanian women, among healthcare professionals there is a very firm and stereotyped belief that Albanian women: do not speak Slovene; are under the control of the husband and the wider family; are not emancipated, but are isolated, ignorant, poor, and do not want to integrate, etc. In short, they are seen as a homogeneous ethnic group without internal differentiation. In attitudes towards them, compassion (they are perceived as helpless victims of their own culture) and victimization (they do not want to speak Slovenian and do not want to integrate into Slovenian society) can simultaneously be observed.

These are women who are in a closed circle, who usually do not make contact, do not go to the store, do not go to meetings, do not go to kindergarten, unlike all these other immigrants that we also have. Let's say the Russians recently, who want to integrate. Maybe they have a different interest.

If you have our insurance, come with our insurance, by staying here, excuse me, but for every country that you go to, you should do the training course, the basic language. I mean three words: bleeding, pain, I can't do it anymore, breast, milk ... and goodbye - that's it. Nobody asks you for anything special. They look at you stupidly, do not know, they do not know. At 2 pm 'my husband.' Well, what is the matter with you? I am a midwife, I am not a multinational, not even on television, nor do I know how to say it [...]

A special form of difference - behaviour based on 'exoticism' - was experienced by one migrant woman. According to her, this was not offensive, more a mixture of 'affectionate treatment' and fascination over 'differentiation.' Her chosen gynaecologist addressed her with words like 'my little chocolate' and 
'my little darky.' Despite the fact that she points out that it did not bother her, it is necessary to draw attention to the problem of these forms of address.

Some migrants highlight the discriminatory behaviour of healthcare professionals towards migrant women.

When I gave birth, it was a little bit problematic for me too, the nurses, I think they were racists, some of them. You cannot avoid it, so for me it was $\mathrm{OK}$, as long as you are doing your job. As long as you are treating me as the others, it is not necessary to talk with me. I see that some of them are like that. You noticed it. And not only me, also towards other women who come from different countries.

As presented below, discriminatory behaviour is often based on visual distinctiveness:

She behaved as if she was better than me [the nurse, MS], I felt that she was watching me. [...] She only sees a person from the outside. Then I told her that I was also a secretary that [...] that like her, I, know how to use a computer, I can work. Then she was quiet.

While migrant women also presented positive experiences, we exposed practices that are problematic because they violate the right to equal treatment in the Slovenian health system (defined in the Patients' Rights Act ${ }^{5}$.) - those that are based on unequal power positions and reproduce existing social relations on the axis of domination and subordination.

\section{Healthcare Access}

Despite the declarative universality of the right to healthcare, the inclusion or exclusion of beneficiaries of health services depends on their legal status. The Slovenian system of access to health services is based on health insurance, which means that migrants have access to health services if they are included in health insurance; otherwise, they will only be entitled to free emergency treatment. In this respect, the Slovenian system mostly protects regular employees and their family members with permanent residence in Slovenia (Rajgelj, 2012). Bofulin and Bešter (2010) highlight the existence of a gap between relatively well-regulated formal access to Slovenian healthcare and actual unimpeded access to quality healthcare. They identify one of the obstacles as the lack of information about the health system and the rights de-

${ }^{5}$ Zakon o pacientovih pravicah, see http://pisrs.si/Pis.web/pregledPredpisa?id=ZAKO4281 
riving from it. In this context, loannidi-Kapolou (2007) also highlights, among other things, health risks arising from lack of information. This was confirmed also by informants in our study:

I think migrant women do not care enough about their health because they are not well informed about the rights and opportunities they have. What often gets complicated is when they need to have medical checks, but they don't have a chosen general physician or a chosen gynaecologist, so that before discharge from hospital we talk about it and provide appropriate instructions for checking. Because a certain part of the treatment is carried out at home, it must be under control, under the supervision of either a general practitioner or gynaecologist.

Migrant women highlighted also the lack of information and, consequently, difficult access to (quality) health services. They do not have comprehensive and accessible information on the health system and other aspects of life in Slovenia in their own language or in a language they can understand.

As a foreigner, you do not have information [for example, who is a good doctor/gynaecologist, ZM], you start from scratch in Slovenia. You do not know anything, you do not have information in another language or a website that you can understand. [...] We need information for the school, for a health centre.

The statement of the informant, who informally translates from Russian, points to the importance of being informed about adequate access to health services, highlights that migrant women's access to health services is closely connected to their legal status, employment or a proper form of insurance, and, last but not least, emphasizes the importance of (informal) social ties in ensuring the (reproductive) health of migrants.

I translate for the Russians in Izola [Hospital, MS]. They call me. [...] One lady called me, how much would it cost to pay for the birth, if she would be self-paying - she was not insured, she was a foreigner. Is it better to become an independent entrepreneur and be insured through it or just pay for it? At that time, I found out all the information for her, they told me everything, they were very friendly. It is better for her to have insurance, they told me, and so she did.

Access to a health system, which is particularly important for migrant 
women (Ioannidi-Kapolou, 2007; Bofulin \& Bešter, 2010), is sometimes limited in Slovenia due to long waiting lists, which were often mentioned by the interviewees. The issue of access to health services in connection with the socio-economic status of migrants is highlighted here: those with a better economic status have access to private (and faster) health services.

I cannot have an ultrasound, 45 days is supposed to be fast - this is not fast for me, I need it now. If I have a problem, I need to know now [...] If I need anything, I go to the private doctor.

In the case of access to health services, it should be mentioned that in Koper there exists a pro bono clinic that operates once a week. Among other people, it is intended for migrants without regular status and therefore without insurance. There are few similar clinics in Slovenia that provide access for migrants without organized health insurance. In Koper there is no specialized gynaecological pro bono clinic, but there is one in Ljubljana and, according to the social worker who works there, it also receives a considerable number of visits. This suggests that such clinics are important for ensuring adequate access to health services for migrants without insurance and represent a protective network for this particularly vulnerable group of migrant women.

\section{Social Network and Reproductive Health of Migrant Women}

In ensuring their (reproductive) health, migrants' social networks play an important role. These are people who are trusted by migrant women, and who at the same time facilitate their integration into the new environment (Brovč, Ahčin, Šlajpah, \& Rotar-Pavlič, 2009); here both aspects are important - social ties in the environment in which they currently live as well as those from the country of origin. When migrating to a new environment, migrants are often confronted with personal distress and social isolation. The migrant community may play an important role in the process of adaptation as well as in obtaining information, etc. in relation to healthcare and specifically reproductive health. In this context, migrant women stressed the importance of information to facilitate choosing a doctor, a gynaecologist, information on health insurance and the organization of healthcare in general, as well as information on postnatal care.

I have friends here, from Indonesia, and what I can [I tell them, ZM] [...] they ask, I tell them [...] I go here [to this doctor, ZM]. 
Sometimes they seek gynaecologists who understand their language. I have a feeling that they will not attend maternity school, I have the feeling that any information she will want she would rather ask her colleague, sister, mother, father-in-law, mother-in-law, anyone more trusted. She knows she will get information there.

As previously mentioned, existing social contacts and social networks also play an important role in communicating with healthcare professionals, as in the case of a nurse visit at home after the birth.

Even if being involved in ethnic community can be a source of support to migrant women, including with regard to the access to health services, it may in some cases also present a restriction, in particular in terms of access to sexual and reproductive care by migrant women at the institutional level. In the following example, a healthcare worker sees the community as an inhibiting factor for joining a maternity school.

They are very strong as a community and they will not attend classes for future parents.

The migrant community can play an important role in providing assistance to women - for example, directly after giving birth, when they get support from other women, relatives or members of the ethnic community who help to care for her and the child.

But they also like to help. I had, for example, one house, there were three families in it, one in each room. They had a common kitchen, at the same time there was a bunch of children - you did not know from which door one came - but when she gave birth, all these girls helped her. They took care of her children, they looked after her.

On the other hand, women who are not integrated in the community and do not have additional help in the local environment can face social isolation and distress.

It was difficult for me when I had my first son. It was only me and XXX [husband, ZM] and XXX. She came to help, she is my husband's colleague. [...] In the Philippines everyone would help you, you call, they come - neighbour, friend ... here everyone is for themselves, you have to pay someone to watch your child ... when you go to give birth, for example. 


\section{Conclusions}

Migrant women, as shown in our case study, face unequal treatment, discriminatory practices and restrictions in access to adequate institutional healthcare in the field of sexual and reproductive health. The key challenges in this area are communication with healthcare professionals and lack of information, and consequently lack of adequate access to (relevant) health services. Poor information and lack of or inadequate communication between medical staff and migrant women may lead to social exclusion, marginalization and stigmatization of migrant women, and this may also encourage unequal power relations between the women and healthcare professionals. Ineffective and/or inadequate communication can ultimately lead to professional errors or problems with treatment or medical procedures. A further important problem is the lack of intercultural competencies of health professionals and a lack of systemic solutions which would address the needs of migrant women in the field of sexual and reproductive health.

In this view, an important aspect that should be addressed in the future is action towards the sensitization of healthcare professionals with regard to intercultural issues as well as discriminatory practices and behaviour, which would facilitate the healthcare of migrant women, as well as help to prevent misunderstandings and possible professional mistakes. There exists also the need to introduce additional (systemic) education in the field of intercultural competencies, whereby special attention in the context of sexual and reproductive health should be given to attitudes of migrant women towards the body, privacy and gender relations. A step in this direction is certainly taken with the recently published Handbook for the Development of Cultural Competencies developed by the National Institute of Public Health (Bofulin et al., 2016), which aims to improve sensitivity to cultural differences and to increase understanding and acceptance of diversity in society. The final goal would be the introduction of these principles at all levels of healthcare education. Good practices indicate that it would be necessary to introduce a cultural mediator in the health system who could have significant impact on the reduction of discriminatory practices and treatment. Systemic regulation of interpretation in the health system is also necessary, as the problem of communicating is currently left to the creativity of medical staff and migrants. It should be emphasized, however, that for proper communication interpreters should also have (at least basic) healthcare knowledge (Zelalem et al., 2018).

Another important issue is that of providing proper information about institutional aspects of the sexual and reproductive health of migrant women. 
Due to lack of information and poor language knowledge, migrants are often excluded from institutionally provided prenatal and partially also postnatal care. One of the possible solutions to the integration of migrant women into prenatal care would be the organization of maternity schools also in a foreign language (e.g. English and Albanian), or the introduction of an interpreter in maternity schools. Experiences elsewhere (e.g. Villadsen et al., 2017) show that, in order to ensure the equal treatment of migrant women, it is necessary to provide professional interpreters in maternity care, to establish trust between medical staff and migrant women and to provide information that will enable them to 'properly navigate through the health system' (p. 109), which can significantly reduce delays in providing healthcare and appropriate treatment. A holistic and inclusive approach to health policies to ensure adequate healthcare for migrant women, especially in the field of sexual and reproductive health, is an important future challenge for public health throughout Europe (Keygnaert et al., 2013).

\section{References}

Bofulin, M., \& Bešter, R. (2010). Enako zdravstvo za vse? Imigranti v slovenskem zdravstvenem sistemu. In M. Medvešek \& R. Bešter (Eds.), Državljani tretjih držav ali tretjerazredni državljani? Integracija državljanov tretjih držav $v$ Sloveniji (pp. 270-311). Ljubljana, Slovenia: Inštitut za narodnostna vprašanja.

Bofulin, M., Farkaš Lainščak, J., Gosenca, K., Jelenc, A., Keršič Svetel, M., Lipovec Čebron, U., Pistotnik, S., Škraban, Š., \& Zaviršek, D. (2016). Kulturne kompetence in zdravstvena oskrba: priročnik za razvijanje kulturnih kompetenc zdravstvenih delavcev. Ljubljana, Slovenia: Nacionalni inštitut za javno zdravje.

Brovč, M., Ahčin, J. Šlajpah, M., \& Rotar-Pavlič, D. (2009). Ekonomski imigranti v Sloveniji in njihova stališča o boleznih. Zdravstveno varstvo, 48(1), 26-32.

Ioannidi-Kapolou, E. (2007). Health barriers and inequities for migrants. In Y. Apostolopoulos, \& S. Sonmez (Eds.), Population mobility and infectious disease (pp. 41-54). New York, NY: Springer.

Lipovec-Čebron, U. (2009). Od kulture nezaupanja do selektivnega sočutja: prosilci in prosilke za mednarodno zaščito v slovenskem zdravstvenem sistemu. Časopis za kritiko znanosti, 37(235/236), 190-203.

Lipovec Čebron, U. (2010). The construction of a health uninsurant. People without medical citizenship as seen by some Slovene health workers. Studia ethnologica Croatica, 22, 187-212.

Lipovec-Čebron, U. (2017). Ko nujno postane nenujno: raziskovanje zdravstvenih vidikov migracije v Slovenije. Glasnik Slovenskega etnološkega društva, $57(1 / 2), 54-64$. 
Jazbinšek, S., \& Palaić, T. (2009). Zdravje - človekova pravica? Prosilke in prosilci za mednarodno zaščito. Časopis za kritiko znanosti, 37(238), 154-162.

Keygnaert, I., \& Guieu, A. 2015. What the eye does not see: A critical interpretive synthesis of European Union policies addressing sexual violence in vulnerable migrants. Reproductive Health Matters, 23(46), 45-55.

Keygnaert, I., Guieu, A., Ooms, G., Vettenburg, N., Temmerman, M., \& Roelens, K. (2014). Sexual and reproductive health of migrants: Does the EU care? Health Policy, 114(2/3), 215-225.

Rajgelj, B. (2012). Vpliv delovnopravnega, državljanskega in družinskopravnega statusa na neenako obravnavo v zdravstvenem zavarovanju. Zdravstveno varstvo, 51(1), 43-52.

Sedmak, M. (2003). Stališča mladih slovenske Istre do (med)kulturnih fenomenov okolja bivanja. Annales, Series historia et sociologia, 13(2), 405-424.

Sedmak, M. (2005). Social inclusion/exclusion of immigrant groups in urban Slovenia: The case of Istria. Ethnologia Balkanica, 9, 241-259,

Sedmak, M., Medarić, Z., Lenarčič, B., \& Gornik, B. (2018a). Report on demographic, social and economic characteristics of migrant women in Slovenia. Koper, Slovenia: Znanstveno-raziskovalno središče Koper.

Sedmak, M., Medarić, Z., Lenarčič, B., \& Zago, M. (2018b). Principali caratteristiche demografiche delle donne straniere in Slovenia e Friuli Venezia Giulia. Koper, Slovenia: Znanstveno-raziskovalno središče Koper; Trieste, Italy: Edizioni Università di Trieste.

Sedmak, M., Medarić, Z., Lenarčič, B., \& Gornik, B. (2018c.) Spolno in reproduktivno zdravje migrantk $v$ sloveniji: študija primera treh obalnih občin. Koper, Slovenia: Znanstveno-raziskovalno središče Koper.

Small, R. C. R., Manjri, R., Touran, S., Dineke, K., Maureen, H., McCourt, C., \& Gagnon, A. (2014). Immigrant and non-immigrant women's experiences of maternity care: A systematic and comparative review of studies in five countries. BMC Pregnancy and Childbirth, 14(152), 1-17.

Villadsen, S. F., Mortensen, L. H., \& Andersen, A. (2017). Care during pregnancy and childbirth for migrant women: How do we advance? Development of intervention studies - The case of the MAMAACT intervention in Denmark. Best Practice \& Research Clinical Obstetrics \& Gynaecology, 32, 100-112.

Zelalem, B. M., Janette, P., Tinashe, D., \& Ussher, J. (2018). Talking about sexual and reproductive health through interpreters: The experiences of health care professionals consulting refugee and migrant women. Sexual \& Reproductive Healthcare, 16, 199-205.

S. Ličen, I. Karnjuš, \& M. Prosen (Eds.). (2019). Women, migrations and health: Ensuring transcultural healthcare (pp. 155-171).

Koper, Slovenia: University of Primorska Press.

https://doi.org/10.26493/978-961-7055-43-6.155-171 



\title{
Cultural Competence in Nursing and Its Impact on the Quality of Care for Patients from Culturally Diverse Groups: A Systematic Literature Review
}

\author{
Sabina Ličen \\ University of Primorska, Slovenia \\ sabina.licen@fvz.upr.si \\ Igor Karnjuš \\ University of Primorska, Slovenia \\ igor.karnjus@fvz.upr.si \\ Urška Bogataj \\ University of Primorska, Slovenia \\ urska.bogataj@fvz.upr.si \\ Doroteja Rebec \\ University of Primorska, Slovenia \\ doroteja.rebec@fvz.upr.si

\section{Mirko Prosen} \\ University of Primorska, Slovenia \\ mirko.prosen@fvz.upr.si
}

The growth of culturally diverse segments of the population in Slovenia means the need for culturally competent nurses has never been greater. Cultural competence has already been a topic of interest for several years among all healthcare provider groups. In Slovenia, however, the effect of culturally competent nursing on the quality of care for patients from culturally diverse groups has never been systematic reviewed. A review of the literature was conducted in May 2018 to identify the evidence available on the effectiveness of culturally competent nursing on the quality of care. Based on the research purpose, terms combining Medical Subject Headings (MeSH), phrases, as well as free text or keywords were searched for. The literature published between 2000 and 2018 was extracted and a sample of 533 papers was obtained. Four studies meeting the criteria were finally included in the qualitative analysis. Two studies revealed that the effectiveness of cultural training is shown in increased patient self-care behaviours, a higher level of social functioning and improved overall functional capacity. The two other studies used in our study did not describe patient outcomes as they mainly looked at improvements in cultural competency among nurses. Our review shows several important considerations for future research and supports calls for greater methodological rigour in studies of cultural competence education for health professionals. 


\section{Introduction}

Demographic changes in the Slovenian population over the decades have transformed the country into a multicultural society. The war in different parts of former Yugoslavia in 1991 triggered the first major migration flows of people from the former republics (especially Bosnia and Herzegovina, Macedonia, Serbia and Kosovo). Even today, these migration flows represent the highest number of foreign immigrants in Slovenia.' Further, estimates show that approximately 1.9 million people from non-EU countries immigrated to the European Union in 2014. These figures all show that immigrant is both growing and altering the population structure of the European Union, suggesting the need for education in transcultural nursing to ensure nurses are able to provide culturally competent care (Ličen, Karnjuš, \& Prosen, 2017). Transcultural nursing is an essential aspect of today's healthcare and represents both a speciality and a general practice area. It focuses on worldwide cultures and comparative cultural caring, health and nursing phenomena. Established as a formal area of inquiry and practice more than 40 years ago, transcultural nursing's goal is to provide culturally congruent care (Truong, Paradies, \& Priest, 2014). Nurses must acquire the necessary knowledge and skills in cultural competency since culturally competent nursing care helps ensure patient satisfaction and positive outcomes (Maier-Lorentz, 2008).

There are as many varying definitions for the term cultural competence as there are for the term culture. Culture can be defined as the learned and shared knowledge and symbols that specific groups use to interpret their experience of reality and to guide their thinking and behaviour (Prosen, 2015). Thus, cultural competence can be defined as a continual process of striving to become increasingly self-aware, to value diversity and to become knowledgeable about cultural strengths (Bonecutter \& Gleeson, 1997). Cultural competence may be defined in various ways but it is usually understood as possessing the attitudes, knowledge and skills necessary for providing quality care to a diverse population; in other words, the capacity to deliver culturally appropriate care. However, according to Leininger $(2002,1999)$, the term cultural competence was first coined by her in the 1960 s as part of her theory of cultural care diversity and universality.

Embedding cultural competence in healthcare systems enables systems to provide appropriate care to patients with a range of values, beliefs and behaviours, including meeting patients' social, cultural and linguistic needs (Horvat, Horey, Romios, \& Kis-Rigo, 2014). The cultural competence in the

\footnotetext{
${ }^{1}$ See https://emm.si/en/migration-and-slovenia.
} 
healthcare paradigm commits healthcare organisations, institutions and professionals to understand and respect cultural differences, and adjust their care accordingly. The leading concept of cultural competence in healthcare integrates three fundamental components: linguistic competence, workforce diversity, and workforce cultural competence (Baldwin, 2003; Gallagher \& Polanin, 2015). At this point, we can conclude that cultural competency is a broad concept used to describe a variety of interventions that aim to improve the accessibility and effectiveness of healthcare services for people from culturally diverse groups (Truong et al., 2014).

Today, it is well known that nurses who provide culturally competent nursing hold the potential to improve the quality of care and improve patient satisfaction, therefore leading to better health outcomes for culturally diverse groups (Gallagher \& Polanin, 2015; Waite \& Calamaro, 2010). In Slovenia, the effect of culturally competent nursing on the quality of care for patients from culturally diverse groups has never been systematically reviewed. On the other hand, some foreign studies have evaluated the effects of training interventions in cultural competence. The learning activities and length of the interventions varied, and the most common target learners were nursing and medical students (Beach et al., 2005; Peña Dolhun, Muñoz, \& Grumbach, 2003; Price et al., 2005). Further, scientific evidence suggests a significant correlation between the cultural and linguistic competencies of healthcare providers and improved patient nursing outcomes (Betancourt, Green, Carrillo, \& Ananeh-Firempong, 2003).

What emerges from the literature is training in cultural competence may be an effective way to support nurses in their clinical work and therefore an important area to study. For these reasons, this systematic review aimed to evaluate the literature on the ways effective cultural competence training for nurses improves cultural competency and determine whether professionals undergoing such training increased the quality of their care given to patients from culturally diverse groups.

\section{Methodology}

A systematic literature review was conducted to address the question: 'How effective is non-formal training for nurses on culturally competent healthcare for improving the quality of care for patients from culturally diverse groups?'

\section{Search Strategy}

A review of the literature was conducted in May 2018 to identify available evidence on how culturally competent nursing impacts the quality of care 
of patients from culturally diverse groups. A search was conducted using online bibliographic databases such as PubMed, CINAHL and ScienceDirect. For the search terms, a combination of the following Medical Subject Headings (MeSH): 'transcultural nursing,' 'culturally competent care,' 'cultural competency,' 'cultural diversity,' 'cultural competence training,' 'cultural sensitivity training' and 'education, nursing' was used. The search was performed using the following keywords in English with Boolean operators 'and' and 'or.'

\section{Study Selection}

A search was undertaken in each database and, to further the research's relevance, literature published between January 2000 and May 2018 was considered. A sample of 533 papers was obtained. The titles and abstracts were screened by the authors, duplicates were removed and the inclusion criteria (English language, full-text availability, and primary study in a peer-reviewed journal) were applied. After the removal of duplicates, 69 articles were left, of which a further 64 were then excluded due to inadequately meeting the inclusion criteria. Four studies satisfying the criteria were finally included in the qualitative analysis.

A systematic review of literature on the effect of culturally competent nursing on the quality of care for patients from culturally diverse groups was conducted according to the Preferred Reporting Items for Systematic Reviews and Meta-Analyses (PRISMA), using the PRISMA checklist and the PRISMA flowchart methodology (Moher, Liberati, Tetzlaff, Altman, \& PRISMA Group, 2009). The PRISMA flow diagram (Figure 1) summarises the article selection process.

\section{Results}

The final four studies identified in the current review were (listed in order of publication): (1) (Majumdar, Browne, Roberts, \& Carpio, 2004); (2) (McElmurry et al., 2009); (3) (Berlin, Nilsson, \& Törnkvist, 2010); and (4) (Chapman, Martin, \& Smith, 2014). These studies varied in their stated aims, settings, participants and how they were described, interventions and the outcomes measured. Data extraction included author/year, country where the research was conducted, study aim, study design, and descriptions of patients involved in the study (Table 1).

\section{Description of the Interventions}

Competence training for health professionals generally includes components such as cultural awareness, cultural knowledge and cultural skills (Sue, 
Table 1 Comparison of Study Aims, Settings and Descriptions of Patients

\begin{tabular}{|c|c|c|c|c|}
\hline Author/Year & Country & Study aim & Study design & Patient descriptions \\
\hline $\begin{array}{l}\text { Berlin et al. } \\
(2010)\end{array}$ & Sweden & $\begin{array}{l}\text { To evaluate the ex- } \\
\text { tent to which spe- } \\
\text { cific training affected } \\
\text { how nurses rated } \\
\text { their own cultural } \\
\text { competence, diffi- } \\
\text { culties, and concerns } \\
\text { and to study how } \\
\text { nurses evaluated the } \\
\text { training }\end{array}$ & $\begin{array}{l}\text { The study partici- } \\
\text { pants were an inter- } \\
\text { vention group and } \\
\text { a control group of } \\
\text { nurses working in } \\
\text { health services in } \\
\text { the Stockholm and } \\
\text { Sörmlands coun- } \\
\text { ties. The clinical part } \\
\text { of these services is } \\
\text { provided at primary } \\
\text { child healthcare cen- } \\
\text { tres. }\end{array}$ & $\begin{array}{l}\text { Of the } 39 \text { municipal- } \\
\text { ities in Stockholm } \\
\text { County, } 27 \text { had reg- } \\
\text { istered a having at } \\
\text { least } 20 \% \text { of the chil- } \\
\text { dren with immigrant } \\
\text { parents. Fifteen of } \\
\text { those municipalities } \\
\text { were randomly cho- } \\
\text { sen. }\end{array}$ \\
\hline $\begin{array}{l}\text { Chapman } \\
\text { et al. (2014) }\end{array}$ & Australia & $\begin{array}{l}\text { To determine if an } \\
\text { accredited cultural } \\
\text { awareness training } \\
\text { programme affected } \\
\text { emergency depart- } \\
\text { ment staff knowl- } \\
\text { edge, familiarity, at- } \\
\text { titude of and percep- } \\
\text { tion regarding Aus- } \\
\text { tralian Aboriginal } \\
\text { and Torres Strait Is- } \\
\text { lander people }\end{array}$ & $\begin{array}{l}\text { Group pre-test/post- } \\
\text { test intervention de- } \\
\text { sign involved mea- } \\
\text { suring staff cultural } \\
\text { awareness before } \\
\text { and after training }\end{array}$ & $\begin{array}{l}\text { Aboriginal and Tor- } \\
\text { res Strait Islander } \\
\text { people }\end{array}$ \\
\hline $\begin{array}{l}\text { Majumdar } \\
\text { et al. (2004) }\end{array}$ & Canada & $\begin{array}{l}\text { To determine the } \\
\text { effectiveness of } \\
\text { cultural sensitiv- } \\
\text { ity training on the } \\
\text { knowledge and atti- } \\
\text { tudes of healthcare } \\
\text { providers, and to as- } \\
\text { sess the satisfaction } \\
\text { and health outcomes } \\
\text { of patients from dif- } \\
\text { ferent culturally di- } \\
\text { verse groups with } \\
\text { healthcare providers } \\
\text { who received train- } \\
\text { ing }\end{array}$ & $\begin{array}{l}\text { In a randomised } \\
\text { controlled trial, } 114 \\
\text { healthcare providers } \\
\text { (nurses and home- } \\
\text { care workers) and } 133 \\
\text { patients (from two } \\
\text { community agen- } \\
\text { cies and one hospi- } \\
\text { tal) were randomly } \\
\text { assigned to experi- } \\
\text { mental (training) and } \\
\text { control groups and } \\
\text { were followed for } 18 \\
\text { months }\end{array}$ & $\begin{array}{l}\text { Most participants } \\
\text { were either Roman } \\
\text { Catholic or Protes- } \\
\text { tant. Although all } \\
\text { participants spoke } \\
\text { English, a small } \\
\text { share (below } 15 \% \text { for } \\
\text { both groups) spoke } \\
\text { French as their na- } \\
\text { tive language. }\end{array}$ \\
\hline $\begin{array}{l}\text { McElmurry } \\
\text { et al. (2009) }\end{array}$ & USA & $\begin{array}{l}\text { To improve diabetes } \\
\text { care among limited } \\
\text { English-proficient } \\
\text { Latino patients }\end{array}$ & $\begin{array}{l}\text { Health promoters } \\
\text { served a total of } \\
1,994 \text { Latino diabetes } \\
\text { patients, providing a } \\
\text { total of } 4,242 \text { patients }\end{array}$ & $\begin{array}{l}\text { Latino diabetes pa- } \\
\text { tients }\end{array}$ \\
\hline
\end{tabular}




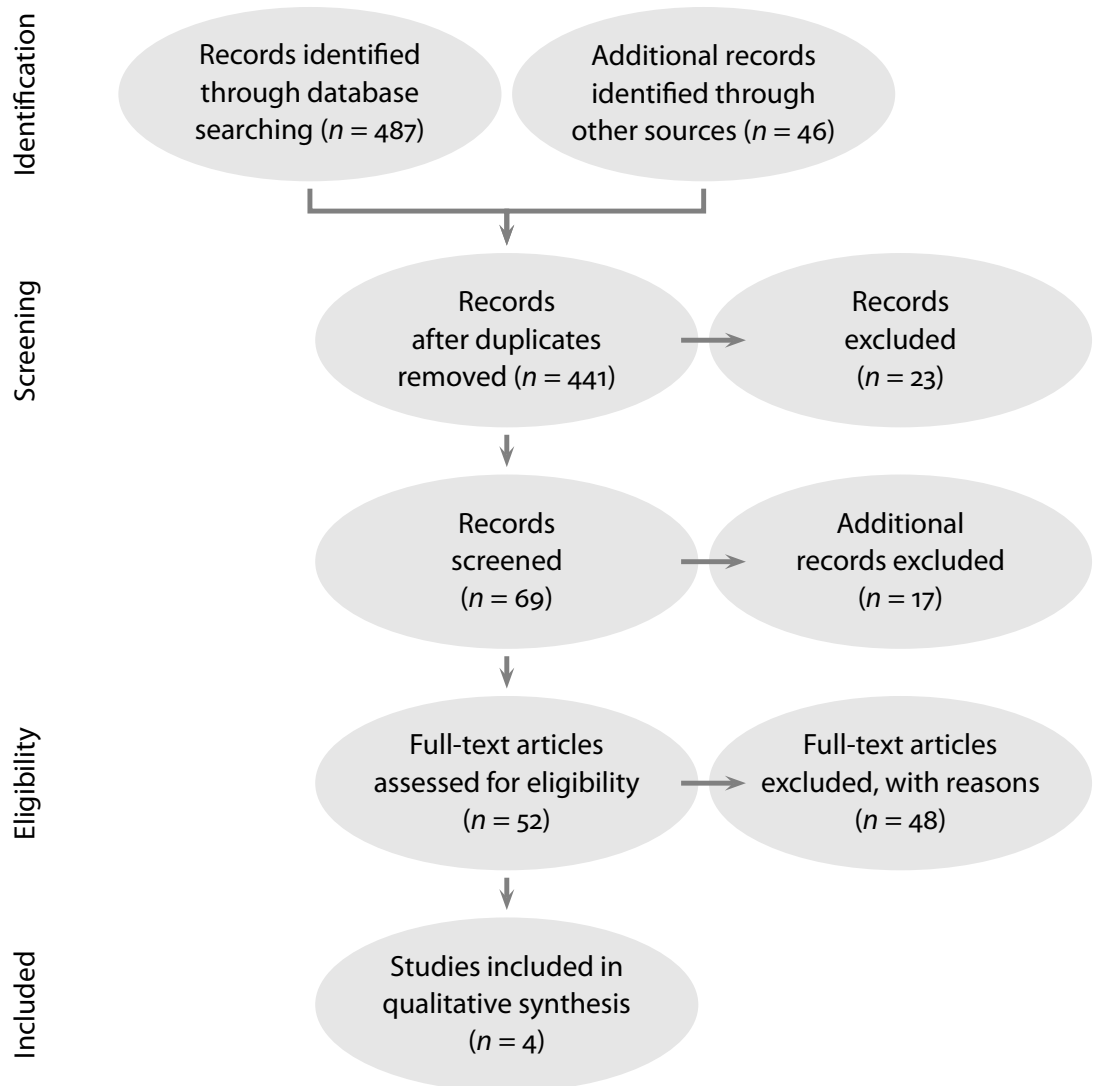

Figure 1 Presentation of the Selection Process through the PRISMA Flow Diagram

Zane, Nagayama Hall, \& Berger, 2009). Teaching and learning methods and the content of cultural competence in education interventions range from simple approaches that specify aspects of cultural self-awareness and intercultural communication skills to more complex understandings that show a deeper analysis of socio-cultural barriers to healthcare at the clinical, organisational level and structural levels (Betancourt et al., 2003). After reviewing the literature, a conceptual framework derived from a synthesis of key cultural competence models and educational intervention frameworks is suggested to ensure a consistent approach to describing and assessing the interventions. A conceptual framework (Table 2) comprises three domains that describe the core ingredients of cultural competence education/training interventions. 
Table 2 Conceptual Framework

\begin{tabular}{lll}
\hline Educational content & Pedagogical approach & Structure of the intervention \\
\hline Types of knowledge & Teaching and learning & Delivery and format \\
Skills & method & Frequency and timing \\
& Theoretical constructs and \\
principles & $\begin{array}{l}\text { Assessment and evaluation } \\
\text { of intervention }\end{array}$ \\
\hline
\end{tabular}

There was considerable heterogeneity in the stated purpose, content, duration and nature of the interventions assessed in each study. A summary of the interventions derived from the four studies identified is shown in Tables 3-6.

Table 3 Summary of the Interventions: Educational Content - Types of knowledge

\begin{tabular}{|c|c|c|c|c|}
\hline Item & $\begin{array}{l}\text { Berlin et al. } \\
(2010)\end{array}$ & $\begin{array}{l}\text { Chapman et al. } \\
(2014)\end{array}$ & $\begin{array}{l}\text { Majumdar et al. } \\
(2004)\end{array}$ & $\begin{array}{l}\text { McElmurry et al. } \\
(2009)\end{array}$ \\
\hline $\begin{array}{l}\text { Culture/cultural } \\
\text { competence }\end{array}$ & $\begin{array}{l}\text { Cultural compe- } \\
\text { tency }\end{array}$ & $\begin{array}{l}\text { Cultural aware- } \\
\text { ness }\end{array}$ & $\begin{array}{l}\text { Cultural sensitiv- } \\
\text { ity }\end{array}$ & $\begin{array}{l}\text { Cultural compe- } \\
\text { tency }\end{array}$ \\
\hline $\begin{array}{l}\text { Socio-cultural } \\
\text { context of } \\
\text { health dispari- } \\
\text { ties }\end{array}$ & $\begin{array}{l}\text { Contribution to } \\
\text { improved qual- } \\
\text { ity of health ser- } \\
\text { vices, with re- } \\
\text { duced risk of } \\
\text { healthcare dis- } \\
\text { parities among } \\
\text { children of im- } \\
\text { migrant parents }\end{array}$ & Not reported & Not reported & $\begin{array}{l}\text { Bridges to } \\
\text { Health pro- } \\
\text { gramme to im- } \\
\text { prove care and } \\
\text { reduce health } \\
\text { disparities }\end{array}$ \\
\hline $\begin{array}{l}\text { Epidemiology } \\
\text { and social deter- } \\
\text { minants }\end{array}$ & Not reported & Not reported & Not reported & $\begin{array}{l}\text { Latino diabetes } \\
\text { patients }\end{array}$ \\
\hline $\begin{array}{l}\text { Constructs of } \\
\text { racism and prej- } \\
\text { udice }\end{array}$ & $\begin{array}{l}\text { Training in- } \\
\text { cluded new } \\
\text { knowledge } \\
\text { about experi- } \\
\text { ences of being } \\
\text { different, ethno- } \\
\text { centrism and on } \\
\text { racism and prej- } \\
\text { udice }\end{array}$ & Not reported & Not reported & Not reported \\
\hline $\begin{array}{l}\text { Specific theoret- } \\
\text { ical models }\end{array}$ & $\begin{array}{l}\text { Campinha- } \\
\text { Bacote's defini- } \\
\text { tion and cultural } \\
\text { competence } \\
\text { model }\end{array}$ & Not reported & Not reported & Not reported \\
\hline
\end{tabular}


Table 4 Summary of the Interventions: Educational Content - Skills

\begin{tabular}{|c|c|c|c|c|}
\hline Item & $\begin{array}{l}\text { Berlin et al. } \\
(2010)\end{array}$ & $\begin{array}{l}\text { Chapman et al. } \\
\text { (2014) }\end{array}$ & $\begin{array}{l}\text { Majumdar et al. } \\
(2004)\end{array}$ & $\begin{array}{l}\text { McElmurry et al. } \\
(2009)\end{array}$ \\
\hline $\begin{array}{l}\text { Cultural self- } \\
\text { assessment }\end{array}$ & Unclear & Not reported & $\begin{array}{l}\text { Cultural Self- } \\
\text { Awareness } \\
\text { Questionnaire } \\
\text { and the Dog- } \\
\text { matism Scale in- } \\
\text { struments }\end{array}$ & Not reported \\
\hline $\begin{array}{l}\text { Communication, } \\
\text { collaboration } \\
\text { and non-verbal } \\
\text { communication }\end{array}$ & $\begin{array}{l}\text { Training in- } \\
\text { cluded skills in } \\
\text { different com- } \\
\text { munication } \\
\text { styles and bar- } \\
\text { riers to intercul- } \\
\text { tural communi- } \\
\text { cation }\end{array}$ & Not reported & Not reported & $\begin{array}{l}\text { Spanish im- } \\
\text { mersion pro- } \\
\text { gramme, Span- } \\
\text { ish language } \\
\text { classes, and cul- } \\
\text { tural workshops }\end{array}$ \\
\hline $\begin{array}{l}\text { Deconstructing } \\
\text { stereotypes }\end{array}$ & $\begin{array}{l}\text { Face-to-face cul- } \\
\text { tural interac- } \\
\text { tions with clients } \\
\text { from different } \\
\text { cultural back- } \\
\text { grounds, trying } \\
\text { to modify exist- } \\
\text { ing beliefs, or to } \\
\text { prevent the pos- } \\
\text { sible stereo- typ- } \\
\text { ing of these indi- } \\
\text { viduals }\end{array}$ & Unclear & Unclear & Unclear \\
\hline
\end{tabular}

\section{Patient Outcomes}

- McElmurry et al. (2009). To assess the outcomes of certain patientdirected interventions, data from patient encounter forms were analysed using frequencies, correlations, paired t tests, and logistic regression. Their analysis of the available data (for the 392 patients for whom data were available who had two health-promoter encounters at least 30 days or more apart; range $=30$ days to $>1$ year) revealed that limited English-proficient Latino diabetes patients who received healthpromoter services demonstrated improvement in blood glucose control as measured by a drop in percentage of $\mathrm{HbA1c}$. For these $392 \mathrm{pa-}$ tients, their mean drop in $\mathrm{HbA}_{1} \mathrm{c}$ from 9.65 to 8.61 was statistically significant (paired $t$-test, $t=-8.5344, p<0.001$ ). It follows that the healthpromoter intervention was associated with enhanced access to care, 
Table 5 Summary of the Interventions: Pedagogical Approach

\begin{tabular}{lllll}
\hline Item & $\begin{array}{l}\text { Berlin et al. } \\
(\text { 2010) }\end{array}$ & $\begin{array}{l}\text { Chapman et al. } \\
(2014)\end{array}$ & $\begin{array}{l}\text { Majumdar et al. } \\
(2004)\end{array}$ & $\begin{array}{l}\text { McElmurry et al. } \\
(2009)\end{array}$ \\
\hline $\begin{array}{l}\text { Teaching and } \\
\text { learning method }\end{array}$ & $\begin{array}{l}\text { A participatory } \\
\text { learning ap- } \\
\text { proach, link- } \\
\text { ing theory to } \\
\text { practice, case } \\
\text { methodology, } \\
\text { specific study } \\
\text { derived from } \\
\text { previous re- } \\
\text { search }\end{array}$ & $\begin{array}{l}\text { Cultural aware- } \\
\text { ness training }\end{array}$ & & $\begin{array}{l}\text { Spanish lan- } \\
\text { guage skills and } \\
\text { cultural compe- } \\
\text { tency training } \\
\text { for healthcare } \\
\text { providers }\end{array}$ \\
& & & \\
\hline $\begin{array}{l}\text { Key theoretical } \\
\text { construct and } \\
\text { principles }\end{array}$ & $\begin{array}{l}\text { Campinha- } \\
\text { Bacote's cultural } \\
\text { competence } \\
\text { model }\end{array}$ & Not reported & Unclear & Not reported \\
\hline
\end{tabular}

increased patient self-care behaviours, and improved blood glucose control.

- Majumdar et al. (2004) No statistically significant differences in mean scores were found between patients in the control and experimental groups in relation to 'client satisfaction,' 'mental health,' 'physical health,' and 'activities of daily living.' In addition, patients of mostly European and British origin who received care from providers trained in cultural sensitivity had a higher level of social functioning and improved overall functional capacity without a significant increase in healthcare expenditures, after 1.5 years.

The two other studies used in our study did not describe patient outcomes. They mainly described improvements in cultural competency among nurses.

- Berlin et al. (2010). The authors report the training may have had positive effects on the nurses' working conditions as they rated it to have impacted their ability to cope with the demands of their work tasks in the health services. These effects are presumed to contribute to improved quality health services, with a reduced risk of healthcare disparities among the children of immigrant parents.

- Chapman et al. (2014). This study shows that cultural awareness training, given in staggered sessions over six weeks, changed the perception of emergency healthcare workers towards Aboriginal and Torres Strait Islander people, but did not affect their attitude to them. 
Table 6 Summary of the Interventions: Structure

\begin{tabular}{|c|c|c|c|c|}
\hline Item & Berlin et al. (2010) & $\begin{array}{l}\text { Chapman et al. } \\
\text { (2014) }\end{array}$ & $\begin{array}{l}\text { Majumdar et } \\
\text { al. (2004) }\end{array}$ & $\begin{array}{l}\text { McElmurry et al. } \\
(2009)\end{array}$ \\
\hline Delivery & Face-to-face & Face-to-face & Unclear & Unclear \\
\hline Format & $\begin{array}{l}\text { Over } 4 \text { weeks of } \\
\text { clinical work and } \\
\text { in at least one } \\
\text { case, nurses were } \\
\text { instructed to con- } \\
\text { sider direct face- } \\
\text { to-face cultural } \\
\text { interactions by } \\
\text { using the study- } \\
\text { specific theoreti- } \\
\text { cal models }\end{array}$ & $\begin{array}{l}\text { Face-to-face in- } \\
\text { struction, case } \\
\text { studies, interac- } \\
\text { tive activities, } \\
\text { group discussions } \\
\text { and personal re- } \\
\text { flection }\end{array}$ & Unclear & $\begin{array}{l}\text { Interventions: } \\
\text { Spanish immer- } \\
\text { sion programme, } \\
\text { Spanish language } \\
\text { classes, and cultural } \\
\text { workshops }\end{array}$ \\
\hline $\begin{array}{l}\text { Frequency } \\
\text { and duration }\end{array}$ & $\begin{array}{l}\text { Training lasted for } \\
3 \text { days, with the } \\
\text { third day coming } \\
\text { after } 4 \text { weeks of } \\
\text { clinical work at } \\
\text { health centres }\end{array}$ & $\begin{array}{l}\text { The cultural } \\
\text { awareness train- } \\
\text { ing was delivered } \\
\text { in six weeks and } \\
\text { consisted of three } \\
\text { 2-hour workshops }\end{array}$ & $\begin{array}{l}36 \text { hours of } \\
\text { cultural sen- } \\
\text { sitivity train- } \\
\text { ing }\end{array}$ & 3-year period \\
\hline $\begin{array}{l}\text { Method of } \\
\text { assessment }\end{array}$ & $\begin{array}{l}\text { The Clinical Cul- } \\
\text { tural Compe- } \\
\text { tence Training } \\
\text { Questionnaire- } \\
\text { pre and the Clini- } \\
\text { cal Cultural Com- } \\
\text { petency Train- } \\
\text { ing Evaluation } \\
\text { Questionnaire- } \\
\text { post }\end{array}$ & $\begin{array}{l}\text { 'Area human re- } \\
\text { sources develop- } \\
\text { ment/population } \\
\text { health survey of } \\
\text { participation in } \\
\text { Aboriginal aware- } \\
\text { ness training } \\
\text { workshop' tool }\end{array}$ & Unclear & $\begin{array}{l}\text { Assessment instru- } \\
\text { ment used to assess } \\
\text { patients' knowl- } \\
\text { edge of diabetes } \\
\text { and its manage- } \\
\text { ment. Health pro- } \\
\text { moters received ori- } \\
\text { entation to the clin- } \\
\text { ical site, assessment } \\
\text { of knowledge com- } \\
\text { petency, and ongo- } \\
\text { ing supervision and } \\
\text { in-service training }\end{array}$ \\
\hline $\begin{array}{l}\text { Evaluation } \\
\text { method }\end{array}$ & Unclear & Not reported & Unclear & $\begin{array}{l}\text { A combination of } \\
\text { open-ended ques- } \\
\text { tions in written } \\
\text { evaluations of both } \\
\text { the Spanish immer- } \\
\text { sion programme } \\
\text { and cultural work- } \\
\text { shops and pre- and } \\
\text { post-immersion } \\
\text { programme focus } \\
\text { groups with pro- } \\
\text { gramme partici- } \\
\text { pants }\end{array}$ \\
\hline
\end{tabular}




\section{Discussion}

There is a deficit of studies on changes in nurses' knowledge and behaviour in the area of cultural competence and subsequent impacts on patient outcomes. The four reviewed studies focused on different types of intervention, different targeted groups in various settings and measured dissimilar outcomes. This heterogeneity in intervention strategies and how they are implemented makes it difficult to offer empirical evidence on their effectiveness on the quality of care for patients from culturally diverse groups. However, despite some methodological limitations of the four studies included, this review contains the available evidence on interventions used with the aim to improve cultural competence among nurses working with patients from culturally diverse groups.

It has been shown that various forms of cultural training improve the cultural competence of nurses (Govere \& Govere, 2016). The general focus of cultural competence interventions has been on educating and training nurses, like other healthcare workers, in the knowledge, attitudes and skills needed to effectively respond to socio-cultural issues arising in clinical encounters (Betancourt et al., 2003). Cultural competence training can include: understanding the central role of culture in all lives and how it shapes behaviour; respect and acceptance of cultural differences; learning to effectively utilise culturally adapted and culturally specific practices; and, continuous development of healthcare employees' awareness of personal cultural influences and prejudices (Jongen, McCalman, \& Bainbridge, 2018; Warren, 2002).

Intervention strategies in the reviewed studies showed some evidence of their effectiveness, although there is limited research revealing a positive relationship between cultural competency training and improved patient outcomes. While cultural competency training is an important component of an overall framework for cultural competence, it is generally insufficient to merely change health professionals' behaviour if we wish to influence patient-related outcomes such as patient satisfaction, adherence and health outcomes (Beach et al., 2005; Lie, Lee-Rey, Gomez, Bereknyei, \& Braddock, 2011). Improving patient-related outcomes based on cultural competency training requires structural changes at the level of the organisation (Betancourt et al., 2003; Clifford, McCalman, Bainbridge, \& Tsey, 2015). Further, building up the cultural competence of healthcare professionals and organisations may be one of the best strategies for narrowing healthcare disparities. Although there is some evidence that organisations which have integrated cultural competency standards into policies and practices influ- 
ence health professionals to develop more culturally competent behaviours, more methodologically rigorous research is needed in this area (Paez, Allen, Carson, \& Cooper, 2008). The fact is that cultural competence continues to be developed as a major strategy to address health inequities. We identified four studies assessing the effects of cultural competence education/training for health professionals on patient-related outcomes.

\section{Conclusions}

The four studies included in the final analysis showed some degree of effectiveness regarding patient-related outcomes or nurses' acquisition of cultural competencies. They differed in their experimental designs, intervention and patient participants, and intervention treatments (e.g., cultural competence training content, duration, and methods). The results of this review suggest that the evidence found in published evaluations is still insufficient to allow any conclusions on which intervention strategies are the most effective for improving cultural competency in healthcare. Attempts to improve the cultural competence of health professionals should continue and educators and researchers should evaluate these interventions in methodologically rigorous research.

\section{References}

Baldwin, D. M. (2003). Disparities in health and health care: Focusing efforts to eliminate unequal burdens. Online Journal of Issues in Nursing, 8(1), 2. Retrieved from http://www.ncbi.nlm.nih.gov/pubmed/12729451

Beach, M. C., Price, E. G., Gary, T. L., Robinson, K. A., Gozu, A., Palacio, A., ... Cooper, L. A. (2005). Cultural competence: A systematic review of health care provider educational interventions. Medical Care, 43(4), 356-373.

Berlin, A., Nilsson, G., \& Törnkvist, L. (2010). Cultural competence among Swedish child health nurses after specific training: A randomized trial. Nursing \& Health Sciences, 12(3), 381-391.

Betancourt, J. R., Green, A. R., Carrillo, J. E., \& Ananeh-Firempong, O. (2003). Defining cultural competence: A practical framework for addressing racial/ ethnic disparities in health and health care. Public Health Reports, 118(4), 293-302.

Bonecutter, F. J., \& Gleeson, J. P. (1997). Broadening our view. Journal of Multicultural Social Work, 5(1-2), 99-119.

Chapman, R., Martin, C., \& Smith, T. (2014). Evaluation of staff cultural awareness before and after attending cultural awareness training in an Australian emergency department. International Emergency Nursing, 22(4), 179-184.

Clifford, A., McCalman, J., Bainbridge, R., \& Tsey, K. (2015). Interventions to improve cultural competency in health care for Indigenous peoples of Aus- 
tralia, New Zealand, Canada and the USA: A systematic review. International Journal for Quality in Health Care, 27(2), 89-98.

Gallagher, R. W., \& Polanin, J. R. (2015). A meta-analysis of educational interventions designed to enhance cultural competence in professional nurses and nursing students. Nurse Education Today, 35(2), 333-340.

Govere, L., \& Govere, E. M. (2016). How effective is cultural competence training of healthcare providers on improving patient satisfaction of minority groups? A systematic review of literature. Worldviews on Evidence-Based Nursing, 13(6), 402-410.

Horvat, L., Horey, D., Romios, P., \& Kis-Rigo, J. (2014). Cultural competence education for health professionals. Cochrane Database of Systematic Reviews. retrieved from https://doi.org/10.1002/14651858.CDo09405.pub2

Jongen, C., McCalman, J., \& Bainbridge, R. (2018). Health workforce cultural competency interventions: A systematic scoping review. BMC Health Services Research, 18(1), 232. Retrieved from https://doi.org/10.1186/s12913-018 $-3001-5$

Leininger, M. M. (1999). What is transcultural nursing and culturally competent care? Journal of Transcultural Nursing, 10(1), 9-9.

Leininger, M. M. (2002). The theory of culture care and the ethnonursing research method. In M. M. Leininger \& M. R. McFarland (Eds.), Transcultural nursing: Concepts, theories, research \& practice (3rd ed., pp. 71-116). New York, NY: McGraw-Hill.

Ličen, S., Karnjuš, I., \& Prosen, M. (2017). Ensuring equality through the acquisition of cultural competencies. In A. Petelin, N. Šarabon, \& B. Žvanut (Eds.), Health of the working-age population (p. 113). Koper, Slovenia: University of Primorska Press.

Lie, D. A., Lee-Rey, E., Gomez, A., Bereknyei, S., \& Braddock, C. H. (2011). Does cultural competency training of health professionals improve patient outcomes? Journal of General Internal Medicine, 26(3), 317-325.

Maier-Lorentz, M. M. (2008). Transcultural nursing: Its importance in nursing practice. Journal of Cultural Diversity, 15(1), 37-43.

Majumdar, B., Browne, G., Roberts, J., \& Carpio, B. (2004). Effects of cultural sensitivity training on health care provider attitudes and patient outcomes. Journal of Nursing Scholarship, 36(2), 161-166.

McElmurry, B. J., McCreary, L. L., Park, C. G., Ramos, L., Martinez, E., Parikh, R., ... Fogelfeld, L. (2009). Implementation, outcomes, and lessons learned from a collaborative primary health care program to improve diabetes care among urban Latino populations. Health Promotion Practice, 10(2), 293-302.

Moher, D., Liberati, A., Tetzlaff, J., Altman, D. G., \& PRISMA Group. (2009). Preferred reporting items for systematic reviews and meta-analyses: The PRISMA statement. PLoS Medicine, 6(7), e1000097. 
Paez, K. A., Allen, J. K., Carson, K. A., \& Cooper, L. A. (2008). Provider and clinic cultural competence in a primary care setting. Social Science \& Medicine, 66(5), 1204-1216.

Peña Dolhun, E., Muñoz, C., \& Grumbach, K. (2003). Cross-cultural education in U.S. medical schools: Development of an assessment tool. Academic Medicine, 78(6), 615-622.

Price, E. G., Beach, M. C., Gary, T. L., Robinson, K. A., Gozu, A., Palacio, A., ... Cooper, L. A. (2005). A systematic review of the methodological rigor of studies evaluating cultural competence training of health professionals. Academic Medicine, 80(6), 578-586.

Prosen, M. (2015). Introducing transcultural nursing education: implementation of transcultural nursing in the postgraduate nursing curriculum. Procedia: Social and Behavioral Sciences, 174, 149-155.

Sue, S., Zane, N., Nagayama Hall, G. C., \& Berger, L. K. (2009). The case for cultural competency in psychotherapeutic interventions. Annual Review of Psychology, 60, 525-548.

Truong, M., Paradies, Y., \& Priest, N. (2014). Interventions to improve cultural competency in healthcare: A systematic review of reviews. BMC Health Services Research, 14, 99. Retrieved from https://doi.org/10.1186/1472-6963-1499

Waite, R., \& Calamaro, C. J. (2010). Cultural competence: A systemic challenge to nursing education, knowledge exchange, and the knowledge development process. Perspectives in Psychiatric Care, 46(1), 74-80.

Warren, B. J. (2002). The interlocking paradigm of cultural competence: A best practice approach. Journal of the American Psychiatric Nurses Association, 8(6), 209-213.

S. Ličen, I. Karnjuš, \& M. Prosen (Eds.). (2019). Women, migrations and health: Ensuring transcultural healthcare (pp. 173-186).

Koper, Slovenia: University of Primorska Press.

https://doi.org/10.26493/978-961-7055-43-6.173-186 


\title{
Strengthening Cultural Awareness of Nursing Students
}

\author{
Barbara Donik \\ University of Maribor, Slovenia \\ barbara.donik@um.si \\ Mateja Lorber \\ University of Maribor, Slovenia \\ mateja.lorber@um.si \\ Majda Pajnkihar \\ University of Maribor, Slovenia \\ majda.pajnkihar@um.si
}

Cultural awareness by nurses is key for ensuring quality and person-centred care, therefore, strengthening cultural awareness in nursing students is very important. By measuring cultural awareness of nursing students and involving them in various educational modules in the field of transcultural nursing, we can influence their cultural awareness and sensitivity. The purpose of the research is to measure the level of cultural awareness in nursing students. A quantitative research approach was used. A descriptive cross-sectional survey was performed. For measuring cultural awareness in nursing students, a Cultural awareness scale (CAS) was used. Descriptive statistical methods and inferential statistics were used. The results showed a moderate level of cultural awareness in nursing students. The results indicated that female nursing students' average cultural awareness was higher than in male nursing students. The gender difference was especially high in the dimension Behaviours/Comfort with interactions. The inter-correlation between dimensions that measured cultural awareness was mostly positive. To ensure culturally competent nursing care, it is necessary to start teaching and gaining cultural competences early in their studies as education in the field of cultural competences represents a strategy for improving the knowledge, attitudes and skills of nursing students.

\section{Introduction}

Nurses are faced with an increased need to care for culturally diverse patients (Seal \& Wiske, 2018). This brings the opportunity for strengthening cultural awareness and sensitivity in nurses. Cultural awareness and cultural sensitivity are the key aspects of cultural competence among nurses (Clinton, 1996; Rew, Becker, Cookston, Khosropour, \& Martinez, 2003; Lonneman, 2015). This 
is crucial component in ensuring quality healthcare and has a large impact on the elimination of disparities arising from the perspectives of cultural diversity (Seal \& Wiske, 2018). In order to develop cultural competencies it is necessary to incorporate the contents of cultural diversity into nursing education (Prosen, 2015; Prosen, Karnjuš, \& Ličen, 2017).

Nurses are aware that they have to consider the patients' differences in age, gender, disability, ethnicity, beliefs, and desires for care, norms, and perspectives. Cultural awareness reflects the respect for cultural needs and beliefs (Conway-Klaassen \& Maness, 2017). This is the ability to understand that the cultural background of an individual affects behaviour and interpersonal relationships (Rew et al., 2003; Giger \& Davidhizar, 2007). The response made by individuals and the ability to critically examine personal bias towards other cultures, lifestyles and beliefs (McElroy, Smith-Miller, Madigan, $\& \mathrm{Li}, 2016)$ is therefore the basis for developing explicit views by nurses and their behaviour towards patients from diverse cultural backgrounds (Steed, 2015; Hall, Lee, Clark, \& Perilla, 2016). This reflects an affective dimension of knowledge and adaptation by nurses of awareness of themselves and others (Chen \& Young, 2012).

\section{Strategies for Strengthening Cultural Awareness of Nursing Students}

A critical component of nursing education, practice and research is therefore an integration of multidimensional domains of cultural awareness in nursing curricula (Rew et al., 2003). The challenge, in preparing nursing students to acquire cultural knowledge, is to evaluate whether nursing students are culturally aware, sensitive and competent.

To increase cultural awareness and improve the cultural competence of nursing students, the educational programs must include different learning activities based on patients' social and physical environments as the socioeconomic and political realities that are affecting the patients' varies, as does their access to healthcare (US Department of Health and Human Services, n. d.; Institute of Medicine, 2002; Agency for Healthcare Research and Quality, 2012; Lonneman, 2015). Students brings their own values, beliefs and behavior pattern in the educational setting. These values influence students' thinking, decisions and actions (Jeffreys, 2016). To improve the self-awareness of nursing students of their own culture, including biases and prejudices, are also critical aspects in the educational process (Institute of Medicine, 2002; Agency for Healthcare Research and Quality, 2012). From this perspective, meeting the needs of students who are culturally diverse is a growing challenge in nursing education (Jeffreys, 2016). 
Lonneman (2015) describe six teaching strategies for increasing cultural awareness of nursing students: (1) strategies (games) for raising issues for racism, classism and privilege, (2) reading assigning journal about personal thoughts, feelings and actions, (3) preparing personal history reflection paper and prepare the analysis of personal critical incidents, (4) using different video materials about how racism, classism, and other social factors effects on people's health, (5) performing an interview with someone from vulnerable population and preparing a written report, (6) discussions and purposeful exploration of cultural and health disparities and environmental impacts on health.

It is important to encourage critical thinking among nursing students about, own values and beliefs and the influence of lack of understanding of cultural differences on the patient's outcomes. Studies has shown that educational interventions (workshops, training, educational modules) in the field of learning and acquiring nursing student's cultural competences have a major impact on student's cultural awareness, cultural knowledge, cultural understanding and cultural skills (Brathwaite, 2005; Liu, Stone, \& McMaster, 2018). Because nursing students have less clinical experience with patients from diverse cultural backgrounds, Liu et al. (2018) find out that it is necessary to include into nursing educational programs and curriculums different contents that will have impact on cultural respect. Cultural respect is defined as an essential attitude towards patients coming from a diverse cultural background (Cai, Kunaviktikul, Klunklin, Sripusanapan, \& Avant, 2017). It is also important for students to increase the sense of comfort when they come into interaction with culturally diverse patients, as well as to increase awareness of equality treatment and respect for patient's beliefs, values and behaviors (Cai et al., 2017; Liu et al., 2018).

For increasing cultural awareness of nursing students, different methods for teaching can be included into nursing curricula such as: traditional lecture courses, case studies, role playing and using simulations (Grossman, Mager, Opheim, \& Torbjornsen, 2012; Long, 2012; Lonneman, 2015) and gaming (OngFlaherty, Valencia-Garcia, \& Martinez, 2017). During simulation course that include cultural diversity content students can gain experiences in specific cultural needs of patients based on protective characteristics (age, gender, ethnicity, disability, ...), they can improve communication skills and improve ability in cultural assessment.

The purpose of our research was to measure cultural awareness of nursing students. The aim was to find out the level of cultural awareness of University of Maribor, Faculty of Health Studies (UM FHS) nursing students. 
Three research questions were developed: (1) What is the level of cultural awareness of nursing students on UM FHS? (2) How are dimensions of cultural awareness related with gender, year of study and level of nursing program? (3) How dimensions of cultural awareness are correlating?

\section{Methods}

A descriptive cross-sectional research design was used with a convenience sample of University of Maribor Faculty of Health Sciences nursing students $(N=204)$ : undergraduate 1st year $(n=9)$ 2nd year $(n=102)$, 3rd year $(n=$ $85)$, postgraduates $(n=8)$. Participation rate was $38.9 \%$. Data was collected during summer semester. Before or during the collection of data students haven't received any transcultural educational intervention or course. A combination of online and paper questionnaire was administrated. The data was collected between 17th of May and 31st of August 2018.

\section{Instrument}

For measuring cultural awareness of nursing students, we used Cultural awareness tool (CAS) which was developed by Rew, Becker, Cookston, Khosropour, and Martinez (2003). CAS consisted of 36 items. According to the authors of CAS there are 5 different dimensions that best fit the data. Those are: General Education Experience, Cognitive Awareness, Research Issues, Behaviour/Comfort with Interactions, and Patient Care/Clinical Issues (Rew et al. 2003). The questionnaire was translated into Slovene language by two researchers (BD, $\mathrm{ML})$. For ensuring semantic equivalence we performed the back translation by a professional translator. The evidence of the reliability of the questionnaire (internal consistency) was computed with Cronbach's alpha coefficient, which was 0.51 .

\section{Ethical Considerations}

Permission from University of Maribor, Faculty of Health Studies Ethic Committee was obtained before the study. Students were informed of the purpose of the study. On each questionnaire (paper and online version) there was short description of purpose of the study and other information related to the confidentiality. Those who have been asked to fulfil the paper form of the questionnaire returned them into the sealed envelope. The link with online questionnaire was distributed via social media (Facebook group profiles of each study year).

The anonymity of the participants to the researchers was obtained, because there were no identifying data collected. 
Table 1 Sample Demographics

\begin{tabular}{llrr}
\hline Demographic characteristics & & $N$ & $\%$ \\
\hline Gender & Female & 179 & 87.7 \\
& Male & 25 & 12.3 \\
\hline Program & 2st year & 9 & 4.4 \\
& 2nd year & 102 & 50.0 \\
& 3rd year & 85 & 41.6 \\
& 1st year postgraduate & 5 & 2.5 \\
& 2nd year postgraduate & 3 & 1.5 \\
\hline Type of study & Full time & 174 & 85.3 \\
& Part time & 29 & 14.2 \\
& Unmarked & 1 & 0.5 \\
\hline Ethnicity & Slovene & 192 & 94.1 \\
& Croatian & 2 & 1.0 \\
& Serbian & 4 & 2.0 \\
& Bosnian & 4 & 2.0 \\
& Macedonian & 1 & 0.5 \\
& Hungarian & 1 & 0.5 \\
\hline Language that is used at home & Slovene & 200 & 98.0 \\
& Serbian & 1 & 0.5 \\
& Macedonian & 1 & 0.5 \\
& Bosnian & 1 & 1.0 \\
\hline
\end{tabular}

\section{Data Analysis}

Data was analysed with IBM SPSS Statistics (version 23.0). Descriptive statistics were computed, for answering the research question the arithmetic mean, Mann-Witney test and Spearman's correlation test were used.

\section{Results}

In overall sample, $(N=204)$ students were included, $87.7 \%$ women and $12.3 \%$ male students. The mean age was 22 years old $(s=3.34)$ ranging from min 19 to 45 years old. The sample represent students among undergraduate nursing program and postgraduate nursing program (Table 1). The findings are limited because of small sample of postgraduate nursing students. There were also small group of respondents that vary regarding ethnicity and use of language at home. Descriptive statistic was used to analyze the demographic data. Our results showed, that students accessed two statements inside the 'Research Issues' dimension as not applicable. Because of missing data, the 'Research Issues' dimension was excluded from further analyzing. 
Table 2 Differences between Gender and Dimensions of Cultural Awareness

\begin{tabular}{|c|c|c|c|c|c|c|}
\hline \multirow[t]{2}{*}{ CAS Dimensions } & \multicolumn{2}{|c|}{ Man } & \multicolumn{2}{|c|}{ Woman } & \multirow[t]{2}{*}{$Z$} & \multirow[t]{2}{*}{$p$} \\
\hline & $\bar{x}$ & $\bar{s}$ & $\overline{\bar{x}}$ & $\bar{s}$ & & \\
\hline General Education Experience & 3.73 & 0.326 & 3.59 & 0.407 & -1.689 & 0.091 \\
\hline Cognitive Awareness & 3.76 & 0.677 & 3.79 & 0.599 & -0.105 & 0.916 \\
\hline Behaviors/Comfort with Interactions & 3.32 & 0.703 & 3.64 & 0.663 & -2.058 & 0.040 \\
\hline Patient Care/Clinical Issues & 3.57 & 0.628 & 3.46 & 0.505 & -0.851 & 0.395 \\
\hline Total & 3.58 & 0.345 & 3.62 & 0.303 & -0.361 & 0.718 \\
\hline
\end{tabular}

Notes Column headings are as follows: $\bar{x}$ - average, $s$ - standard deviation, $Z-$ Mann-Whitney test value, $p$ - statistical significance.

The results showed that the average score of self-assessment for the cultures awareness for nursing students was $3.61(s=0.40)$ (72\% of total score). General Education Experience $3.60(s=0.40)$ (72\% of total score), Cognitive Awareness 3.78 ( $s=0.61$ ) (76\% of total score); Behavior/Comfort with Interaction $3.61(s=0.67)$ ( $72 \%$ of total score); Patient Care/Clinical Issues $3.47(s=0.52)$ (69\% of total score). For undergraduate program $15 t$ year nursing students average score was $3.64(s=0.19)$, 2nd year student average score was 3.59 ( $s$ $=0.33)$ and 3 rd year nursing students average score was $3.59(s=0.32)$. For postgraduate program average cultural awareness score was $3.73(s=0.29)$ and 2 nd year nursing students average score was $3.63(s=0.20)$.

The Mann-Whitney test showed that the differences between gender in the dimension 'Behavior/Comfort with Interaction' are perceived. Female students access dimension Behavior/Comfort statistically significantly higher $(z=-2.058 ; p=0.040$ ) (Table 2).

Table 3 presents the results of differences between part time and full-time nursing students. Part time nursing students access the dimension 'General Education Experience' statistically significantly higher $(z=-1.988, p=0.047)$.

Table 3 Mann-Whitney Test between Dimensions of Cultural Awareness and Type of the Study

\begin{tabular}{|c|c|c|c|c|c|c|}
\hline \multirow[t]{2}{*}{ CAS Dimensions } & \multicolumn{2}{|c|}{ Full time } & \multicolumn{2}{|c|}{ Part time } & \multirow[t]{2}{*}{$Z$} & \multirow[t]{2}{*}{$p$} \\
\hline & $\bar{x}$ & $\bar{s}$ & $\overline{\bar{x}}$ & $\bar{s}$ & & \\
\hline General Education Experience & 3.58 & 0.402 & 3.75 & 0.339 & -1.988 & 0.047 \\
\hline Cognitive Awareness & 3.79 & 0.604 & 3.70 & 0.609 & -0.757 & 0.449 \\
\hline Behaviors/Comfort with Interactions & 3.60 & 0.641 & 3.63 & 0.661 & -0.563 & 0.574 \\
\hline Patient Care/Clinical Issues & 3.48 & 0.497 & 3.41 & 0.661 & -0.279 & 0.780 \\
\hline Total & 3.61 & 0.299 & 3.62 & 0.349 & -0.248 & 0.804 \\
\hline
\end{tabular}

Notes Column headings are as follows: $\bar{x}$ - average, $s$ - standard deviation, $Z$ - Mann-Whitney test value, $p$ - statistical significance. 
Table 4 Inter-Correlation between Measured Dimension of Cultural Awareness Scale

\begin{tabular}{lrrrr}
\hline CAS Dimensions & $(1)$ & $(2)$ & $(3)$ & $(4)$ \\
\hline General Education Experience & 1 & $0.349^{* *}$ & 0.117 & $0.308^{* *}$ \\
Cognitive Awareness & - & 1 & -0.085 & $0.420^{* *}$ \\
Behaviors/Comfort with Interactions & - & - & 1 & $-0.203^{* *}$ \\
Patient Care/Clinical Issues & - & - & - & 1 \\
\hline
\end{tabular}

Notes Column headings are as follows: (1) General Education Experience, (2) Cognitive Awareness, (3) Behaviors/Comfort with Interactions, (4) Patient Care/Clinical Issues. ${ }^{*}$ correlation is significant at the 0.05 level or less. ${ }^{* *}$ Correlation is significant at the 0.001 level or less.

In the Table 4 the inter-correlation between measured dimensions in CAS are performed. Spearman's correlation test was performed. The results showed that there is statistically significant weak correlation between the dimensions 'General Education Experience' and 'Cognitive Awareness' ( $r=$ $0.349 ; p<0.001)$ and 'Patient Care/Clinical Issues' $(r=0.308 ; p<0.001)$. There is a moderate correlation between the dimension: 'Cognitive Awareness' and 'Patient Care/Clinical Issues' ( $r=0.420 ; p=0.004)$ and the weak correlation between the 'Behaviors/Comfort with Interactions' and 'Patient Care/Clinical Issues' dimension $(r=0.203 ; p<0.001)$.

\section{Discussion}

The purpose of this study was to measure and analyse cultural awareness of nursing students as first step to improve cultural competencies of nursing students in UM FHS. Results showed that nursing students assessed their level of cultural awareness as moderate (the total average value was 3.61 out of max. 5). According to Starr Tate (2016) slightly lower average mean scores show that there is a space and a need for improvement of student's cultural awareness and cultural competency education courses. To develop cultural awareness, nursing students should have the opportunity to increase their knowledge in transcultural aspect of care. The key for increasing cultural awareness is to improve the understanding of health inequities and health disparities (Cantey, Randolph, Molloy, \& Cary, 2017). It is also crucial that nursing students raise their awareness on the communication and cultural beliefs of people (Goodman, Edge, Agazio, \& Prue-Owens, 2015). There are different strategies to promote cultural awareness and competency within nursing programs (Eshleman \& Davidhizar, 2006). Lonneman (2015) and Long (2012) state that current approaches for increasing cultural competencies are lectures, group discussion, written reports, clinical experiences, simulations, role playing, journal keeping, studying abroad and working experiences in 
community settings. It is important to investigate in further research how effective those strategies are. Cultural competence can be increased by including structured cultural content in the nursing curricula (Sargent, Sedlak, \& Martsolf, 2005).

In our study, the results didn't vary between age, level of nursing program, way of study and year of study. Safipour, Hadziabdic, Hultsjö, and BachrachLindström (2017) also find out an insignificant correlation between demographic variables and the level of cultural awareness. In comparison between female nursing students and male nursing students, the results showed statistically significant higher scores accessed by female students in one dimension: 'Behaviors/Comfort with Interactions.' This can be explained by the results of the study (Parlar Kılıç \& Sevinç, 2018) that female students are more sensitive toward cultural differences, have more positive attitudes toward cultural factors, and that they feel more responsible than male students. Also, Yilmaz, Toksoy, Denizci Direk, Bezirgan, and Boylu (2016) find out, that female scored the determinant: respect for cultural differences higher than male.

Testing the inter-correlation between dimensions was important due to investigate how some dimensions vary between. We can conclude that interesting inter-correlations were found. The negative correlation between Cognitive awareness and Behaviors/Comfort was identified. Positive correlation between 'General Education Experience' and 'Patient Care/Clinical Issues' was identified. There is also a moderate correlation between the dimension: 'Cognitive Awareness' and 'Patient Care/Clinical Issues. Hadziabdic, Safipour, Bachrach-Lindström, and Hultsjö (2016) report the negative intercorrelation between those dimensions.

However, there are some limitation of this study that can be outlined. In this research, the number of male participants, 1st year undergraduate nursing students and postgraduate nursing students is smaller, therefore the results must be interpreted wit conscious. Also, due to small sample there was impossible to measure the relation between demographic variables such as ethnicity and language that participants speak at home with cultural awareness score. The nature of research was quantitative, therefore the results can't provide the impact of some variables that can increase cultural awareness of nursing students.

\section{Conclusions}

Culture is having a huge impact on peoples every day live. During undergraduate or postgraduate nursing education, students must achieve an adequate level of competences, also cultural competences. Concept of culture 
diversity care can be learned and adopted in every nursing education curriculum. This will result the high level of student's cultural awareness. In nursing education there is a need that students perform their clinical settings in diverse - intercultural clinical settings. Further researches are needed to measure cultural awareness among nursing students for identifying strategies for improving their cultural awareness and implementing various teaching strategies in nursing educational programs. The main finding of our study, that there is a moderate level of cultural awareness score among nursing students in our faculty, suggests the importance of continuously measuring the level of cultural awareness between nursing students and recognize the important steps in incorporating strategies for improving cultural awareness of students in nursing education.

\section{References}

Agency for Healthcare Research and Quality. (2012). National Healthcare Disparities Report 2011. Rockville, MD: Agency for Healthcare Research and Quality.

Brathwaite, A. E. (2005). Evaluation of a cultural competence course. Journal of Trancultural Nursing, 16(4), 361-369.

Cai, D., Kunaviktikul, W., Klunklin, A., Sripusanapan, A., \& Avant, P. K. (2017). Developing a cultural competence inventory for nurses in China. International Nursing Review, 64(2), 207-214.

Cantey, D. D., Randolph, S. D., Molloy, M. A., \& Cary, M. P. (2017). Studentdeveloped simulations. Journal of Nursing Education, 56(4), 234-246.

Chen, G. M., \& Young, P. (2012). Intercultural communication competence. In A. Goodboy, \& K. Shultz (Eds.), Introduction to communication studies: Translating scholarship into meaningful practice higher education (pp. 175-188). Dobuque, IA: Kendall-Hunt.

Clinton, J. F. (1996). Cultural diversity and health care in America: Knowledge fundamental to cultural competence in baccalaureate nursing students. Journal of Cultural Diversity, 3(1), 4-8.

Conway-Klaassen, J., \& Maness, L. (2017). Critical conversations: Cultural awareness, sensitivity, and competency. Clinical Laboratory Science, 30(1), 34-37.

Eshleman, J., \& Davidhizar, R. E. (2006). Strategies for developing cultural competency in an RN-BSN program. Journal of Transcultural Nursing, 17, 179183.

Giger, J., \& Davidhizar, J. (2007). Trancultural nursing: Assessments and intervention (5th ed.). St. Louis, MO: Mosby.

Goodman, P., Edge, B., Agazio, J., \& Prue-Owens, K. (2015). Cultural awareness nursing care of Iraqi patients. Journal of Trancultural Nursing, 26(2), 395-401.

Grossman, S., Mager, D., Opheim, H. M., \& Torbjornsen, A. (2012). A bi-national 
simulation study to improve cultural awareness in nursing students. Clinical Simulation in Nursing, 8, e341-e346.

Hadziabdic, E., Safipour, J., Bachrach-Lindström, M., \& Hultsjö, S. (2016). Swedish version of measuring cultural awareness in nursing students: Validity and reliability test. BMC Nursing, 15(25). Retrieved from https://bmcnurs .biomedcentral.com/articles/10.1186/s12912-016-0146-6

Hall, E., Lee, S. Y., Clark, P. C., \& Perilla, J. (2016). Social ecology of adherence to hypertension treatment in latino migrant and seasonal farmworkers. Journal of Transcultural Nursing, 27(1), 33-41.

Institute of Medicine. (2002). Unequal treatment: What healthcare providers need to know about racial and ethnic disparities in health care. Washington, DC: National Academies Press.

Jeffreys, M. R. (2016). Teaching cultural competence in nursing and health care. New York, NY: Springer.

Liu, W., Stone, T. E., \& McMaster, R. (2018). Increasing undergraduate nursing students' cultural competence: An evaluation study. Global Health Research and Policy, 3(7), 1-10.

Long, T. B. (2012). Overview of teaching strategies for cultural competence in nursing students. Journal of Cultural Diversity, 19(3), 102-108.

Lonneman, W. (2015). Teaching strategies to increase cultural. Nurse Educator, 40(6), 285-288.

McElroy, J., Smith-Miller, C. A., Madigan, C. K., \& Li, Y. (2016). Cultural awareness among nursing staff at an academic medical center. The Journal of Nursing Administration, 46(3), 146-153.

Ong-Flaherty, C., Valencia-Garcia, D., \& Martinez, D. A. (2017). Effectiveness of gaming in creating cultural awareness. Learning, Culture and Social Interaction, 12, 149-158.

Parlar Kılıç, S., \& Sevinç, S. (2018). The relationship between cultural sensitivity and assertiveness in nursing students from Turkey. Journal of Transcultural Nursing, 29(4), 379-386.

Prosen, M. (2015). Introducing transcultural nursing education: Implementation of transcultural nursing in the postgraduate nursing curriculum. Procedia: Social and Behavioral Sciences, 174, 149-155.

Prosen, M., Karnjuš, I., \& Ličen, S. (2017). Razvijanje medkulturnih kompetenc med študenti zdravstvene nege. In S. Rutar, K. Čotar, T. Štemberger, \& S. Bratož (Ed.), Vidiki internacionalizacije in kakovosti $v$ visokem šolstvu (pp. 139-153). Koper, Slovenia: University of Primorska Press.

Rew, L., Becker, H., Cookston, J., Khosropour, S., \& Martinez, S. (2003). Measuring cultural awareness in nursing students. Journal of Nursing Education, 42(6), 249-257.

Sargent, S. E., Sedlak, C. A., \& Martsolf, D. S. (2005). Cultural competence among nursing students and faculty. Nurse Education Today, 25(3), 214-221. 
Safipour, J., Hadziabdic, E., Hultsjö, S., \& Bachrach-Lindström, M. (2017). Measuring nursing students' cultural awareness: A cross-sectional study among three universities in southern Sweden. Journal of Nursing Education and Practice, 7(1), 107-113.

Seal, N., \& Wiske, M. (2018, 24 May). 5 ways to improve cultural competence in nursing care. Retrieved from https://minoritynurse.com/5-ways-to -improve-cultural-competence-in-nursing-care/

Starr Tate, A. (2016). Culture counts: An analysis of cultural awareness and competency among nursing students (Undergraduate thesis). Gardner-Web University, Boiling Springs, NC.

Steed, M. R. (2015). Cultural competence in certified registered nurse anesthetists (Doctoral dissertation). Walden University, Minneapolis, MN.

US Department of Health and Human Services. (N. d.). Healty people 2020. Retrieved from https://www.healthypeople.gov/sites/default/files/ HP2020Framework.pdf

Yilmaz, M., Toksoy, S., Denizci Direk, Z., Bezirgan, S., \& Boylu, M. (2016). Cultural sensitivity among clinical nurses: A descriptive study. Journal of Nursing Scholarship, 49(2), 1-9.

S. Ličen, I. Karnjuš, \& M. Prosen (Eds.). (2019). Women, migrations and health: Ensuring transcultural healthcare (pp. 187-197).

Koper, Slovenia: University of Primorska Press.

https://doi.org/10.26493/978-961-7055-43-6.187-197 



\title{
Culturally Sound Midwifery Care for Migrant Mothers: How Well the Midwifery Curriculum Prepares Graduates
}

\author{
Ana Polona Mivšek \\ University of Ljubljana, Slovenia \\ polona.mivsek@zf.uni-lj.si \\ Nastja Pavel \\ University of Ljubljana, Slovenia \\ nastja.pavel@zf.uni-lj.si \\ Mateja Kusterle \\ General Hospital Jesenice \\ mateja.kusterle@zf.uni-lj.si \\ Petra Petročnik \\ University of Ljubljana, Slovenia \\ petra.petrocnik@zf.uni-lj.si
}

There are no publicly available data on how many migrant mothers in Slovenia are cared for during pre-, intra- and post-natal period. Nevertheless, with the refugees' situation during the years 2016-2018, Slovenia faced a challenge where not only quality but also culturally sensitive midwifery care was of crucial importance. Foreign midwifery curriculums emphasize cultural competencies of graduates, however; there has not been any study conducted in order to evaluate Slovene midwifery students' cultural awareness. Therefore, a study was performed among the final year midwifery students using a Cultural Awareness Scale (CAS). The findings reveal that the current curriculum lacks specific information on cultural competencies; nevertheless the students expressed high levels of cultural awareness. Midwifery teachers were described as positive role models and it could be estimated that also indirect teaching, using good examples, can be a way students successfully learn cultural awareness.

\section{Introduction}

Anthropologists find it very difficult to define culture because the term itself is very complex in meaning, underpinned also with political or ideological agendas (Spencer-Oatey, 2012). Hundreds of definitions have been written so far, but for the purpose of our project the one by Spencer-Oatey (2008, p. 3) is cited: 'Culture is a fuzzy set of basic assumptions and values, orien- 
tations to life, beliefs, policies, procedures and behavioural conventions that are shared by a group of people, and that influence (but do not determine) each member's behaviour and his/her interpretations of the "meaning" of other people's behaviour.'

Hofstede, Hofstede, and Minkov (2010) wrote that since the majority of people identify with different cultural groups at different levels (nationally, regionally, ethnically, religiously, linguistically, at the levels of gender, social class, corporate level, and role categories of parent/daughter/teacher) we all basically have multicultural identities. In times of increased global migrations, the cultural context of every individual is becoming recognized as crucial for all aspects of quality living. In the context of healthcare and also midwifery-led maternity care, midwives should continuously strive to provide individualized and culturally appropriate care of the client (New Zealand College of Midwives, 2015). On the one hand, it is valuable if midwives themselves come from diverse cultural and ethnic backgrounds (Rew, Becker, Cookston, Khosropour, \& Martinez, 2003), however, the multi-ethnic environment alone does not imply the midwife is intrinsically culturally competent and sensitive (Briscoe, 2013).

\section{Background}

Cultural competency is a complex construct and there is no standardized definition. Campinha-Bacote (2007) writes it is an ongoing process in which the health professional (hence midwife) continuously strives to achieve the ability and availability to work effectively within the cultural context of the patient (individual, family, community). According to Camplin-Welch and Lim (2018), cultural competency refers to an ability to interact effectively with people of different cultures. Bofulin et al. (2016) define cultural competency as a wide range of knowledge and skills involved in human interaction that enable an individual to improve one's understanding, sensitivity, acceptance, respect and reactions to cultural differences and intercultural relationships. It enables healthcare workers to provide better quality healthcare and to successfully cooperate with people from different cultural and social backgrounds.

Cultural competency is subdivided into components/steps/constructs that are interrelated and interdependent. According to to Camplin-Welch and Lim (2018), all (four) dimensions (cultural awareness, cultural knowledge, cultural sensitivity and cross-cultural skills) should be applied in the context of research, clinical practice and midwifery teaching.

Campinha-Bacote (2007) presents a slightly different model of cultural 
competency, called The Process of Cultural Competence in the Delivery of Healthcare Services - PCCDHS. It describes five constructs, namely cultural desire, cultural awareness, cultural knowledge, cultural skills, and cultural encounters. She intertwines cultural sensitivity into the other four constructs, especially into encounters and skills. However, she introduces two new concepts, namely cultural encounters and cultural desire. The foundational construct of the model that creates the possibility to develop the other four constructs is cultural encounters. It consists of continuous interaction with patients from diverse backgrounds in order to validate, refine, or modify existing values, beliefs, and practices about a cultural group. Continuous because health professionals should not make generalisations over one ethnic or religious group from just a few encounters they have had. Cultural desire is the midwife's motivation to intrinsically want to engage in the process of becoming culturally competent versus to be forced into it.

\section{The Need for Culturally Sensitive Health and Midwifery care in Slovenia}

Slovenia as the member country of the European Union (EU), faced numerous refugee and migration flows from 2016 to 2018. According to the latest data from Eurostat (see http://ec.europa.eu/eurostat), 4.7 million people moved to one of the countries of the EU in 2015 and 2.7 million of them were from the countries that are not EU members. Although the flow of immigrants passed Slovenia many times, the majority wanted to achieve western countries of the EU (Germany, the UK, France, Spain, Italy), which made Slovenia merely a transit country. Despite that, a proportion of immigrants and refugees stopped in Slovenia due to different reasons. According to the data from the Ministry of the interior of the Republic of Slovenia from 2018 (see http://www.mnz.gov.si), the biggest numbers of the valid licences for domiciles were given to persons from Bosnia and Herzegovina, Kosovo, Macedonia and Serbia, which indicates that the key migration flow is still from the Balkan countries. At the same time, according to the Ministry, the number of applications for international protection has increased during the period from 2016 to 2018. In 2018, the number of applicants for international protection was 1430, of which $91 \%$ were men. The majority of applicants came from countries such as Pakistan, Algeria, Afghanistan, Morocco, Syria, Iran and Iraq (see http://www.mnz.gov.si). Slovenia as an EU member and a part of the Geneva Convention is obliged to offer international protection to the persons who do not receive protection in their own country. This includes refugee status or subsidiary protection.

The migration flows also leave many challenges in the field of healthcare. 
While most citizens feel that access to compulsory and supplementary health insurance is self-evident, non-nationals of Slovenia must fulfil certain conditions defined in the Law on Health Care and Health Insurance Act ${ }^{1}$. At the same time, Slovene legislation (Article 7 of the Law on Health Care and Health Insurance Act) enables urgent treatment to persons of unknown residence and foreigners from countries which Slovenia has not signed international treaties with. Emergency treatment includes urgent health services for recovery and preservation of life and prevention of deterioration of the health condition of the diseased or injured (Article 25); childbirth also fits into that category. According to the International Protection Act, ${ }^{2}$ applicants for international protection (asylum) also have the right to emergency treatment, including emergency medical assistance and emergency rescue, emergency dental care and emergency treatment prescribed by a treating physician. Juvenile persons who are applying for international protection are entitled to healthcare under the same conditions as the nationals of Slovenia. Vulnerable people with special needs have the right to an additional amount of health services, including psychotherapy. In addition to emergency treatment, female applicants for international protection have the right to healthcare for women, including contraceptives, termination of pregnancy and medical care during pregnancy and childbirth. Persons without health insurance can also seek medical assistance in the 'Pro Bono' Clinic with a counselling service set up to help people without permanent residence and basic health insurance, as well as foreigners, refugees and applicants for international protection who need different forms of assistance but do not have the right to additional health insurance (see pro-bono.ordinacija.net). The clinic also provides healthcare and counselling to pregnant women.

In the past, a negative attitude towards immigrants was sometimes present among Slovene citizens since some believed that the Slovene space was culturally homogeneous. Immigrants were sometimes treated as undesirable with some degree of intolerance and even discrimination (Kulovec, 2012). Today, the Slovene society is much more adaptable to the needs of immigrants, since successful integration into the Slovene society is not only a responsibility of immigrants but also a responsibility of the entire society. ${ }^{3}$ Health professionals are by professional conduct and code of ethics obliged to pro-

\footnotetext{
${ }^{1}$ Zakon o zdravstvenem varstvu in zdravstvenem zavarovanju, see http://www.pisrs.si/Pis.web/ pregledPredpisa?id=ZAKO213.

${ }^{2}$ Zakon o mednarodni zaščiti, see http://pisrs.si/Pis.web/pregledPredpisa?id=ZAKO7103.

${ }^{3}$ See http://www.mnz.gov.si.
} 
vide the same quality care for all people. However, providing treatment to migrants presents health professionals as well as midwives a particular challenge due to specific socio-cultural characteristics that are often difficult to understand or even unknown to us. Establishment of successful communication and vulnerability of individuals also present great challenges (Bombač, Brecelj, Liberšar, \& Zelko, 2017). For this reason, Lipovec Čebron (2017) emphasizes an important role of intercultural mediation which can effectively prevent misunderstandings due to linguistic, cultural, social or other differences between users and providers in individual health institutions. With the recent migration flows, the Slovene healthcare is facing constant needs for tolerance towards different cultures. With proper preparation of health professionals and students of health sciences, we can have a positive influence on improving the understanding and reducing inequalities in the health system.

Eurostat (see http://appsso.eurostat.ec.europa.eu) for the year 2016 quotes 2005 women who gave birth to a child in Slovenia and were not Slovene citizens. The number of women who give birth in Slovenia each year and are not Slovene citizens is increasing according to the Eurostat data. Taking this into account, it is very important Slovene midwives deliver empathic and culturally sensitive care to foreign mothers. It is crucial to begin developing cultural awareness of future midwives as early as during the education process in order to obtain midwifery graduates who are culturally sensitive and provide quality and culturally sound midwifery care. Health education programs include cultural awareness into important outcomes of study programs (Loredan \& Prosen, 2013) and cultural competence is high on the list of Essential Competencies for Basic Midwifery Practice issued by International Confederation of Midwives (2013).

Evaluation of the current Slovene undergraduate midwifery curriculum (Stanek Zidarič, Mivšek, \& Skoberne, 2011) revealed that cultural awareness is not specifically addressed. The main aim of the present study was therefore to evaluate the current degree of cultural awareness among the students of the final year of the midwifery studies at the Faculty of Health Sciences in Ljubljana, Slovenia.

\section{Methods}

A causal non-experimental method of empirical research was applied. The research instrument was a survey questionnaire Cultural Awareness Scale - CAS (Rew et al., 2003) that was translated through a process of double blind translation and adapted to the midwifery context. The tool measures 
36 statements with the 7-point Lykert scale (1 - strongly disagree, 7- strongly agree).

Ethical issues of the research were considered and the proposal for the research was approved by the Cathedra of midwifery. The survey questionnaire was sent to all 3 rd year students of the midwifery study program and to the students of the additional year $(N=58)$ in July 2018. Participation in the survey was anonymous and voluntary.

The analysis is founded on basic descriptive statistics, calculating mean values and standard deviation (SD) using SPSS program version 23.

\section{Results}

The questionnaire was answered by 32 students which equals a $55.2 \%$ response rate. The mean values of their answers for each tested statement are gathered in Table 1. The majority of the answers reveal that the existing midwifery curriculum educates culturally sensitive midwives. The statement Midwifery program provides opportunities for activities relating to multiculturalism earned 4.3 mean value and the statement During midwifery studies, my knowledge of multiculturalism has improved scored as high as 4.6. Also the midwifery teachers were evaluated as sensitive regarding this topic - the statement Midwifery teachers appropriately address the topic of different cultures in midwifery practice reached 4.8 mean value and Midwifery teachers are my role models for learning how to be sensitive and consider intercultural differences even as high as 5.4.

The statements that were most frequently strongly agreed upon ( 7 on the Lykert scale) were:

- If I needed more information on a patient's culture, I would not be uncomfortable asking my colleagues about it (mean 6.2).

- If I need more information on a patient's culture, I use available sources at hand (e.g. books, videos etc.) (mean 5.9).

- I respect patients' decisions that are culturally conditioned although I personally disagree with them (mean 6.1).

The statements that were most frequently strongly disagreed upon ( 1 on the Lykert scale) were:

- I feel somewhat uncomfortable working for patients and their families from other cultures (mean 2.1).

- When there is an opportunity to help someone, I less often do it for members of certain cultural groups (mean 2.1). 
Table 1 Means and Standard Deviations (SD) for CAS Statements

\begin{tabular}{|c|c|c|}
\hline Statement & $(1)$ & $(2)$ \\
\hline $\begin{array}{l}\text { Midwifery teachers appropriately address the topic of different cultures in mid- } \\
\text { wifery practice. }\end{array}$ & 4.8 & 1.6 \\
\hline $\begin{array}{l}\text { Midwifery program provides opportunities for activities relating to multicultur- } \\
\text { alism. }\end{array}$ & 4.3 & 1.7 \\
\hline During midwifery studies, my knowledge of multiculturalism has improved. & 4.6 & 1.5 \\
\hline $\begin{array}{l}\text { The experiences I gained during midwifery studies educated me about the } \\
\text { health problems that afflict members of different cultural groups. }\end{array}$ & 4.6 & 1.6 \\
\hline I think my beliefs and attitudes are influenced by the $c$ & 4.6 & 1.7 \\
\hline I believe my attitudes are constructed by my culture. & 4.7 & 1.4 \\
\hline $\begin{array}{l}\text { I often think about the ways culture influences beliefs and attitudes of an indi- } \\
\text { vidual. }\end{array}$ & 5.5 & 1.6 \\
\hline $\begin{array}{l}\text { When there is an opportunity to help someone, I less often do it for members } \\
\text { of certain cultural groups. }\end{array}$ & 2.1 & 1.3 \\
\hline nembers of certain cultures. & 2.1 & 1.5 \\
\hline I enjoy working with patients of diverse ethnic groups. & 5.5 & 1.6 \\
\hline $\begin{array}{l}\text { I think that a midwife's personal beliefs influence her decisions on midwifery } \\
\text { care. }\end{array}$ & 5.5 & 1.7 \\
\hline $\begin{array}{l}\text { I usually feel awkward when I am in the company of people from other cultural } \\
\text { and ethnic groups. }\end{array}$ & 2.7 & 1.8 \\
\hline $\begin{array}{l}\text { I noticed that midwifery teachers talk to students from a certain culture when } \\
\text { there is an issue related to the classmates from the same ethnic minority. }\end{array}$ & 5.2 & 1.0 \\
\hline $\begin{array}{l}\text { When there is a discussion within our class, I noticed that midwifery teachers } \\
\text { strive against excluding any students. }\end{array}$ & 5.7 & 1.7 \\
\hline $\begin{array}{l}\text { I believe that a student's cultural values influence his/her behaviour in the } \\
\text { classroom (e.g. asking questions, participating in a group, commenting etc.). }\end{array}$ & 5.1 & 1.5 \\
\hline Midwifery teachers behave in a way that excludes students of certain cultures. & 2.1 & 1.2 \\
\hline $\begin{array}{l}\text { I think it is a midwifery teacher's job to adapt to different learning needs of stu- } \\
\text { dents. }\end{array}$ & 5.3 & 1.9 \\
\hline $\begin{array}{l}\text { In the course of teaching, midwifery teachers sovereignly discuss intercultural } \\
\text { issues. }\end{array}$ & 4.8 & 1.4 \\
\hline $\begin{array}{l}\text { Midwifery teachers appear keen to find out how their teaching behaviour can } \\
\text { dissuade students from a certain ethnic group or culture. }\end{array}$ & 4.6 & 1.5 \\
\hline $\begin{array}{l}\text { I think that cultural values of those who teach midwifery influence their be- } \\
\text { haviours in a clinical setting. }\end{array}$ & 4.9 & 1.2 \\
\hline $\begin{array}{l}\text { I think that experiences from theoretical midwifery teachings impact students } \\
\text { in a way that they feel less awkward interacting with people from different cul- } \\
\text { tural backgrounds. }\end{array}$ & 5.4 & 1.5 \\
\hline $\begin{array}{l}\text { I think that some aspects of theoretical midwifery teachings could discourage } \\
\text { students of certain cultures. }\end{array}$ & 3.4 & 1.5 \\
\hline I am not uncomfortable discussing intercultural topics in class. & 5.3 & 2.3 \\
\hline
\end{tabular}

Continued on the following page 
Table 1 Continued from the previous page

\begin{tabular}{lcc}
\hline Statement & $(1)$ & $(2)$ \\
\hline $\begin{array}{l}\text { Clinical placements during midwifery studies have helped me to become more } \\
\text { comfortable interacting with people from different cultures. }\end{array}$ & 5.3 & 1.9 \\
$\begin{array}{l}\text { I believe that midwifery teachers respect the differences among individuals } \\
\text { that arise from their different cultural backgrounds. }\end{array}$ & 5.3 & 1.8 \\
$\begin{array}{l}\text { Midwifery teachers are my role models for learning how to be sensitive and } \\
\text { consider intercultural differences. }\end{array}$ & 5.4 & 1.5 \\
$\begin{array}{l}\text { Midwifery teachers use case studies which integrate knowledge of various cul- } \\
\text { tures into the learning process. }\end{array}$ & 4.8 & 1.8 \\
$\begin{array}{l}\text { The Department of Midwifery carries out research that takes into account the } \\
\text { intercultural aspects of health. }\end{array}$ & 4.4 & 1.7 \\
$\begin{array}{l}\text { Midwifery students write graduation theses which also take into account the } \\
\text { intercultural aspect of health. }\end{array}$ & 5.1 & 1.7 \\
$\begin{array}{l}\text { When researchers at The Department of Midwifery conduct research on differ- } \\
\text { ent cultures, they take into consideration relevant measurement instruments } \\
\text { for data collection. }\end{array}$ & 5.3 & 1.0 \\
$\begin{array}{l}\text { When researchers at The Department of Midwifery interpret results of their } \\
\text { own research, they also consider the cultural aspects. }\end{array}$ & 4.7 & 1.4 \\
$\begin{array}{l}\text { I respect patients' decisions that are culturally conditioned although I person- } \\
\text { ally disagree with them. }\end{array}$ & 6.1 & 1.6 \\
$\begin{array}{l}\text { If I need more information on a patient's culture, I use available sources at hand } \\
\text { (e.g. books, videos etc.). }\end{array}$ & 5.9 & 2.0 \\
$\begin{array}{l}\text { If I needed more information on a patient's culture, I would not be uncomfort- } \\
\text { able asking my colleagues about it. }\end{array}$ & 6.2 & 1.6 \\
$\begin{array}{l}\text { If I needed more information on a patient's culture, I would not be uncomfort- } \\
\text { able asking the patient or his/her family members about it. }\end{array}$ & 5.4 & 1.9 \\
$\begin{array}{l}\text { I feel somewhat uncomfortable working for patients and their families from } \\
\text { other cultures. }\end{array}$ & 2.1 & 1.5 \\
\hline
\end{tabular}

Notes Column headings are as follows: (1) mean value, (2) standard deviation.

\section{Discussion with Conclusions}

There are many linguistic and cultural misunderstandings between health professionals and patients who migrated to Slovenia and origin from different cultural backgrounds. All this contributes to poorer access to healthcare services and lower quality of healthcare, poses a risk to patient safety and creates a sense of dissatisfaction with everyone involved in healthcare. Accordingly, it is very important that health professionals develop knowledge and appropriate relationships and skills in the field of cultural competencies for the treatment of people from other cultural and linguistic environments (see http://multilingualhealth.ff.uni-lj.si).

The authors of this study believe that development of cultural competen- 
cies is an ongoing process and an important part of every health-oriented study program, including the program of midwifery. It coincides with other authors who outlined cultural competency as not something static and definite, but rather an ongoing ever-changing process or a journey (Bofulin et al., 2016; Campinha-Bacote, 2007; Camplin-Welch \& Lim, 2018). According to the results of our study, student midwives showed the current midwifery study program is adopting a culturally sensitive approach. Moreover, it equips student midwives with the knowledge and practical implementation of culturally sensitive midwifery care by providing a midwifery curriculum that embeds different aspects of cultural competencies. Although the results of this study show that the existing midwifery study program enhances the students' knowledge on multiculturalism, it is still questionable whether newly graduated midwives incorporate this knowledge into their practice. According to the answers from student midwives, midwifery teachers are appropriately addressing the multicultural midwifery practice and have been considered as role models for the majority of students. It might be that indirect teaching (using good examples) truly is a way students can successfully learn cultural sensitivity. Another positive aspect was also the recognition of students to find some external resources in case they do not know the patient's culture in enough detail. Moreover, student midwives do not feel uncomfortable with providing midwifery care to persons from different cultural background. In the context of midwifery education, Rew et al. (2003) pointed out the importance of midwifery teachers' cultural competencies that help them recognize their students' needs, understand how students from different cultural or ethnic backgrounds may experience the learning environment, incorporate diverse cultural and social perspectives into the curriculum and apply a variety of teaching methods to more effectively accommodate learning styles of students from different backgrounds. By setting an example, a culturally competent midwifery teacher strives to help students move on the cultural competency continuum themselves (Rew et al., 2003).

Although the past findings showed that the Slovene curriculum lacked specific information on cultural competencies, this study is important as it firstly addressed the self-assessment of midwifery students regarding their cultural awareness and secondly revealed a predominance of high levels of cultural awareness among the students. We recognise there is an increasing need for further development of cultural awareness among health professionals, which potentially includes specific, culturally sensitive updates of study curriculums, including in the field of midwifery. Becoming culturally competent is firstly a journey of self-reflection upon the components of one's 
own culture and understanding how cultural differences influence effective interaction, and secondly it is gaining knowledge and learning certain skills to function effectively as an individual within the context of the cultural beliefs, behaviours, and needs of others. In a healthcare context, cultural competency is an essential component in providing effective and culturally responsive care to clients. Every patient should be treated as an individual and there may be several ways to achieve competent interaction (Camplin-Welch \& Lim, 2018). As outlined by Campinha-Bacote (2007), the midwife's level of cultural competency is positively and directly related to positive maternal and neonatal outcomes. Acknowledging this, we as midwifery teachers will strive to enable student midwives to become health professionals who provide culturally sensitive care to patients.

We are aware our study has some limitations as it could include a larger sample of student midwives. Moreover, it would be reasonable to perform a longitudinal study and research how cultural competencies evolve from the period of students' enrolment in the midwifery study program upon the graduation. Nevertheless, more effort needs to be invested at the state level into cultural competencies in midwifery. Amendments of the study program with the culturally sensitive contents using national guidelines (Nacionalni inštitut za javno zdravje, 2016) and international recommendations (International Confederation of Midwives, 2013) would be necessary. Besides the existing documents (Nacionalni inšitut za javno zdravje, 2016), there is a need to prepare more documents that will help health professionals provide healthcare to people from different cultural backgrounds. There is also a need to organise more educational workshops on cultural awareness for health professionals and to help implement the theoretical knowledge into practice in all healthcare institutions.

\section{References}

Bofulin, M., Farkaš Lainščak, J., Gosenca, K., Jelenc, A., Keršič Svetel, M., Lipovec Čebron, U., Pistotnik, S., Škraban, Š., \& Zaviršek, D. (2016). Kulturne kompetence in zdravstvena oskrba: priročnik za razvijanje kulturnih kompetenc zdravstvenih delavcev. Ljubljana, Slovenia: Nacionalni inštitut za javno zdravje.

Bombač, L., Brecelj Š., Liberšar H., \& Zelko E. (2017). Zdravstvena obravnava in oskrba prosilcev za mednarodno zaščito ter delo v okviru projekta. In $\mathrm{H}$. Liberšar (Ed.), Zdravstvena obravnava prosilcev za mednarodno zaščito (pp. 32-38). Ljubljana: Slovenska filantropija.

Briscoe, L. (2013). Becoming culturally sensitive: A painful process? Midwifery, 29(6), 559-565. 
Campinha-Bacote, J. (2007). The process of cultural competence in the delivery of healthcare services: A culturally competent model of care (5th ed.). Cincinnati, $\mathrm{OH}$ : Transcultural C.A.R.E. Associates.

Camplin-Welch, V., \& Lim, S. (2018). Cross-cultural resource for health practitioners (2nd ed.). Auckland: WDHB.

Hofstede, G., Hofstede G. J., \& Minkov M. (2010). Cultures and organizations: Software of the mind. London, England: McGraw-Hill.

International Confederation of Midwives. (2013). Essential competencies for basic midwifery practice. Retrieved from http://internationalmidwives.org/ what-we-do/education-coredocuments/essential-competencies-basic -midwifery-practice/

Kulovec, J. (2012). Health of female immigrants in Slovenia (Undergraduate thesis). University of Ljubljana, Ljubljana.

Lipovec Čebron, U. (2017). O pomenu vpeljevanja medkulturne mediacije v zdravstvene ustanove v Sloveniji. In H. Liberšar. (Ed.), Zdravstvena obravnava prosilcev za mednarodno zaščito (pp. 54-60). Ljubljana: Slovenska filantropija.

Loredan, I., \& Prosen, M. (2013). Kulturne competence medicinskih sester in babic. Obzornik zdravstvene nege, 47(1), 83-89.

Nacionalni inšitut za javno zdravje. (2016). Kulturne kompetence in zdravstvena oskrba: priročnik za razvijanje kulturnih kompetenc zdravstvenih delavcev. Ljubljana: Inštitut za javno zdravje.

New Zealand College of Midwives. (2015). Midwives handbook for practice (5th ed.). Christchurch, New Zealand: Authors.

Rew, L., Becker, H., Cookston, J., Khosropour, S., \& Martinez, C. (2003). Measuring cultural awarness in nursing students. Journal of Nursing Education, 42(6): 249-257.

Spencer-Oatey, H. (2008). Culturally speaking: Culture, communication and politeness theory (2nd ed.). London, England: Continuum.

Spencer-Oatey, H. (2012). What is culture? A compilation of quotations. GlobalPAD Core Concepts. GlobalPAD Open House. Retrieved from https:// warwick.ac.uk/fac/soc/al/globalpad/openhouse/interculturalskills/global _pad_-what_is_culture.pdf

Stanek Zidarič, T., Mivšek, A. P., \& Skoberne, M. (2011). Babištvo: visokošolski strokovni študijski program prve stopnje (2nd ed.). Ljubljana, Slovenija: Zdravstvena fakulteta.

S. Ličen, I. Karnjuš, \& M. Prosen (Eds.). (2019). Women, migrations and health: Ensuring transcultural healthcare (pp. 199-209).

Koper, Slovenia: University of Primorska Press.

https://doi.org/10.26493/978-961-7055-43-6.199-209 



\section{Sintesi}

\section{Le migrazioni di genere e l'integrazione sociale dei migranti in Slovenia Karmen Medica}

Nel capitolo vengono messe a confronto alcune questioni attuali nel attuale contesto migratorio, sia a livello regionale (area di confine sloveno-italiana) che globale. In particolare, per quanto riguarda il contesto dell'UE, I'enfasi è posta sui problemi di integrazione, da una parte, e sulla situazione della sicurezza, dall'altra. Le donne sono sempre state molto coinvolte nel mantenimento delle loro famiglie e comunità, oggi invece sono presenti i processi della «femminilizzazione delle migrazioni» e della «femminilizzazione della sopravvivenza». Entrambe le voci sottolineano l'aumento di forme pubbliche e sempre più visibili del contributo delle donne alle famiglie, allo stato e alla società (emigrata e immigrata) e, in particolare, la crescente domanda mondiale dei loro servizi. Sebbene le donne siano sempre state migranti, lo sviluppo negli ultimi decenni ha confermato non solo la loro presenza nei flussi migratori, ma anche il loro riconoscimento come migranti. Le esperienze delle immigrate moderne in Slovenia non riflettono pienamente tutti gli effetti della discriminazione di genere, della stratificazione degli immigrati e dell'influenza di politiche di immigrazione mutevoli e, in molti casi, caotiche. Uno degli elementi essenziali della loro integrazione interattiva è legato al loro status sociale, all'occupazione e allo stato di salute.

\section{La salute sessuale e riproduttiva come indicatore dell'integrazione sociale: I'ostacolo di una cultura patriarcale e i matrimoni forzati nelle comunità dei migranti \\ Ornella Urpis}

La struttura patriarcale della famiglia è il paradigma delle relazioni umane in molte parti del mondo. In queste società le relazioni si strutturano sulla rigida separazione dei sessi e sulla diversa capacità di empowerment di uomini e donne. Nei processi migratori le lealtà al modello tradizionale della famiglia patriarcale spesso rimangono invariate. Le dinamiche migratorie si intrecciano alle strategie matrimoniali delle famiglie o delle comunità, e il mantenimento di certe pratiche tradizionali, fra cui il matrimonio forzato, diventa funzionale al mantenimento dei confini dell'identità e al sistema sociale «tradizionale». Osservare la salute sessuale e riproduttiva delle donne può diventare un buon indicatore di integrazione delle comunità culturali poiché rivela le capacità di 
autonomia e autodeterminazione delle donne, condizione fondamentale per il riconoscimento dei loro diritti e di identificazione con i modelli e con i valori della società democratica. L'accesso delle donne alle strutture sanitarie e del territorio, gli aborti ripetuti, la presenza di ripetute malattie sessuali, la conoscenza della pianificazione familiare, la conoscenza della lingua del Paese di accoglienza, le capacità di autonomia e di scelta sulla riproduzione, l'abbandono dei comportamenti di sottomissione alle tradizioni (matrimoni endogamici, matrimoni forzati e mutilazioni dei genitali femminili) sono tutti indicatori utili per comprendere il grado di inclusione sociale delle donne e di integrazione delle comunità nel paese di accoglienza.

\section{La salute riproduttiva delle donne migranti in Slovenia: gli ultimi dati Blaž Lenarčič e Mateja Sedmak}

Questo capitolo è un quadro di valutazione in materia della salute riproduttiva delle donne migranti in Slovenia. A tale scopo vengono prima presentate le caratteristiche demografiche e socioeconomiche delle migranti, una rassegna della legislazione nazionale che regola l'ambito della salute riproduttiva delle donne (migranti), una panoramica delle fonti e ricerche svolte in questo ambito nonché una presentazione di buone pratiche. I dati relativi al numero delle migranti in Slovenia mostrano che il loro numero è in costante aumento (sestuplicato tra il 1995 e 2016), e si prevede che questa tendenza continui anche in futuro. Allo stesso tempo notiamo l'assenza di un approccio globale e sistematico alla salute riproduttiva delle migranti. La panoramica delle fonti e delle buone pratiche porta alla conclusione che una delle pietre miliari in questo processo è proprio l'educazione interculturale del personale sanitario con l'obiettivo di riconoscere le norme e pratiche della salute riproduttiva in contesti culturali diversi. In questo modo il personale sanitario garantirebbe alle migranti un'assistenza sanitaria, educazione e promozione della salute culturalmente adeguate migliorando così il loro accesso alla salute riproduttiva.

\section{Lavoro su dati epidemiologici: problemi incontrati e esperienze acquisite Giovanni Delli Zotti}

Il Progetto INTEGRA, oltre all'analisi epidemiologica dei ricoveri ospedalieri e dei servizi ambulatoriali, prevede lo sviluppo di un indice di salute sessuale e riproduttiva che mira a identificare le situazioni a rischio o che richiedono interventi «mirati». Ciò implica la necessità di identificare indicatori adatti, le cui caratteristiche sono descritte nella prima parte dell'articolo, con riferimento alle esigenze specifiche del Progetto INTEGRA. Segue una discussione sulla distinzione tra indicatori di micro e macro livello e viene illustrata qualche esemplificazione. Alcuni problemi riscontrati analizzando le Schede di Dimissione Ospedaliera sono poi illustrati e vengono proposte alcune soluzioni. Un tema specifico affrontato riguarda le implicazioni del passaggio da database 
che utilizzano il «ricovero ospedaliero» come unità di analisi ad archivi di dati basati sull'unità di analisi «paziente».

\section{L'infezione da papillomavirus umano e il cancro al collo dell'utero tra le migranti e le profughe}

Andrej Cör

Il cancro al collo dell'utero, conseguenza primaria dell'infezione con il papilloma virus umano (HPV), causa ogni anno la morte di 266.000 donne in tutto il mondo. Strategie efficaci hanno fatto sì che in Slovenia l'incidenza e la mortalità a causa della malattia siano in calo, grazie soprattutto al programma di screening ZORA. Tuttavia, il cancro al collo dell'utero rimane ancora un problema sanitario importante per le immigrate e le profughe. Tra quelle che provengono dai paesi della fascia di reddito bassa e medio-alta, la diffusione dell'infezione e di conseguenza anche il rischio di contrarre la malattia, risulta superiore rispetto alle donne nata in Slovenia. I fattori essenziali riconducibili ad un aumento del rischio sono lo scarso coinvolgimento delle immigrate nei programmi di screening e una minor adesione alle vaccinazioni. I dati raccolti nei paesi occidentali dimostrano che tra le bambine profughe il grado di immunizzazione contro I'HPV risulta significativamente inferiore rispetto a quelle nate in Occidente. Pertanto risulta necessario che tutti i soggetti interessati del settore sanitario comprendano le barriere socio-culturali, in merito all'inclusione nei programmi di vaccinazione e screening di tutte le immigrate e profughe, garantendo loro una copertura sanitaria completa.

\section{L'uso dei metodi contracettivi moderni tra le migranti in Slovenia Igor Karnjuš, Mirko Prosen, Urška Bogataj, Doroteja Rebec e Sabina Ličen}

L'uso della moderna contraccezione può essere limitato tra i migranti a causa di vari fattori, quali la scarsa conoscenza della lingua, la situazione socioeconomica precaria o la scarsa conoscenza della contraccezione stessa. Per la Slovenia, non ci sono dati disponibili sui fattori che influenzano l'uso della moderna contraccezione tra i migranti o sono molto scarsi. L'indagine ha incluso 52 donne migranti che tra marzo e settembre 2018 sono state curate in un ospedale regionale sloveno per malattie femminili e ostetricia. I dati sono stati raccolti utilizzando un questionario che includeva domande relative alla salute sessuale e riproduttiva. È stata utilizzata un'analisi bivariata (coefficiente di correlazione di Spearman e test di Hi-square) per determinare la relazione tra variabili indipendenti e l'uso di metodi di contraccezione. I risultati dello studio hanno mostrato due fattori principali che influenzano l'uso della contraccezione: (a) le donne immigrate che hanno maggiore conoscenza dei metodi moderni di contraccezione sono anche più propense ad usarli ( $r=0.69$; $p<0.05$ ); (b) se il partner/marito ha un atteggiamento positivo verso l'uso dei contraccettivi moderni, c'è una maggiore probabilità che le donne immigrate li 
usino $\left(\chi^{2}=14.465 ; p=0.001\right)$. Sulla base dei risultati ottenuti, si può concludere che bisognerebbe porre maggiore enfasi sull'educazione dei migranti, sia uomini che donne, sulla salute sessuale e riproduttiva, in particolare per quanto riguarda l'uso della moderna contraccezione.

\section{L'esperienza dei migranti con il sistema sanitario}

\section{Marie-Louise Luiking, Birgit Heckermann e Harshida Patel}

Le migrazioni di massa in Europa sollevano molte questioni di importanza sociale. I migranti affrontano gravi problemi di salute legati alle cause e alle conseguenze delle migrazioni. Oggi non trattiamo solo questioni relative ai migranti che hanno bisogni, preoccupazioni e sfide di salute in sé. L'effetto delle differenze linguistiche e culturali, la mancanza di accesso a trasporti adeguati e altri ostacoli sono molto comuni. Questi ostacoli impediscono agli infermieri e altri operatori sanitari di garantire un'assistenza sanitaria di alta qualità. Una dimensione essenziale nella qualità dell'assistenza sanitaria che riflette le aspettative dei pazienti e la loro esposizione è l'esperienza dei pazienti migranti nell'assistenza sanitaria. Questo capitolo tratta i fattori legati all'esperienza sanitaria dei migranti nel paese ospitante. Il modello presentato può facilitare la sensibilizzazione degli infermieri professionisti per fornire l'assistenza incentrata sul paziente e superare le differenze transculturali.

\section{I problemi attuali e le opportunità di miglioramento dell'assistenza sanitaria alle migranti in Slovenia \\ Urška Bogataj, Mirko Prosen, Igor Karnjuš, Doroteja Rebec e Sabina Ličen}

Lo scopo della ricerca era di studiare il processo di integrazione sociale delle donne migranti in termini di salute riproduttiva in relazione al sistema di assistenza sanitaria vigente in Slovenia. La presente indagine include 52 donne migranti che sono state curate alla Clinica per malattie femminili e ostetricia nel periodo da marzo a settembre 2018. I dati sono stati ottenuti con un questionario, che comprendeva anche domande relative alle competenze linguistiche e agli ostacoli legati alla comunicazione, nonché alle questioni di discriminazione e violenza. Sono state utilizzate le statistiche descrittive di base e i risultati sono stati mostrati in frequenze e percentuali. In alcune domande a cui le intervistate hanno risposto in modo descrittivo, i risultati vengono presentati in base alla frequenza di occorrenza e alla somiglianza delle singole unità di contenuto. È chiaro che i servizi sanitari svolgono lo stesso ruolo nella prestazione di cure sanitarie sia per i migranti che per il resto della popolazione, e cioè fornire assistenza accessibile e di qualità, attività di promozione della salute ed educazione istruzione. Sulla base dei risultati è evidente che uno dei maggiori problemi percepiti dalle intervistate è la «barriera linguistica», che si riferisce sia alle intervistate che alle utenti del sistema sanitario, nonché alle caratteristiche delle istituzioni sanitarie in Slovenia in generale. In alcuni rari 
casi le intervistate hanno anche riferito di intolleranza da parte del personale sanitario.

\section{Le prospettive delle migranti relative alle questioni della salute riproduttiva e dei loro incontri con il personale sanitario \\ Mirko Prosen, Sabina Ličen, Urška Bogataj, Doroteja Rebec e Igor Karnjuš}

A causa delle migrazioni le donne sono esposte a maggiori rischi e diseguaglianze nell'ambito della sanità. Il personale sanitario deve identificare, dare priorità e affrontare le esigenze delle donne, come pure i rischi sanitari in modo olistico. L'articolo descrive le esperienze delle migranti con il sistema sanitario e mette in risalto il loro parere riguardo alla salute riproduttiva all'interno del sistema nel paese ospitante. La ricerca si basa su un approccio descrittivo qualitativo utilizzando il metodo di analisi del contenuto. Il campione include dieci migranti ospedalizzate in uno dei reparti maternità in Slovenia. L'analisi verte su due temi: (1) le esperienze, le aspettative e gli ostacoli in diversi sistemi sanitari, e (2) l'influenza che hanno comportamenti culturalmente specifici sulla salute riproduttiva delle donne. La maggioranza delle donne intervistate era dell'opinione di aver ricevuto un'assistenza sanitaria culturalmente sensibile, sebbene la barriera linguistica avesse comportato l'ostacolo maggiore nell'accesso ad essa. Le donne hanno valutato la migrazione come un fattore liberatorio dal punto di vista della salute riproduttiva e sessuale. II personale sanitario deve essere a conoscenza delle pratiche culturalmente specifiche legate alla salute, dato che alcune di loro sono risultate dannose. Per questo motivo in futuro si prevedono interventi mirati alla loro eliminazione.

\section{Salute monolingue? Le barriere linguistiche nella sanità slovena vissute dalle migranti/profughe}

Uršula Lipovec Čebron, Lea Bombač, Nike Kocijančič Pokorn e Miha Lučovnik

L'obiettivo del presente contributo è identificare i principali ostacoli nel campo della ginecologia e dell'ostetricia causati dalle barriere linguistiche che intercorrono tra le immigrate e le profughe da una parte e i lavoratori sanitari dalI'altra. Le suddette barriere sono state individuate in base a una ricerca qualitativa durata da maggio 2017 a giugno 2018, svolta tra le immigrate/profughe e il personale sanitario in Slovenia. La ricerca ha portato a tre conclusioni principali: primo, le barriere linguistiche sono spesso causate dall'assenza di interpreti/mediatori culturali specialisti; secondo, la mancanza di una formazione che spieghi la dimensione linguistica nell'assistenza sanitaria di qualità fa sì che i lavoratori sanitari non comprendano l'importanza degli interpreti/mediatori culturali; e terzo, le barriere linguistiche con le quali le immigrate/profughe si scontrano rendono più difficile l'accesso ai loro diritti alla salute, inclusi i diritti nell'ambito della salute riproduttiva. Questi ostacoli impediscono al sistema della sanità sloveno di assicurare una comunicazione di qualità con le im- 
migrate/profughe e garantisca loro un'assistenza adeguata il che può causare diseguaglianza nell'accesso alle cure sanitarie degli stranieri.

\section{Quando la lingua e la cultura interferiscono: la salute sessuale e riproduttiva delle donne migranti nell'area del Litorale sloveno Zorana Medarić e Mateja Sedmak}

II presente capitolo intende presentare e discutere il campo della salute riproduttiva delle donne migranti, ponendo l'accento sulle loro prospettive e su quelle degli operatori sanitari (medici, ostetriche, infermiere, ecc.) e riguardanti le pratiche esistenti, le differenze interculturali, l'accesso ai servizi di salute riproduttiva, ecc. Nel capitolo discutiamo i risultati dello studio qualitativo, effettuato con delle interviste approfondite che sono state svolte nella regione costiera della Slovenia. Il capitolo presenta diverse questioni emerse dallo studio, incentrate su: (1) barriere linguistiche, (2) competenze interculturali degli operatori sanitari (3) pratiche/attitudini discriminatorie (nascoste) del personale medico, (4) informazioni e accesso di donne migranti ai servizi sanitari e (5) l'importanza che i legami sociali hanno sulla loro salute riproduttiva. Infine, l'articolo propone alcune linee guida per ulteriori interventi in questo settore.

\section{Le competenze culturali nell'assistenza sanitaria e il loro influsso sulla qualità delle cure ai pazienti di gruppi culturalmente diversificati: analisi sistematica della bibliografia}

Sabina Ličen, Igor Karnjuš, Urška Bogataj, Doroteja Rebec e Mirko Prosen

Con l'aumento delle diversità culturali in Slovenia, il bisogno di competenze culturali nei servizi sanitari sta diventando sempre più una necessità impellente. Negli ultimi anni l'argomento di discussione centrale dei servizi sanitari, ma anche della sanità in generale, è proprio lo sviluppo di questa competenza nel personale sanitario. Fino ad oggi in Slovenia non è stato ancora pubblicato un contributo scientifico basato su un'analisi sistematica delle fonti, incentrato sull'effetto che servizi sanitari culturalmente adeguati hanno sulla qualità di assistenza nei pazienti facenti parte di gruppi minoritari. Un'analisi sistematica delle fonti è stata svolta nel maggio 2018 con l'intento di ottenere e studiare tutti i dati in base ai quali è possibile valutare l'efficacia di servizi sanitari culturalmente adeguati sulla qualità dell'assistenza ai pazienti appartenenti a gruppi minoritari. La ricerca è stata effettuata in base a determinate parole chiave in inglese e ai loro sinonimi, legati agli operatori Booleani AND (E) e OR (O). L'analisi include tutte le ricerche pubblicate tra il 2000 e maggio 2018. Da un risultato iniziale di 533 occorrenze sono stati inclusi nell'analisi finale 4 studi che adempivano ai criteri. Due di questi hanno provato che l'efficacia dell'educazione culturale si riflette su un miglioramento del comportamento dei pazienti nella cura personale, del tasso di interazione sociale e delle capacità funzionali in generale. Gli altri due studi non comprendevano la descrizione dell'efficacia 
di un servizio sanitario culturalmente adeguato sulla qualità dell'assistenza ai pazienti, ma si concentravano soprattutto sui miglioramenti nell'ambito delle competenze culturali tra infermiere. L'analisi sistematica delle fonti qui presentata ha fatto affiorare una serie di questioni importanti per possibili ricerche future con particolare attenzione a un maggiore rigore metodologico nell'analisi dei corsi di formazione dedicati all'acquisizione di competenze culturali di infermiere e altri lavoratori nella sanità.

\section{Rafforzare la consapevolezza culturale tra gli studenti dell'assistenza sanitaria}

Barbara Donik, Mateja Lorber e Majda Pajnkihar

La consapevolezza culturale del personale infermieristico è di fondamentale importanza per garantire un'assistenza infermieristica di qualità e incentrata sul paziente, pertanto, il suo rafforzamento tra gli studenti di infermieristica è molto importante nel campo dello sviluppo delle competenze culturali. Misurando la consapevolezza culturale e coinvolgendo gli studenti in vari moduli educativi nel campo dell'assistenza transculturale, è possibile influire sulla loro consapevolezza e sensibilità culturale. Lo scopo della ricerca era di determinare il livello di consapevolezza culturale tra gli studenti di infermieristica. È stato usato un approccio di ricerca quantitativo, all'interno del quale è stato effettuato un sondaggio descrittivo trasversale. Per misurare la sensibilità culturale (CAS) tra gli studenti di infermieristica è stato usato il metodo di indagine del questionario, per l'elaborazione e l'analisi dei dati sono stati utilizzati invece metodi statistici descrittivi e inferenziali. I risultati hanno mostrato un livello moderato di consapevolezza culturale. Si è arrivati alla conclusione che le studentesse di infermieristica hanno, in media, valutato la consapevolezza culturale leggermente più alta degli studenti, e in particolare, la differenza nella valutazione legata al genere si riflette nella valutazione della dimensione: sapere/agio nelle interazioni. L'interconnessione delle singole dimensioni che misurano la consapevolezza culturale è risultata essere per lo più positiva. Al fine di garantire lo sviluppo delle competenze culturali nell'assistenza sanitaria, è necessario cominciare lo studio e l'acquisizione delle competenze culturali già durante i corsi di studi, poiché proprio l'istruzione nel campo delle competenze culturali rappresenta una strategia per migliorare le conoscenze, le relazioni e le competenze degli studenti di infermieristica.

\section{Un'assistenza ostetrica culturalmente efficace per le future madri migranti: come può un buon corso di studi per l'assistenza ostetrica preparare i laureandi}

Ana Polona Mivšek, Nastja Pavel, Mateja Kusterle e Petra Petročnik

Non ci sono dati precisi sul numero di donne appartenenti a culture diverse a cui ogni anno viene garantita l'assistenza nella fase pre-, durante e post-parto. 
Tuttavia, nell'anno passato, visto il grande aumento del numero di migranti in Slovenia, ci si è dovuti confrontare con situazioni in cui è stato di fondamentale importanza offrire cure ostetriche non soltanto di qualità, ma soprattutto culturalmente sensibili. Gli studi di ostetricia all'estero danno molta importanza alle competenze culturali dei laureati. In Slovenia non è ancora stata fatta una valutazione del percorso di studi da questo punto di vista. Per questo motivo le autrici hanno effettuato una ricerca in cui è stato determinato il grado di sensibilità culturale dei laureandi di ostetricia attraverso l'uso della scala CAS (Cultural Awareness Scale). Un'analisi del programma di studio fa affiorare la mancanza di informazioni specifiche sulle competenze culturali. Ciò nonostante, gli studenti indagati hanno dimostrato un alto livello di sensibilità culturale. I docenti di ostetricia sono stati valutati come esempi di buone pratiche il che può portare alla conclusione che l'apprendimento indiretto della sensibilità culturale tramite buone pratiche possa dare altrettanto buoni risultati. 


\section{Povzetki}

\section{Migracija po spolu in socialna integracija migrantov v Sloveniji}

Karmen Medica

V poglavju soočamo nekatere aktualnosti iz sodobnega migrantskega konteksta, na regionalni (slovensko-italijansko obmejno območje) in na globalni ravni. Predvsem kadar gre za kontekst EU, je poudarek na vprašanjih integracije na eni in varnostne situacije na drugi strani. Ženske so bile vedno močno vključene v preživljanje svojih družin in skupnosti, danes pa je zelo prisoten proces »feminizacije migracij« in ravno tako »feminizacije preživetja«. Obe postavki poudarjata vedno bolj javne in vidne oblike prispevka žensk k družinam, prispevek k državi in družbi (emigrantski in imigrantski) in še posebej vse večje svetovno povpraševanje po njihovih storitvah. Čeprav so ženske od nekdaj tudi migrantke, je razvoj $v$ zadnjih desetletjih potrdil ne samo njihovo prisotnost v migracijskih tokovih, ampak tudi priznanje njih kot migrantk. Sodobne izkušnje priseljenk v Sloveniji ne izražajo v celoti vseh učinkov spolnega razlikovanja, stratifikacije priseljencev ter vpliva spremenljivih in v mnogih primerih kaotičnih politik priseljevanja. Eden bistvenih elementov njihove interaktivne integracije je povezan z njihovim socialnim statusom, zaposlitvijo in zdravstvenim stanjem.

\section{Spolno in reproduktivno zdravje kot kazalnik socialne integracije: ovira za patriarhalno kulturo in prisilne poroke v priseljenskih skupnostih \\ Ornella Urpis}

V mnogih predelih sveta je patriarhalna družinska ureditev osrednja paradigma medčloveških odnosov. V takšnih družbah so medosebni odnosi strukturirani na rigidni ločnici med spoloma in različni sposobnosti opolnomočenja moških in žensk. V migracijskih procesih pripadnost tradicionalnemu modelu patriarhalne družine običajno ostaja nespremenjena. Migracijska dinamika, prepletena s poročnimi strategijami družin ali skupnosti in ohranjanjem določenih tradicionalnih praks, vključno s prisiljenimi porokami, postane funkcionalna z vzdrževanjem meja identitete in »tradicionalnih« družbenih sistemov. Opazovanje spolnega in reproduktivnega zdravja žensk prispeva k oblikovanju dobrega indikatorja integracije kulturnih skupin, ker razkriva stopnjo avtonomije in samodoločenosti žensk, kar je temeljni pogoj za priznanje njihovih pravic in identifikacijo z modeli in vrednotami demokratične družbe. 
Dostop žensk do zdravstvenih in drugih ustanov, pogoste umetne prekinitve nosečnosti, pogoste spolno nalezljive bolezni, znanje o načrtovanju družine, znanje jezika v državi gostiteljici, avtonomija in svoboda glede reprodukcije, opustitev tradicionalnih praks (endogamija, prisiljene poroke in pohabljanje ženskih spolnih organov) so vse koristni indikatorji, ki pripomorejo k razumevanju stopnje socialne vključenosti žensk in integracije v skupnost v državi gostiteljici.

\section{Reproduktivno zdravje migrantk v Sloveniji}

Blaž Lenarčič in Mateja Sedmak

Poglavje predstavlja pregled stanja na področju reproduktivnega zdravja migrantk v Sloveniji. S tem namenom so najprej predstavljeni demografske in socio-ekonomske značilnosti migrantk, pregled nacionalne zakonodaje, ki regulira področje reproduktivnega zdravja (imigrantskih) žensk, pregled znanstvene literature in raziskav, ki obravnavajo to področje, ter predstavitev dobrih praks. Podatki o številu migrantk v Sloveniji nakazujejo nenehno povečanje (šestkratni porast med letoma 1995 in 2016), za katerega se pričakuje, da se bo nadaljevalo tudi v bodoče. Istočasno smo priča odsotnosti celovitega in sistematičnega pristopa $\mathrm{k}$ reproduktivnemu zdravju migrantk. Pregled literature in dobrih praks nakazuje, da ključni korak k izboljšanju stanja na tem področju predstavlja interkulturno izobraževanje zdravstvenih delavcev s ciljem prepoznavanja reproduktivnih zdravstvenih norm in praks v različnih kulturnih kontekstih. S tem bi zdravstveni delavci migrantkam zagotovili s kulturnega vidika primerno zdravstveno oskrbo, zdravstveno vzgojo, promocijo zdravja in nenazadnje povečali dostop do reproduktivnega zdravja.

\section{Delo z epidemiološkimi podatki: težave, ki so se pojavljale, in pridobljene izkušnje Giovanni Delli Zotti}

Projekt INTEGRA, poleg epidemiološke analize bolnišničnih sprejemov in ambulantnih obravnav migrantk, predvideva razvoj dodatnega kazalca spolnega in reproduktivnega zdravja, ki bi omogočil lažjo identifikacijo tveganih situacij oz. situacij, ki zahtevajo ciljane intervencije. To zahteva opredelitev ustreznih kazalnikov, katerih značilnosti so opisane v prvem delu članka, v povezavi s specifičnimi zahtevami projekta INTEGRA. Temu sledi razprava o razlikah med kazalniki mikro in makro nivojev, ponazarjamo pa tudi nekaj primerov. Sledi prikaz nekaterih težav s katerimi smo se srečali med analizo bolnišnične odpustne dokumentacije, ter predlog možnih rešitev. Ena izmed težav, ki so se pojavile, je bil prehod iz zbirk podatkov »hospitalizacija« kot enote analize na arhiv podatkov, ki temelji na »pacientu« kot enoti analize. 


\section{Okužba s papiloma virusom in rak materničnega vratu pri imigrantkah in begunkah Andrej Cör}

Rak materničnega vratu, ki je primarno posledica okužbe s humanim papilomavirusom (HPV) je vsako leto vzrok smrti 266.000 žensk po vsem svetu. V Sloveniji so učinkovite strategije, zlasti presejalni program ZORA, znatno zmanjšale pojavnost in smrtnost zaradi raka materničnega vratu, vendar pa je rak materničnega vratu še vedno pomemben zdravstveni problem za priseljenke in begunke. Pri priseljenkah iz držav z nizkimi in s srednje velikimi dohodki je razširjenost okužbe s HPV večja kot pri ženskah, rojenih v Sloveniji, s tem pa je posledično tudi tveganje za raka materničnega vratu večje. Ključna dejavnika za tako povečano tveganje sta slabša vključenost begunk v presejalne programe ter njihova manjša odzivnost na cepljenje proti HPV. Podatki iz zahodnih držav kažejo, da je pri deklicah begunkah stopnja imunizacije proti HPV znatno nižja v primerjavi z deklicami, rojenimi v zahodnih državah. Zato je nujno, da vsi deležniki v zdravstvu razumejo socialno-kulturne ovire za vključevanje v program cepljenja in presajanja za HPV, s čimer bi zagotovili celovito zdravstveno varstvo vsem migrantkam in begunkam.

\section{Uporaba sodobnih kontracepcijskih metod med migrantkami, ki živijo v Sloveniji \\ Igor Karnjuš, Mirko Prosen, Urška Bogataj, Doroteja Rebec in Sabina Ličen}

Uporaba sodobne kontracepcije je med migranti lahko omejena zaradi različnih dejavnikov, kot so slabo poznavanje jezika, slabo socialno-ekonomsko ozadje ali nezadostno znanje o kontracepciji. Za Slovenijo podatkov o dejavnikih, ki vplivajo na uporabo sodobne kontracepcije med migrantkami, nimamo oz. so ti zelo pomanjkljivi. $V$ raziskavo je bilo vključenih 52 migrantk, ki so bile med marcem in septembrom 2018 obravnavane v eni slovenski regionalni bolnišnici za ženske bolezni in porodništvo. Podatki so bili zbrani s pomočjo vprašalnika, ki je vključeval vprašanja povezana s spolnim in z reproduktivnim zdravjem. Uporabljena je bila bivariantna analiza (Spearmanov koeficient korelacije in test $\chi^{2}$ ), s katero smo ugotavljali povezanost med neodvisnimi spremenljivkami in uporabo kontracepcijskih metod. Rezultati raziskave so pokazali na dva glavna dejavnika, ki vplivata na uporabo kontracepcije: (a) migrantke, ki so bolj seznanjene s sodobnimi metodami kontracepcije: jo tudi pogosteje uporabljajo $(r=0.69 ; p<0.05)$; (b) v kolikor ima partner/mož pozitiven odnos do uporabe sodobnih kontracepcijskih sredstev, obstaja večja verjetnost, da jih bodo migrantke tudi uporabljale $\left(\chi^{2}=14.465 ; p=0.001\right)$. Na podlagi pridobljenih rezultatov bi bilo potrebno dajati večji poudarek izobraževanju migrantov, tako žensk kot moških, o spolnem in reproduktivnem zdravju, zlasti glede uporabe sodobne kontracepcije. 


\section{Izkušnje migrantov v sistemu zdravstvene oskrbe}

Marie-Louise Luiking, Birgit Heckermann in Harshida Patel

Množične migracije v Evropi sprožajo številna vprašanja družbenega pomena. Migranti se borijo s kompleksnimi zdravstvenimi težavami, povezanimi z vzroki in s posledicami migracij. Danes ne govorimo le o vprašanjih, povezanih z migranti, ki imajo edinstvene zdravstvene potrebe, skrbi in izzive. Učinek jezikovnih in kulturnih razlik, pomanjkanje dostopa do ustreznega prevoza in druge ovire so zelo pogosti. Te ovire ovirajo medicinske sestre in druge zdravstvene delavce pri zagotavljanju visokokakovostne zdravstvene nege in oskrbe. Bistvena razsežnost kakovosti zdravstvene nege, ki odraža pričakovanja pacientov in njihovo izpostavljenost, je izkušnja pacientov migrantov pri zdravstvenem varstvu. To poglavje obravnava dejavnike, povezane z izkušnjami migrantskega zdravstvenega varstva v državi gostiteljici. Tu predstavljeni model lahko olajša ozaveščanje strokovnjakov s področja zdravstvene nege v smeri zagotovitve oskrbe, usmerjene v osebo, in premagovanja transkulturnih razlik.

\section{Aktualna vprašanja in možnosti za izboljšanje zdravstvene oskrbe migrantk v Sloveniji \\ Urška Bogataj, Mirko Prosen, Igor Karnjuš, Doroteja Rebec in Sabina Ličen}

Namen raziskave je bil preučiti proces socialne intergracije žensk migrantk z vidika njihovega reproduktivnega zdravja glede na obstoječi sistem zdravstvenega varstva v Sloveniji. Pričujoča raziskava vključuje 52 žensk migrantk, ki so se $v$ obdobju od marca do septembra 2018 zdravile v Bolnišnici za ženske bolezni in porodništvo. Podatki so bili pridobljeni z vprašalnikom, ki med drugim vključuje tudi vprašanja o znanju jezika in ovirah, povezanih s komuniciranjem, pa tudi vprašanja o diskriminaciji in nasilju. Uporabljena je bila osnovna deskriptiva statistika, rezultati pa so prikazani v frekvencah in odstotkih. Pri določenih vprašanjih, kjer so anketirane odgovarjale opisno, so rezultati predstavljeni glede na pogostost pojavljanja in sorodnost posameznih vsebinskih enot. Dejstvo je, da imajo zdravstvene službe v zagotavljanju zdravstvene oskrbe migrantov enako vlogo, kot jo imajo pri preostali populaciji ljudi, tj. zagotavljanje dostopne in kakovoste oskrbe, izvajanje aktivnosti promocije zdravja in izobraževanje. Na podlagi rezultatov je razvidno, da je ena od največjih težav, ki jih anketirane zaznavajo, »jezikovna ovira«, nanašajoča se tako na anketiranke kot na uporabnike sistema zdravstvenega varstva kot tudi na značilnosti zdravstvenih institucij v Sloveniji na splošno. $V$ redkih primerih so anketiranke poročale tudi o nestrpnosti s strani zdravstvenih delavcev. 


\section{Perspektive migrantk glede vprašanj, povezanih z reproduktivnim zdravjem in njihovimi zdravstvenimi srečanji \\ Mirko Prosen, Sabina Ličen, Urška Bogataj, Doroteja Rebec in Igor Karnjuš}

Zaradi migracije so ženske izpostavljene večjim zdravstvenim tveganjem in neenakostim v zdravju. Zdravstveni delavci morajo identificirati, prioritizirati in nasloviti potrebe žensk kot tudi zdravstvena tveganja na holističen način. Poglavje opisuje izkušnje migrantk z zdravstvenim sistemom ter specifično izpostavlja njihove poglede na reproduktivno zdravje znotraj tega sistema v državi gostiteljici. V raziskavi je bil uporabljen deskriptivni kvalitativni pristop z uporabo metode analize vsebine. Namenski vzorec je vključeval 10 hospitaliziranih migrantk $v$ eni izmed slovenskih porodnišnic. V analizi sta bil identificirani dve temi: (1) izkušnje, pričakovanja in ovire različnih zdravstvenih sistemov, (2) vpliv na kulturi zasnovanih vedenj na reproduktivno zdravje žensk. Večina intervjuvank je bila mnenja, da so bile deležne kulturno dovzetne zdravstvene oskrbe, čeprav je jezikovna bariera predstavljala največjo oviro pri dostopanju do zdravstvene oskrbe. Migracija je bila z vidika spolnega in reproduktivnega zdravja osvobojujoča za ženske. Zdravstveni delavci morajo poznati kulturno zasnovane prakse, povezane z zdravjem, saj so bile nekatere izmed njih škodljive in so $v$ bodoče potrebne intervencije za njihovo odpravo.

\section{Enojezično zdravje? Jezikovne ovire v slovenskem zdravstvu, kot jih doživljajo migrantke/begunke}

\section{Uršula Lipovec Čebron, Lea Bombač, Nike Kocijančič Pokorn in Miha Lučovnik}

Namen prispevka je identificirati ključne ovire, ki se pojavljajo na področju ginekologije in porodništva med beguntkami/migrantkami in zdravstvenimi delavci/-kami ter so povezane z jezikovnimi problemi. Te ovire so bile identificirane na osnovi kvalitativne raziskave, ki je potekala od maja 2017 do junija 2018 med migrantkami/begunkami in zdravstvenim osebjem v Sloveniji. Na osnovi rezultatov raziskave lahko ugotovimo: prvič, jezikovne ovire so pogosto posledica odsotnosti dostopnih profesionalnih tolmačev/medkulturnih mediatorjev; drugič, pomanjkanje usposabljanj o jezikovnih dimenzijah kakovostne zdravstvene oskrbe povzroča, da se zdravstveno osebje ne zaveda pomena tolmačev/medkulturnih mediatorjev; in tretjič, jezikovne ovire, s katerimi se soočajo migrantke/begunke, otežujejo njihov dostop do zdravstvenih pravic, vključno s pravicami na področju reproduktivnega zdravja. Naštete ovire preprečujejo, da bi slovenski zdravstveni sistem zagotavljal kakovostno komunikacijo z migrantkami/begunkami in jim zagotavljal kakovostno zdravstveno oskrbo, ter lahko povzročajo neenakosti v dostopu do zdravstvene oskrbe za tujejezične uporabnike. 


\section{Ko se jezik in kultura izključujeta: spolno in reproduktivno zdravje migrantk na obalnem območju Slovenije \\ Zorana Medarić in Mateja Sedmak}

V poglavju predstavljamo področje reproduktivnega zdravja migrantk, s poudarkom na stališčih migrantk in zdravstvenega osebja (zdravniki, babice, patronažno osebje itd.) o obstoječih praksah, medkulturnih razlikah, dostopu migrantk do storitev reproduktivnega zdravstvenega varstva in drugem. Predstavljeni temelji na rezultatih kvalitativne študije, poglobljenih intervjujih, izvedenih v obalni regiji. Izpostavljeni so naslednji vidiki: (1) jezikovne ovire, (2) medkulturne kompetence zdravstvenega osebja (3) (prikrite) diskriminatorne prakse/odnosi s strani zdravstvenega osebja, (4) informiranost in dostop do zdravstvenih storitev ter (5) pomen socialnih vezi za reproduktivno zdravje migrantk. V zaključku so predstavljene smernice in priporočila za nadaljnje delovanje na tem področju.

\section{Kulturne kompetence $v$ zdravstveni negi in njihov vpliv na kakovost oskrbe pacientov iz kulturno raznolikih skupin: sistematičen pregled literature}

Sabina Ličen, Igor Karnjuš, Urška Bogataj, Doroteja Rebec in Mirko Prosen

S povečevanjem kulturne raznolikosti prebivalstva Slovenije je potreba po kulturnih kompetencah v zdravstveni negi še kako nujna. Kulturne kompetence med zdravstvenimi delavci so že vrsto let glavna tema razpravljanj tako v zdravstveni negi kot na področju zdravstva na splošno. Na podlagi sistematičnega pregleda literature lahko rečemo, da v Sloveniji do danes še ni nastal prispevek, ki bi se osredotočal na učinek kulturno kompetentne zdravstvene nege pri doseganju kakovosti oskrbe pacientov iz manjšinskih skupin. Sistematičen pregled literature je bil tako opravljen meseca maja 2018, z namenom pridobiti in preučiti vse razpoložljive dokaze, ki ocenjujejo učinkovitost kulturno kompetentne zdravstvene nege na kakovost oskrbe pacientov iz manjšinskih skupin. Iskanje je bilo izvedeno z določenimi angleškimi ključnimi besedami in njihovimi sopomenkami, povezanimi z Boolovima operatorjema AND (IN) oz. OR (ALI). V analizo so bile vključene raziskave, objavljene od leta 2000 do maja 2018. Iz iskalnega nabora 533 zadetkov so bile v končno analizo vključene 4 raziskave, ki so izpolnjevale kriterije. Dve raziskavi sta pokazali, da učinkovitost treningov/izobraževanj na področju kulture kaže na izboljšano vedenje pacienta v okviru samooskrbe, višjo raven socialnega delovanja in izboljšanje splošne funkcionalne zmogljivosti pri pacientih. $V$ drugih dveh raziskavah ni bilo opisananega učinkovanja kulturno kompetentne zdravstvene nege na kakovost oskrbe pacientov in so bile v glavnem opisane izboljšave v okviru kulturnih kompetenc med medicinskimi sestrami. Naš sistematični pregled literature je hkrati razkril več pomembnih vprašanj za prihodnje raziskave; podali smo predlog za večjo metodološko strogost pri raziskovanju treningov/izobraževanj v 
okviru pridobivanja kulturnih kompetenc med medicinskimi sestrami in ostalimi zdravstvenimi delavci.

\section{Krepitev kulturnega zavedanja študentov zdravstvene nege Barbara Donik, Mateja Lorber in Majda Pajnkihar}

Kulturno zavedanje zaposlenih v zdravstveni negi je ključnega pomena za zagotavljanje kakovostne in na posameznika usmerjene zdravstvene nege, zato je krepitev kulturnega zavedanja med študenti zdravstvene nege še kako pomembno na področju razvoja kulturnih kompetenc. Z merjenjem kulturnega zavedanja in vključevanjem študentov $v$ različne izobraževalne module na področju transkulturne zdravstvene nege lahko vplivamo na njihovo kulturno zavedanje in občutljivost. Namen raziskave je bil ugotoviti stopnjo kulturnega zavedanja med študenti zdravstvene nege. Uporabili smo kvantitativni raziskovalni pristop. Izvedli smo deskriptivno presečno raziskavo. Pri anketiranju študentov smo uporabili metodo anketiranja z vprašalnikom za merjenje kulturne občutljivosti (CAS). Za obdelavo in analizo podatkov smo uporabili deskriptivne statistične metode in metode inferenčne statistike. Rezultati so pokazali zmerno raven kulturnega zavedanja študentov zdravstvene nege. Ugotavljamo, da so študentke zdravstvene nege v povprečju kulturno zavedanje ocenile nekoliko višje od študentov zdravstvene nege, še posebej se razlika v oceni med spoloma kaže pri oceni dimenzije: vedenje/udobje $z$ interakcijami. Medsebojna povezanost posameznih dimenzij, ki merijo kulturno zavedanje, je bila večinoma pozitivna. Za zagotavljanje razvoja kulturnih kompetenc $v$ zdravstveni negi je potrebno pričeti s poučevanjem in pridobivanjem kulturnih kompetenc že v času študija, saj prav izobraževanje na področju kulturnih kompetenc predstavlja strategijo za izboljševanje znanja, odnosov in spretnosti študentov zdravstvene nege.

\section{Kulturno uspešna babiška nega za matere migrantke: kako dobro učni načrt za babiško nego pripravlja diplomante}

Ana Polona Mivšek, Nastja Pavel, Mateja Kusterle in Petra Petročnik

Natančnih podatkov o številu žensk, ki so pripadnice drugih kultur in so letno obravnavane v sklopu pred-, med- in poporodnega varstva, ni, se je pa Slovenija lansko leto, ob povečanih migracijah, soočila s situacijo, v kateri je bilo izrednega pomena, da je bila nudena babiška obravnava ne le kakovostna, pač pa tudi kulturno tankočutna. Tuji babiški študijski programi poudarjajo pomen kulturnih kompetenc diplomantov. V slovenskem kontekstu evalvacije študijskega programa s tega vidika še ni bilo. Avtorice so $v$ ta namen izvedle raziskavo, kjer so z uporabo lestvice CAS (Cultural Awarness Scale) določale kulturno zavest med študenti babištva ob zaključku študija. Pregled študijskega 
programa izkazuje pomanjkanje specifičnih informacij o kulturnih kompetencah, vseeno pa anketirani študenti izkazujejo visoko stopnjo kulturne tankočutnosti. Učitelje babištva ocenjujejo kot dobre zglede, kar daje misliti, da indirektno učenje kulturne zavesti, preko dobrih praks, prav tako lahko daje učinkovite rezultate. 
The texts of the book are instructive and educational because readers receive information and knowledge about real health problems confronted by migrant women and the health system.

The monograph's authors have already presented their ideas to their colleagues, students and the public. They were all able to assess the practical application of material in the book and use it to define their own place and role in contacts with those in need of professional and human help.

\section{Nada Gosić}

The publication of a book forms part of the Integra project. The added value of this volume lies in its unique and innovative content that seeks to enhance health professionals' knowledge and cross-border cooperation. The monograph benefits from the input of internationally well-regarded researchers in the field of sexual and reproductive healthcare, which make it particularly valuable. The book builds on the results of a literature search, original research and well-established good practices and guidelines. The topics range from cultural competencies, health education, barriers to healthcare, social integration through to migrant women's perspectives on sexual and reproductive health issues. The various chapters may be seen as a comprehensive, consistent and logical whole that includes a variety of evidence-based guidelines as part of an interdisciplinary approach.

This volume is able to inform health professionals, researchers and policymakers in their efforts to ensure adequate healthcare for migrant women and their families. As such, we strongly believe this publication holds the potential to promote inclusive transcultural healthcare across Europe. 
